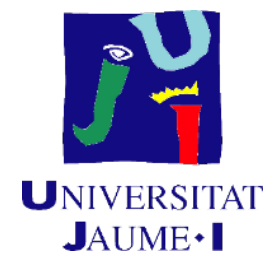

Programa de Doctorat en Tecnologies Industrials i Materials

Escola de Doctorat de la Universitat Jaume I

\title{
Development of a modelling tool to perform hydrodynamics coupled with biological processes in the secondary stage of wastewater treatment plants PhD Thesis
}

Memòria presentada per Javier Climent Agustina per optar al grau de doctor/a per la Universitat Jaume I

Author

Javier Climent Agustina
Director

Sergio Chiva Vicent

Castelló de la Plana, December 2019 

“En l'aigua, espill, la imatge sura, i al fang de llim negre del fons es fa les ondes la Natura"

[Bernat Artola] 



\section{Thesis by compendium of publications:}

J. Climent, L. Basiero, R. Martínez-Cuenca, J. G. Berlanga, B. Julián-López and S. Chiva (2018). Biological reactor retrofitting using CFD-ASM modelling. Chemical Engineering Journal. 348, 1 - 14. https://doi.org/10.1016/j.cej.2018.04.058

J. Climent, R. Martínez-Cuenca, P. Carratalà, M. J. González-Ortega, M. Abellán, G. Monrós and S. Chiva (2019). A comprehensive hydrodynamic analysis of a fullscale oxidation ditch using Population Balance Modelling in CFD simulation. Chemical Engineering Journal. 760-775.

https://doi.org/10.1016/j.cej.2019.05.195

\begin{tabular}{|c|c|}
\hline & $\begin{array}{c}\text { Universitat Jaume I (UJI) } \\
\text { Address: }\end{array}$ \\
& $\begin{array}{c}\text { Escola Superior de Ciències i Tecnologies Experimentals } \\
\text { (ESCTE) }\end{array}$ \\
& $\begin{array}{c}\text { Mechanical Engineering and Construction Department. } \\
\text { Av. de Vicent Sos Baynat, s/n 12071 Castellon (Spain) } \\
\text { Universitat Jaume I }\end{array}$ \\
\hline Phone & +34964728141 \\
\hline Fax: & +34964728106 \\
\hline Homepage: & http://www.uji.es/ \\
\hline E-mail: & jcliment@uji.es \\
\hline
\end{tabular}

"This thesis has been accepted by the co-authors of the publications listed above that have waved the right to present them as a part of another PhD thesis" 



\section{Agraïments}

Aquesta tesi doctoral no s'hauria pogut dur a terme sense el recolzament del Grup d'investigació de Fluids Multifàsics de la Universitat Jaume I, equip on vaig començar a formar-me en aquesta matèria a 2010 i del qual estic orgullós de formar part.

Començaré per agrair a Sergio tot l'esforç dedicat a aquesta tesi i tot el temps invertit en l'activitat que ha envoltat aquesta línia d'investigació d'on m'he pogut nodrir, ja van 8 anys des de la idea inicial. Ha sigut essencial la seua aportació tècnica en totes i cadascuna de les fites aconseguides $i$ ha estat la guia fonamental per la consecució dels objectius. D'altra banda, agrair-li la oportunitat de poder participar a nombrosos i prestigiosos congressos arreu del món, i per tot el que suposa això per una persona que pràcticament no "havia sortit de casa". A més a més, gràcies per tota la docència impartida, així com totes les converses tècniques $\mathrm{i}$ no tècniques que $m$ 'han permès formar-me professionalment $i$ créixer personalment.

En segon lloc, agrair a Raúl tota la dedicació i l'esforç necessari per abordar la part més complexa de la tesi com és la de treballar amb els models, i també la més esgotadora com és la verificació del codi amb l'anàlisi dels missatges d'error així com el tractament de dades experimentals; i a Salva per la seua disponibilitat incondicional per idear dispositius, desenvolupar instruments i resoldre aspectes enrevessats per abordar les mesures en camp. Moltes gràcies a tota la secció del Grup de Fluids que han treballat al taller aquests anys: Guillem, Jose, Lledó, Pablo, Rosario, Rubén i Aina, qui han participat directament amb la tesi o han contribuït d'una manera o altra als nombrosos treballs que l'envolten.

No vull deixar de tindre bones paraules per la gent de l'àrea que pertany al grup de recerca a la part de Nanofluids i la Càtedra amb qui he conviscut els darrers anys, així com la resta dels grups de recerca de la UJI amb qui he col·laborat tant al departament com als laboratoris, especialment amb qui he conviscut al despatx: Rosa, Fran i Carlos.

Vull agrair la confiança de la empresa FACSA per creure des del inicis en aquesta tesi i per facilitar els mitjos necessaris per la investigació. Estaré eternament agraït a tot el personal que pertany a l'àrea de sanejament i depuració que ha col·laborat en aquests estudis, la gent de planta i laboratori amb qui he coincidit, i de forma especial a Luis i a José Guillermo, qui es van involucrar des del principi d'una forma més pròpia.

És clau recordar-me del coautors dels treballs publicats, en particular Manuel Jesús, així com de la resta dels professionals del sector amb qui he tingut el gust de treballar: tècnics d'empresa (especialment Cadagua i Trargisa), investigadors als centres de recerca (ICRA, CEIT i AINA) i els tècnics d'entitats de sanejament 
(ESAMUR i EPSAR), que m'han aportat coneixement amb contribucions de qualitat als diferents treballs relacionats amb aquesta línia d'investigació, incomptables granets de sorra que han enriquit aquesta tesi.

També estic agraït al personal dels grups de recerca d'altres universitats que m'han traslladat el seu coneixement, professors i investigadors de: UPV, UPC, UB, UdG, USC, UC3M, DTU i KUSTAR, especialment a Benedek de la Universitat de Bath per acollir-me durant una profitosa estada doctoral. També, als investigadors amb qui he coincidit als intensos congressos WWTMod / WRRMod i que m'han aportat el seu punt de vista tècnic sobre aquests treballs. De la mateixa manera, als membres del grup de treball CFD de la IWA amb qui tinc l'honor de collaborar i reunir-me periòdicament, especialment a Randal Samstag, professional i fervent d'aquesta temàtica que malauradament ens ha deixat recentment.

Finalment però no menys important, a tota la meua família, en particular a ma mare. 


\section{Preface}

This thesis is based on the work carried out at the Multi-phase Flow Research Group of the Mechanical Engineering and Construction Department at the Universitat Jaume I (Spain) from March 2013 to June 2019. This thesis was prepared as part of different research studies carried out in the Research Group focusing on two main research lines applied to wastewater treatment: CFD Modelling coupled with biokinetics and hydrodynamics validation at full-scale. The work presented in this dissertation can be considered multi-disciplinary as it includes CFD simulation, two-phase flow modelling, laboratory and full-scale experimental measurements, experimental techniques and applied engineering.

The research was performed under the main supervision of Associate Professor S. Chiva (Universitat Jaume I).

The final work was supervised by Associate Professor Ayesa E. (Universidad de Navarra, CEIT), Associate Professor J. Colprim (Universitat de Girona, UdG), Associate Professor Rodríguez J. (Khalifa University of Abu Dhabi) and Associate Professor O. Potier (University of Lorraine).

The thesis is made in two main parts: the first part puts into context the state of the art of the $\mathrm{PhD}$ in an introductory review; and the second part consists of two research articles listed below. These will be referred to in the text by their paper number written with the Roman capital letter A and B. The articles are included in the Appendix A and B, respectively.

A. J. Climent, L. Basiero, R. Martínez-Cuenca, J. G. Berlanga, B. Julián-López and S. Chiva (2018). Biological reactor retrofitting using CFD-ASM modelling. Chemical Engineering Journal. 348, 1 - 14.

B. J. Climent, R. Martínez-Cuenca, P. Carratalà, M. J. González-Ortega, G., M. Abellán, Monrós and S. Chiva (2018). A comprehensive hydrodynamic analysis of a full-scale oxidation ditch using Population Balance Modelling in CFD simulation. Chemical Engineering Journal. 374, 760-775 
In addition, the following co-authored publications were also established during this $\mathrm{PhD}$ study, but are not included in this thesis:

L. Prades, A.D. Dorado, J. Climent, X. Guimerà, S. Chiva and X. Gamisans (2017). CFD modeling of a fixed-bed biofilm reactor coupling hydrodynamics and biokinetics. Chemical Engineering Journal, 313, 680-692.

This $\mathrm{PhD}$ study also contributed to international conferences with the following proceeding papers (Oral presentation):

J. Climent, R. Martínez-Cuenca, J.G. Berlanga, B. Julián-López and S. Chiva (2014). CFD simulation of hydrodynamics and biological reactions in an activated sludge process of WWTP. The IWA World Water Congress \& Exhibition, Portugal, Lisbon, 21 - 26 September 2014.

J. Climent and S. Chiva (2014). CFD modelling coupled with biological reactions in activated sludge process of WWTP. 7th European Postgraduate Fluid Dynamics Conference (EPFDC), Germany, Ilmenau, 14 July - 17 July 2014.

J. Climent, R. Martínez-Cuenca, P. Carratalà, M. Polo, M. González, M. Abellán, P. Simón and S. Chiva (2016). Two-phase flow CFD simulation of hydrodynamics coupled with biological reactions in an aerated biological reactor. The IWA World Water Congress \& Exhibition, Australia, Brisbane, 8 13 October 2016.

J. Climent, L. Basiero, R. Martínez-Cuenca, C. Peña, P. Carratalá, J. Vilarroig, G. Monrós, A. Macias, R. Arnau, R. García and S. Chiva (2017). CFD Coupled with kinetic models in wastewater treatment applications. HydroSenSoft, International Symposium and Exhibition on Hydro-Environment Sensors and Software, Madrid, Spain, 1 -3 March 2017.

J. Climent, R. Martínez-Cuenca, L. Basiero, J.G. Berlanga, S. Chiva (2017). Hydro-swapping: an innovative CFD approach applied to a real bioreactor. Frontiers International Conference of Wastewater Treatment (FICWTM2017), Palermo, Italy, 21-24 May 2017.

L. Basiero, C. Peña-Monferrer, J. Climent, P. Carratalá, J. Vilarroig, R. MartínezCuenca, J.G. Berlanga and S. Chiva. (2017). HYDRODECA: CFD Modelling Platform for Full-Scale Secondary Clarifiers of WWTPs. Frontiers International Conference of Wastewater Treatment (FICWTM2017), Palermo, Italy, 21-24 May 2017. 
B.G. Plósz, J. Climent, C.T. Griffin, Y. Li, P. Haecky., N. Blackburn, S. Chiva, and B. Valverde-Pérez (2018). Model identification for hindered-compression settling velocity. $6^{\text {th }}$ IWA/WEF Water Resource Recovery Modelling Seminar, Québec, Canada, 10-14 March 2018.

R. Garcia-Tirado, R. Martínez-Cuenca, J. Climent, R. Arnau, D. Miguel, S. Chiva (2018). Study and optimization of the hydraulic performance of a real scale subsurface flow wetland using CFD simulation techniques and tracer experiments. IWA Specialist Conference on Wetland Systems for Water Pollution Control. 30 September - 4 October 2018, UPV, Valencia, Spain.

J. Climent, A. Kiser, R. Arnau, C. Pita, A. Bonmatí-Blasi, S. Chiva, L. Corominas (2019). Comparison between Potassium Bromide and Lithium Chloride as feasible tracer for assessing hydraulic performance in anaerobic digesters. Tracer $8^{\text {th }}$ International Conference on Tracers and Tracing Methods. February 2019. Da Nang City (Vietnam).

J. Climent, R. Arnau, R. Martínez-Cuenca, S. Chiva (2019). Anaerobic Digesters Mixing Optimization through tracer test and CFD modelling. Tracer $8^{\text {th }}$ International Conference on Tracers and Tracing Methods. February 2019. Da Nang City (Vietnam).

Y. Qiu, C.T. Griffin, S. Ekström, B.F. Smets, B. Valverde-Pérez, J. Climent, B.G. Plósz (2019). Numerical modelling of $\mathrm{N}_{2} \mathrm{O}$ emission from surface aerated oxidation ditch activated sludge reactors. Watermatex 2019 IWA. Copenhaguen. 
This $\mathrm{PhD}$ study also contributed to international conferences with the following works (Poster presentations):

J. Climent, B. Julian-Lopez, N. Portes, C. Ferrer, I. Pastor, J.G. Berlanga and S. Chiva (2013). Computational fluid dynamics modeling of hydrodynamic flow behaviour inside anaerobic digester tank. 13th World Congress on Anaerobic Digestion, Santiago de Compostela, Spain, 25- 28 June 2013.

J. Climent, L. Basiero, R. Martínez-Cuenca, J.I. Briones, J.G. Berlanga, B. JuliánLópez and S. Chiva (2014). CFD modelling of hydrodynamics and biochemical reactions in the anoxic zone of an activated sludge process of WWTP The IWA World Water Congress \& Exhibition, Portugal, Lisbon, 21 - 26 September 2014.

J. Climent, R. Martínez-Cuenca, P. Carratalà, M. Polo, M. J. González, M. Abellán, P. Simón, S. Chiva. CFD simulation of hydrodynamics using a twophase flow model in full-scale biological reactor performance (2016). The 13th IWA Leading Edge Conference on Water and Waste and Wastewater Technologies, Jerez de la Frontera, Spain, 13-16 June 2016.

J. Climent, L. Basiero, R. Martínez-Cuenca, J.I. Briones, J.G. Berlanga, B. JuliánLópez, S. Chiva and J.A. Basiero. CFD modelling of hydrodynamics and biokinetic reactions in the anoxic zone of an activated sludge process of WWTP (2016). The 13th IWA Leading Edge Conference on Water and Waste and Wastewater Technologies, Jerez de la Frontera, Spain, 13-16 June 2016.

J. Climent, L. Basiero, R. Martínez-Cuenca, J. Vilarroig, J.G. Berlanga, S. Chiva (2016). Hydrodynamics and sedimentation CFD modelling of a full-scale secondary clarifier in a transient state performance. The IWA World Water Congress \& Exhibition, Australia, Brisbane, 8 - 13 October 2016.

J. Climent, R. Arnau, R. Martínez-Cuenca, M. Ayla Kiser, L. Corominas, J. Rodriguez, S. Chiva. A comprehensive hydrodynamic analysis of municipal anaerobic digesters (2018). $6^{\text {th }}$ IWA/WEF Water Resource Recovery Modelling Seminar, Québec, Canada, 10-14 March 2018.

J. Climent, R. Martínez-Cuenca, P. Carratalà ${ }^{2}$, S. Gargallo, M. García and S. Chiva (2019) Tracer techniques for validating CFD modelling of open channel UV disinfection systems. Tracer 8th International Conference on Tracers and Tracing Methods. February 2019. Da Nang City (Vietnam). March 2019. 


\section{Summary}

During recent years, initiatives related to the protection of the environment have undergone a great growth worldwide. This has been encouraged by a substantial increase in the concern for environmental and sustainable consumption of natural resources, mainly water. Thus, the increases in population and industrial growth have made it necessary to improve the infrastructures for the sanitation of wastewater, promoting the strengthening of the wastewater treatment sector.

It is necessary to maintain the pace of improvement and efficacy of the different processes in WWTP, mainly the biological treatment which is the core of the WWTP. Obtaining the effluent quality limits established by current legislation implies the virtual universal application of biological treatment systems. The conventional aerobic process of culture in suspension (activated sludge systems in any of its configurations), has been the most widely used in full-scale WWTPs among all the new biological treatment processes available at present, and it will continue to be in the coming years due to its effectiveness, robustness, versatility and economy. On the scope of environmental science, water quality management, especially WWTP, has in last few years attracted the interest of researchers in the field of modelling. Nowadays, within the field of wastewater treatment there are already specific simulation tools applied to reproduce the operation of the majority of the WWTP process units, these have been extended in recent years and are currently widely used not only by modelling experts; but by the WWTP's operators themselves. These tools have raised the level of knowledge and improved the operation since they are able to reproduce a global behavior of the different process units and provide WWTP results in comparatively short computing times. However, these tools present serious limitations when proposing new designs or improvements based on hydrodynamics of the current processes, thereby limiting the specialisation of the sector.

The implementation of the most sophisticated calculation tools based on computational fluid mechanics (Computational Fluid Dynamics - CFD) have been successfully incorporated in different areas of the scientific/technical fields. CFD is the analysis of systems involving fluid flow, heat transfer and associated phenomena such as chemical reactions by means of computer-based simulation. The incorporation of these tools in the wastewater treatment sector supposes a substantial advance, they are more powerful and sophisticated than the conventional process simulations because allow hydrodynamics to be calculated in detail. This allows us a deeper knowledge of the operation, design, retrofitting and optimization of process units.

Using computational simulation of 3D fluids, complex studies can be carried out in those process units where hydrodynamics play a leading role in the process, even for multiphase systems (solid, liquid and gas). 
The 3D performance of the fluid flow can be reproduced in detail within the tanks, as well as delve into the specific models that govern the operation of the different units in the study process.

However, to date in the field of wastewater treatment; CFD models have been used mainly to address specific hydraulic problems. This is due to the fact that they present a series of disadvantages compared to the other process simulation tools such as: a more demanding experimental validation, high computation times, and in the specific case that concern us, the implementation of specific sub-models such as the biochemical or population balance models (PBM).

The validation of the CFD model results in one of the key aspects of providing confidence in the system. Especially in large-scale configurations where fluid dynamics associated with multidimensional unsteady flow, geometric complexity, and the effect of the internal elements, can influence the performance of the process significantly. For this experimental data is required to be compared to CFD results in order to provide credibility of the predictions which are related to the level of complexity of the problem to be tackled, as is the case of the two-phase flow simulations.

The thesis developed presents two different 3D CFD modelling case studies that reproduce the physical and biochemical phenomena of biological reactors at real scale. On the one hand, the hydrodynamic models have been studied to characterise the flow behavior with the implementation of specific submodels (bio kinetics of the active sludge, PBM and rheology) in the code. One of the topics of interest has been to work on the ability to define strategies of reducing the time to run simulations in order to obtain CFD results in WWT modelling on a real scale; in reasonable computing times. Efforts have been made to simplify cases through more practical approaches, based on the objective needs, without renouncing the accuracy of results. On the other hand, a full-scale experimental validation has been carried out using tracer techniques and specific instrumentation, which was necessary to verify the results of the fluid performance. This demonstrated that the process performance strongly depends on the hydrodynamics, which was influenced by slight changes in the configuration.

This thesis lends credibility to the potential that CFD techniques offer viability to the wastewater treatment sector. They are an excellent complement to the conventional simulation tools used in the sector. It requires qualified people to run these complex codes, and experts in the water treatment in order to define the simulations and interpret the CFD results applied to the design and operation. Based on this work, multiphase models can be studied in greater detail while limiting the computational cost in order to faithfully reproduce the real processes. CFD codes can produce extremely large amounts of results at virtually no added expense reducing costs by performing virtual analysis to optimise biological reactors. 


\section{Resumen}

Durante los últimos años, las iniciativas relacionadas con la protección del medio ambiente han experimentado un gran crecimiento en todo el mundo. Esto ha sido fomentado principalmente por un aumento sustancial en la preocupación por el medio ambiente y la sostenibilidad del consumo de recursos naturales, como el agua. Así, el aumento de población y el crecimiento industrial han hecho necesario mejorar las infraestructuras para el saneamiento, promoviendo el fortalecimiento del sector de tratamiento de aguas residuales.

Es necesario mantener el ritmo de mejora de la eficiencia de los diferentes procesos en la EDAR, principalmente el tratamiento biológico, que es el corazón de la EDAR. La obtención de los límites de calidad del efluente establecidos por la legislación actual implica la aplicación virtualmente universal de los sistemas de tratamiento biológico. El proceso aeróbico convencional de cultivo en suspensión (sistemas de lodos activados en cualquiera de sus configuraciones), ha sido el más utilizado en las plantas de tratamiento de aguas residuales a gran escala entre todos los nuevos procesos de tratamiento biológico disponibles en la actualidad, y continuará estando presente en los próximos años por su efectividad, robustez, versatilidad y economía.

En el ámbito de la ciencia ambiental, la gestión de la calidad del agua, especialmente la EDAR, ha atraído en los últimos años el interés de los investigadores en el campo de la modelización. Hoy en día, dentro del campo del tratamiento de aguas residuales ya existen herramientas de simulación específicas aplicadas para reproducir el funcionamiento de la mayoría de las unidades de proceso de la EDAR, que se han extendido en los últimos años y actualmente son ampliamente utilizadas no solo por expertos en modelado sino también por los propios operadores. Estas herramientas han elevado el nivel de conocimiento y mejorado la operación, ya que pueden reproducir a nivel global el comportamiento de las diferentes unidades de proceso y proporcionar resultados de EDAR en tiempos de computación relativamente cortos. Sin embargo, estas herramientas presentan serias limitaciones a la hora de proponer nuevos diseños o mejoras basadas en la hidrodinámica de los procesos actuales, lo que limita la especialización del sector.

La implementación de las herramientas de cálculo más sofisticadas basadas en la mecánica de fluidos computacional (Computational Fluid Dynamics, CFD) se ha incorporado con éxito en diferentes áreas de los campos científico / técnico. CFD es el análisis de sistemas que involucran flujo de fluidos, transferencia de calor y otros fenómenos asociados, como reacciones químicas, mediante simulación por computadora. La incorporación de estas herramientas en el sector de tratamiento de aguas residuales supone un avance sustancial, son más potentes y sofisticadas que la simulación de procesos convencionales, ya que permiten calcular la hidrodinámica 
en detalle. Esto permite profundizar en nuestro conocimiento de la operación, diseño, innovación y optimización de las unidades de proceso.

Usando simulación computacional de fluidos 3D, se pueden realizar estudios complejos en aquellas unidades de proceso donde la hidrodinámica juega un papel importante en el proceso, incluso para sistemas multifásicos (sólido, líquido y gas). El rendimiento en 3D del flujo de fluido se puede reproducir en detalle dentro de los tanques, así como profundizar en los modelos específicos que rigen el funcionamiento de las diferentes unidades del proceso en estudio. Sin embargo, hasta la fecha y en el campo del tratamiento de aguas residuales, los modelos CFD se han utilizado principalmente para abordar problemas hidráulicos específicos. Esto se debe al hecho de que presentan una serie de desventajas en comparación con las otras herramientas de simulación de procesos, tales como: una validación experimental más exigente, tiempos de computación elevados $\mathrm{y}$, en el caso específico que nos concierne, la implementación de submodelos específicos tales como como los modelos bioquímicos o de balance poblacional (PBM).

La validación de los resultados del modelo CFD es uno de los aspectos clave para brindar confianza al sistema, especialmente en configuraciones a gran escala en las que la dinámica de fluidos asociada con el flujo inestable multidimensional, la complejidad geométrica y el efecto de los elementos internos pueden influir en el rendimiento del proceso de manera significativa. Para esto, se requiere que los datos experimentales se comparen con los resultados de CFD para dotar de credibilidad a las predicciones, que están relacionadas con el nivel de complejidad del problema a abordar, como en el caso de las simulaciones de flujo de dos fases.

La tesis desarrollada presenta dos estudios de casos de modelos de CFD 3D diferentes que reproducen los fenómenos físicos y bioquímicos reactores biológicos a escala real. Por un lado, los modelos hidrodinámicos se han estudiado para caracterizar el comportamiento del flujo con la implementación de submodelos específicos (biocinética de los lodos activos, PBM y reología) en el código. Un tema de interés ha sido trabajar en la capacidad de definir estrategias para reducir el tiempo de cálculo de las simulaciones, con el fin de obtener resultados de CFD en el modelado del tratamiento de aguas residuales a escala real en tiempos de computación razonables. Se han realizado esfuerzos para simplificar los casos a través de enfoques más prácticos, basados en las necesidades objetivas, sin renunciar a la exactitud de los resultados. Por otro lado, se ha llevado a cabo una validación experimental a gran escala utilizando técnicas de trazadores inertes e instrumentación específica, que fue necesaria para verificar los resultados del rendimiento del fluido. Esto ha demostrado que el rendimiento del proceso depende en gran medida del comportamiento hidrodinámico.

Esta tesis otorga valor al potencial que ofrecen las técnicas de CFD para el sector de tratamiento de aguas residuales. Son un excelente complemento de las herramientas de simulación convencionales utilizadas en el sector. Así, se necesitan personas 
cualificadas para ejecutar estos códigos complejos, pero que a la vez, también sean expertos en el proceso de tratamiento del agua, de forma que puedan definir las simulaciones e interpretar los resultados de CFD aplicados al diseño y la operación. Sobre la base de este trabajo, los modelos multifásicos se pueden estudiar con mayor detalle al tiempo que limitan el costo computacional para reproducir fielmente los procesos reales. Los códigos CFD pueden producir cantidades extremadamente grandes de resultados prácticamente sin ningún gasto adicional, lo que reduce los costos al realizar análisis virtuales, por ejemplo, para optimizar los reactores biológicos. 



\section{Resum}

Durant els darrers anys, les iniciatives relacionades amb la protecció del medi ambient han experimentat un gran creixement arreu del món. Això s'ha impulsat principalment per un augment substancial de la preocupació pel medi ambient i la sostenibilitat del consum de recursos naturals, com ara l'aigua. Així, l'augment de la població i el creixement industrial han fet necessari millorar les infraestructures per al sanejament, afavorint l'enfortiment del sector del tractament d'aigües residuals. Cal mantenir el ritme de millora de l'eficiència dels diferents processos a l'EDAR, principalment el tractament biològic, que és el cor de la depuradora. L'obtenció dels límits de qualitat de l'efluent establerts per la legislació vigent implica l'aplicació pràcticament universal dels sistemes de tractament biològic. El procés aeròbic convencional de cultiu en suspensió (sistemes de fangs actius en qualsevol de les seves configuracions), ha estat el més utilitzat a les plantes depuradores d'aigües residuals a gran escala entre tots els nous processos de tractament biològic disponibles actualment, $i$ continuarà estant present en els propers anys per la seva eficàcia, robustesa, versatilitat $i$ economia. Pel que fa a l'àmbit de les ciències ambientals, en els darrers anys, la gestió de la qualitat de l'aigua, especialment a l'EDAR, ha atret l'interès dels investigadors en el camp de la modelització. Avui dia, dins del camp del tractament d'aigües residuals, hi ha ja aplicades eines de simulació específiques per reproduir el funcionament de la majoria de les unitats de procés d'EDAR, que s'han ampliat en els darrers anys i que actualment són àmpliament utilitzades no només per experts en modelització, sinó també pels propis operadors de l'EDAR. Aquestes eines han elevat el nivell de coneixement i milloren el funcionament, ja que són capaços de reproduir globalment el comportament de les diferents unitats de procés i proporcionar resultats d'EDAR en temps de computació relativament curts. No obstant això, aquestes eines presenten serioses limitacions a l'hora de proposar nous dissenys o millores basades en la hidrodinàmica dels processos actuals, limitant així l'especialització del sector.

La implementació de les eines de càlcul més sofisticades basades en la mecànica computacional de fluids (Computational Fluid Dynamics, CFD) s'han incorporat amb èxit a diferents àrees dels camps científic i tècnic. El CFD és l'anàlisi de sistemes que impliquen flux de fluids, transferència de calor $\mathrm{i}$ altres fenòmens associats, com ara reaccions químiques mitjançant simulació basada en ordinador. La incorporació d'aquestes eines al sector del tractament d'aigües residuals suposa un avanç substancial, són més potents i sofisticades que la simulació de processos convencionals, ja que permeten calcular detalladament la hidrodinàmica. Això ens permet aprofundir en el coneixement de l'operació, el disseny, la innovació i l'optimització de les unitats de procés. Mitjançant la simulació computacional de fluids en 3D, es poden realitzar estudis complexos en aquelles unitats de procés en què la hidrodinàmica juga un paper protagonista en el procés, fins $i$ tot per als sistemes multifàsics (sòlid, líquid i gasós). El rendiment en 3D del flux de fluids es 
pot reproduir detalladament en els tancs, així com aprofundir en els models específics que regeixen el funcionament de les diferents unitats de procés que siguen objecte d'estudi. Malgrat tot, fins ara i en l'àmbit del tractament d'aigües residuals, els models CFD només s'han utilitzat per abordar problemes hidràulics específics. Això es deu al fet que presenten una sèrie d'inconvenients en comparació amb altres eines de simulació de processos, com ara: una validació experimental més exigent, temps de càlcul elevats $i$, en el cas específic que ens aplica, la implementació de submodels específics com models bioquímics o de balanç poblacional (PBM).

La validació dels resultats del model CFD és un dels aspectes clau per proporcionar confiança al sistema, especialment en configuracions a gran escala on la dinàmica de fluids associada al flux inestable multidimensional, la complexitat geomètrica $\mathrm{i}$ l'efecte dels elements interns, poden influir en el rendiment del procés de manera significativa. Per això, es necessita comparar les dades experimentals amb els resultats extrets del CFD per tal de proporcionar credibilitat a les prediccions, que estan relacionades amb el nivell de complexitat del problema a tractar, com el cas de les simulacions de flux en dues fases (líquid-gas).

La tesi desenvolupada presenta dos estudis de casos de modelització de CFD 3D que reprodueixen els fenòmens físics i bioquímics dels reactors biològics a escala real. D'una banda, s'han estudiat els models hidrodinàmics per caracteritzar el comportament del flux amb la implementació de submodels específics (biocinètica del fang actiu, PBM i reologia) al codi. Un dels temes d'interès ha estat treballar en la capacitat de definir estratègies per reduir el temps de càlcul de les simulacions per tal d'obtenir resultats de CFD en la modelització a escala real en temps de computació raonables. S'han fet esforços per simplificar els casos mitjançant enfocaments més pràctics, basats en les necessitats objectives, sense renunciar a la precisió dels resultats. D'altra banda, s'ha realitzat una validació experimental a gran escala mitjançant tècniques de traçador $\mathrm{i}$ instrumentació específica, que va ser necessària per verificar els resultats del rendiment del fluid. Això ha demostrat que el rendiment del procés depèn fortament pel comportament hidrpdinàmic.

Aquesta tesi valora el potencial que ofereixen les tècniques CFD per al sector del tractament d'aigües residuals. Són un excel·lent complement per les eines de simulació convencionals utilitzades al sector. Es necessiten persones qualificades per executar aquests codis complexos, i que al mateix temps siguen expertes en procés del tractament de l'aigua, per definir les simulacions i interpretar els resultats del CFD aplicats al disseny i al funcionament. A partir d'aquest treball, els models multifàsics es poden estudiar amb més detall mentre es limita el cost computacional per reproduir fidelment els processos reals. Els codis CFD poden produir grans quantitats de resultats pràcticament sense cap despesa addicional, reduint els costos mitjançant l'anàlisi virtual, per exemple per optimitzar els reactors biològics. 


\section{Index}

Introduction 1

1.1 Background 1

1.2 Objectives and Present Contribution 4

1.3 Outline 6

State of the art 9

2.1 CFD Modelling 9

$\begin{array}{ll}2.1 .1 \text { Single phase flow } & 10\end{array}$

$\begin{array}{ll}2.1 .2 \text { Two-phase flow } & 14\end{array}$

$\begin{array}{ll}2.1 .3 \text { Population Balance Model } & 19\end{array}$

2.1.4 RANS Turbulence modelling 23

2.1.5 Two-Phase Flow Turbulence Modeling 28

2.1.5.1 Additional Viscosity Term 29

2.1.5.2 Additional Source Terms in the Turbulence Equations 29

$\begin{array}{ll}2.1 .6 \text { Numerical resolution } & 30\end{array}$

2.1.7 Verification and validation $\quad 32$

2.2 Activated Sludge Configurations studied 36

2.2.1 The Modified Ludzack-Ettinger (MLE) biological reactor 38

2.2.2 Oxidation Ditch configuration $\quad 40$

2.3 Biological models 43

2.3.1 Description of ASM model 43

2.3.2 Implementation of the ASM models in CFD 52

CFD Modelling applied to WWT 55

3.1 CFD applied to wastewater treatment 56

3.2 The CFD work flow 62

3.2.1 Boundary Conditions $\quad 63$

$\begin{array}{ll}\text { 3.2.2 Mesh definition } & 64\end{array}$ 
3.2.3 Discretisation Scheme $\quad 68$

3.2.4 Solution of multi-Phase Flow 69

$\begin{array}{ll}3.2 .5 \text { Interfacial forces } & 74\end{array}$

3.2.5.1 Drag Force $\quad 74$

3.2.5.2 Lift Force $\quad 75$

3.2.5.3 Wall Lubrication Force $\quad 75$

3.2.5.4 Turbulent Dispersion Force 76

$\begin{array}{ll}\text { 3.2.6 Mixers performance } & 77\end{array}$

3.3 Experimental Validation $\quad 80$

3.3.1 Tracer test procedure and analysis $\quad 81$

3.3.2 Velocity measurements 91

3.3.3 Non Newtonian fluid performance 93

3.3.4 Physic-chemical species $\quad 95$

3.4 Calculation strategies 96

3.4.1 RTD scalar field 96

$\begin{array}{ll}\text { 3.4.2 Solver in two steps } & 97\end{array}$

$\begin{array}{ll}3.4 .3 \text { Timestep variable } & 97\end{array}$

$\begin{array}{ll}\text { 3.4.4 Hydroswapping formulation } & 101\end{array}$

Analysis of results 103

4.1 Modified Lutzack Ettinger configuration 103

4.1.1 Hydrodynamic analysis using CFD Modelling 104

4.1.2 Retrofitting of the configuration using CFD Modelling 105

$\begin{array}{ll}\text { 4.1.3 Tracer tests in dynamic state } & 110\end{array}$

4.1.4 Validation of the CFD-ASM model 111

$\begin{array}{ll}4.1 .5 \text { Hydroswapping } & 117\end{array}$

$\begin{array}{ll}4.2 \text { Orbal configuration } & 120\end{array}$

4.2.1 Hydrodynamic analysis using CFD Modelling $\quad 120$

$\begin{array}{ll}\text { 4.2.2 Tracer tests and velocity measurements } & 121\end{array}$

4.2.3 Validation of the CFD-ASM model 122 
$\begin{array}{ll}4.3 \text { Oxidation ditch configuration } & 127\end{array}$

4.3.1 Hydrodynamic analysis using CFD 127

4.3.2 Velocity measurements in single-phase 130

4.3.3 Velocity measurements in two-phase flow $\quad 134$

4.3.4 Two-phase flow performance using PBM 136

4.3.5 Optimization study using CFD 140

4.3.6 Nutrient removal performance using CFD-ASM 141

Conclusions 143

5.1 Future work 146

Appendix A 151

Abstract 153

A.1 Introduction 154

A.2 Materials \& methods 157

A.2.1 Description and operation of the biological reactor 157

A.2.2 Experimental measurements for CFD validation $\quad 159$

A.2.3 CFD Modelling 160

A.2.3.1 Tracer runs in transient state 163

A.2.3.2 RTD calculation in steady state 163

A.2.3.3 CFD-ASM runs 164

A.2.3.4 Saving computational time $\quad 165$

A.2.3.5. Rheological properties 166

A.3. Results \& Discussion $\quad 167$

A.3.1 Hydrodynamics 167

A.3.1.1 Tracer tests and simulations $\quad 167$

$\begin{array}{ll}\text { A.3.1.2 Optimization study } & 172\end{array}$

$\begin{array}{ll}\text { A.4. Conclusions } & 184\end{array}$

$\begin{array}{ll}\text { Appendix B } & 185\end{array}$

$\begin{array}{ll}\text { Abstract } & 187\end{array}$

$\begin{array}{ll}\text { B.1 Introduction } & 187\end{array}$ 
B.2 Materials \& methods $\quad 190$

B.2.1 Description of the biological reactor 190

$\begin{array}{ll}\text { B.2.2 CFD Modelling } & 191\end{array}$

$\begin{array}{ll}\text { B.2.2.1 Single-phase } & 191\end{array}$

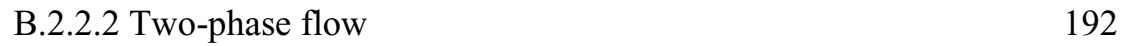

$\begin{array}{ll}\text { B.2.3 Experimental measurements } & 196\end{array}$

$\begin{array}{ll}\text { B.2.3.1 Tracer test } & 196\end{array}$

$\begin{array}{ll}\text { B.2.3.2 Fluid velocity profiles } & 197\end{array}$

B.3. Results \& Discussion 198

$\begin{array}{ll}\text { B.3.1 Tracer test } & 198\end{array}$

$\begin{array}{ll}\text { B.3.2 CFD models } & 201\end{array}$

B.3.2.1 Hydrodynamic performance of the oxidation ditch 201

B.3.2.2 Single-phase CFD model validation 205

B.3.2.3 Two-phase flow CFD model validation 209

B.3.2.4 Two-phase flow performance using PBM 212

$\begin{array}{ll}\text { B.3.3 Optimization } & 216\end{array}$

$\begin{array}{ll}\text { B.4 Conclusions } & 218\end{array}$

$\begin{array}{ll}\text { References } & 219\end{array}$ 


\section{List of Figures}

Figure 1.1. Modelling approaches applied to wastewater treatment................2

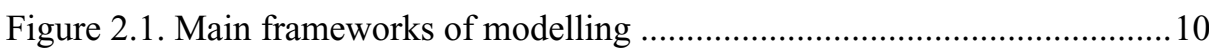

Figure 2.2. Decomposition of Reynolds in a pipe.................................................. 11

Figure 2.3. Wall-function and turbulence models scheme for wall distance (y)...28

Figure 2.4. Overview of ANSYS CFX code structure (ANSYS $\left.{ }^{\circledR}, 2019\right)$...............31

Figure 2.5. Energy cost in WWTP- LIFE13 env/es/000704-RENEWAT..............37

Figure 2.6. Scheme of the internal elements of a reactor, propellers and grid of

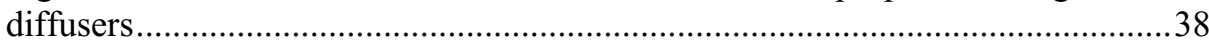

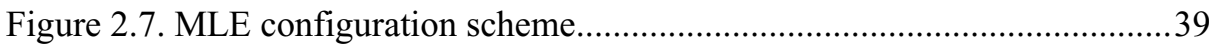

Figure 2.8. 3D scheme of the MLE biological reactor of one WWTL...................40

Figure 2.9. Scheme of the Oxidation ditch and Orbal configurations .....................41

Figure 2.10. Oxidation ditch (left) and Orbal (right) CFD models ........................42

Figure 2.11. COD frations (left) and Nitrogen frations (right) in ASM1 model (Figure from Jeppsson, 1996)...........................................................................4

Figure 2.12. Typical values for parameters at neutral $\mathrm{pH}$ and $20^{\circ} \mathrm{C}$ urban waste

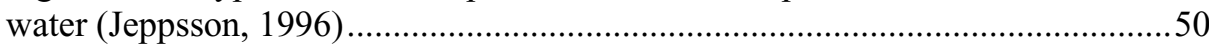

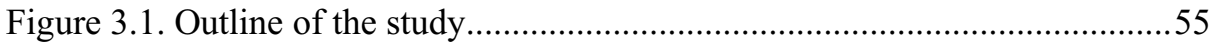

Figure 3.2. Overview of ANSYS CFX code structure $\left(\right.$ ANSYS $\left.^{\circledR}\right)$. ........................63

Figure 3.3. Structured Mesh of the Lutzack Ettinger configuration (anoxic).......64

Figure 3.4. Unstructured mesh of the Oxidation ditch configuration (diffusers). . 65

Figure 3.5. Cost effectiveness of the meshes tested ............................................65

Figure 3.6. Scheme of the MUSIG model (Coalescense and Break-up models) ..70

Figure 3.7. Types of horizontal axis-oriented stirrers depending on the rotational velocity (Low, Medium and High)........................................................77

Figure 3.8. Velocity field of the jet from the two-blade horizontal axis-oriented stirrer and the velocity field inside the subdomain of the stirrer...... 
Figure 3. 9. Scheme of the disc shape subdomain and its implementation in a full-scale tank in a 3D CFD model

Figure 3.10. Conceptual protocol for the potential use of CFD as a supportive tool for WWT process modelling. (Laurent et al., 2014)................................. 81

Figure 3.11. Two extrems of aggregation of fluid ........................................ 82

Figure 3.12. Earliness and Lateness of Mixing ......................................... 82

Figure 3.13. Scheme of the tracer test procedure .......................................... 84

Figure 3.14. Different $\mathrm{C}(\mathrm{t})$ response curve and their analysis .......................... 85

Figure 3.15. Tracer response curves for closed vessels and large deviations from plug flow (Metcalf and Eddy, 2004)................................................... 89

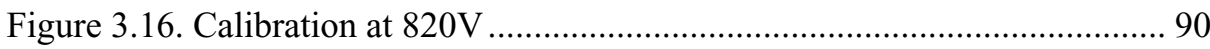

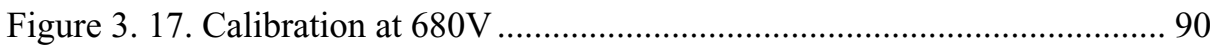

Figure 3.18. Velocity component acquired and filtered .................................. 92

Figure 3.19. Velocity measures at the channel spacing .................................. 93

Figure 3.20. Measures at the otter channel ................................................... 93

Figure 3.21. Laboratory probe (left) and field probe (right) of the Vectrino

Nortek measuring in full-scale tanks and the scheme of functioning.................. 93

Figure 3.22. Typical rheological behaviour of fluids (Ratkovich et al., 2013).... 94

Figure 3.23. Rheological measurements at $2850 \mathrm{~g} / \mathrm{m} 3$. Shear stress (left) and

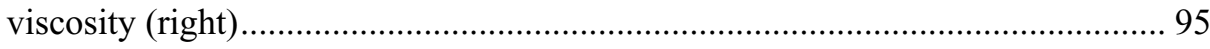

Figure 3.24. Evolution of the state variable value in steady state for different

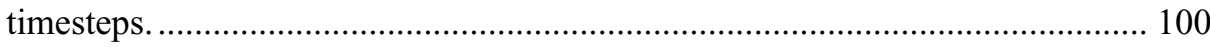

Figure 3.25. Value of timestep depending on number of iteration. .................. 100

Figure 4.1. 3D model of biological reactor LEM configuration (left) and the two first anoxic tanks retroffited (right) ................................................... 103

Figure 4.2. Short-circuiting a) detected at Original configuration and b) corrected at Modified configuration. .................................................................. 104

Figure 4.3. Streamline of a) short-circuiting at Original b) Modified configuration.

Figure 4.4. Horizontal cross-sections for tm variable in a) configuration $1, \mathrm{~b}$ ) configuration 2, c) configuration 5, d) configuration 6, e) configuration 7 and f) configuration 8 
Figure 4.5. Fluid velocity field in a) configuration 1 and b) configuration $2 \ldots . . .107$

Figure 4.6. Fluid velocity field in a) configuration 5 and b) configuration $6 \ldots . . .107$

Figure 4.7. Positioning of the stirrer depending on its location (left) and the angle (right).

Figure 4.8. Tracer concentration calculated at the crossing section for different

a) positions and b) angle

Figure 4.9. Comparison of the fluid velocity field between the Original configuration (left) and the Modified configuration (right)

Figure 4.10. Comparison and validation of both RTD obtained in WWWT1 configurations: Original and Modified.

Figure 4.11. Comparison of Nitrate measured at different times at outlet of both WWTLs.

Figure 4.12. Comparison between nitrate concentration measured and calculated.

Figure 4.13. Comparison between filtered BOD measured and readily biodegradable substrate concentrations calculated at both configurations

Figure 4.14. Nitrate (Sno) at Original configuration (left) and at Modified configuration (right)

Figure 4.15. Readily biodegradable substrate (Ss) at Original configuration (left) and at Modified configuration (right).

Figure 4.16. Nitrate (Sno) at Original configuration (left) and at Modified configuration (right).

Figure 4.17. Readily biodegradable substrate (Ss) at Original configuration (left) and at Modified configuration (right).

Figure 4.18. Nitrate consumption rate (g m-3 s-1) at Original configuration (left) and at Modified configuration (right).

Figure 4.19. Readily biodegradable substrate consumption rate (g m-3 s-1) at Original configuration (left) and at Modified configuration (right).

Figure 4.20. Streamlines velocity and void fraction. Configuration of $\mathrm{Ri}=$ $400 \%$ with aeration. Hydrodynamics 1

Figure 4.21. Streamlines velocity and void fraction. Configuration of $\mathrm{Ri}=$ $400 \%$ without aeration. Hydrodynamics 2

Figure 4.22. Nitrification-denitrification rate with aeration 118

Figure 4.23. Denitrification rate without aeration 118 
Figure 4.24. Nitrification-denitrification rate with aeration .......................... 118

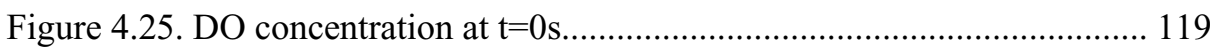

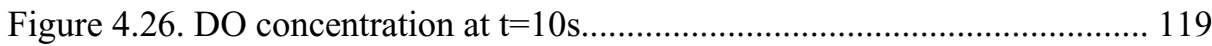

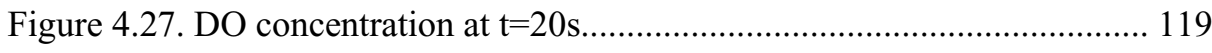

Figure 4.28. Distribution of bubble diameter for the Configuration of $\mathrm{Ri}=$

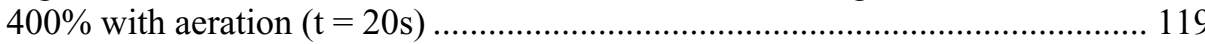

Figure 4.29. Description of the orbal oxidation ditch (left), and experimental data measurement points (right)............................................................ 120

Figure 4.30. Streamlines with one rotor (left) and two rotors (right) ............... 121

Figure 4.31. Velocity profile at position 2 ............................................... 121

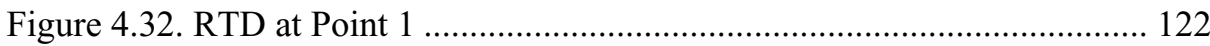

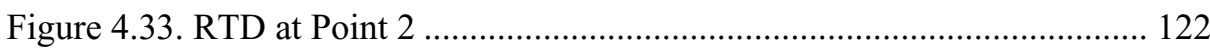

Figure 4.34 Dissolved oxygen concentration distribution at different positions 122 Figure 4.35. Dissolved oxygen concentration distributions at $2.85 \mathrm{~m}$ height (left) and $2.50 \mathrm{~m}$ height (right).

Figure 4.36. Dissolved oxygen concentration distributions at $2 \mathrm{~m}$ and $1.5 \mathrm{~m}$ height.

Figure 4.37. Dissolved oxygen and percentage of aerobic volume for one rotor (left) and two rotor (right) .................................................................. 124

Figure 4.38. COD, Ammonia and nitrates distribution calculated ................... 124

Figure 4. 39. Comparison of COD, ammonia and nitrates ............................. 125

Figure 4.40. Velocity of the streamlines without air (left) and with air (right) .. 127

Figure 4. 41. Velocity contour at $0.5 \mathrm{~m}, 1.5 \mathrm{~m}, 2.5 \mathrm{~m}, 3.5 \mathrm{~m}$ and $4.5 \mathrm{~m}$ high (from top to bottom) without air (left) and with air (right)............................ 129

Figure 4.42. Vertical velocity profiles around the outer channel (P1 - P5) without and with air.

Figure 4.43. Comparison of the fluid velocity components calculated and measured without air.

Figure 4.44. Comparison of fluid velocity components calculated and measured with air. 136

Figure 4.45. Contour of gas hold-up air bubble plumes (above) and the vortex core regions in 3D (below) both plotted in section d-d' (figure 4.44). 
Figure 4.46. Isovolume of all the groups of bubbles (left) and its bubble size distribution (right).

Figure 4.47. Isovolume of bubbles of groups 7 to 108 (left), and Isovolume of bubbles of groups 1 and 2 (right)

Figure 4.48. Isovolume of holdup represented up to $3.5 \%$ (left), and its corresponding interfacial area density (right).

Figure 4.49. Hold-up (left) and bubble diameter (right) both in section e-e' ......139

Figure 4.50. Mass flow rate incoming and outcoming through the channel

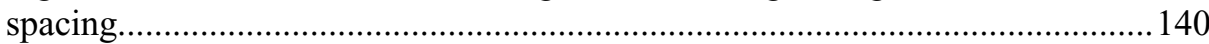

Figure 4.51. Velocity of the streamlines at the optimum configuration ................141

Figure 4.52. Ammonia contours inside the tank................................................. 142

Figure 4.53. Transient calculation of State Variables .......................................... 142 


\section{List of Tables}

Table 2.1. Turbulence calculation procedures ............................................... 24

Table 2.2. ASM1 implementation ............................................................ 44

Table 3.1. Mesh quality parameters depending on the Aspect ratio value ... 66

Table 3.2. Mesh quality parameters depending on the Skewness value....... 66

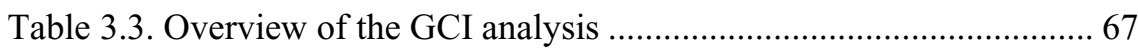

Table 3.4. Comparison of the of simulation depending on the timestep.... 99

Table 4.1. Description of the configurations tested .................................... 105

Table 4.2. Description of the different locations tested .............................. 108

Table 4.3. Main parameters of experimental RTD analysis ......................... 111 


\section{Nomenclature}

\section{Latin letters}

\begin{tabular}{|c|c|}
\hline Variable & Description \\
\hline$A$ & Area \\
\hline$C$ & Constant \\
\hline$D$ & Particle/bubble diameter \\
\hline$E$ & Energy \\
\hline Eo & Eötvös number \\
\hline$F$ & Interfacial force \\
\hline$I$ & Turbulence intensity \\
\hline$K$ & Constant \\
\hline$L$ & Distance \\
\hline Mo & Morton number \\
\hline$P$ & $\begin{array}{l}\text { Maxwell distribution } \\
\text { function, } \\
\text { Pressure, }\end{array}$ \\
\hline$R e$ & Reynolds number \\
\hline$S$ & $\begin{array}{l}\text { Source or sink term, } \\
\text { Cross sectional collision area }\end{array}$ \\
\hline$S c$ & Schmidt number \\
\hline$V$ & Volume \\
\hline$a$ & Interfacial Area \\
\hline$a$ & Acceleration \\
\hline$g$ & Gravitational acceleration \\
\hline$k$ & Turbulence kinetic energy \\
\hline$l$ & Mean path length \\
\hline$n$ & $\begin{array}{l}\text { Particle/bubble number } \\
\text { density }\end{array}$ \\
\hline$p$ & $\begin{array}{l}\text { Pressure, } \\
\text { Probability }\end{array}$ \\
\hline$t$ & Time \\
\hline$u$ & Velocity \\
\hline$v$ & Velocity \\
\hline$x$ & Position \\
\hline
\end{tabular}




\section{Greek letters}

$\begin{array}{cl}\text { Variable } & \text { Description } \\ \Gamma & \text { Rate of mass production } \\ \alpha & \text { Gas volume fraction } \\ \varepsilon & \text { Turbulent energy } \\ & \text { dissipation } \\ \mu & \text { Dynamic viscosity } \\ \rho & \text { Density } \\ \sigma & \text { Surface tension } \\ \tau & \text { Stress tensor } \\ & \text { Time constant } \\ \varphi & \text { Time } \\ & \text { Source and sink term } \\ \omega & \text { Specific turbulence } \\ & \text { dissipation } \\ \phi & \text { Mean frequency of } \\ & \text { turbulence } \\ & \text { Source and sink term }\end{array}$

\section{Acronyms}

1D

2D

3D

ADV

AOB

ASM

ASM1

CFD

CSTR 1-dimensional

2-dimensional

3-dimensional

Acoustic Doppler Velocimeter

Ammonia oxidising bacteria

Activated sludge models

Activated sludge model number 1

Computational Fluid Dynamics

Continuous stirred tank reactor 
BIT

DNS

DO

DQMOM

FVM

HEM

HRT

IATE

MUSIG

PDE

PBE

PBM

QMOM

RANS

RMS

SND

SST

VOF

WWT

WWTP

1D

2D

$3 \mathrm{D}$
Bubble Induced Turbulence

Direct Numerical Simulation

Dissolved oxygen

Direct Quadrature Method Of Moments

Finite Volume Method

Homogeneous Equilibrium Model

Hydraulic retention time

Interfacial Area Transport Equation

MUltiple SIze Group

Partial differential equation

Population balance equation

Population balance model

Quadrature Method Of Moments

Reynolds averaged Navier-Stokes

Root Mean Square

Simultaneous Nitrification Denitrification

Shear Stress Transport

Volume Of Fluid

Wastewater treatment

Wastewater treatment plants

1-dimensional

2-dimensional

3-dimensional 



\section{Chapter 1}

\section{Introduction}

In this Chapter, a brief description of the research work carried out is provided beginning with introduction of background and the concept of CFD simulation applied to wastewater treatment modelling. This is followed by the objectives and the present contribution of the study. Finally, an outline of the overall dissertation is provided.

\subsection{Background}

To a large extent the problems derived from the accumulation of nitrogen and phosphorus, the discharge of wastewater into seas, rivers and lakes has led to an increase on the studies relating to new technologies and methods of wastewater treatment, based mainly in biological processes. These processes taking place in WWTP, consist of biochemical transformations the microorganisms make during their growth.

The biological treatment or secondary stage is one of the most important among the different processes that can be found in a WWTP (C. P. L. Grady et al, 2011); it is composed by the biological reactor and the secondary settling tank and it is considered the most critical and sensitive stage in the wastewater treatment cycle (Metcalf \& Eddy, 2004). It is at this stage where most of the efforts of process optimization in WWTP focus in order to reduce the costs associated with its operation since the energy consumption and the economic resources destined to the biological treatment represent up to $40 \%$ of the total energy consumption of the whole plant, depending on the type of WWTP (Water Environment Federation, 2006). Over the last decade, new bioprocesses have been investigated as innovative solutions for nitrogen removal, which can reduce significantly the energy consumption in WWTPs. However, activated sludge is the most wide-spread due to its robustness and effectiveness versus the new technologies, which while considered more sustainable, have severe limitations for full-scale implementation 
and only can find their application in sidestream treatments in WWTPs (A. van Haandel and J. van der Lubbe, 2012).

Recently, mathematical modelling and numerical simulation have become essential for most of the physical and biochemical processes that take place in the WWTP, they have been extended as tools of great potential in design, operation and process control of a WWTP (Makinia and Zaborouska, 2010). Their main aim is to enhance the efficiency and saving costs on resources by exploring the dynamic behavior of the process units under different conditions. This is usually carried out using Systemic Modelling (Le Moullec et al., 2010) through simulators with a visual programming environment (Simulink(C) based on ASM models (Henze et al., 2000) implementation (Jeppsson, 1996), which are very widespread because of its robustness, its quick calculation response, and its simplicity to run the model. They have been well accepted on the water sector by both the industry and the scientific community. On the one hand, most of the water treatment companies around the world design and operate their WWTP configurations using commercial software simulators such us Biowin, GPS-X, WEST, SSSP, Aquasim, Simba, SUMO, DESSAS, etc. which count on ASM-ADM state variable interface (Elawwad et al., 2019). On the other hand, researchers use plant-wide modelling focused on WWTP process control (Coop et el., 2003); (Seco et al., 2004); (Grau et al., 2007); (Alex et al., 2008).

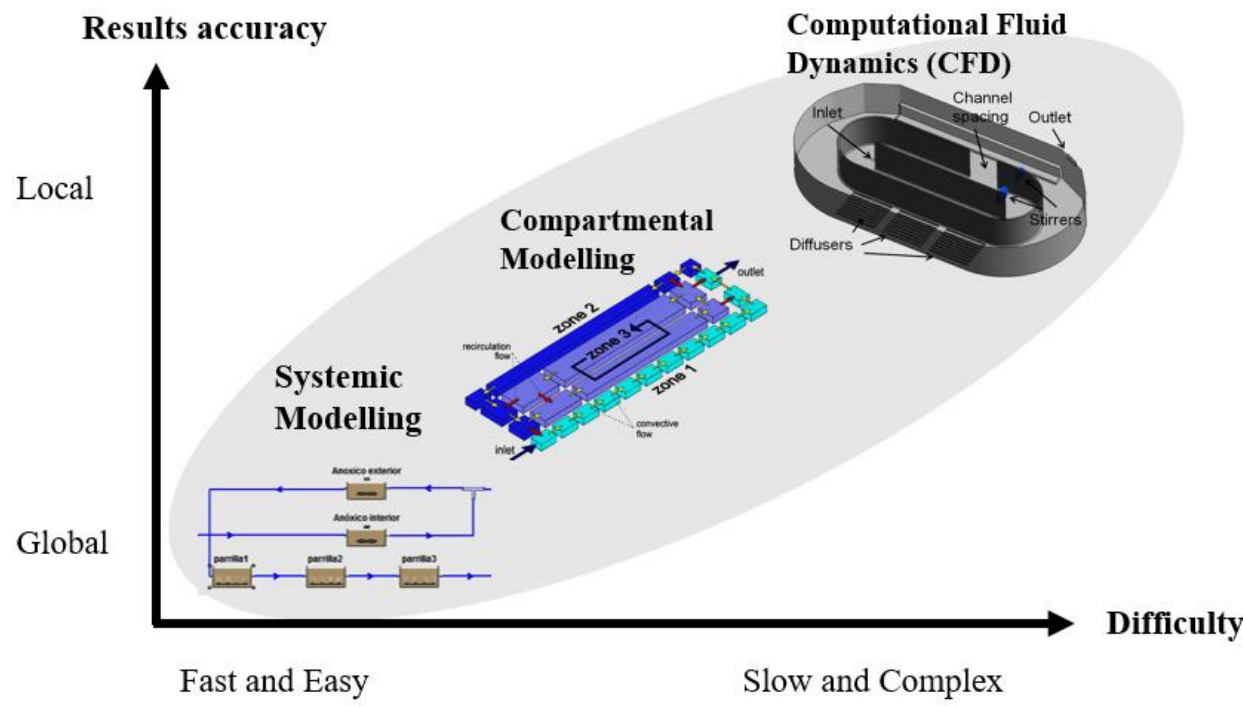

Figure 1.1. Modelling approaches applied to wastewater treatment.

Mathematical modelling applied to wastewater treatment simulation use Systemic Modelling to reproduce hydrodynamics, which consists in completely stirred tank reactors (CSTR) connected in series (Levenspiel, 1999) with recirculations. Once 
the activated sludge system is calibrated dynamically (Hulsbeek et al, 2002), they provide global results very fast. From this, one can obtain the value of the state variables in one dimension, in each of the tanks that represent the system. However, this hydraulic modelling approach does not take into account the geometry of the tanks, the gradient of the state variables and the spatial distribution of the internal elements inside the tank, and it is not able to detect problems in the fluid behavior such as short-circuiting and dead volumes, insufficient mixing or solid sedimentation, typical phenomena that takes place in real tanks and play a key role in the pollutant removal efficiency.

In recent years, there has been a notable increase in scientific production related to modelling applied to wastewater treatment using CFD techniques (Glover et al. 2006), (Samstag, 2008) from basic research to engineering design. As has already happened in other industries, these complex simulation tools have become a robust and accurate technique for the design and optimization of the tanks in a WWTP. The success of these lies in the capacity of reproducing hydrodynamics in detail, but in order to be fully applied (retroffiting of the tanks to reduce costs and improve water quality calculating nutrient removal, oxygenation, etc.), specific submodels as biokinetics, non-Newtonian fluid, turbulence, multi-phase flow must be implemented and defined in the code, with all the difficulties that its calibration and validation entail. Therefore, CFD results in long development and response times versus quick simulations of Systemic Modelling. Hence, in order to reduce the computing cost of CFD, Compartmental Modelling has been applied to wastewater treatment modelling (Le Moullec et al., 2011); (Delafosse et al., 2010). It consists on defining the reactor by compartments of different sizes connected through convective, and exchange fluxes (back-mixing rate) to better reproduce the hydraulics in a $2 \mathrm{D}$ or $3 \mathrm{D}$ domain. Thus, based on a CFD solution previously converged and/or tracer studies, a methodology to parametrize the turbulent exchange among the compartments is applied to approach the velocity field resulting from the CFD calculation (Rigopoulos and Jones, 2003); (Alvarado et al., 2012); (Le Moullec et al., 2011). This simplification allows reducing drastically the number of nodes (from $1 \mathrm{M}$ or hundreds of thousands of the CFD, to hundred or tens of the Compartmental Modelling) in order to calculate faster different kinetic scenarios. However, this Compartmental Modelling is only calibrated for a specific hydraulic configuration, it does not admit changes of inlet/outlets or internal elements without a previous CFD simulation from which calculate the hydrodynamic pattern in detail.

Reactors in WWTP are typically designed as mixed or as plug flow configurations (Metcalf and Eddy, 2004). However, real reactors often show more complex macroscopic flow structures with negative effects on plant performance which are essential to consider (Gresch et al., 2010). That said, among the different modeling tools available, CFD represents the most sophisticated mechanism of simulation able to analyze specific hydraulic problems in $3 \mathrm{D}$, considering multi-phase flow 
(solid-liquid-gas) modelling coupled to biokinetics as well as to other specific submodels (aeration, sedimentation, non-Newtonian fluid, etc.) characteristic of wastewater treatment modelling. Since the biological treatment takes place in large tanks, and hydrodynamics plays an important role in the operation, it is essential to study carefully the common fluid dynamics troubleshooting: mixing rate, residence time, solid sedimentation, dead volumes, internal recirculation, stratification/inhomogeneity, short-circuiting, etc. if we desire to account for the real performance of the systems.

CFD applied to biological reactors modelling entails difficulties that need research development focused in three main topics. Firstly, those of modelling: the complex study of the multiphase flow (gas, liquid and solid phases) linked to biokinetics, and the interaction of mixing and turbulence with biochemical reaction rates. Then, the non-Newtonian viscosity and extensions of the population balance models (PBM) to couple flocculation with CFD. Secondly, the need of reducing the high computing time by defining strategies to simplify the submodels keeping the accuracy in results. Finally, the assessment of the verification and the validation of CFD modelling applied to full-scale biological reactors.

\subsection{Objectives and Present Contribution}

The aim of this thesis is to analyze, develop and validate two full-scale CFD models based on single-phase and two-phase flow applied to biological reactors.

The general objective is to extend the knowledge in the application of CFD simulation techniques to the biological reactors implementing specific submodels. This has been achieved through the study of real tanks where the effects of the internal elements of the tanks (mixers and diffusers) and the influence of the geometrical configuration have been analysed.

The specific objectives have been:

a) To evaluate changes in full-scale configurations by CFD-ASM-modelling.

b) To define strategies for reducing the computational cost of CFD-ASMmodels.

c) To implement a PBM to study an aerated bioreactor through a two-phase flow approach.

d) To study the influence of the two most common internal elements over the hydrodynamics in real tanks.

e) To better understand the validation of full-scale configurations and their limitations. 
In this way, the defective hydraulic behavior of an anoxic zone of a biological reactor (Article A) has been studied. Through experimental measures it has been possible to verify the hydrodynamics and validate the CFD model. Subsequently, modifications of the internal elements and geometry have been made, executing in real scale and verifying again experimentally. In addition to the purely hydraulic improvement, through the implementation of the ASM1 model, it has been possible to verify the improvement denitrification efficiency. In addition to this single-phase model, the study of two-phase flow models in an oxidation ditch biological reactor configuration has been deepened (Article B). Besides to tracer tests, an extensive measurement campaign has been carried out to validate the hydraulic behavior and propose new configurations in the arrangement of the internal elements of the reactor. It has been possible to study the population balance model applied to the study of bubble dynamics. In this work we have also studied a new approach to perform the oxygen transfer from the submerged aeration system, since the computation time is extremely high when the oxygen transfer is made from the gas phase. With this, the denitrification nitrification in the reactor has been reproduced through the implementation of a simple control system that reproduces the behavior in the plant consisting of ON-OFF cycles.

These give some remarkable inputs for the knowledge of this topic. We think the paper present the quality expected for this type of research by including as the main valuable inputs to consider as follows:

- The implementation of the free-surface approach instead of the free-slip approach, which is most commonly used. It allowed the hydrodynamic behaviour at the interface (liquid -gas) to be reproduced in detail.

- The PBM analysis allowed the bubble size distribution to be studied in a nonstandard full-scale configuration, where only the $20 \%$ of the bottom zone is covered with diffusers.

- The rheology was considered for both CFD models (single and two-phase flow) based on the experimental measurements.

- The interaction between the internal elements, 3 grids of diffusers located at the other side of the 2 propellers, was successfully studied.

- The CFD model was used to optimize the process through different alternatives. For this, a specific criterion based in the nutrient removal improvement was defined.

- The validation is extensive in both scenarios (single-phase and two-phase flow) by measuring in many locations, also covering all the section of the channel (height and width) and thus, providing ample information of the fluid behaviour from the three components of the velocity. 


\subsection{Outline}

The outline of the Thesis is divided in five Chapters and two Appendices.

Chapter 1 provides the Introduction which consists in the description of the Background, the Objectives, the main points of the present contribution, and the outline where the structure of the document is detailed.

Chapter 2 describes the State of the Art. It is composed by three sections. Firstly, basics of the CFD Modelling used in this work are presented: single and two-phase flow equations, turbulence, numerical resolution, verification and validation of the models. Secondly, the essentials of the Activated Sludge configurations studied are described. Finally, biological models implemented and used to conduct this work are presented.

Chapter 3 consists on the description of the Materials and Methods defined to develop the CFD models and to carry out the CFD simulations as well as the experimental techniques used to validate the CFD models experimentally. Firstly, brief state of the art of the CFD Modelling applied to wastewater treatment is exposed. Then, the boundary conditions, the performance of the mesh, the discretization scheme chosen to solve the equations, the Multi-phase flow solver and how to implement the biochemical models and to define the mixers in a fullscale CFD simulation are defined. After that, the validation conducted in the field to validate hydrodynamics is described starting with an explanation of tracer test procedure. Finally, the strategies developed and implemented in the CFD models to calculate faster the simulations are described.

Chapter 4 contains the analysis of the main results obtained in the configurations studied: MLE, Orbal and Oxidation Ditch configurations. These are the main contributions of the articles A and B which are included entirely in the Appendix.

Chapter 5: This chapter exhibits the conclusions and the future work of this thesis.

Appendix A and B are included at the end of this document, they consist on the paper $\mathrm{A}$ and the paper $\mathrm{B}$, correspondingly.

\section{Article A (Appendix A)}

Paper A is included in Appendix A. The outline of this work was divided into three different steps. The two symmetrical wastewater treatment lanes (WWTL1, WWTL2) of the MLE bioreactor were used to carry out this study. Firstly, a CFD model (L1CFDo) was developed to study hydrodynamics in the Original configuration of WWTL1 (WWTL1o), validated experimentally by means of tracer tests (I). Secondly, the CFD model was used to perform improvements in the fluid behaviour over WWTL1 (L1CFDmod), which was eventually retrofitted. After the 
full-scale modifications in WWTL1, the modified configuration (WWTL1mod) was validated using tracer tests and velocity measurements (II). Finally, the CFD-ASM1 model for each configuration was developed calculating differences in denitrification performance, which were validated experimentally comparing WWTL1mod and WWTL2 (Original) (III).

As a result, we demonstrate that the retrofitted configuration WWTL1 (WWTL1mod) provides an effluent with higher quality compared with the unchanged WWTL2.

\section{Article B (Appendix B)}

The outline of the work was divided in three parts. Firstly, tracer tests are analysed to describe the global fluid behaviour. Subsequently, tracer results are related to the detailed description of the hydrodynamics provided by the CFD results. These were obtained for single-phase and two-phase flow models, depending on whether the air is supplied or not. A valuable comparison of the two hydrodynamic regimes is shown in this section. Secondly, the experimental validation for both cases is discussed and then, the PBM results are analysed. Finally, the improvement of the hydraulic behaviour carried out using CFD modelling is shown. 



\section{Chapter 2}

\section{State of the art}

\subsection{CFD Modelling}

Among all the definitions of CFD that one can find, it can be held that CFD is the science focused on the study of the fluid flow to predict the transfer of mass, energy and momentum, solving all the mathematical equations that lead these processes through the use of numerical methods. The complex set of partial differential equations are solved on in geometrical domain divided into small volumes, commonly known as a mesh (or grid), (Versteeg and Malalasekera, 2007).

The flow is divided in two regimes according to its structure: laminar flow and turbulent flow. In laminar flow, the movement is well-ordered and smooth, with layers of fluid moving and sliding some on others. The fields of velocity and pressure change smoothly both in space and time. In turbulent flow, the movement is stochastic, characterized by the presence of eddies and swirls. Velocity and pressure fields change rapidly either with position and time.

In order to compute the dynamics of the turbulent flow, three main frameworks of modelling have been proposed:

- Direct numerical simulation (DNS): these simulations aim at resolving all the scales of turbulence, i.e. big and small eddies, by directly computing the Navier-Stokes equations. These calculations are highly costly in terms of computing time, so the method is not used for industrial flow computations.

- Large eddy simulation (LES): this approach aims at resolving the behaviour of the larger eddies and model the effects of the smaller ones. Although the demands on computing resources in terms of storage and volume of calculations are still large, this technique is starting to address CFD problems with complex geometry. 
- Turbulence models for Reynolds-averaged Navier-Stokes (RANS) equations: it is focused on the computation of the mean flow and the effects of turbulence on mean flow properties. For most applications in engineering it is not necessarily know the instantaneous value of fields with high resolution of the space-time, but it is enough to know the averaged value of it and having a certain idea of how intense the fluctuations are. Hence, for full-scale biological reactors as for most engineering purposes it is unnecessary to resolve the details of the turbulent flow. CFD users may be satisfied with information about the time-averaged properties of the flow (e.g. mean velocities, mean pressures, mean stresses etc.). Therefore, most turbulent flow computations have been and for the foreseeable future will continue to be carried out with procedures based on the Reynoldsaveraged Navier-Stokes (RANS) equations.

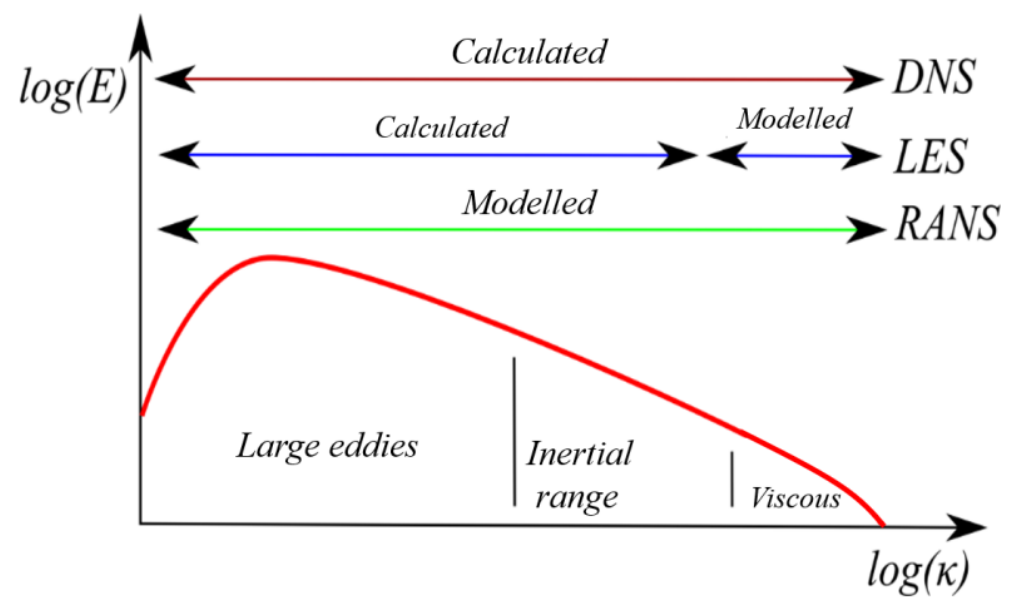

Figure 2.1. Main frameworks of modelling

In this section, the focus is on the definition of the Reynolds-Averaged NavierStokes equations for the single and the two-phase fluid flow approaches, the corresponding turbulence models, population balance model and the verification and validation used to perform the CFD simulations.

\subsubsection{Single phase flow}

RANS equations are used to model the single-phase flow regime. As described above, turbulence models aims to solve a modified set of transport equations by introducing averaged and fluctuating components. For example, a velocity $U_{i}$ may be divided into an average component, $\bar{U}_{i}$, and a time varying component, $u_{i}$. The averaged component is given by: 


$$
\bar{U}_{i}(t)=\frac{1}{\Delta t} \int_{t}^{t+\Delta t} U_{i}(\mathrm{t}) d t
$$

where $\Delta t$ is a time scale that is large relative to the turbulent fluctuations, but small relative to the time scale to which the equations are solved. For compressible flows, the averaging is weighted by density (Favre-averaging), but for simplicity, the following presentation assumes that density fluctuations are negligible. For transient flows, the equations are ensemble averaged. This allows the averaged equations to be solved for transient simulations too.

a)

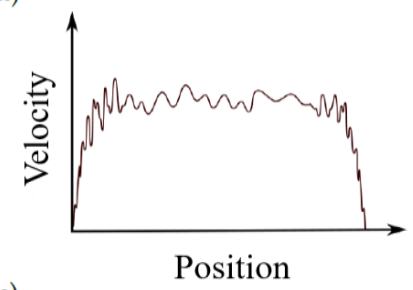

c)

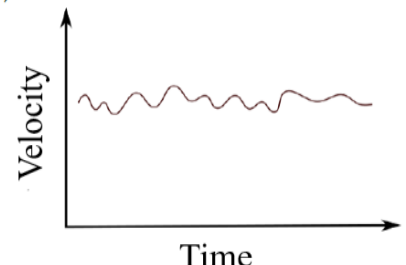

b)

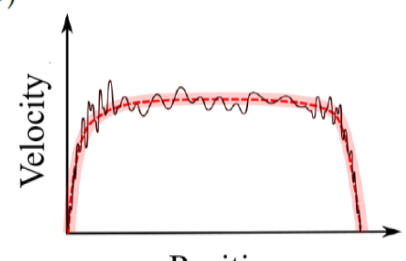

d)

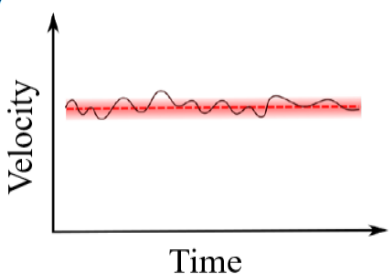

Figure 2.2. Decomposition of Reynolds in a pipe.

This type of information can be obtained by entering the so-called decomposition of Reynolds. As an example, Fig. 2.2a) illustrates the radial profile of instantaneous velocity in a tubular flow. The velocity is maximum in the centre and zero at the wall of the pipe. The profile is not smooth as it is in the laminar case, but there are small oscillations very close to each other. According to this decomposition, this field can be split into two fields as appears in Fig. 2.2.b), that is, in a field of soft spatial variation (dashed line) and a field that expresses the amplitude of the oscillations (degraded). In the same way, Fig. 2.2.c) illustrates the evolution of velocity at the central point of the pipe. The velocity does not remain constant in time. Although the pumping power can be considered as constant, it presents small temporary fluctuations. The decomposition of Reynolds takes this behaviour as shown in Fig. 2.2.d), that is, as a field of average velocity (dashed line) and a field that determines the amplitude of fluctuations (degraded). 
Substituting the averaged quantities into the original transport equations results in the Reynolds averaged equations given below. In the following equations, the bar is dropped for averaged quantities, except for products of fluctuating quantities.

\section{Mass Conservation}

$$
\frac{\delta \rho}{\delta t}+\operatorname{div}\left(\rho U_{i}\right)=0
$$

\section{Linear Momentum Conservation}

$$
\begin{aligned}
& \frac{\delta\left(\rho U_{1}\right)}{\delta t}+\operatorname{div}\left(\rho U_{1} U_{1}\right) \\
& =-\frac{\delta p}{\delta x_{1}}+\operatorname{div}\left(\tau \operatorname{grad} U_{1}\right) \\
& +\left[-\frac{\delta\left(\rho \overline{u_{1}^{2}}\right)}{\delta x_{1}}-\frac{\delta\left(\rho \overline{u_{1} u_{2}}\right)}{\delta x_{2}}-\frac{\delta\left(\rho \overline{u_{1} u_{3}}\right)}{\delta x_{3}}\right]+S_{M x_{1}} \\
& \frac{\delta\left(\rho U_{2}\right)}{\delta t}+\operatorname{div}\left(\rho U_{2} U_{1}\right) \\
& =-\frac{\delta p}{\delta x_{2}}+\operatorname{div}\left(\tau \operatorname{grad} U_{2}\right) \\
& +\left[-\frac{\delta\left(\rho \overline{u_{1} u_{2}}\right)}{\delta x_{1}}-\frac{\delta\left(\rho \overline{u_{2}^{2}}\right)}{\delta x_{2}}-\frac{\delta\left(\rho \overline{u_{2} u_{3}}\right)}{\delta x_{3}}\right]+S_{M x_{2}} \\
& \frac{\delta\left(\rho U_{3}\right)}{\delta t}+\operatorname{div}\left(\rho U_{3} U_{1}\right) \\
& =-\frac{\delta p}{\delta x_{3}}+\operatorname{div}\left(\tau \operatorname{grad} U_{3}\right) \\
& +\left[-\frac{\delta\left(\rho \overline{u_{1} u_{3}}\right)}{\delta x_{1}}-\frac{\delta\left(\rho \overline{u_{2} u_{3}}\right)}{\delta x_{2}}-\frac{\delta\left(\rho \overline{u_{3}^{2}}\right)}{\delta x_{3}}\right]+S_{M x_{3}}
\end{aligned}
$$

where $\tau$ is the molecular stress tensor (including both normal and shear components of the stress. 
The continuity equation has not been modified but the momentum and scalar transport equations contain turbulent flux terms additional to the molecular diffusive fluxes. These are the Reynolds stresses, $\overline{u_{\imath} u_{\jmath}}$. These terms stand up from the nonlinear convective term in the un-averaged equations. They reproduce the convective transport due to turbulent velocity fluctuations which will act to enhance mixing over and above that caused by thermal fluctuations at the molecular scale. Consequently, at high Reynolds numbers, turbulent velocity fluctuations the turbulent fluxes are much larger than the molecular fluxes. The additional variable $\Phi$ may be divided into an average component, $\bar{\Phi}$, and a time varying component, $\varphi$. After dropping the bar for averaged quantities, except for products of fluctuating quantities, the Additional Variable equation becomes

\section{Energy conservation}

$$
\begin{aligned}
\frac{\delta(\rho \Phi)}{\delta t}+\operatorname{div}\left(\rho U_{i} \Phi\right) & \\
& =\operatorname{div}(\Gamma \operatorname{grad} \Phi) \\
& +\left[-\frac{\delta\left(\rho \overline{u_{1} \varphi}\right)}{\delta x_{1}}-\frac{\delta\left(\rho \overline{u_{2} \varphi}\right)}{\delta x_{2}}-\frac{\delta\left(\rho \overline{u_{3} \varphi}\right)}{\delta x_{3}}\right]+S_{\Phi}
\end{aligned}
$$

where $\rho \overline{u_{j} \varphi}$ is the Reynolds flux

To better understand the effect of each of the parameters below, it is indicated which term corresponds to each effect. For the case of the conservation equation of the moment of the $\mathrm{X}$ coordinate:

Local acceleration Pressure gradient Diffusive term

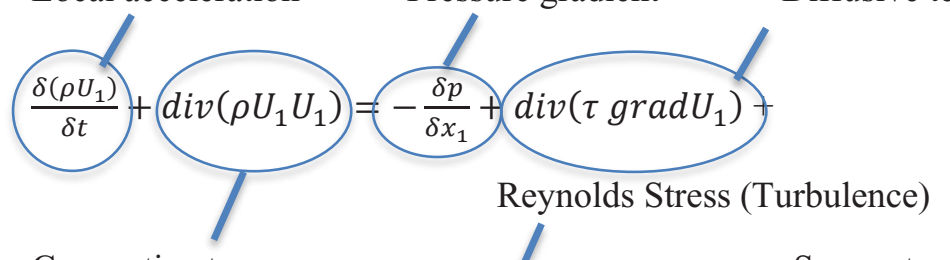

Convective term

Source term

$$
\left.+-\frac{\delta\left(\rho \overline{u_{1}^{2}}\right)}{\delta x_{1}}-\frac{\delta\left(\rho \overline{u_{1} u_{2}}\right)}{\delta x_{2}}-\frac{\delta\left(\rho \overline{u_{1} u_{3}}\right)}{\delta x_{3}}\right] S_{M x_{1}}
$$




\subsubsection{Two-phase flow}

Multiphase flow refers to the situation where more than one fluid is present. Each fluid may possess its own flow field, or all fluids may share a common flow field. Two-phase flow states to any fluid flow consisting of two phases of the same or of two different materials which can be classified according to the combinations of the two phases as: solid-liquid, liquid-liquid, solid-gas, and liquid-gas. The focus of the present study has been focused on gas-liquid two-phase flow. Two-phase flow as any other flow in nature follows the laws of fluid mechanics, and therefore, the Navier-Stokes equations are valid to describe the flow in each condition. Its description is much more complex than single phase flow since the presence of a deformable gas-liquid interface leads to an infinite number of possible configurations (Hewitt, 2012). Gas-liquid is probably the most important form of two-phase flow and it can be found frequently in a wide range of industrial applications. These include chemical reactors, wastewater treatment plants, pipeline systems for the transport of liquid and gas, automotive industry, etc.

The use of CFD aims to reproduce the hydrodynamic behaviour, mass transfer, flow regime and mixing behaviour in practical industrial applications. It allows numerical simulations to be performed like experimental work with the capability to provide detailed, visualized and comprehensive information of the model which might be difficult to get experimentally. There are two main approaches of gasliquid two-phase flow simulations: Euler-Lagrangian (E-L) model and Euler-Euler (E-E) model.

The Eulerian-Lagrangian model (Delnoij et al., 1997), (Laín et al., 2001) also named discrete bubble model can be used where the primary phase is solved by phase-averaged equations whereas bubbles are modelled by point force distributions at the discrete location of bubbles and the equation of motion is solved by considering each bubble or particle has a velocity and very distinct properties (such as bubble size, shape, void fraction), which allows for a detailed description of the flow of the individual particles. This method is particularly useful to study the effect of bubble-wall and/or bubble-bubble interactions but it presents the main disadvantage of the high computational effort that increases as the total number of bubbles or particles to be tracked.

Conversely, the Eulerian-Eulerian model can be used for modelling any type of two-phase flows where both the liquid and gas phases are regarded as two interpenetrating phases, and each phase has its own set of conservation equations of mass, momentum and energy, coupled with some phase interaction terms. The governing equations are derived from various averaging techniques: time averaging (Ishii, 1975), volume averaging (Nigmatulin, 1979) and ensemble averaging (Buyevich and Schchelchkova, 1978). This method is the most computationally effective and is capable to model large scale gas-liquid flows in full-scale tanks. To date, more efforts are still needed to develop mechanistic closure models for bubble 
forces, turbulence generated by the bubble and bubble dynamics such us coalescence and breakup models, which should be accounted for through a proper model, as shown in this work, rather through relatively simple constitutive equations.

Three main approaches to the modelling of two-phase flow using the EulerianEulerian formulation can be distinguished: the homogeneous equilibrium model (HEM), the drift flux model, and the two-fluid model.

In the HEM is assumed that the velocity, temperature and pressure between the phases or components are equal and in thermodynamic equilibrium. The HEM solves the mass, momentum and energy conservation equations for the mixture only.

The drift flux model (Zuber and Findlay, 1965) is an approximate formulation in comparison with the more rigorous two-fluid formulation. The basic concept of the drift-flux model is to consider the mixture rather than as two separated phases. The most important assumption associated with the drift-flux model is that the dynamics of two phases can be expressed by the mixture-momentum equation with the kinematic constitutive equation specifying the relative velocity between phases. The model can decrease the computing cost by reducing two momentum equations to one mixture momentum equation; however, the major difficulty is to obtain the relative velocity correlations which can appropriately and simultaneously represent the dynamic behaviours of both phases under a wide range of flow conditions.

The two-fluid model is the most detailed and accurate macroscopic formulation of the fluid dynamics of two-phase systems (Ishii, 1975). The model can predict more detailed changes and phase interactions than those presented above. The complexity of the model is not only in terms of the number of field equations involved but also in terms of the necessary constitutive equations for the mass, momentum and energy transfer between the phases at the interface vapour-liquid or gas-liquid. In wastewater treatment modelling this is the most used to reproduce aeration. The effects of the air injection significantly change the hydrodynamics flow when the aeration is applied. Momentum transfer from bubble swarms have a clear influence on the velocity field of the mixed liquor, especially in the region located right on the top of the aerators. The internal flow structure of two-phase gas-liquid flows are characterized by the interfacial area concentration, the gas volume fraction, and mean bubble diameter. This last serves as a link between the gas volume fraction and interfacial area concentration (Kocamustafaogullari and Huang, 1994). The interfacial area concentration can mathematically be represented by the bubble number density, and the variation of bubble number density occurs when bubbles coalesce and/or breakup, which can be described by the population balance model. In industrial applications like aerated biological reactors, with high gas volume fraction leads to a broader bubble size distribution due to bubble breakup and coalescence. The population balance model, a well-established method for 
calculating the size distribution of a poly-dispersed phase and accounting for the breakage and coalescence effects in bubbly flows has become a useful approach in gas-liquid flows (Lehr et al., 2002), (Wang et al., 2010).

In modern 3D CFD codes, the interfacial area density prediction is based on a simplification of the structure of the interface between the phases. Furthermore, the flow morphology is a required user input that needs to be defined by the user. For example, this is the case of Eulerian multiphase flow modelling where, for the moment, no predictive model for flow morphology exists.

\section{Continuity Equations}

$$
\frac{\partial}{\partial t}\left(r_{\alpha} \rho_{\alpha}\right)+\nabla \cdot\left(r_{\alpha} \rho_{\alpha} \boldsymbol{U}_{\alpha}\right)=\boldsymbol{S}_{M S \alpha}+\sum_{\beta=1}^{N_{p}} \Gamma_{\alpha \beta}
$$

Where $r_{\alpha}$ is the volume fraction, $\rho_{\alpha}$ is the density, $U_{\alpha}$ is the velocity of phase $\alpha$.

- $S_{M S \alpha}$ describes user specified mass sources.

- $\Gamma_{\alpha \beta}$ is the mass flow rate per unit volume from phase $\beta$ to phase $\alpha$. This term only occurs if interphase mass transfer takes place.

\section{Volume Conservation Equations}

This is simply the constraint that the volume fractions sum to unity:

$$
\sum_{\alpha=1}^{N_{p}} r_{\alpha}=1
$$

This equation may also be combined with the phasic continuity equations to obtain a transported volume conservation equation. Dividing by phasic density, and sum over all phases. This yields:

$$
\sum_{\alpha} \frac{1}{\rho_{\alpha}}\left(\frac{\partial}{\partial t}\left(r_{\alpha} \rho_{\alpha}\right)+\nabla \cdot\left(r_{\alpha} \rho_{\alpha} \boldsymbol{U}_{\alpha}\right)\right)=\sum_{\alpha} \frac{1}{\rho_{\alpha}}\left(\boldsymbol{S}_{M S \alpha}+\sum_{\beta=1}^{N_{P}} \Gamma_{\alpha \beta}\right)
$$

Interpreting this equation is simpler if you consider the special case of incompressible phases with no sources, in which it simplifies to:

$$
\sum_{\alpha} \nabla \cdot\left(r_{\alpha} \boldsymbol{U}_{\alpha}\right)=0
$$

which requires the volume flows to have zero divergence. 


\section{Momentum Equations}

$$
\begin{gathered}
\frac{\partial}{\partial t}\left(r_{\alpha} \rho_{\alpha} \boldsymbol{U}_{\alpha}\right)+\nabla \cdot\left(r_{\alpha}\left(\rho_{\alpha} \boldsymbol{U}_{\alpha} \otimes \boldsymbol{U}_{\alpha}\right)\right) \\
=-r_{\alpha} \nabla p_{\alpha}+\nabla \cdot\left(r_{\alpha} \mu_{\alpha}\left(\nabla \boldsymbol{U}_{\alpha}+\left(\nabla \boldsymbol{U}_{\alpha}\right)^{T}\right)\right) \\
+\sum_{\beta=1}^{N_{p}}\left(\Gamma_{\alpha \beta}^{+} \boldsymbol{U}_{\beta}-\Gamma_{\beta \alpha}^{+} \boldsymbol{U}_{\alpha}\right)+\boldsymbol{S}_{M \alpha}+\boldsymbol{M}_{\alpha}
\end{gathered}
$$

Where $r_{\alpha}$ is the volume fraction, $\mu_{\alpha}$ is the viscosity, $r_{\alpha}$ is the volume fraction, $U_{\alpha}$ and $U_{\beta}$ is the velocity of phase $\alpha$ and $\beta$, respectively.

- $S_{M \alpha}$ describes momentum sources due to external body forces, and userdefined momentum sources.

- $\quad M_{\alpha}$ describes the interfacial forces acting on phase $\alpha$ due to the presence of other phases. Additional information for the models available for interfacial forces is available in Interphase Momentum Transfer Models.

- $\Gamma_{\alpha \beta}$ is the mass flow rate per unit volume from phase to phase where $\Gamma_{\alpha \beta}=\Gamma_{\alpha \beta}^{+}-\Gamma_{\beta \alpha}^{+}$, and the term $\Gamma_{\alpha \beta}^{+}>0$ represents the positive mass flow rate per unit volume from phase to phase.

The term:

$$
\left(\Gamma_{\alpha \beta}^{+} \boldsymbol{U}_{\beta}-\Gamma_{\beta \alpha}^{+} \boldsymbol{U}_{\alpha}\right)
$$

represents momentum transfer induced by interphase mass transfer.

The above momentum equations are valid for fluid phases only. For dispersed solid phases, additional terms are present representing additional stresses due to particle collisions.

The viscous stress term contains the product of $r_{\alpha}$ and $\mu_{\alpha}$. Consequently, as the volume fraction approaches zero, so does the dissipation. However, for a dilute phase, the magnitude of the dissipation is still significant because the mass of the dilute phase also goes to zero as $r_{\alpha}$ approaches zero. This is true not only for momentum but also for any other transported quantity that includes a diffusion term (such as energy). If the volume fraction gradient is very large, the diffusion term can cause convergence problems because the cell with the smaller volume fraction will "perceive" a very large relative flux.

Within the Eulerian-Eulerian model, certain inter-phase transfer terms used in the momentum and other inter-phase transfer models, can be modelled using the Particle Model, the Mixture Model or the Free Surface Model (ANSYS, 2019). Hence, the calculation of the interfacial area density, used for all inhomogeneous transfer models for a given fluid pair, is calculated according to one of these 
models. The Particle Model used in this study considers one of the two phases to be continuous and the other dispersed. The dispersed phase can be considered as:

- Mono-dispersed

- $\quad$ Poly-dispersed

In case of monodispersed flow calculations, a unique constant bubble diameter is set by the user and the void fraction is calculated by the solution of the mass conservation equation. Considering bubbles as rigid spheres it is possible to determine the interfacial area concentration by means of the following equation:

$$
a_{i}=\frac{6 \alpha}{D_{s}}
$$

where $\alpha$ is the gas volume fraction and $\mathrm{D}_{\mathrm{s}}$ is the Sauter mean diameter. It is defined as the diameter of a sphere that has the same volume/surface area ratio as a particle of interest.

In case of polydispersed flow, the prediction of the interfacial area concentration is similarly determined considering the contributions of the various bubble groups that have been defined by the user. Each bubble group is contributing to the global value of the interfacial area concentration based on its size fraction. In this case the size fractions are dynamically modified by the interactions between bubbles of the same and different groups.

The theory described below only applies to inhomogeneous multiphase flow (for example MUSIG model which is described later).

Interphase momentum transfer, $M_{\alpha \beta}$, occurs due to interfacial forces acting on each phase $\alpha$ due to interaction with another phase $\beta$. The total force on phase $\alpha$ due to interaction with other phases is denoted $M_{\alpha}$, and is given by:

$$
M_{\alpha}=\sum_{\beta \neq \alpha} M_{\alpha \beta}
$$

Note that interfacial forces between two phases are equal and opposite, so the net interfacial forces sum to zero:

$$
\left(M_{\alpha \beta}=-M_{\alpha \beta}\right) \rightarrow \sum_{\alpha} M_{\alpha}=0
$$

The total interfacial force acting between two phases may arise from several independent physical effects:

$$
M_{\alpha \beta}=M_{\alpha \beta}^{D}+M_{\alpha \beta}^{L}+M_{\alpha \beta}^{L U B}+M_{\alpha \beta}^{V M}+M_{\alpha \beta}^{T D}+M_{S}+\ldots
$$


The forces indicated above respectively represent the interphase drag force, lift force, wall lubrication force, virtual mass force, turbulence dispersion force and solids pressure force (for dense solid particle phases only). The definition of the interfacial forces will be described in the section 3.2.5 Interfacial forces.

\section{$\underline{\text { 2.1.3 Population Balance Model }}$}

The population balance of any system is a record for the number of elements, which may be solid particles, liquid, bubbles or, variables (in mathematical terms) whose presence governs the overall behaviour of the system under study (Nopens, 2005). Population balance is a well-established method for calculating the size distribution of a polydispersed phase, including breakup and coalescence effects. These equations are particularly useful for situations where particulates continually lose their identities, e.g. in crystallizers, liquid-liquid and gas-liquid contactors, microbial fermentors, fluidized beds and polymer reactors (D. Ramkrishna, 1985). Gas-liquid flows are commonly encountered in industrial flow systems where the record of these bubbles is dynamically depended on the "birth" and "death" processes that terminate existing bubbles and create new bubbles within a finite or defined space. A variety of approximation methods exists. Thus, several works offering comparisons between these methods over the same system to better fit the experimental data can be found in literature (Yeoh et al. 2012), (Deju et al., 2013).

Analytical methods to solve the PBE requires extensive computational efforts, and for this reason numerical methods are usually applied. The original technique to solve this numerically was to discretize the equation in several equations, the discretized population balance (DPB) or class method (CM) (Kumar and Ramkrishna. 1996a, 1996b) with the disadvantage that high number of equations were required. Class method typified by the MUltiple SIze Group (MUSIG) model appeared to be one of the most direct methods to solve the PBE using a finite series of discrete classes (Yeo et al., 2012) while Interfacial Area Transport Equation (IATE) can be considered the cheapest approximation of the PBE in terms of computation time (Kocamustafaogullari and Ishii., 1995). An approximation to solve PBE with a reduced number of equations are the Quadrature Method Of Moments (QMOM) (McGraw, 1997), (Sanyal et al. 2005) which was implemented to reduce the computational requirements without compromising accuracy. Then, simulations of bubbly flows with a two-fluid model using the Direct Quadrature Method Of Moments (DQMOM), which solves the equations for the weights and abscissae directly, can be found in the literature for ANSYS in (Cheung et al. 2013).

A general form of the population balance equation is given by Kocamustafaogullari and Ishii, (1995) in terms of a conservation equation for the number density of particles or bubbles as: 


$$
\frac{\partial f(V, x, t)}{\partial t}+\nabla \cdot[f(V, x, t) \vec{v}(V, x, t)]=\sum_{j} S_{j}+S_{p h}
$$

where $f(V, x, t)$ is the number probability density function, $V$ is the bubble volume, $\vec{v}$ is the bubble velocity, $t$ is time, and $x$ is the position vector.

The first term on the right-hand side of (Eq. 2.16) refers to the production or destruction of bubble of a given volume by processes of breakup and coalescence, while the second term relates to bubble generation by processes such as nucleation and gas-liquid mass transfer. Due to the forms of the terms describing breakup and coalescence processes, the population balance equation (Eq. 2.16) is too detailed to be used in practice. As said above, a variety of approximate methods exist.

Based on the two-fluid model approach, different modelling frameworks can be found in literature that have been proposed to obtain practical solution to the population balance model equation. As mentioned, the class method (CM), due to its rather straight-forward implementation, has received greater attention and increasingly being adopted as the preferred method for population balance modelling.

Kocamustafaogullari and Ishii, (1995) proposed an interfacial area transport equation (IATE) for tracking the interfacial area concentration between gas and liquid phase in bubbly flow problems based on the Boltzmann transport equation. The value of interfacial area is modified along the flow path due to several effects, in particular: particle volume change, change in pressure, interaction mechanisms between the phases, and phase change phenomena. The IATE was achieved through implementation and testing of some typical models for bubble breakup and coalescence mechanisms taken from literature. It uses an averaged quantity to represent the overall changes of the particle population.

If IATE is compared to the polydispersed calculation methods, since only one group of bubbles is considered in it, there is no need to implement complicated and resources intensive integrals for the statistical calculation of the size of the child bubbles produced after the breakup. As the population of particle is represented by a single average scalar, such average quantity approach requires very limited computational time in solving the PBE.

The MUltiple-SIze-Group (MUSIG) model which was first introduced by Lo, (1996) is a classic example of the population balance model. The model has been widely implemented for the study of gas-liquid two-phase flow simulations. A series of discrete bubble size classes can be calculated describing the spectrum of bubble size, and the dynamical changes of size distribution can thus be tracked. The method then becomes more feasible with appropriate coalescence and breakup mechanisms to lead the inter-group mass transfer. The MUSIG model by Lo, (1996) is called homogeneous MUSIG since it assumes that all the discrete bubble size 
classes move with the same velocity field. Conversely, in order to address the coexistence of small and large bubbles travelling within the gas-liquid flows, (Rzehak et al., 2013) proposed the inhomogeneous MUSIG model which consists of subdividing the dispersed phase discrete bubble size classes into $\mathrm{N}$ number of velocity fields. This flexibility represents a robust feature for multiphase flows modelling, especially for bubbly flow simulations where bubbles may deform into different shapes.

The starting point of the formulation of the MUSIG model originates from the discretized population balance equation given by:

$$
\frac{\partial n_{i}}{\partial t}+\nabla \cdot\left(n_{i} \vec{v}_{i}\right)=\sum_{j} R_{j}
$$

In order to guarantee overall mass conservation for all poly-dispersed vapour phases, the above bubble number density equation for the homogeneous MUSIG model can be re-expressed in terms of size fraction of bubble size groups according to (Kumar and Ramkrishna, 1996a, 1996b):

$$
\frac{\partial \rho_{j} \alpha_{j} f_{i}}{\partial t}+\nabla \cdot\left(\rho_{j} \alpha_{j} \vec{v}_{j} f_{i}\right)=S_{i}
$$

with additional relations and constrains:

$$
\begin{gathered}
\alpha_{g}=\sum_{j=1}^{N} \alpha_{j} \\
\alpha_{g}+\alpha_{l}=1 \\
\sum_{i=1}^{M_{j}} f_{i}=1
\end{gathered}
$$

For adiabatic condition, the source term $S_{i}$ accounts for: (i) the birth of bubbles of size $i$ due to breakup of bubbles of larger size and coalescence of bubbles of smaller size, $B_{b i}, B_{c i}$; and (ii) the death of bubbles of size $i$ due to break up and coalescence encountered in this size group, $D_{b i}, D_{c i}$. Thus, the source term $S_{i}$ can be expressed as:

$$
S_{i}=B_{b i}-D_{b i}+B_{c i}-D_{c i}
$$

The contribution of the birth rate due to breakup of larger bubbles to the source term in equation (2.22) is expressed as: 


$$
B_{b i}=\rho_{j} \alpha_{j}\left(\sum_{j>i} \Omega\left(m_{j}, m_{i}\right) f_{j}\right)
$$

Similarly, the contribution of the death rate due to breakup into smaller particles is expressed as:

$$
D_{b i}=\rho_{j} \alpha_{j}\left(f_{i} \sum_{j<i} \Omega\left(m_{i}, m_{j}\right)\right)
$$

The contribution of the birth rate due to coalescence of smaller bubbles to the source term in equation (2.22) is expressed as:

$$
B_{c i}=\left(\rho_{j} \alpha_{j}\right)^{2}\left(\frac{1}{2} \sum_{j \leq i} \sum_{k \leq i} \Gamma\left(m_{j}, m_{k}\right) X_{j k i} f_{j} f_{k} \frac{m_{j}+m_{k}}{m_{j} m_{k}}\right)
$$

Similarly, the contribution of the death rate due to coalescence into larger groups is expressed as:

$$
D_{c i}=\left(\rho_{j} \alpha_{j}\right)^{2}\left(\sum_{j} \Gamma\left(m_{i}, m_{j}\right) f_{i} f_{j} \frac{1}{m_{j}}\right)
$$

where $X_{j k i}$ is the coalescence mass matrix defined as the fraction of mass due to coalescence between groups $j$ at $t$, which goes into group $\mathrm{i}, \mathrm{m}_{\mathrm{i}}$ is the mass fraction of the particular size group $i, \Omega$ and $\Gamma$ are breakup and coalescence kernel functions, respectively.

The coalescence mass matrix is expressed as:

$$
X_{j k i}=\left\{\begin{array}{l}
\frac{\left(m_{j}+m_{k}\right)-m_{i-1}}{m_{i}-m_{i-1}} \text { if }_{i-1}<m_{j}+m_{k}<m_{i} \\
\frac{m_{i+1}-\left(m_{j}+m_{k}\right)}{m_{i+1}-m_{i}} \text { if }_{i}<m_{j}+m_{k}<m_{i+1} \\
0 \quad \text { otherwise }
\end{array}\right.
$$

In summary, for bubbly flow the phenomenological mechanisms of bubble coalescence and breakup must be known to trace the spatial and temporary evolution of bubble size using the methods described above. During last years, many experimental and theoretical investigations have been focused on the mechanisms of bubble coalescence and breakup and a variety of theories and models have been proposed in literature for the calculation of bubble coalescence and breakup rate in gas-liquid two-phase flow. MUSIG provides a framework in which the population balance method can be incorporated into three-dimensional 
CFD calculations; it has been chosen in this work to perform the PBM simulations in CFD.

Finally, the bubble size distribution which can be calculated through PBE is a parameter of paramount importance from which critical information for simulation process of bubbly flow can be obtained, even though it is not directly required by the two-fluid model equations. As said, it is a key parameter that has been studied in this work, not only to calculate the interfacial force and effective turbulent viscosity but also to assess the efficiency of industrial processes such us aeration. Thereby, the accuracies solving population balance equation, interfacial force model and turbulent model in two-fluid model are the key parameters of simulating bubbly flow.

\subsubsection{RANS Turbulence modelling}

Turbulence modelling is one of three key parameters in CFD. Very precise mathematical theories have evolved for the other two key elements: grid generation and algorithm development (Wilcox, 1994). Turbulence causes the appearance in the flow of eddies with a wide range of length and time scales that interact in a dynamically complex way. Due to the importance of the preferment of turbulence in engineering applications, a significant amount of research effort has been dedicated to the development of numerical methods to reproduce the substantial effects due to turbulence.

In order to be able to compute turbulent flows with the RANS equations it is necessary to develop turbulence models to predict the Reynolds stresses and the scalar transport terms and close the system of mean flow equations. From the age of computers since the 1960's, further development of the four main categories of turbulence models (Algebraic Models, One Equation Models, Two-Equation and Second Order Closure Models) has evolved. In order to provide a turbulence model useful in a general-purpose CFD code, it must have wide applicability, be accurate, simple and economical to run. The most common RANS turbulence models are classified based on the number of additional transport equations that need to be solved along with the RANS flow equations.

These models constitute the basis of standard turbulence calculation procedures in currently available commercial CFD codes such us ANSYS-CFX.

The Zero Equation model implemented in CFX is simple to implement and use, can produce approximate results very quickly, and provides a good initial supposition for simulations using more advanced turbulence models. In CFX, a constant turbulent eddy viscosity is calculated for the entire flow domain. 
Table 2.1. Turbulence calculation procedures

\begin{tabular}{|l|l|}
\hline No of extra transport equations & Name of the model \\
\hline Zero & Mixing length \\
\hline One & Spalart-Allmaras \\
\hline Two & $\mathrm{k}-\varepsilon$ \\
& $\mathrm{k}-w$ \\
& $\mathrm{SST}$ \\
\hline Seven & Reynolds stress \\
\hline
\end{tabular}

Very simple eddy viscosity models compute a global value for $\mu_{t}$ from the mean velocity and a geometric length scale using an empirical formula. Because no additional transport equations are solved, these models are termed "zero equation".

The zero equation model in ANSYS CFX uses an algebraic equation to calculate the viscous contribution from turbulent eddies. A constant turbulent eddy viscosity is calculated for the entire flow domain.

The turbulence viscosity is modelled as the product of a turbulent velocity scale, $U_{t}$, and the turbulence length scale, $I_{t}$, as poposed by Prand and Kolmogorov,

$$
\mu_{t}=\rho f_{\mu} U_{t} I_{t}
$$

Where $f_{\mu}$ is a proportionality constant. The velocity scale is taken to be the maximum velocity in the fluid domain. The length scale is derived using the formula:

$$
I_{t}=\left(V_{D}^{\frac{1}{3}}\right) / 7
$$

Where $V_{D}$ is the fluid domain volume. This model has little physical foundation and is not recommended.

The two Equation Models are the most widespread models together with the Algebraic Models while the One-Equation Models are the least used. The Second Order Closure Models just find their way into a relatively small number of applications due to their large number of equations and complexity. One can distinguish fundamentally three types of approach in Two-Equation Models which can be distinguished by the way an equation for the dissipative term can be done either directly or indirectly:

- $\quad k-\varepsilon$ models (direct)

- $\quad k-\omega$ models (indirect)

- Models Shear Stress Transport, SST (combines the previous ones)

The most widely used in case of CFD calculations are the so-called k- $\varepsilon$ or $k-\omega$ models. Rodi and Scheuerer, (Rodi and Scheurer, 1986) demonstrated that models 
based on the $\varepsilon$-equation lead to an over-prediction of the turbulent length scale in flows with adverse pressure gradients (static pressure increase in the direction of the flow so that $\partial \mathrm{P} /(\partial \mathrm{x}>0))$, resulting in higher wall shear stress and higher heat transfer rates. Additionally, these models require a very fine near-wall resolution, which is typically one order of magnitude higher than for other one- and two-equation turbulence models (Vieser et al. 2008). In order to improve this limitation, the concept of a two-layer formulation (Patel et al. 1985) has been derived. In this case, the $\varepsilon$-equation is solved in the outer part of the boundary layer and the inner part is treated by a mixing length formulation. As this location is usually determined by user input, the uniqueness of the solution is not guaranteed (Vieser et al. 2008) and alternative formulations, both scale-equation and of the near-wall treatment are required.

Alternative to the $\varepsilon$-equation is the $\omega$-equation. In this case, instead of an equation for the turbulence eddy dissipation $\varepsilon$, an equation for the turbulence eddy frequency of the large turbulent scales $\omega$ is solved. Two main advantages of the k- $\omega$ formulation over the $\mathrm{k}-\varepsilon$ formulation can be highlighted. The $\omega$-equation shows significant advantages near the solid surface and can precisely calculate the turbulent length scale in adverse pressure gradient flows, leading to improved wall shear stress and heat transfer predictions. The model has a very simple lowReynolds number formulation, which does not require additional non-linear wall damping terms. Menter (Menter, 1992) pointed out that the main deficiency of the standard k- $\omega$ model is the strong sensitivity of the solution to free-stream turbulence quantities (like turbulence intensity, turbulent length scale or eddy viscosity) for $\omega$ outside the wall boundary layer.

In order to avoid the sensitivity problem based on these considerations, Menter (Menter, 1992) proposed a combination of the k- $\omega$ near the wall the k- $\varepsilon$ model away from it. Such a model led to the formulation of the Shear Stress Transport (SST) model.

There are many models $k-\varepsilon$, which focuses on the mechanisms that affect the turbulent kinetic energy. Its form is more complex, including various methods of modelling $\varepsilon$ and form functions for coefficients such as $C_{b}$, for example (JonesLaunder 1972), and (Yakhot-Orszag, 1986), who developed the Re-Normalisation Group (RNG) methods to re-normalise the Navier-Stokes equations in order to account for the effects of smaller scales of motion, (RNG $k-\varepsilon$ ). Among the main features, it is worth mentioning that they do not depend severely on geometry and it allows dealing with more complex flows, with separation in adverse gradients, but the average values located far from the walls are far from the experimental ones.

$$
\mathcal{N}\left(u_{i}\right) \equiv \rho \frac{\partial u_{i}}{\partial t}+\rho \sum_{k=1}^{3} u_{k} \frac{\partial u_{i}}{\partial x_{k}}+\frac{\partial p}{\partial x_{i}}-\mu \sum_{k=1}^{3} \frac{\partial}{\partial x_{k}}\left(\frac{\partial u_{i}}{\partial x_{k}}+\frac{\partial u_{k}}{\partial x_{i}}\right)=0
$$




$$
\begin{aligned}
& \sum_{i, k=1}^{3} \frac{2 \mu}{\rho} \overline{\frac{\partial u_{\imath}^{\prime}}{\partial x_{k}} \frac{\partial}{\partial x_{k}} \mathcal{N}\left(u_{\imath}\right)}=0 \\
& \frac{\partial \epsilon}{\partial t}+\sum_{\ell=1}^{3} U_{\ell} \frac{\partial \epsilon}{\partial x_{\ell}}=C_{a} \frac{\epsilon}{k} \sum_{i, \ell=1}^{3} \tau_{i \ell} \frac{\partial U_{i}}{\partial x_{\ell}}-C_{b} \frac{\epsilon^{2}}{k}+\frac{1}{\rho} \sum_{\ell=1}^{3} \frac{\partial}{\partial x_{\ell}}\left[\left(\mu+\frac{\mu_{T}}{C_{c}}\right) \frac{\partial \epsilon}{x_{\ell}}\right]
\end{aligned}
$$

Where $\mathrm{C}_{\mathrm{a}}, \mathrm{C}_{\mathrm{b}}$ and $\mathrm{C}_{\mathrm{c}}$ terms are coefficient which must be adjusted.

On the other hand, in the $k$ - $\omega$ turbulence models, a magnitude with frequency dimensions, $\omega$, is defined as

$$
\omega \equiv k \frac{\rho}{\mu}
$$

An equation for $\omega$ formally like the previous ones is postulated:

$$
\frac{\partial \omega}{\partial t}+\sum_{\ell=1}^{3} U_{\ell} \frac{\partial \omega}{\partial x_{\ell}}=-C_{\beta} \omega^{2}+C_{\alpha} \sum_{\ell=1}^{3} \frac{\partial}{\partial x_{\ell}}\left[\frac{\mu_{T}}{\rho} \frac{\partial \omega}{\partial x_{\ell}}\right]
$$

Where $C_{\alpha}$ and $C_{\beta}$ terms are coefficient which must be adjusted.

As occur for $k-\varepsilon$ models, there are multitude of $k-\omega$ models. Its form is more complex, including various methods of modeling $\omega$, shape functions for coefficients such as $C_{\beta}$ and even source terms of $\omega$, (Wilcox, 1994).

The models of two previous equations cannot predict the behaviour of the flows in adverse gradients because they do not transport the Reynolds efforts. The Shear Stress Transport (SST) model uses the $k-\omega$ model near the walls, and the $k-\varepsilon$ in the remote areas. First, the location of the border area is resolved. The link is made in a zone around the border, by means of a link function (blend function) $F_{1}$ such that, for any field $\emptyset$.

$$
\emptyset=F_{1} \emptyset_{1}+\left(1-F_{1}\right) \emptyset_{2}
$$

where $\emptyset_{1}$ and $\emptyset_{2}$ are the solutions of the $k-\omega$ and $k-\varepsilon$ models.

Although an equation for the main Reynolds effort (which composes the directions of the flow and perpendicular to the wall) is not solved, it does model its transition between its behavior near the wall with its behavior in the inner zone, according to the model $k-\omega$.

The union of both regions is done through the link function $F_{1}$, and it models the transport of the main Reynolds stress between the boundary layer and the flow 
sinus. They do not depend strongly on geometry, although the first node must be in $y^{+} \sim 2$ (parameter Yplus, $y^{+}$, is explained below).

As the previous models, their results do not depend severely on geometry and it allows dealing with more complex flows, even with separation in adverse gradients. It is robust and of low cost in computational terms. The limitation is that this model assumes an isotropic turbulence.

Modelling Flow Near the Wall is possibly the most problematic area in turbulence modelling, it is found that all components of the velocity-pressure-gradient correlation vanish at the wall in presence of strong gradients in the dependent variables. In addition, viscous effects on the transport processes are large. The representation of these processes within a numerical simulation raises the following problems: (1) How to account for viscous effects at the wall, (2) How to resolve the rapid variation of flow variables that occurs within the boundary layer region.

Two approaches are commonly used to model the flow in the near-wall region: (1) The wall function method which uses empirical formulas that impose suitable conditions near the wall without resolving the boundary layer, thus saving computational resources, and (2) The Low-Reynolds-Number method which resolves the details of the boundary layer profile by using very small mesh length scales in the direction normal to the wall (very thin layers) and it can therefore be used even in simulations with very high Reynolds numbers, as long as the viscous sublayer has been resolved.

In ANSYS ${ }^{\circledR}$ CFX, Scalable Wall Functions are used for all turbulence models based on the $\mathcal{E}$-equation. For (k-w) based models (including the SST model), an Automatic near-wall treatment method is applied overcome one of the major drawbacks of the standard wall function approach in that they can be applied on arbitrarily fine meshes. If the boundary layer is not fully resolved, one will be relying on the logarithmic wall function approximation to model the boundary layer without affecting the validity of the scalable wall function approach. If one is not interested in the details of the boundary layer, then it may not be worth fully resolving it. However, if the aim is to examine detailly the boundary layer for which a very fine near-wall mesh has been produced, then one should use the SST model with Automatic near-wall treatment to take advantage of the additional effect in the viscous sublayer.

The flows have certain properties in common near the walls (indicated by both experimental measurements and DNS simulations), regardless of the geometry or its average velocity. To obtain these invariant profiles, both the components related to the fields and the distances in standard units (wall units) must be represented:

$$
y^{+} \equiv \frac{u_{\tau} \rho}{\mu} y \quad u^{+} \equiv \frac{U}{u_{\tau}} \quad u_{\tau} \equiv \sqrt{\frac{\tau_{w a l l}}{\rho}}
$$


where $\tau_{\text {wall }}$ is the wall shear stress and the Yplus variable, $y^{+}$, is very used as the dimensionless distance of the first node of the mesh to the wall.

This regularity near the walls allows to substitute certain magnitudes for their "universal" values, so that it is not necessary to solve the equations in the nodes closest to the wall.

For the SST model, it is necessary to use a mesh with a Yplus below 2, so that the model is able to determine and use the functions of the wall or not, such as in those places where flow separation occurs, where they must be deactivated. In addition, it is recommended to insert about 10-15 nodes within the boundary layer (ANSYS ${ }^{\circledR}$, 2019).

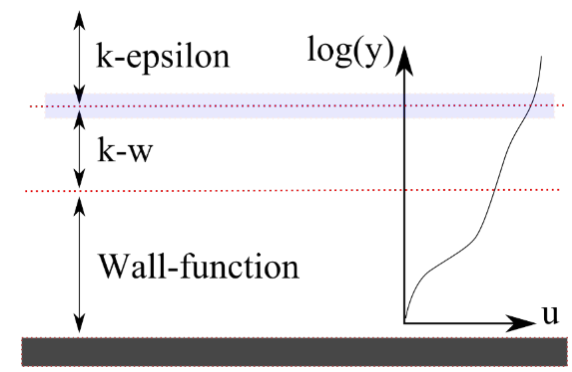

Figure 2.3. Wall-function and turbulence models scheme for wall distance (y)

\subsubsection{Two-Phase Flow Turbulence Modeling}

The influence of bubbles on turbulence must be considered additionally and modelled properly, especially for the improvement of models describing bubble coalescence and bubble breakup. In bubbly flows without phase changes, the development of physical models for bubble breakup and coalescence requires the consideration of bubble size distribution as well as the dynamic interaction between bubbles or bubble and liquid turbulence.

The dispersed bubbles are transported by the turbulent fluctuations of the continuous phase. Thus, bubbly two-phase flow turbulence modelling is based on a two-equation model formulated for single phase flow, and the turbulence of the gas phase calculated by means of a zero equation model, essentially an algebraic formula based on a geometric length scale and on the mean calculated velocity (ANSYS $\left.{ }^{\circledR}, 2019\right)$.

In order to consider the observed turbulence enhancement generated by the presence of the gas phase on the turbulence of the liquid phase, two approaches are considered in the literature:

- an additional viscosity term, or

- an additional source terms for the turbulence equations 


\subsubsection{Additional Viscosity Term}

The dynamic viscosity of the liquid phase is modified by adding and additional Bubble Induced Turbulence (BIT) viscosity term $\mu_{b}$ similarly to the case of the eddy viscosity $\mu_{t}$. The effective viscosity of the liquid phase is modified to be

$$
\mu_{\text {eff }}=\mu_{l}+\mu_{t}+\mu_{b}
$$

In case of the Sato model (Ansys 2019), the BIT term is written as follows:

$$
\mu_{b}=\mathrm{C}_{\mu_{b}} \rho_{l} \alpha D\left|\vec{u}_{l}-\vec{u}_{g}\right|
$$

where $\rho_{l}$ is the liquid density, $\alpha$ is the gas volume fraction, $D$ is the bubble diameter, $u_{l}$ and $u_{g}$ are the gas and liquid velocity, respectively, and the variable $\mathrm{C}_{\mu_{b}}$ has a value of 0.6 .

\subsubsection{Additional Source Terms in the Turbulence Equations}

Different from the additional viscosity term model explained above is the model explained in this paragraph where the general single-phase two-equation turbulence model is modified by means of the additional source terms $\varphi_{k}$ and $\varphi_{\omega}$ as follows:

$$
\begin{aligned}
\frac{\partial \rho_{l} k}{\partial \mathrm{t}}+\nabla \cdot\left(\rho_{l} \vec{v}_{l} k\right)=\nabla \cdot\left[\left(\mu_{l}+\frac{\mu_{t}}{\sigma_{k_{3}}}\right) \nabla k\right]+P_{k}-\beta^{\prime} \rho_{l} k \omega+\varphi_{k} \\
\frac{\partial \rho_{l} \omega}{\partial \mathrm{t}}+\nabla \cdot\left(\rho_{l} \vec{v}_{l} \omega\right) \\
=\nabla \cdot\left[\left(\mu_{l}+\frac{\mu_{t}}{\sigma_{\omega_{3}}}\right) \nabla \omega\right]+\left(1-F_{1}\right) 2 \rho_{l} \frac{1}{\sigma_{\omega_{2}} \omega} \nabla k \nabla \omega \\
+a_{3} \frac{\omega}{k} P_{k}-\beta_{3} \rho_{l} \omega^{2}+\varphi_{\omega}
\end{aligned}
$$

Most of BIT correlations for $\varphi_{k}$ and $\varphi_{\omega}$ in the literature consider the influence of the interfacial drag forces; in some correlations a contribution of non-drag forces is considered (Al Issa and Lucas 2009).

In case of the Yao and Morel model (Yao and Morel, 2004), the BIT terms are written as follows:

$$
\begin{gathered}
\varphi_{k}=0.75 \frac{C_{D}}{D_{s}} \alpha \rho_{l}\left|\vec{u}_{l}-\vec{u}_{g}\right|^{3} \\
\varphi_{\varepsilon}=\frac{\varphi_{k}}{\tau}=\frac{\varphi_{k}}{\left(\frac{D_{S}^{2}}{\varepsilon}\right)^{1 / 3}}
\end{gathered}
$$

The turbulence eddy frequency term is given by 


$$
\varphi_{\omega}=\frac{1}{\beta^{\prime} k} \varphi_{\varepsilon}-\frac{\omega}{k} \varphi_{k}
$$

The term $C_{D}$ in (2.41) is the interfacial drag coefficient.

\section{$\underline{\text { 2.1.6 Numerical resolution }}$}

The laws of conservation: conservation of mass, momentum and energy are applied to reach at partial differential equations (PDE) which mathematically represent the functional relationship between the influencing state variables in the domain of analysis. There are different numerical methods available for solving these PDEs.

A finite volume method (FVM) discretization is based on an integral form of the partial differential equations (PDE) to be solved (e.g. conservation of mass, momentum, or energy). The PDEs are written in a form which can be solved for a given finite volume (or cell). The computational domain is discretized into finite volumes where for every volume the equations are solved. The resulting system of equations usually involves fluxes of the conserved variable, and thus the calculation of fluxes is very important in FVM. It provides a discrete solution, the properties are calculated for every cell instead of a node. Based on the integral form of conservation laws and can handle discontinuities in solutions, in simple terms, what comes in, must go out. It is efficient in solving fluid flow problems.

ANSYS CFX software supports arbitrary mesh topologies, including hexahedral, tetrahedral, wedge and pyramid elements. It uses a unique hybrid finiteelement/finite-volume approach to discretizing Navier-Stokes equations. As a finite volume method, it satisfies strict global conservation by enforcing local conservation over control volumes that are constructed around each mesh vertex or node. The finite element methodology is used to describe the solution variation (needed for various surface fluxes and source terms) within each element. Advection fluxes are evaluated using a high-resolution scheme that essentially is second-order accurate and bounded. For transient flows, an implicit second order accurate time differencing scheme is used.

In our case, from the several different discretization methods that are used in CFD codes, the one on which CFX is based, is the finite volume technique. In this technique, the region of interest is divided into small sub-regions, called control volumes. The equations are discretized and solved iteratively for each control volume. As a result, an approximation of the value of each variable at specific points throughout the domain can be obtained (ANSYS ${ }^{\circledR}, 2019$ ).

The process of performing a single CFD simulation using ANSYS CFX consists of four software modules that take a geometry and mesh and pass the information required to perform a CFD analysis: (1) creating the geometry/mesh; (2) defining the physics of the model; (3) solving the CFD problem and (4) visualizing the 
results in the post-processor. These processes are schematically shown in Figure 2.4.

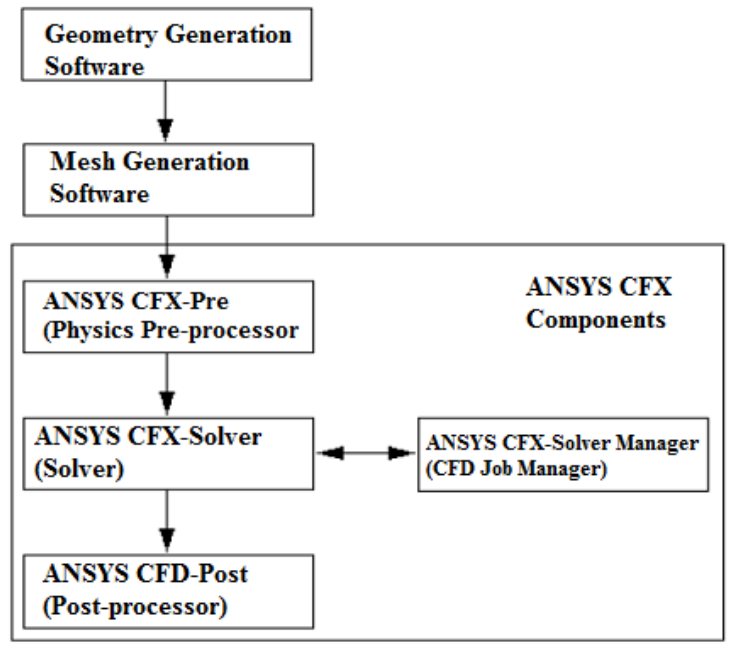

Figure 2.4. Overview of ANSYS CFX code structure (ANSYS $\left.{ }^{\circledR}, 2019\right)$.

The incompressible liquid phase modelling in industrial applications can be explained by the FVM. In a similar way to the FDM or FEM, this technique allows to discretize small volumes that are defined from a centroid and its external faces. The analysis begins with a mathematical model of a physical problem where the volume integrals that appear in the differential equations are converted to surface integrals with the divergence theorem. The incompressible single flow is calculated on each of the faces through the equations of conservation of mass, momentum and energy which must be fulfilled in the region of the study.

The Geometry/Mesh process is the first pre-processing stage. The objective is to produce a mesh for input to the physics pre-processor. Before a mesh can be produced, a closed geometric solid is required. The geometry and mesh can be created in the meshing application or any of the other geometry/mesh creation tools and involves the following steps: (1) define the geometry of the region of interest; (2) create regions of fluid flow, solid regions and surface boundary names; and (3) set properties for the mesh.

The physics pre-processor is the second pre-processing stage and is used to create input required by the solver. First the mesh file(s) are loaded into the physics preprocessor, CFX-Pre. The physical models that are to be included in the simulation are selected. Analyses, which consist of flow physics, initial and boundary conditions, fluid properties, and the numerical scheme, are specified.

The solver is the component that solves the CFD problem and produces the required results in a non-interactive/batch process that is passed to the post-processor. The 
solution proceeds as follows: The partial differential equations are integrated over all the control volumes in the region of interest. These integral equations are converted to a system of algebraic equations by generating a set of approximations for the terms in the integral equations. The algebraic equations are solved iteratively. An iterative approach is required because of the nonlinear nature of the equations. As the solution approaches the exact solution, it is said to converge. For each iteration, an error, or residual, is reported as a measure of the overall conservation of the flow properties. How close the final solution is to the exact solution depends on several factors, including the size and shape of the control volumes and the size of the final residuals. The solution process requires no user interaction and is, therefore, usually carried out as a batch process.

The post-processor provides state-of-the-art interactive post-processing graphics tools to analyses and present the ANSYS CFX simulation results.

\section{$\underline{\text { 2.1.7 Verification and validation }}$}

One must study the concepts of errors and uncertainty in CFD to address the issue of the confidence in CFD (AIAA, 1998); (ERCOFTAC (2000). A widely accepted definition of Error and Uncertainty by Oberkampf and Trucano, 2002) is: the deficiencies in a CFD model that are not caused by lack of knowledge, and are caused by lack of knowledge, respectively. On the one hand, the causes of errors are classified as Numerical errors, Coding errors and User errors. On the other hand, the sources of uncertainty are: Input uncertainty (information limited, geometry simplifications, etc.) and Physical model uncertainty (due to physical or chemical processes and modelling approach). For this last there are different specific parameters to verify the submodels, for example, the dimensionless wall distance parameter $y^{+}$to determine the proper size of the cells near domain walls for turbulence modeling validation.

In order to easy understand the difference between Verification and Validation, (Roache, 1998) coined the phrases 'solving the equations right' and 'solving the right equations', respectively. Hence, the process of Verification quantifies the errors and involves Roundoff error (precision of calculation using different levels of machine accuracy), Iterative convergence error (analysis of residuals and closeness to a converged solution), and Discretization error (mesh refinement). Then, the process of Validation consists of determining the degree of accuracy to represent the real world from the perspective of the intended uses of the CFD model. This process quantifies the uncertainty: input uncertainty and physical model uncertainty. On the one hand, the model must be tested for different scenarios (input data) from probability distributions and considering possible interactions due to the simultaneous variations of input data (Monte Carlo techniques for test runs design). On the other hand, high-quality experimental data results are required to be compared to CFD results. 
Verification can be understood as the estimation of the numerical uncertainty which is usually split into two categories: code and solution verification. Code verification evaluates the mathematical correctness of the code and is accomplished by simulating a problem that has an exact solution and verifying if that solution is obtained.

Procedures must be developed to evaluate the error and uncertainty due to features such as mesh refinement, turbulence model, wall treatment and appropriate definition of boundary conditions. These procedures are referred to as Verification and Validation (V\&V) processes. In 2009 a standard was published by the American Society of Mechanical Engineers (ASME) establishing detailed procedures for V\&V of CFD simulations (Santos et. al, 2011). These standardization processes using more sophisticated models are long and complex. They are interesting methodologies that are worth continuing to deepen.

Despite the ever-increasing need and importance for standards for CFD uncertainty analysis and accuracy estimation, there are currently many points of view covering all aspects from basic concepts and definitions to detailed methodology and procedures. Although most of them agree that solution verification procedures involve assessing numerical errors, especially iterative, grid size, and time step errors, there are some variances in detailed verification procedures for evaluating iterative and grid or time convergence, e.g. use of residuals vs dependent variable time histories and GCI vs correction factors, and there is a continuing need for identification of additional error sources and improved estimation methods (Stern et al, 2006).

The Grid Convergence Index (GCI) presented by Roache (1998) is one of the most used to ensure the mesh independency of the results (discretization error), i.e. if a mesh is suitable for a simulation. It is based on the CFD calculated values, usually fluid velocity, obtained in different points or planes of the domain and compared for different types of mesh.

For example, for three meshes studied, the fluid velocity values obtained from the simulations carried out can be indicated as: $\mathrm{f} 1, \mathrm{f} 2$ and $\mathrm{f} 3$. These values are taken at different points inside (it is worth to choose critical points, that is, points inside the domain where hydrodynamic activity is expected).

The error value is obtained as the absolute error from the fluid velocity values as follows:

$$
\text { error }_{21}=f_{2}-f_{1} ; \quad \text { error }_{32}=f_{3}-f_{2}
$$

Then, the parameter $r$ can be calculated from the number of nodes of the different meshes, $\mathrm{N}$, as follows: 


$$
r_{21}=\left(\frac{N_{1}}{N_{2}}\right)^{\frac{1}{d}} ; \quad r_{32}=\left(\frac{N_{2}}{N_{3}}\right)^{\frac{1}{d}}
$$

Where $\mathrm{N}_{3}, \mathrm{~N}_{2}$, and $\mathrm{N}_{1}$, correspond to the coarse mesh, the medium mesh and the fine mesh and $d$ corresponds to the value of the dimension of the domain, $d=3$ for a three-dimensional mesh.

With these values, the value of $p_{j}$ can be calculated as:

$$
p_{j}=\frac{\ln \left[\frac{\text { error }_{32}}{\text { error }_{21}}+q\left(p_{j}\right)\right]}{\ln \left(r_{21}\right)}
$$

Where $q_{j}$ is calculated through an iterative process that can be started by taking an initial value of $p j=2$.

$$
q\left(p_{j}\right)=\ln \left[\frac{r_{21} p_{j}-s_{j}}{r_{32} p_{j}-s_{j}}\right]
$$

The value of $s j$ is taken as the sign of the relationship between errors 21 and 32 as:

$$
s_{j}=1 \times \operatorname{sign}\left\{\frac{\text { error }_{21}}{\text { error }_{32}}\right\}
$$

Finally, the GCI value is calculated as:

$$
G C I=F_{S} \cdot \frac{\left|\frac{\text { error }_{21}}{f_{1}}\right|}{\left(r_{21}^{p j}-1\right)}
$$

where the value of $F_{S}$ is the safety factor and can be obtained as follows:

$$
\begin{gathered}
F_{S}=1.25 \text { if }\left\{1<p_{j} \leq 2\right\} \\
F_{s}=3 \text { if }\left\{p_{j} \leq 1 \text { o } 2<p_{j}\right\}
\end{gathered}
$$

A good GCI value is considered when it is under $0.03(3 \%)$.

As other methods which use truncation, GCI only quantifies the numerical error in a CFD solution and do not test whether the code itself accurately reflects the mathematical model of the flow. Quantitative assessment of the physical modelling 
uncertainty requires comparison of CFD results with high-quality experimental results, (Oberkampf and Trucano, 2002).

Respect to the convergence procedure for the calculation, the following three criteria are used to assess the convergence of a steady state CFD analysis: the residual level, the solution imbalances, and monitor points tracking quantities of interest as the analysis progresses.

The residual is the most fundamental measure of convergence as it directly evaluates the error in the solution of a specific variable. The residual measures the local imbalance of a conserved variable in each control volume, so each control volume will have a residual value for each equation being solved. The lower the residual value is, the more numerically accurate the solution.

The residuals convergence criteria for all calculations have been set to a RMS value of 1E-4. This value has been considered a good compromise between accuracy of the results and the speed-up of the calculation process.

The Courant number is of fundamental importance for transient flows. For a onedimensional grid, it is defined by:

$$
\text { Courant }=\frac{u \Delta t}{\Delta x}
$$

where $u$ is the fluid velocity, $\Delta t$ is the timestep and $\Delta x$ is the mesh size. The Courant number calculated in ANSYS CFX is a multidimensional generalization of this expression where the velocity and length scale are based on the mass flow into the control volume and the dimension of the control volume. For explicit CFD methods, the timestep must be chosen such that the Courant number is sufficiently small. The details depend on the specific scheme, but it is usually of order unity.

It is very useful to monitor the variation of the dependent variables at specific locations throughout the calculation domain in order to observe the point at which they stabilize. In the case of CFX code, one can define monitor points to plot specific variables, for example Fluid Velocity, in order to follow the evolution of its value. It may be acceptable, once the residuals have arrived at their defined termination values, to terminate a calculation as soon as the dependent variables have achieved adequate stability. Moreover, it is recommendable to check the value of the imbalances while the simulation is running in order to ensure the conservation of the variables at the end of the run (especially for the state variables when implementing biokinetic model). 


\subsection{Activated Sludge Configurations studied}

The activated sludge process was discovered in the UK by (Ardern and Lockett, 1914), following experiments carried out to the water treatment in a filling and emptying reactor (the precursor of the current sequential batch reactor) which produced a highly treated effluent. Believing that sludge had been activated, like activated carbon, the process was called "activated sludge". During the first half of the 20th century, the wastewater was discharge into the rivers which were considered as an integral part of the process treatment. In the book "Stream Sanitation" by Phelps (1944), mathematical models are used to calculate the maximum organic load from the oxygen curve, in order to prevent the concentration of dissolved oxygen decreased below the minimum value in relation to the wastewater discharge. In the second half of the 20th century, a new problem in surface water came, eutrophication. The eutrophication is caused by the rapid growth of algae and other aquatic plants due to the presence of fertilizer effect of nitrogen and phosphorus discharged. In the decade of the $60 \mathrm{~s}$ it was already very evident that nitrogen and phosphorus should be eliminated from wastewater to prevent eutrophication. (Downing et al., 1964), applying the kinetic model of Monod (1949), demonstrated that the nitrification depended on the maximum specific growth rate of autotrophic microorganisms. For the scale-up of a WWTP, a minimum sludge age must be guaranteed to reach low ammonium concentrations in the effluent (nitrification process). Later, with the work of McCarty (1964), it was understood that the nitrate produced by nitrification can be used by some heterotrophic bacteria instead of oxygen and turn it into gas nitrogen (denitrification process).

In the present, many plants are either being designed for nutrient removal or are being retrofitted to meet regulations whether it is for nitrogen removal and / or phosphorus removal. In practice, under normal operating conditions, the recovery of oxygen for nitrification by means of denitrification reaches about $50 \%$. For this reason, if there is a possibility that nitrification occurs in the system, it is always beneficial to include denitrification in such a way that alkalinity and oxygen can be recovered. The biological removal of nitrogen and phosphorus takes place in different configurations where the reactor is subdivided into a series of non-aerated (anoxic and anaerobic) and aerated zones. This is particularly significant in oxidation ditch systems where operational costs related to aeration make up between $15 \%$ and $25 \%$ (Bischof, $\mathrm{F}$ et al, 1999), and $70 \%$ of the energy costs (Ovezea, A., 2002).

Aeration is the key process in most of activated sludge systems in WWTP. It involves the highest costs of energy consumption, reaching up to $75 \%$ of the total energy consumption of the plants (Randon, 1995). For this reason, when efficient 
energy use practices are applied, the efficient operation of the aeration systems is of crucial importance.

Once nitrification occurs, it is possible to carry out the biological nitrogen removal by denitrification and should be included in the treatment systems even when the removal of $\mathrm{N}$ is not a requirement by intentionally incorporating non-aerated zones into the reactor. Because nitrifying organisms are strictly aerobic, nitrification is not carried out in non-aerated areas, so to compensate for this situation it is necessary to increase the sludge age in the system. Denitrification is carried out in the nonaerated but mixed zones because they receive mixed liquor from the aerated areas through internal recirculation/s to produce the process known as nitrificationdenitrification.

The key parameters that affects nitrogen removal are (Randall et al., 1992): anoxic vessel detention time, anoxic conditions (absence of oxygen), mixed-liquor volatile suspended solids concentration, internal recycle rate and external recirculation, BOD, Readily biodegradable COD fraction and Temperature.

Figure 2.5 shows a scheme of the use of energy in a conventional WWTP, where the Secondary treatment (Activated Sludge) represents 44\%. Aeration supply represents $86 \%$ of the Secondary Treatment energy consumption. The rest is mostly the energy for Mixing.

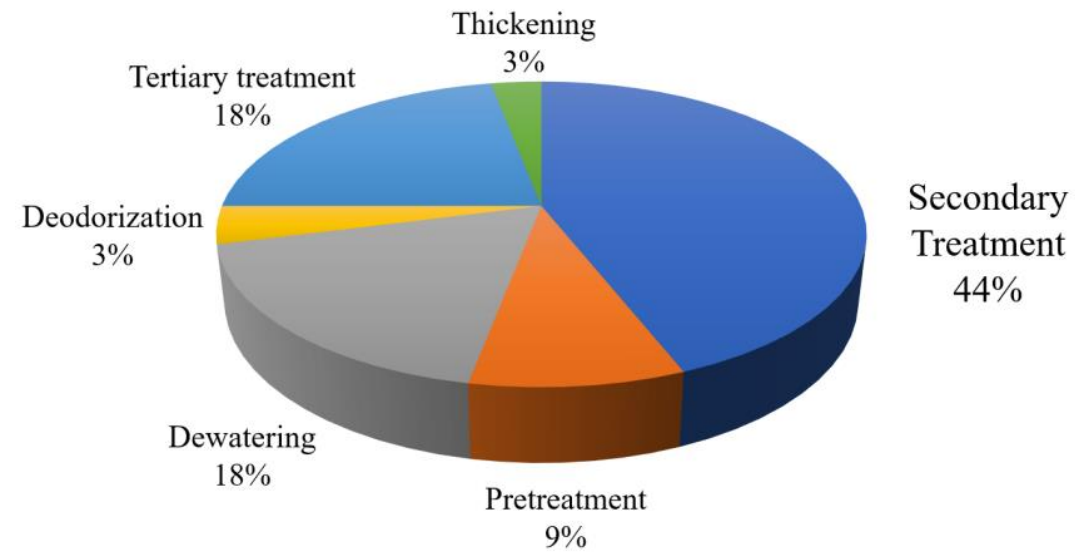

Figure 2.5. Energy cost in WWTP- LIFE13 env/es/000704-RENEWAT

In activated sludge systems, two types of biological reactor configurations are generally defined based on the mixing regimes: completely mixed and plug-flow reactor. Both configurations require the recirculation of the biomass (solids) from the clarifier (secondary settling tank) to give back the microorganisms to the biological reactor. As it shown later, plug-flow reactor takes place in an elongated channel or in a configuration made up by several compartments in series. 
The most important internal elements in a biological reactor are the aerators (superficial or submerged) and the mixers (stirrers or propellers) as shown in figure 2.6. The aeration system provides the oxygen to the aerobic process by different technologies that should be compared depending on the type of biological reactor configuration. Fine bubble diffusers is the most wide-spread technology in terms of efficiency parameters for medium-large bioreactors.

Mixing systems are needed to maintain good contact between the biomass (solids) and substrates (liquid) providing homogeneity to the fluid, to prevent malfunctioning of the flow such us short-circuiting, and to maintain solids in suspensions (to prevent sedimentation). Other important functions are: to induce the desired flow type, to disperse a specific phase (solid-liq-gas) throughout the mixture, to intensify heat transmission, and to provide the shear conditions for the aggregation/breakage of flocs (Höfken et al., 1996; Perry, 1999; Ullmann, 1996).

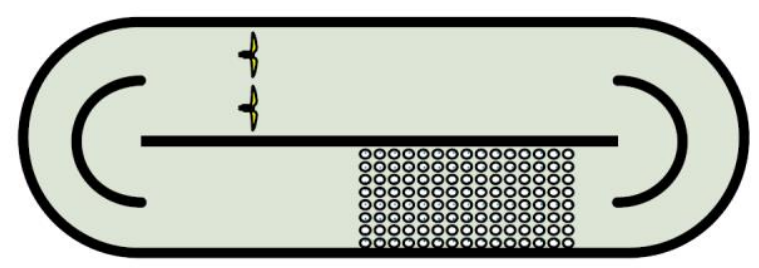

Figure 2.6. Scheme of the internal elements of a reactor, propellers and grid of diffusers

In this subsection, the two nitrification-denitrification system configurations studied will be explained: the modified Ludzack Ettinger (MLE) system, with an internal recirculation to an anoxic compartment, and the oxidation ditch systems and the Orbal reactor, where the anoxic zones are created along different lengths within different or the same channels of the biological reactor.

\subsubsection{The Modified Ludzack-Ettinger (MLE) biological reactor}

The MLE biological reactor is a commonly used nutrient removal configuration, typical of municipal wastewater treatment (WWT) plants, composed of anoxic and aerobic tanks. As known, this system represents one of the simplest configurations to provide nitrification-denitrification with greater efficiency (van Haandel and van der Lubbe, 2012). This increase in efficiency comes from two main factors: recovering lost oxygen, potentially up to $63 \%$ of the energy expended in nitrification, and alkalinity, about half of the lost through the nitrification is recovered when nitrate is used as electron acceptor of readily biodegradable organic substrate (Metcalf \& Eddy, 2004). Denitrifying bacteria prefer to use molecular oxygen, but if the environment contains less than 0.3 to $0.5 \mathrm{mg} / \mathrm{L}$ of dissolved oxygen (DO), they will use the oxygen from nitrate- $\mathrm{N}$ molecules to oxidize carbon 
compounds (e.g., BOD) (Grady et al, 2011). Hence, sufficient amounts of substrate must be ensured in anoxic conditions to carry out the denitrification process and thereby saving aeration energy consumption of the activated sludge (AS) system.

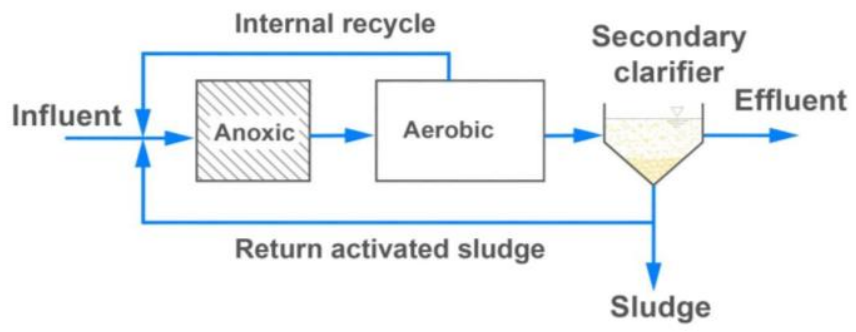

Figure 2.7. MLE configuration scheme

The main disadvantage of the MLE reactor configuration is that the effluent will always contain appreciable quantities of nitrate- $\mathrm{N}$ because nitrification occurs in the last bioreactor (Water Environment Federation, 2006). Consequently, the adjustment of the internal recycling ratio, which provides nitrate to the anoxic zone, is a critical operational parameter. In this case study, a common mode of operation consists of setting relatively a high internal recirculation rate in order to maintain the effluent under control. But, a high recycling ratio will strongly influence the retention time of the anoxic tank, decreasing the denitrification efficiency. Accordingly, if the mean residence time of the anoxic tank is not enough, the aerobic tank must often be controlled stopping aeration to provide (sufficient) further anoxic volume.

The study conducted in this work applied to this configuration is designed to treat a flow of $22486\left(\mathrm{~m}^{3} /\right.$ day) (50 786 equivalent inhabitants). The configuration consisted in a MLE activated sludge process composed of 3 tanks in a row. Each tank was communicated to the next one by just one wall-bushing and equipped with one stirrer. Influent flow and external recycling from secondary settlers were previously mixed and equally distributed into the two WWTLs, feeding the first anoxic tanks where the DO is maintained lower than $0.1(\mathrm{mg} / \mathrm{L})$. The third tank was the only one able to form nitrate when operating under aerobic conditions. The internal recirculation stream for each WWTL returned mixed liquor from the Outlet, located after the third tanks, providing nitrate-N to the first tanks.

The discharge point of the internal recycling within the first tanks was located $2.5 \mathrm{~m}$ above the wall bushing between anoxic tanks (Original wall-bushing), whereas the following wall bushing, which communicated to the aerobic tank, was located in front of it causing a significant short-circuiting which induced hydrodynamics malfunctioning within both second tanks.

The biological reactor operates using intermittent aeration to promote both nitrification-denitrification in the aerobic tanks due to a high unintended 
accumulation of nitrates. This raises the difficulty in setting up the optimal aeration cycle time in order to guarantee reasonable concentration of nitrogen compounds in the effluent. That is why the third reactor is often needed to increase the denitrification volume added up to the anoxic tanks.

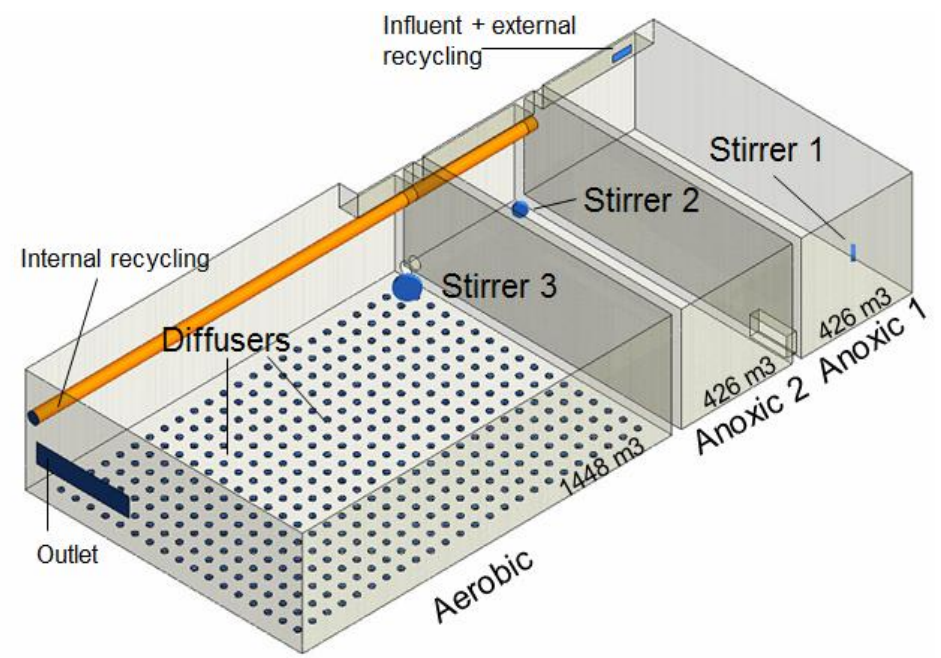

Figure 2.8. 3D scheme of the MLE biological reactor of one WWTL.

\subsubsection{Oxidation Ditch configuration}

Oxidation ditch configurations were developed as a wastewater treatment process in the early of 1960s, and spreading rapidly in Europe for small populations. They are rapidly adaptable processes for carbonaceous oxidation, nitrification and denitrification. The aeration is supplied in one or more places of the channel by means of mechanical horizontal aerators (brush Kessener and rotating discs), or submerged diffusers. Besides organic matter removal, the main interest is focused on studying spatially the Nitritrication-Denitrification process which allows oxidation of ammonia and subsequent reduction into nitrogen gas.

The DO concentration will be higher at the aeration points and will decrease later due to the oxygen consumption by the biomass as the mixed liquor moves along the reactor. After a enough travel time, the anoxic areas will form upstream of the aeration points. The location and size of the anoxic zones will vary over time due to oxygen consumption, and the transfer rates will vary according to the quality of the wastewater and the flow. Therefore, the safety of this mechanism for denitrification requires flexible control of the system to control the oxygen transferred to the body of water and the DO through the reactor.

Also, the input energy for mixing and aeration must be carefully controlled to keep the mixed liquor in suspension. Some systems base their flexibility on the 
placement of adjustable dumps (variable height) or variable speed aerators. During periods of low load the anoxic zones may not develop. In the typical oxidation channels used for nitrogen removal, nitrification and denitrification rates are usually low due to the relatively long cell retention times required for nitrification, the low concentration of COD, and the marginal (leftover) concentrations of DO well for nitrification or denitrification. The large mass of the mixed liquor in the system will compensate for the slow reaction rates.

In these systems, the wastewater is circulated around an oval or circular channel where the nitrification and denitrification of the water takes place by alternating aerobic and anoxic zones. As can be seen in Figure 2.9, the aerobic zone begins in the aeration zone and extends until the dissolved oxygen decreases to zero. Between this point and the aerator, the anoxic zone is established. The entrance of residual water and the recirculation of nitrates is established at the beginning of the anoxic zone to use the carbon of the residual water in denitrification.

The SND (Simultaneous Nitrification and Denitrification) process indicates that nitrification and denitrification occur at the same time in a single reactor (Keller et al., 1997, Helmer and Kunst, 1998). There are two mechanisms in this type of process: physical and biological (Robertson and Kuenen, 1984, Baumann et al., 1996, Hibiya et al., 2003). The physical mechanism is that the SND process occurs because of the gradients of the dissolved oxygen concentration within the activated sludge flocs or biofilms due to diffusion limitations. Autotrophic nitrifying bacteria are found in aerobic regions with OD above 1-2 $\mathrm{mg} / 1$, while denitrifying bacteria develop in anoxic zones with an OD concentration $<0.5 \mathrm{mg} / 1$ (Zhu et al., 2008).
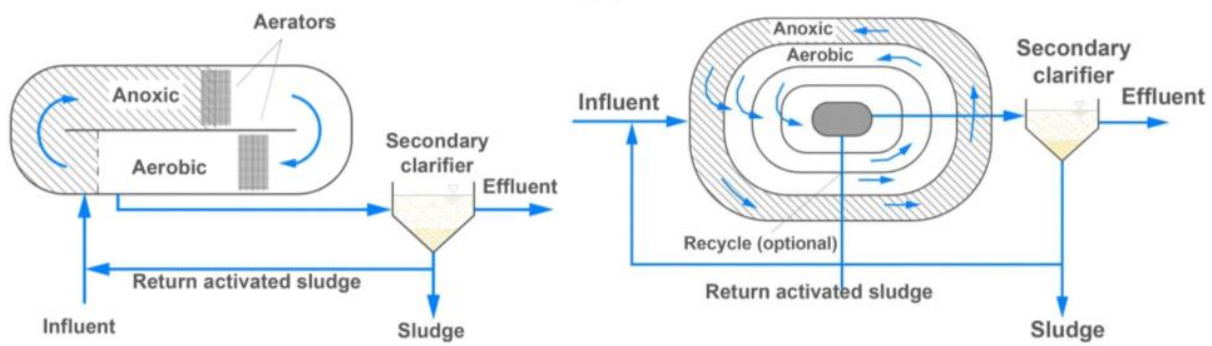

Figure 2.9. Scheme of the Oxidation ditch and Orbal configurations

The SND process has brought advantages over conventional processes (Pochana et al., 1999; Zhang et al., 2005). With a denitrification and nitrification that takes place at the same time in aerated tanks, the process can reduce the costs of anoxic tanks, and simplify the overall design process. Oxidation channel technology was developed to simplify the nitrification - denitrification process, minimize control operations and reduce energy consumption and costs. The configuration in channel is the most efficient because the amount of movement of the process is conserved. 
The channels are hybrids between plug-flow and complete mixing, Weismann (1994). Depending on the number of times the water is recycled, it will tend to mix completely. For a configuration with a single channel, several inflow entry points can be arranged to ensure exogenous carbon. The more times the nitrates pass through the higher anoxic zone, the denitrification efficiency will be. The rate of recirculation with respect to the flow of supply is between 60 and 120 times $(6000 \%-12000 \%)$, which causes a great dilution of the raw water at the entrance of the channel, so the process approaches a system of complete mix. The operational key is in the oxygen transfer rate in the SSLM. The SSLM can be controlled by the recirculation of secondary sludge. In the single channels of a single circuit, aeration can be optimized by placing aerators at selected points along the channel. The oxygen transfer can be adjusted by controlled submergence of the aeration discs or rotors, by varying the speed of rotation or by changing the number of aerators on each axis of the channel, or by controlling the start-up or stopping of diffuser grids. A timing of the aerators could also be employed. Always keep a minimum mix to maintain solids in suspension.

The design of denitrification is similar to that of other anoxic reactors. Generally, they are operated as a prolonged aeration with high HRT and SRT, and with the highest TSS values of conventional active sludge. The hydraulic retention times in the oxidation channels are in a global order between 12 and 24 hours (6 to 12 hours for anoxia and 6 to 12 hours for aerobiosis). Conceptually, the oxidation channel is an "endless channel". Only a part of the mixed liquor is dislodged in each cycle, which allows a high (maximum) rate of internal recirculation. The dimensioning should be based on the speed of passage that has a range between 0.25 and $0.6 \mathrm{~m} / \mathrm{s}$ (with typical values of 0.25 to 0.35 ) and in the duration time of a lap that can be between 10 and 45 minutes. The horizontal speed is achieved by the aeration systems themselves in cases where superficial mechanical aerators (rotors, discs, etc.) are used or by independent impulse systems (current accelerators) in the case of aeration with diffusers. To maintain a uniform velocity in the curves and avoid turbulence, guide walls are used.
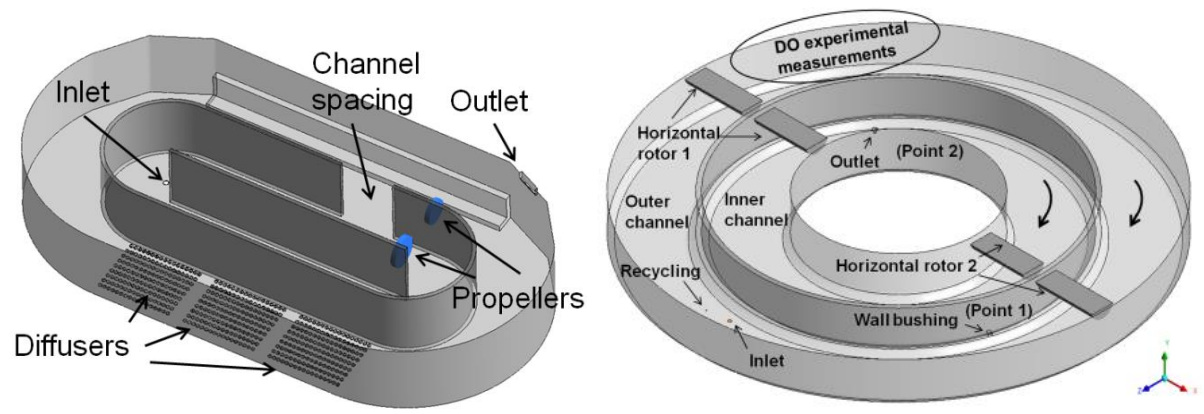

Figure 2.10. Oxidation ditch (left) and Orbal (right) CFD models 
A full-scale oxidation ditch of $7800 \mathrm{~m}^{3}$ has been chosen for this study. The influent flow, about $1300 \mathrm{~m}^{3} /$ day, and the external recycling arrive previously mixed into the inner channel (through the inlet), which is expected to operate in anoxic conditions. Subsequently, fluid flow passes through the channel spacing (Fig. 2.10), which communicates both channels to the outer channel, leaving afterwards the biological reactor (outlet) and going to the secondary settler tanks.

Mixing is provided by two submerged impellers (propellers) and the aeration diffuser system. The aeration area is divided in three grids of 153 diffusers ( 9 rows and 17 columns) located in the outer channel and installed at a height of $22 \mathrm{~cm}$ (Fig. 2.10). The aeration is supplied following on-off cycles set by the ammonia concentration which is measured by a probe located at the outlet. As mentioned above, the hydrodynamic and mixing conditions of the tank become even more important because simultaneous nitrification and denitrification is desired, as this case, at the outer channel, where both aerobic and anoxic conditions are present.

The Orbal reactor selected to conduct the CFD study treats an average daily flow of $528 \mathrm{~m}^{3}$. The mean daily recycled flow is $260 \mathrm{~m}^{3}$. This biological reactor is formed by two channels of $1184 \mathrm{~m}^{3}$ and $705 \mathrm{~m}^{3}$, both of $4.75 \mathrm{~m}$ wide and $3 \mathrm{~m}$ height (Fig. 2.10). The aeration system is provided by horizontal rotator disks. Hence, the energy used for aeration is sufficient to provide mixing in a system with a relatively long hydraulic time. When the WWTP operates in continuous regime limiting the aeration rate, nitrification and denitrification process is carried out.

\subsection{Biological models}

In order to mathematically describe the biochemical reactions that take place in a biological reactor, the majority of models are based the two main processes: microbial growth and decay. Growth rate is described by the hyperbolic rate expression of (Monod, 1942) based on experimental measurements of pure culture studies. The first Activated Sludge Model (ASM1) was published by (Henze et al., 1987). Then, modifications to the original model by the Task Group on Mathematical Modelling for Design and Operation of Biological Wastewater Treatment have been published as the ASM2 (Henze et al., 1995); ASM2d (Henze et al., 1999); (ASM3 Gujer et al., 1999).

The design of WWTP is based on pollutant removal rates. The current standard is ASM1, the easiest to calibrate which provides good results for nutrient removal calculation. Conversely, it cannot calculate phosphorus removal. For this aim ASM2d is needed. Both are described as follows.

\section{$\underline{\text { 2.3.1 Description of ASM model }}$}

The carbonaceous material is divided into biodegradable COD, unbiodegradable COD and biomass. The biodegradable COD is divided into two fractions: 
particulate $X_{S}$ and soluble $S_{S}$. They represent the slowly and the readily biodegradable COD, respectively. Similarly, the un-biodegradable is divided into COD particulate fraction $X_{I}$ and soluble $S_{I}$. The biomass COD is divided in heterotrophic $X_{B H}$ and autotrophic $X_{B A}$. On the one hand, the heterotrophic biomass lead both the carbon removal under aerobic condition and the denitrication of nitrate to nitrogen gas under anoxic condition. On the other hand, the autotrophic biomass is responsible for the aerobic nitrification of ammonia. Finally, there is another COD fraction $X_{P}$, which comes from a fraction of the particulate products of the biomass decay. The COD fractions are expressed in $\mathrm{gCODm}^{-3}(\mathrm{ppm})$.
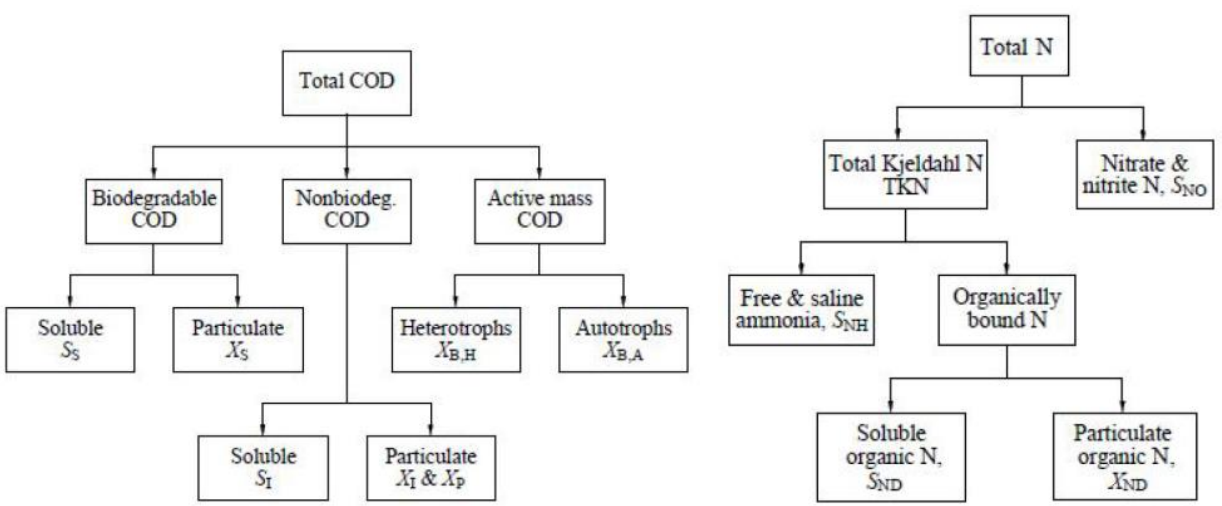

Figure 2.11. COD frations (left) and Nitrogen frations (right) in ASM1 model (Figure from Jeppsson, 1996)

The total nitrogen is divided into four components typically present in urban wastewater: ammonia, nitrate, nitrite and organic nitrogen. Free and saline ammonia is represented by $S_{N H}$, while nitrate and nitrite are expressed as $S_{N O}$. The organic nitrogen is divided into soluble and particulate fraction: $S_{N D}$ and $X_{N D}$, respectively. Nitrogen fractions are expressed in $\mathrm{gNm}^{-3}$. Finally, the other two state variables are the dissolved oxygen concentration, expressed as $\left(\mathrm{g}-\mathrm{CODm} \mathrm{m}^{-3}\right)$, and the alkalinity, expressed in $\left(\mathrm{mol} \mathrm{m}^{-3}\right)$.

This results in 13 state variables, shown in Table 2.2.

Table 2.2. ASM1 implementation

\begin{tabular}{|c|c|c|}
\hline State Variable & Symbol & Unit \\
\hline Readily biodegradable substrate & Ss & $\mathrm{gCOD} \mathrm{m}^{-3}$ \\
\hline Slowly biodegradable substrate & $\mathrm{Xs}$ & $\mathrm{gCOD} \mathrm{m}^{-3}$ \\
\hline
\end{tabular}




\begin{tabular}{|c|c|c|}
\hline Soluble inert organic matter & $\mathrm{Si}$ & $\mathrm{gCOD} \mathrm{m}^{-3}$ \\
\hline Particulate inert organic matter & $\mathrm{Xi}$ & $\mathrm{gCOD} \mathrm{m}^{-3}$ \\
\hline Particulate products from biomass decay & $\mathrm{Xp}$ & $\mathrm{gCOD} \mathrm{m}^{-3}$ \\
\hline Active heterotrophic biomass & $\mathrm{Xbh}$ & $\mathrm{gCOD} \mathrm{m}^{-3}$ \\
\hline Active autotrophic biomass & $\mathrm{Xba}$ & $\mathrm{gCOD} \mathrm{m}^{-3}$ \\
\hline Free and saline ammonia nitrogen & Snh & $\mathrm{gN} \mathrm{m}^{-3}$ \\
\hline Nitrate and nitrite nitrogen & Sno & $\mathrm{gN} \mathrm{m}^{-3}$ \\
\hline Soluble biodegradable organic nitrogen & Snd & $\mathrm{gN} \mathrm{m}^{-3}$ \\
\hline Particulate biodegradable organic nitrogen & Xnd & $\mathrm{gN} \mathrm{m}^{-3}$ \\
\hline Oxygen & So & $\mathrm{g}(-\mathrm{COD}) \mathrm{m}^{-3}$ \\
\hline Alkalinity & Salk & $\mathrm{mol} \mathrm{m}^{-3}$ \\
\hline
\end{tabular}

The default values for the 5 stoichiometric parameters and 14 kinetic parameters that are included in the biochemical reactions are provided in different temperature conditions (Henze et al., 2000; Jeppsson, 1996).

The Stoichiometric parameters related to COD o al N-total are:

- Yield for heterotrophic biomass, $\mathbf{Y}_{\mathbf{H}}\left(\mathrm{g} \mathrm{X}_{\mathrm{bh}}\right.$ COD formed / g COD)

- Yield for autotrophic biomass, $\mathbf{Y}_{\mathrm{A}}\left(\mathrm{g} \mathrm{X}_{\mathrm{ba}} \mathrm{COD}\right.$ formed / $\mathrm{g} \mathrm{N}$ utilized $)$

- Fraction of biomass leading to particulate products, $\mathbf{f}_{\mathbf{p}}$ (dimensionless)

- Mass of nitrogen per mass of COD in biomass, $\mathbf{i}_{\mathbf{x b}}\left(\mathrm{g} \mathrm{N} / \mathrm{g}\right.$ COD in $\left.\mathrm{X}_{\mathrm{bh}} \mathrm{y} \mathrm{X}_{\mathrm{ba}}\right)$

- Mass of nitrogen per mass of COD in products from biomass, $\mathbf{i}_{\mathbf{x p}}(\mathrm{g} \mathrm{N} / \mathrm{g} \mathrm{COD}$ in $\mathrm{X}_{\mathrm{p}}$ )

The Kinetic parameters in day $\mathrm{m}^{-3}$ are:

- Maximum specific growth rate for heterotrophic biomass, $\boldsymbol{\mu}_{\mathbf{H}}\left(\right.$ day $\left.^{-1}\right)$

- Decay coefficient for heterotrophic biomass, $\mathbf{b}_{\mathbf{H}}\left(\right.$ day $\left.^{-1}\right)$

- Half-saturation coefficient for heterotrophic biomass, $\mathbf{K}_{\mathbf{s}}\left(\mathrm{g} \mathrm{COD} / \mathrm{m}^{3}\right)$

- Oxygen half-saturation coefficient for heterotrophic biomass, $\mathbf{K}_{\mathbf{O H}}\left(\mathrm{g} \mathrm{O}_{2} /\right.$ $\left.\mathrm{m}^{3}\right)$ 
- Nitrate half-saturation coefficient for denitrifying heterotrophic biomass, $\mathbf{K}_{\mathrm{NO}}\left(\mathrm{g} \mathrm{NO}_{3} / \mathrm{m}^{3}\right)$

- Maximum specific growth rate for autotrophic biomass, $\boldsymbol{\mu}_{\mathbf{A}}\left(\right.$ day $\left.^{-1}\right)$

- Decay coefficient for autotropic biomass, $\mathbf{b}_{\mathbf{A}}\left(\right.$ day $\left.^{-1}\right)$

- Oxygen half-saturation coefficient for autotrophic biomass, $\mathbf{K}_{\mathbf{O A}}\left(\mathrm{g} \mathrm{O}_{2} / \mathrm{m}^{3}\right)$

- Ammonia half-saturation coefficient for autotrophic biomass, $\mathbf{K}_{\mathbf{N H}}(\mathrm{g} \mathrm{NH} /$ $\left.\mathrm{m}^{3}\right)$

- Correction factor for $\mu_{H}$ under anoxic conditions, $\mathbf{\eta}_{\mathbf{g}}$ (dimensionless)

- Ammonification rate, $\mathbf{k}_{\mathbf{a}}\left(\mathrm{m}^{3} / \mathrm{g}\right.$ COD day)

- Maximum specific hydrolysis rate, $\mathbf{k}_{\mathbf{h}}\left(\mathrm{g} \mathrm{X}_{\mathrm{s}} / \mathrm{g} \mathrm{X}_{\mathrm{bh}} \mathrm{COD}\right.$ dia)

- Half-saturation coefficient for hydrolysis of slowly biodegradable substrate, $\mathbf{K}_{\mathbf{x}}\left(\mathrm{g} \mathrm{X}_{\mathrm{s}} / \mathrm{g} \mathrm{X}_{\mathrm{bh}} \mathrm{COD}\right)$

- Correction factor for hydrolysis under anoxic conditions, $\mathbf{\eta}_{\mathbf{h}}$ (dimensionless)

The eight processes described in the model are presented as follows:

(1) Aerobic growth of heterotrophic biomass. The growth is modelled according to Monod kinetics. A maximum growth rate is defined, and it is limited by the readily biodegradable substrate $S_{S}$, and the dissolved oxygen concentration $S_{O}$. The readily biodegradable substrate is accounts for both heterotrophs $X_{B H}$ growth and energy uptake by means of respiration. This is the most important process for the COD removal.

$$
\rho_{1}=\mu_{H}\left(\frac{S_{S}}{K_{S}+S_{S}}\right)\left(\frac{S_{O}}{K_{O H}+S_{O}}\right) X_{B H}
$$

(2) Anoxic growth of heterotrophic biomass. Nitrates can be used as final electron acceptor for heterotrophs growth and substrate removal in anoxic conditions instead dissolved oxygen. Nitrate is reduced to nitrogen gas (denitrification process) together with alkalinity reduction. It results in heterotrophs growth, modelled through the same Monod formulation as (1) including a reducing factor $\eta_{\mathrm{g}}(<1)$, resulting in a slower reaction than the aerobic growth. The limiting factors are the readily biodegradable substrate $S_{S}$ and nitrates $S_{N O}$. Oxygen $S_{O}$ s also taken into account as a limiting factor, its presence inhibits the process by promoting aerobic growth mechanism (1).

$$
\rho_{2}=\mu_{H}\left(\frac{S_{S}}{K_{S}+S_{S}}\right)\left(\frac{K_{O H}}{K_{O H}+S_{O}}\right)\left(\frac{S_{N O}}{K_{N O}+S_{N O}}\right) \eta_{g} X_{B H}
$$

(3) Aerobic growth of autotrophic biomass. In presence of ammonia, autotrophic and heterotrophic biomass can proliferate together. Autotrophic growth results in a higher oxygen requirement, used for the oxidation of ammonia into nitrate 
(nitrification process). The process follows Monod kinetics, where the limiting factors are ammonia concentration and oxygen concentration. The yield coefficient for this growth is slower than heterotrophic growth.

$$
\rho_{3}=\mu_{A}\left(\frac{S_{N H}}{K_{N H}+S_{N H}}\right)\left(\frac{S_{O}}{K_{O A}+S_{O}}\right) X_{B A}
$$

(4) Decay of heterotrophic biomass. For this process, it is used the deathregeneration hypothesis where it is assumed that the biomass dies at a certain rate $\left(b_{\mathrm{H}}\right)$, defined as constant under both aerobic and anoxic conditions. The dead biomass partially turns into two fractions The factor fp accounts for the particulate matter unbiodegradable which leads the production of the particulate $X_{P}$ component, while the fraction (1-fp) re-enters the system as particulate matter biodegradable (slowly biodegradable substrate, $X_{S}$ ). Also the organic nitrogen tangles up with the particulate substrate $X_{S}$ and becomes available as $X_{N D}$.

$$
\rho_{4}=b_{H} X_{B H}
$$

(5) Decay of autotrophic biomass. It is defined as the same formulation of the heterotrophic decay process (4). This has a smaller extent than heterotrophic process.

$$
\rho_{5}=b_{A} X_{B A}
$$

(6) Ammonification of soluble organic nitrogen. Heterotrophic biomass is also responsible of the conversion of biodegradable soluble organic nitrogen $S_{N D}$ into ammonia, through a first-order process with the constant $k_{a}$.

$$
\rho_{6}=k_{a} S_{N D} X_{B H}
$$

(7) Hydrolysis of entrapped organic substrate. The enzymatic extracellular lysis of slowly biodegradable substrate, $X_{S}$, leads to the production of readily biodegradable substrate, Ss. This process is dependent on the biomass content through surface kinetic reactions. It reaches the saturation when the number of entrapped substrates become larger with reference to the biomass. Substrate hydrolysis is carried out in both under aerobic (faster) and anaerobic conditions (slower). A reducing factor $\eta_{h}$ is then used to consider this difference. 


$$
\begin{aligned}
\rho_{7}=k_{h} \frac{\frac{X_{S}}{X_{B H}}}{K_{X}+\left(X_{S} / X_{B H}\right)}\left[\left(\frac{S_{O}}{K_{O H}+S_{O}}\right)\right. \\
\left.+\eta_{h}\left(\frac{K_{O H}}{K_{O H}+S_{O}}\right)\left(\frac{S_{N O}}{K_{N O}+S_{N O}}\right)\right] X_{B H}
\end{aligned}
$$

(8) Hydrolysis of entrapped organic nitrogen. Particulate organic nitrogen, $X_{N D}$, is hydrolyzed into soluble organic nitrogen, $S_{N D}$. The process is modelled similarly to the particulate organics hydrolysis.

$$
\begin{aligned}
\rho_{8}=k_{h} \frac{X_{N D} / X_{B H}}{K_{X}+\left(X_{S} / X_{B H}\right)}\left[\left(\frac{S_{O}}{K_{O H}+S_{O}}\right)\right. \\
\left.+\eta_{h}\left(\frac{K_{O H}}{K_{O H}+S_{O}}\right)\left(\frac{S_{N O}}{K_{N O}+S_{N O}}\right)\right] X_{B H}
\end{aligned}
$$

These processes may involve more than one state variable at the same time, and therefore, state variable is taking part in more than one process. The inert carbonaceous fractions $X_{I}$ (particulate) and $S_{I}$ (soluble) are considered inert, not being involved in any of the biological processes described previously.

Finally, the conversion processes referring to the state variables are described as ordinary differential equations. Among the 13 state variables, 11 reaction rates are defined including Dissolved Oxygen So, and Alkalinity Salk, since there are two non -reactive state variables (inert).

These reaction rates are:

1. The behaviour of heterotrophic biomass is represented by aerobic, anoxic growth and decay.

$$
\frac{d X_{B H}}{d t}=\rho_{1}+\rho_{2}-\rho_{4}
$$

2. The behaviour of the autotrophic biomass is represented simpler, since it does not grow under anoxic conditions. Therefore, aerobic growth and decay.

$$
\frac{d X_{B A}}{d t}=\rho_{3}-\rho_{5}
$$

3. The behaviour of the rapidly biodegradable organic matter is represented. This concentration is increased by hydrolysis and decreases with the growth of the biomass.

$$
\frac{d S_{S}}{d t}=\rho_{7}-\frac{1}{Y_{H}}\left(\rho_{1}+\rho_{2}\right)
$$


4. The slowly biodegradable organic matter increases with the decay rate of the cells and is reduced by the action of hydrolysis.

$$
\frac{d X_{S}}{d t}=\left(1-f_{P}\right)\left(\rho_{4}+\rho_{5}\right)-\rho_{7}
$$

5. It represents how the inert particulate products grow with the rate of decay.

$$
\frac{d X_{P}}{d t}=f_{P}\left(\rho_{4}+\rho_{5}\right)
$$

6. The concentration of particulate organic nitrogen behaves similarly to slowly biodegradable (particulate) organic matter.

$$
\frac{d X_{N D}}{d t}=\left(i_{X B}-f_{P} i_{X P}\right)\left(\rho_{4}+\rho_{5}\right)-\rho_{7}
$$

7. The concentration of soluble organic nitrogen increases by the ammonification of soluble organic nitrogen, and decreases by the hydrolysis of entrapped organic substrate.

$$
\frac{d S_{N D}}{d t}=\rho_{7}-\rho_{6}
$$

8. The most complex equation is the behaviour of ammoniacal nitrogen, since its concentration increases with ammonification and decreases with nitrification; in addition, it is affected by being the source of nitrogen for the growth of microorganisms.

$$
\frac{d S_{N H}}{d t}=-i_{X B}\left(\rho_{1}+\rho_{2}\right)+\rho_{6}-\left(i_{X B}+\frac{1}{Y_{A}}\right) \rho_{3}
$$

9. The concentration of nitrate is increased by nitrification and decreases with the denitrification process $(2.86$ is the parameter that relates the consumption of nitrate with the production of nitrogen gas).

$$
\frac{d S_{N O}}{d t}=\frac{1}{Y_{A}} \rho_{3}-\left(\frac{1-Y_{H}}{2,86 Y_{H}}\right) \rho_{2}
$$

10. The concentration of oxygen decreases due to the aerobic growth of the biomass. (4.57 relates the grams of oxygen needed to oxidize one gram of ammonium to nitrate). 


$$
\frac{d S_{O}}{d t}=-\left(\frac{1-Y_{H}}{Y_{H}}\right) \rho_{1}-\left(\frac{4,57-Y_{A}}{Y_{A}}\right) \rho_{3}
$$

11. The inclusion of the rate of for the Alkalinity is to detect potential problems with $\mathrm{pH}$ control since the model consider $\mathrm{pH}$ constant and there is not limiting factors that take it into consideration:

$$
\frac{d S_{A L K}}{d t}=-\frac{i_{X B}}{14} \rho_{1}+\left(\frac{1-Y_{H}}{14 * 2,86 Y_{H}}-\frac{i_{X B}}{14}\right) \rho_{2}-\left(\frac{2}{14 Y_{A}}+\frac{i_{X B}}{14}\right) \rho_{3}+\frac{1}{14} \rho_{6}
$$

The main typical values for the stoichiometric parameters and kinetic constants

\begin{tabular}{|c|c|c|c|c|c|c|c|c|c|c|}
\hline & $1 *$ & $2 *$ & $3 *$ & $4 *$ & $5 *$ & $6 *$ & $7 *$ & $8^{*}$ & $9 *$ & $10 *$ \\
\hline $\mathrm{Y}_{\mathrm{H}}$ & 0.67 & 0.67 & 0.67 & - & 0.67 & 0.67 & 0.67 & 0.62 & 0.6 & - \\
\hline $\mathrm{Y}_{\mathrm{A}}$ & 0.24 & 0.24 & 0.24 & - & 0.24 & 0.24 & 0.24 & 0.24 & 0.24 & - \\
\hline$f_{P}$ & 0.08 & 0.08 & - & - & - & - & 0.08 & 0.08 & 0.08 & - \\
\hline $\mathrm{i}_{\mathrm{XB}}$ & 0.086 & 0.086 & - & - & - & - & 0.08 & 0.08 & 0.08 & - \\
\hline $\mathrm{i}_{\mathrm{XP}}$ & 0.06 & 0.06 & - & - & - & - & 0.06 & 0.06 & 0.06 & - \\
\hline$\mu_{\mathrm{H}}$ & 6 & 3 & 6 & 6 & 6 & 6 & 6 & 4.59 & 6 & 2.5 \\
\hline$b_{H}$ & 0.62 & 0.2 & 0.62 & 0.62 & 0.62 & 0.62 & 0.3 & 0.635 & 0.5 & - \\
\hline $\mathrm{K}_{\mathrm{S}}$ & 20 & 20 & 3 & 5 & 3 & 5 & 10 & 20 & 20 & 11 \\
\hline $\mathrm{K}_{\mathrm{OH}}$ & 0.2 & 0.2 & 0.2 & 0.4 & 1 & 0.2 & 0.2 & 0.33 & 1 & - \\
\hline $\mathrm{K}_{\mathrm{NO}}$ & 0.5 & 0.5 & 0.5 & 0.5 & 0.5 & 0.1 & 0.5 & 0.5 & 0.5 & - \\
\hline$\mu_{\mathrm{A}}$ & 0.8 & 0.3 & 0.86 & 1.4 & 0.8 & 0.9 & 0.5 & 0.657 & 0.65 & 0.43 \\
\hline $\mathrm{B}_{\mathrm{A}}$ & 0.2 & 0.1 & 0.13 & 0.15 & 0.15 & 0.13 & 0.05 & 0.098 & 0.15 & - \\
\hline $\mathrm{K}_{\mathrm{OA}}$ & 0.4 & 0.4 & 0.1 & 0.4 & 0.4 & 0.4 & 0.4 & 0.4 & 0.5 & - \\
\hline $\mathrm{K}_{\mathrm{NH}}$ & 1 & 1 & 0.4 & 1 & 0.8 & 0.8 & 1 & 1 & 1 & - \\
\hline$\eta_{\mathrm{g}}$ & 0.8 & 0.8 & 0.6 & 0.6 & 0.6 & - & 0.8 & 1 & 0.6 & - \\
\hline $\mathrm{k}_{\mathrm{a}}$ & 0.08 & 0.04 & - & - & - & 0.05 & 0.05 & 0.092 & 0.08 & - \\
\hline $\mathrm{K}_{\mathrm{h}}$ & 3 & 3 & - & - & - & 2 & 3 & 1.72 & 2 & - \\
\hline $\mathrm{K}_{\mathrm{X}}$ & 0.03 & 0.01 & - & - & - & 0.02 & 0.01 & 0.02 & 0.02 & - \\
\hline$\eta_{\mathrm{h}}$ & 0.4 & 0.4 & - & - & - & 0.5 & 0.8 & 0.32 & 0.4 & - \\
\hline
\end{tabular}
from different calibrations by several authors are presented:

Figure 2.12. Typical values for parameters at neutral $\mathrm{pH}$ and $20^{\circ} \mathrm{C}$ urban wastewater (Jeppsson, 1996)

Finally, it is important to comment that a certain number of simplification and assumptions must be made in order to define a useful model for WWTP application. Some of them are related to the physical model and other with the mathematical part, they are defined in (Jeppsson, 1996). 


\section{Description of the ASM2d}

From its origin, the ASM1 model received very good acceptance by the scientific community, and over the last 20 years, it was the most used in the design of the WWTP and in the study of other communication operation and control strategies. However, at the time of its publication, since the mid-1980s, an extension and modification of the ASM1 model was necessary in order to obtain a model capable of describing the biological elimination of $\mathrm{P}$, together with the elimination of organic matter COD and N. The model obtained, known as ASM2 or ASM2d is briefly presented since it was implemented in one of the simulations presented in the results.

In the previous model ASM1, stoichiometric coefficients are independent of temperature, while kinetic coefficients are affected by temperature changes. The processes in the ASM2 are classified into four groups based on their temperature dependence (zero, low, medium and high dependency). In many coefficients identical values were assigned at 10 and $20^{\circ} \mathrm{C}$. This was justified by the scarcity of available data and the low sensitivity of certain parameters to temperature variations. In this classification, it is considered that the EBPR processes have a low degree of temperature dependence in comparison with other processes incorporated in ASM2. This is generally recommended to be applied in the treatment of wastewater with activated sludge at temperatures between 10 and $25^{\circ} \mathrm{C}$, the authors of the ASM2 model are careful about the applicability of the model outside this range (Henze et al., 2000).

The most significant change of the ASM2 model with respect to the ASM1 model is the consideration of the accumulated populations of $\mathrm{P}\left(\mathrm{X}_{\mathrm{PAO}}\right)$ and its internal structure, a necessary requirement to describe the biological elimination/accumulation of $\mathrm{P}$ by means of Polyphosphate-Accumulating Organisms (PAO bacteria). Thus, the ASM2 model, besides including the transformations corresponding to the biodegradation of organic matter in aerobic and anoxic conditions, and the nitrification process, consider the storage process of $\mathrm{P}$ form of Poly-Hydroxy-Phosphates and release in the form of orthophosphates, which takes place in PAO bacteria in presence of anaerobic and aerobic environmental conditions. From the publication of the ASM2 model, a model that presents a relationship with respect to the capacity of the part of the XPAO bacteria to remain active under anoxic conditions was presented (Kerrn-Jespersen and Henze, 1993; Mino et al., 1998). For this reason, the ASM2 model was extended to the ASM2d model in which the activity of the XPAO bacteria was considered under anoxic conditions.

Besides the previous components presented in ASM1, the main state variables in ASM2d are $S_{F}$ and $S_{A}$, which represent the soluble fermentable substrate and the volatile fatty acids, respectively. This distinction makes it possible to reproduce the release of the $X_{P P}$ Poly Phosphates in the form of $S_{P O 4}$, from the storage only of 
volatile fatty acids $\mathrm{S}_{\mathrm{A}}$ by the $\mathrm{X}_{\mathrm{PAO}}$ bacteria in the form of Polyhydroxy Alkanoates (X $\left.\mathrm{X}_{\mathrm{PHA}}\right)$. Subsequently, from the stored $\mathrm{X}_{\mathrm{PHA}}$, the growth of $\mathrm{X}_{\mathrm{PAO}}$ bacteria occurs in anoxic aerobic conditions. This growth, in turn, is associated with the storage of $\mathrm{S}_{\mathrm{PO} 4}$ by the $\mathrm{X}_{\mathrm{PAO}}$ bacteria in the form of $\mathrm{X}_{\mathrm{PP}}$.

In the ASM2d model, the activity of the $X_{B H}$ bacteria under aerobic and anoxic conditions and the nitrification by the $X_{\mathrm{AUT}}$ bacteria, are described in the same way as in the ASM1 model. Likewise, the disappearance of biomass is described by the concept of lysis-regeneration in which part of the products obtained in the disappearance are converted into inert material $X_{I}$, and another part becomes a slowly biodegradable substrate $X_{S}$. Unlike the ASM1 model, there is no distinction between the inert matter of the influent and the inert matter obtained in the disappearance of the bacteria. This simplification, although it reduces the number of components and therefore the complexity of the model, has been an inconvenience in guaranteeing the continuity of the elementary mass in the model since the elemental mass composition of the inert compounds in the influent does not have that coincide with the composition of the inert compounds obtained in the disappearance of the bacteria.

The component $X_{S}$ obtained in the disappearance of the bacteria and coming from the influent suffers a hydrolysis process and becomes $S_{F}$ and optionally soluble inert $S_{I}$. The $S_{F}$ component can be directly assimilated by the $X_{B H}$ bacteria or, under anaerobic conditions, it can undergo a fermentation obtaining as $S_{A}$ product. Although this fermentation is part of the metabolism of populations of acidogenic bacteria, in the ASM2d model it has been considered that this transformation is metabolized by the $X_{B H}$ bacteria, simplifying the model.

\subsubsection{Implementation of the ASM models in CFD}

The models ASM1 and ASM2d were implemented in the CFD code to perform the simulations carried out in this work. Once the ASM model is coupled to CFD (CFD-ASM model), both the state variables and the biochemical process rates can be calculated by the code. Finally, the ASM fields can be analysed by means of the CFD model in 3D. This enhances the knowledge about the performance within the biological reactors, not only by representing the hydrodynamic performance but also account for the kinetics.

The ASM model can be implemented including an extra scalar transport equation for each of the 13 additional variables, following CFX-Solver Theory-Guide, ANSYS, Inc. as follows:

$$
\frac{\partial}{\partial t}\left(\rho \cdot \varphi_{i}\right)+\nabla \cdot\left(\rho \cdot U \cdot \varphi_{i}\right)=\nabla \cdot\left[\left(\rho \cdot D_{\Phi}+\frac{\mu_{t}}{S c_{t}}\right) \nabla \varphi_{i}\right]+S_{\varphi_{i}}
$$


Where $U$ is the fluid velocity $\left(\mathrm{m} \mathrm{s}^{-1}\right), \rho$ is the mixture density $\left(\mathrm{kg} \mathrm{m}^{-3}\right), \Phi$ is the concentration of the $i$ variable $\left(\mathrm{kg} \mathrm{m}^{-3}\right), \varphi=\Phi / \rho$ is the conserved quantity of $\mathrm{i}$ variable per unit mass of fluid, $S c_{t}$ is the Turbulence Schmidt number, $\mu_{t}$ is the turbulence viscosity term in $\mathrm{Pa} \mathrm{s}, D_{\Phi}$ is the kinematic diffusivity $\left(\mathrm{m}^{2} \mathrm{~s}^{-1}\right)$ and $S_{\varphi_{i}}$ is a volumetric source term $\left(\mathrm{kg} \mathrm{m}^{-3} \mathrm{~s}^{-1}\right)$ that embeds the biochemical reactions.

Temporal and convective terms are in the left-hand side of equation 2.71, while the diffusive term and the Source term are in the right-hand side. The variable rate, according to differential equations from the ASM1 model, are included as the source term (second term on the right-hand side).

On the one hand, although the value of the kinematic diffusivity is not usually neglected, it is very low compared to the turbulence viscosity, in in which more depend the first term of the right-hand side of the Equation. On the other hand, the turbulence Schmidt number (the ratio of momentum diffusivity to mass diffusivity in the turbulent flow) is a parameter of paramount importance still under investigation for activated sludge performance in biological reactors. The CFD models based on the RANS equations, as in our case, the turbulent scalar fluxes are generally estimated by assuming the standard gradient diffusion of the equation 2.71, which requires the definition of the Turbulent Schmidt number.

The value of the Turbulent Schmidt number will strongly affect the transport of a scalar in a turbulent flow. However, there are no universally accepted values of this parameter since it depends on the mixing flow conditions and in the fluid itself, which could be tracer transport (Gualtieri et al., 2016) or sediment transport in suspension (García, 2008). Its value depends on the environmental flow and the conditions. For example, in the case of our concern, tracer transport, (Arnold et al, 1989) performed extensively measurements determining a variation from 0,1 to 1 , with most of the values in between 0.5 and 0.9 . Gualtieri performed an interesting review where it is showed the work of different authors which tested several $S c_{t}$ in environmental flows in order to investigate their case studies. Turbulent diffusivity is decreased as $S c_{t}$ increases, therefore, depending on this, the scalar transport can be dominated by the effects of advection rather than diffusion.

The CFD codes present their default value for the turbulence Schmidt number, for instance, for Ansys Fluent is 0,7. In this work, $S c_{t}=0,9$ has been used as it is the default value for Ansys CFX (ANSYS ${ }^{\circledR}$ ). 



\section{Chapter 3}

\section{CFD Modelling applied to WWT}

The Chapter begins with the description of the main contributions of the CFD Modelling applied to WWT published during the last years. Then, the set-up of the commercial CFD code ANSYS CFX used to perform the simulations is presented. The typical workflow to run a simulation and the main aspects defined in the code are briefly explain including, the computational domain, the boundary conditions, the mesh sensitivity analysis and the discretization scheme for the numerical solution. The description of the interfacial forces implemented to perform the simulations are also included in this chapter. Then, the main aspects of experimental techniques and the measurements carried out to validate the results obtain from the CFD simulations are explained. Finally, the calculation strategies developed to save computing time and used to run the models are presented.

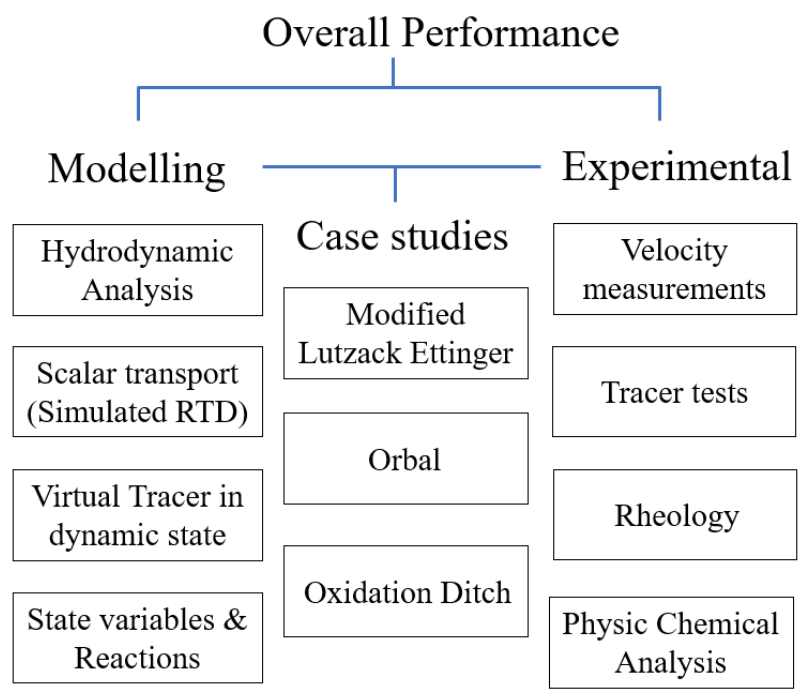

Figure 3.1. Outline of the study 


\subsection{CFD applied to wastewater treatment}

The use of CFD simulation in wastewater industry has become essential for several goals such as design, optimisation, and retrofitting, i.e. the elaboration of alternatives of the configuration for their better operation. The application of CFD to the different process units of the WWTP is broad (Samstag et al, 2016). It can be highlighted the number of studies performed for biological reactors, secondary settling and anaerobic digestion, which have been the most studied during this work. A summary of the two last has been included while a more extended state of the art will be provided for CFD biological reactors.

The operation of the anaerobic digestion in the WWTP presents limitations of control and monitoring due to it takes place in large volumes with a reduced accessibility. CFD is important to better understand the mixing, to study stagnant zones and dead volumes since the configuration does not allow instrumentation to be installed to control the operation inside the tanks. Several works used CFD to quantify them (Karim et al., 2004); (Vesvikar and Al-Dahhan, 2005); (Wu and Chen, 2008); (López-Jiménez et al., 2015). (Lindamark et al., 2014) published a review about the effects of the mixing to the process, which is the main topic of the CFD applied to $\mathrm{AD}$, where the mode and the intensity (to benefit the process) and the power (efficiency) of the mixing for the systems are studied: with mechanical impellers (Bridgeman, 2012; Wu, 2011; Yu et al., 2011) or in a draft tube (Craig et al., 2013); (Meroney and Colorado, 2009); ( Wu, 2010); gas mixing with different configurations (Bel Fdhila et al., 2013; Coughtrie et al., 2013; Karim et al., 2007; López-Jiménez et al., 2015; $\mathrm{Wu}, 2014)$; and hydraulic mixing with external agitation (Hurtado et al., 2015); (Mendoza et al., 2011); (Wu and Chen, 2008). NonNewtonian fluid implementation has been stablished (Meister et al., 2018); (McLeod et al., 2019). The challenges are focused on the implementation of bioreactions (ADM1), and the mass transfer in multi-phase flow.

Secondary settling is one of the most well-developed area of CFD application since (Larsen et al., 1977) performed the first CFD model. The main objectives are to analyse the internal fluid pattern and the solids concentration field taking into account geometry, density currents, deflector effects, etc. that lumped models cannot represent (Samstag, 1989); (Krebs et al., 1995); (Goula et al., 2008); (Brennan, 2001). Most of the CFD modelling work reported in the literature uses the drift flux model to calculate the two-phase mixture of water and activated sludge. Despite the extensive studies on the compression settling behaviour of the activated sludge and the development of advanced settling velocity models (De Clercq et al., 2008); (Kinnear, 2002); (Bürger et al., 2011), (Torfs, 2008), sedimentation sub-models are mostly implemented by the empirical equation of (Takács et al., 1991) which provides good fitting to experimental measurements (Ramin et al., 2014). Other aspects of interests under investigation to be included in the CFD are turbulent mass diffusion of suspended solids, resuspension of the 
settled solids, denitrification and the temperature, wind effect on the water surface, the dynamic effect of the scrapers, the influence of rheology, and the effect of flow (shear rate, G) over the floc growth or breakup (Parker, 1972). This last, controlled by turbulence intensity (Ducoste \& Clark, 1998), is important for biological reactor performance. It has been also studied by population balance models (Nopens et al., 2002); (Nopens et al, 2005) but model improvement is needed.

The dynamic simulation approaches applied to biological reactors can be divided into two levels: (1) The "global" level relying on well-established models, such as the ASM for simulating the nutrient removal, described as a perfectly mixed tankin-series hydraulic model (Printemps et al., 2004); and (2) the "local" process level focusing on the hydrodynamic behaviour using CFD (Essemiani et al., 2004), where a detailed study of the transport phenomena and mixing efficiency, based on the positioning and performance of the internal elements (stirrers and diffusers), can account for the calculation of the minimum velocity to avoid sludge settling and oxygen transfer optimisation (Glover et al., 2006).

Generally, the main scope of CFD applied to biological reactors has been to study hydrodynamics for lot of variety of activated sludge configurations, focused on the mixing performance by the velocity field analysis and residence time distribution. Moreover, there are major challenges, including turbulent hydraulics, multiphase fluid to optimise aeration and calculate flocs sedimentation, and biokinetics by applying CFD-ASM models (Samstag et, al., 2016); (Karpinska and Bridgeman, 2016). A considerable number of CFD studies showed the importance of hydrodynamics for the process and modelling of biological reactors (Karpinska et al., 2016), the WWT efficiency is influenced not only by the bio-reaction of activated sludge, but also by the fluid behaviour including the bubble/liquid flows. Thus, the hydraulic analysis by means of CFD allows to gain a deeper insight on the biological removal processes.

Since authors agree that one of the major bottlenecks of using CFD is its high computational requirement (Laurent et, al., 2014), CFD modelling of full-scale biological reactors defined as single-phase modelling is the most widespread approach because it takes less calculation time than multiphase fluid models to reproduce suspended solids in liquid systems. Good predictions of concentrated solid-liquid systems can be achieved in a short computing time using the singlephase non-Newtonian fluid models (Eshtiaghi et al, 2013); (Littleton et al., 2001); (Littleton et al., 2003); (Brannock et al., 2010). Although flocs sedimentation in the mixed liquor inside biological reactors can be considered by implementing the driftflux model (Xie et al., 2014), single-phase CFD models can be considered the most feasible approach to keep computing time low provided that the minimum velocity of the mixed liquor to keep the solids suspended is ensured (Aubin et al., 2004) (Le Moullec et al., 2011). 
The effect of the solids acting on the other phases is often not considered for biological reactors. The conventional model to define the solids (flocs) present in the mixed liquor in a biological reactor consists on assuming they are included in the liquid phase due they have a similar density of liquid (Lei \& $\mathrm{Ni}, 2014$ ). Therefore, the implementation of the non-Newtonian fluid approach is a common way to consider the presence of the solids through the viscosity of the liquid (Ratkovich et al., 2013). Incorporating the rheological model does not imply a remarkable increase of the computing cost. A better approach to reproduce the solid phase is to perform a three-phase CFD model (sol-liq-gas) (Lei et al., 2014), fairly increasing the computing cost for a full-scale simulation. In this case, the solids are defined as a pseudo-solid phase (sludge), not considering the drag but a denser liquid phase with a specific settling velocity (de Clerq, 2003).

Single-phase can be successfully used to reproduce mechanical aeration. (Littleton et al., 2007) performed a 3D CFD model in a closed loop reactor, where consumption of dissolved oxygen (DO) was included and the identification of zones where simultaneous nitrification-denitrification was carried out. In the studies of submerged aeration systems, a two-phase flow approach must be defined to reproduce the plumes of the air. Authors have mostly investigated the mixing pattern of the aeration tanks from the point of view of the aeration efficiency, e.g. pointing out both the influence of the diffuser layout and the axial liquid velocity on the oxygen mass transfer coefficient (Gresch at. al., 2010); (Hreiz et al., 2008); (Cockx et al., 2001); (Fayolle et al., 2007); (Fayolle et al., 2010). The Eulerian approach is the most commonly used in multiphase gas-liquid flow to perform fullscale aeration tanks. Accordingly, comparing workability of different options in multiphase modelling, the other approaches available (Lagrangian particle tracking or Volume Of Fluid), despite being more accurate, are exceedingly expensive in terms of computing time and memory (Samstag at. al, 2016).

Energy consumption from aeration systems constitutes an important part of the total energy cost in a WWTP. The major part of this energy is used by the aeration system in the biological process. This is particularly significant in oxidation ditch systems where operational costs related to aeration make up between $15 \%$ and $25 \%$ (Bischof, F et al, 1999), and $70 \%$ of the energy costs (Ovezea, A., 2002). Consequently, economic viability of a WWTP depends largely on a proper design and operation of the aeration system. In other words, it is of interest to know the efficiency of a given aeration system in terms of energy consumption (Svenskt Vatten, 2007). If we wish to increase the rate of aerobic biological processes, one must to increase either the gas/liquid interfacial area (a) (Cockx et al., 2000); the mass transfer coefficient, that depends on diffusion and convection (James A. et al., 2002); (Hasanen, 2006), or even both if possible. The complex phenomena of oxygen transfer from gas phase has been largely studied focused on the calculation of the global volumetric mass transfer coefficient $k_{L} a$ (Clarke K. G. and Correia L.D.C., 2008). This is a parameter of paramount importance significantly 
influenced by turbulence and fluid properties (Gresch et al., 2011). For oxidation ditch configurations, the strong impact of gas plumes and horizontal flow velocity in $k_{L} a$ is essential. Authors have developed several approaches to model aeration performance. Thus, Fonade et al. (2001) built a theoretical model based on dividing geometrically into separate volumes introducing known jet aerator flow rate, or (Do-Quang et al., 1999) who defined the $k_{L} a$ as a transport source term determined experimentally. Several authors developed gas-liquid Eulerian approach CFD models of full-scale oxidation ditches (Cockx et al., 2001), (Yang et al. (2011); (Karpinska et al., 2018). On one hand, CFD allows to study the dynamic behaviour of the biological reactors by means of modelling oxygen transfer in multiphase systems (Samstag et al., 2012), Gresch et al. (2011) and (Lei \& Ni, 2014). On the other hand, CFD-ASM models provide greater detail of the state variable distributions and their rates inside the large tanks partially aerated Glover et al. (2006).

It is possible to evaluate the oxygen transfer efficiency applying standard methods for oxygen transfer measurements in clean water such as (ASCE, 2007; Fayolle et al., 2007). Also, the conversion factor to reproduce the impact in field conditions must be taken into account in order to evaluate both aeration performance and devices (Metcal\&Eddy, 2002). Thus, once oxygen demand has been estimated, the air supply can be calculated taking into account the pressure drop and the submerged aerator features (Garcia-Ochoa F. and Gomez E., 2009). Authors have stablished $k_{L} a$ expressions depending on the air flow rate and dimensional analysis parameters of diffusers (Gillot S., 2005). Very recently, a review of (Karpinska, 2016), a CFD model at laboratory scale (Karpinska and Bridgeman, 2017) and CFD model applied to a full-scale bioreactor (Karpinska and Bridgeman, 2018) provided a validated CFD approach based on the SST k- $\omega$ turbulence closure model and the interfacial area concentration model, used to assess the hydrodynamics of a fullscale AS tank.

Predictive correlations for interfacial transfer area, bubble diameter, gas hold up, oxygen transfer coefficient, and $k_{L} a_{i}$ are investigated in different engineering fields to better understand the processes (Clarke and Correia, 2008). In the wastewater treatment modelling using CFD, the mass transfer is caused by the oxygen transfer from the bubbles to the liquid, following:

$$
\frac{d \phi_{o}}{d t}=k_{L} a_{i}\left(C^{*}-C\right),
$$

being $\phi_{o}$ the oxygen transfer rate, $k_{L}$ the transfer coefficient, $a_{i}$ the interfacial area concentration, $\mathrm{C}$ the oxygen concentration in the bubble and $\mathrm{C}^{*}$ the saturation concentration of oxygen in the liquid. The complete fluid mechanics involves a two-phase flow computation where the oxygen transfer is described by Eq. (3.1). In the most complete description, $a_{i}$ is calculated by the flow solver following by Eq. 
(3.2) (Fayolle et al., 2007), so the mass transfer requires only a suitable value for $k_{L}$. It has been considered the following equation from the classical penetration theory of (Higbie R., 1935):

$$
\begin{aligned}
& a_{i}=\frac{6}{\phi_{b}} \frac{\alpha_{G}}{1-\alpha_{G}}, \\
& k_{L}=2 \sqrt{\frac{D_{L} v_{s l i p}}{\pi \phi_{b}}}
\end{aligned}
$$

being $D_{L}$ the molecular diffusivity of oxygen, $v_{\text {slip }}$ the slip velocity between bubbles and liquid, and $\phi_{b}$ the mean bubble diameter and $\alpha_{G}$ is the volume fraction of air phase. This $k_{L}$ expression (Eq. 3.3) strongly depends on the diffusion coefficient, which is difficult to model, especially in turbulent flows. As a first simplification to the model, a constant $k_{L}$ value can be valid through the whole domain.

Several two-phase flow (gas-liquid) CFD models have been developed over the last years focused on aeration of full-scale oxidation ditch configurations (Karpinska and J. Bridgeman, 2016). Multiphase modelling of AS tanks based on gas-liquid neutral density resulted in an overestimation of the mixing degree and its applicability to study bubbly bioreactors is still uncertain (Samstag et al., 2012). The bubble size and the air hold-up are the parameters of paramount importance that govern the interfacial area. The degassing approach and a fixed bubble diameter definition are commonly used as an input in the model, but the code does not calculate the interfacial area density during the simulation (Gresch at. al., 2010); (Hreiz et al., 2008); (Fayolle et al., 2007); (Brannock et al., 2010); (Le Moullec et al., 2018); (Potier et al., 2005).

The oxygen-transfer rate in aeration tanks is governed by several hydrodynamic parameters, namely, bubble size, velocity, and turbulence in the liquid phase and resulting gas holdup; it was studied at laboratory scale by (Karpinska and Bridgeman, 2017) including break-up and coalescence of bubbles. Once these equations of the population balance model (PBM) tested, they were applied to a full-scale tank (Karpinska and Bridgeman, 2018) where the oxygen mass transfer rate was studied, without including the oxygen uptake, biochemical reaction rates and the RTDs.

Population Balance Models (PBMs) represent a powerful modelling basis for the description of the dynamics of the properties that are characterized by statistical distributions (Nopens et al., 2012). CFD models reproduce the dispersed phase motion more correctly when PBM is applied, it can be define to calculate floc aggregation, breakage and floc growth (Nopens, 2005); (Serra and Casamitjana, 1998); (Biggs, 2000), and to reproduce the presence and the interaction of bubbles, 
based on break-up and coalescence models (Wang et al., 2005); (Wang et al., 2011); (Marchisio and Fox, 2005); (Karpinska and J. Bridgeman, 2018). Despite the high computational cost, the PBM is included as a sub-model of the dispersed phase dynamics including the liquid-air interface to calculate the interfacial area density. These equations are extremely difficult to solve, the solution of a PBM is tackled by discretisation of the distribution into size classes as the MUSIG (Lo, 1994).

The CFD-ASM is a 3D mathematical framework describing the flow dynamics (hydrodynamics) and the biochemical interactions (biokinetics) that take place in reactors. These simulations allow the quantification of interactions and transport phenomena between the water-gas, water-sludge and gas-sludge phases. The system equations are one-way coupled, in the sense that the hydrodynamics influences the biokinetics, but the opposite does not hold. In other words, the state variables are simply transported by the main flow. Consequently, both parts can be treated separately. CFD-ASM models provide greater detail of the state variable distributions and their rates inside the large tanks partially aerated (Glover et al., 2006). (Karpinska, 2016) reviewed the main works on the use of CFD to model aeration evaluating mixing and mass transfer coupled with biokinetics, where the study of (Le Moullec et al., 2010) is worth mentioning due to the robust discussion reported to explain the disagreement between experimental data and CFD results obtained about nitrification-denitrification performance. (Rehman, 2016) presented the results of application of an integrated hydrodynamic and biokinetic model to the distribution of velocity, DO and ammonium in a full-scale closed loop reactor. A 3D single phase CFD simulation of an oxidation ditch configuration was implemented by (Pereira et al. 2011) to determine RTD characteristics. Three different turbulence models were compared: RANS with the standard k- $\varepsilon$ model; URANS; and Large Eddy Simulation.

The Residence Time Distribution (RTD) that describes the amount of time a fluid element can spend inside the reactor is commonly used in CFD Modelling as a validation tool for hydrodynamics and mean residence time. Though it is costly to obtain and not all RTD analytical methods provide information about shortcircuiting flow or dead zones when large-volume tanks are examined (Burrows et al., 1999), RTD allows quantitative measurement of mixing, and what is more important the determination of the potential for pollutant removal (Brannock et al., 2010). It is possible to obtain crucial hydrodynamic information of activated sludge systems from CFD tools to provide deep knowledge of the fluid behavior (Howes et al., 2003). The literature offers numerous examples of CFD tracer studies to reproduce the fluid pattern, to determine the axial dispersion index or number of tanks-in-series, and calculate mean residence time, dead volume, mixing, shortcircuiting, etc., always compared to RTD: (Brannock et al., 2010; Howes et al., 2003; Brannock, 2003; Le Moullec et al. 2008; Le Moullec et al., 2010; Guo, et. al, 2012), and even with reactive tracers (Gresch et al., 2011). 
Usually, experimental data supplied to validate CFD models is relatively scarce due to the conflicting interests in terms of economics, time and complexity, especially in full-scale tank studies. In addition to the determination of the global fluid behaviour by tracer tests, very accurate results can be obtained using specific instrumentation to provide local measurements that CFD predictions require (Brannock et al., 2010); (Wicklein et al., 2016).

\subsection{The CFD workflow}

ANSYS CFX is a Computational Fluid Dynamics (CFD) software that combines an advanced solver with powerful pre- and post-processing proficiencies solving a set of equations that describe the processes of momentum, heat and mass transfer known as the Navier-Stokes equations. These partial differential equations with no known analytical solution are discretized and solved numerically. There are several different discretization methods that are used in CFD codes with the most common, and the one on which CFX is based, known as the finite volume technique. In the finite volume technique, the region of interest is divided into small sub-regions, called control volumes as explained in 2.1. The equations are discretized and solved iteratively for each control volume. As a result, an approximation of the value of each variable at specific points throughout the domain is obtained.

An important aspect of modelling is that CFD results appearance superficially accurate. The detailed three-dimensional, colored output is perfect for publications and presentations, but can lead to a false confidence in the results. Even though numerical model results usually trend truthfully, they do not always fully capture the detail of the physical case they are modelling, and they sometimes under-predict or over-predict reality (e.g. Cook and Richmond 2001). It is for this reason that successful models require some error examination. When the results need to be highly accurate for economic reasons for instance, a physical model may be required. In these cases, CFD simulations can guide the implementation of the physical model and thus reduce the final costs of the project (e.g. Gessler and Rasmussen 2005).

The process of performing a CFD simulation using ANSYS consists of six software modules that take a geometry and mesh and pass the information required to perform a CFD analysis: (1) defining the package, (2 and 3) creating the geometry/mesh; (4) defining the physics of the model; (5) solving the CFD problem and (6) visualizing the results in the post-processor. These processes are schematically shown in Figure 3.2. Other option is to start from module 4 by means of importing a mesh (Figure 3.2, right). 

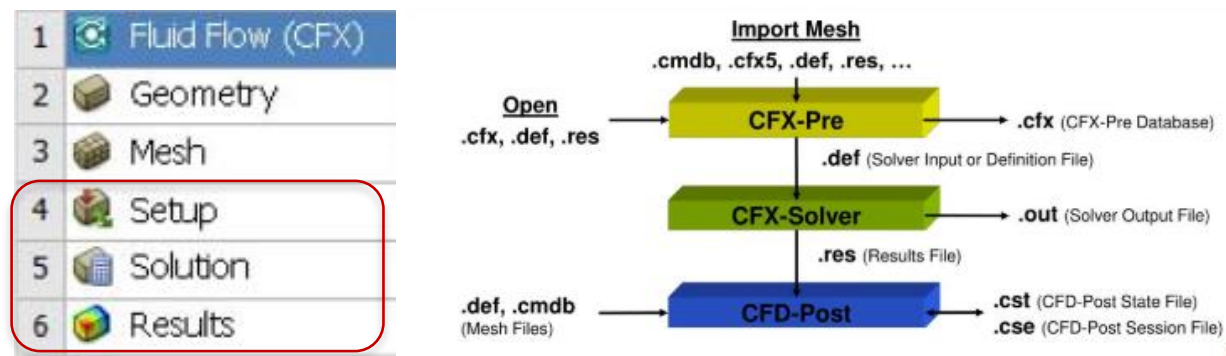

Figure 3.2. Overview of ANSYS CFX code structure $\left(\right.$ ANSYS $\left.^{\circledR}\right)$.

\subsubsection{Boundary Conditions}

Boundary conditions are a set of properties or conditions on surfaces of domains required to fully define the flow simulation. The computational models performed in this study consists of three fluid boundaries namely; inlet, outlet, wall. The following boundary conditions have been set at the boundaries.

Inlet: At the inlet section, the measured radial profiles of the following variables have been set as boundary conditions in accordance with the flow conditions

- $\quad$ Liquid Mass Flowrate $(\mathrm{kg} / \mathrm{s})$

- Gas Velocity (only for diffusers in two-phase flow simulations)

- Liquid Volume Fraction (1- Gas Volume Fraction)

- Gas Volume Fraction

- Gas Liquid Interfacial Area concentration (when needed)

Outlet: At the outlet section, the measured radial profiles of the following variables have been set as boundary conditions in accordance with the flow conditions

- Liquid Mass Flowrate $(\mathrm{kg} / \mathrm{s})$

Wall: On the walls a non-slip boundary condition was set for the liquid phase and a free-slip boundary condition for the top face of the domain (the water surface). For the gas phase, free-slip boundary condition was selected for the walls assuming that direct contacts between the bubbles and the walls are negligible, except for the top face where:

- $\quad$ Free slip (for single phase simulations)

- Free-surface approach was modelled for two-phase simulations

Regarding the inlet for the dispersed phase (air), a total air flowrate $(\mathrm{Nm} 3 / \mathrm{h})$ was distributed equally into the total number disc diffusers. So, each diffuser was modelled as an air inlet boundary condition, providing the specified mass flow rate. The size distribution at the inlet was approximated to a monodisperse $3 \mathrm{~mm}$ (this is the mean size provided by the manufacturer of the diffusers). To complete the boundary condition, the hold-up at the inlet was computed as 


$$
\alpha=\frac{Q_{\text {gas }}}{A_{\text {inj }} v_{t}}
$$

In this equation, $\mathrm{v}_{t}$ stands for the terminal velocity corresponding to $3 \mathrm{~mm}$ air bubbles in clean water (using Jamialahmadi correlation (Jamialahmadi et al., 1994), this resulted in $0.25 \mathrm{~m} / \mathrm{s}$ ) and $A_{\text {inj }}$ represents the diffuser area corresponding to $0.023 \mathrm{~m}$ and $0.050 \mathrm{~m}$ for the internal and the external diffuser diameter, respectively (resulting in an area of $0.039 \mathrm{~m}^{2}$ ). Given these conditions in the setup, the inlet hold-up resulted in a $5.65 \%$.

\subsubsection{Mesh definition}

In order to discretize the geometrical domain occupied by the fluid, two large categories of approaches can be distinguished: unstructured and structured meshing. None of them can be taken for granted the best approach as their performance is highly case specific, mostly depending on the shape of the domain geometry. In order to set up the computational domain for the numerical investigations, Ansys Meshing was used to perform the grids.

In this work, grids have been performed mainly as structured meshes with hexahedral elements except in the parts of the geometry where the shape force to tetrahedral elements. For example, the resulting mesh for the simulations was selected after carrying out a grid dependence procedure and discretization schemes which have been included; finally, a hexahedral dominant mesh with 238,730 nodes was performed to calculate the simulations by means of hexahedral elements with an edge of approximately $17 \mathrm{~cm}$. The guidelines detailed in CFX Best Practices Guide for Numerical Accuracy (ANSYS ${ }^{\circledR}$ 16.2, 2015) were considered, testing mesh dependence and discretization schemes. Then, a sensitivity analysis of the mesh confirmed the null impact of the mesh size element on the simulation results.

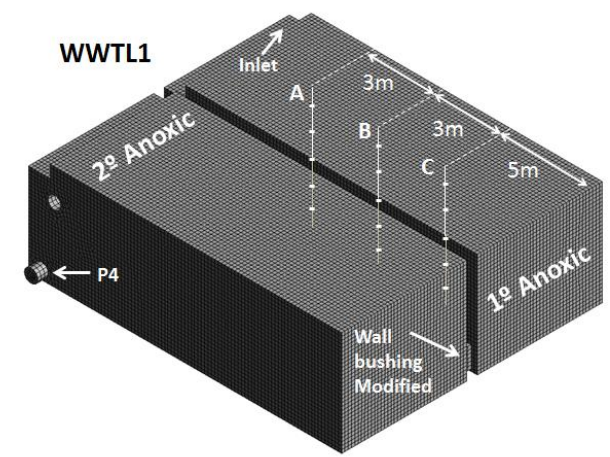

Figure 3.3. Structured Mesh of the Lutzack Ettinger configuration (anoxic) 

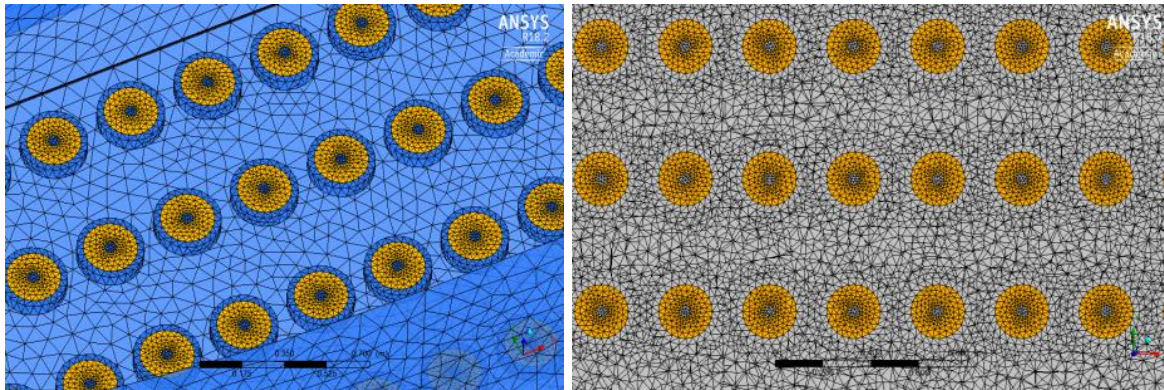

Figure 3.4. Unstructured mesh of the Oxidation ditch configuration (diffusers)

In order to know if a mesh is suitable for carrying out a simulation, an index called the Convergence Index of the mesh or Grid Convergence Index (GCI) (Roache 1998), (Tanaka et al., 2014), (Tanaka et al., 2016) was used to analyse whether a mesh is suitable for a simulation based on the velocity values obtained in different points or planes of the domain as well as the thickness of the elements of the mesh.

For the first model, five different grid sizes have been performed. from approximately $1 \times 10^{5}$ up to $9 \times 10^{5}$ nodes with element sizes from $180 \mathrm{~mm}$ to 280 $\mathrm{mm}$.

It has been considered acceptable number of nodes up to 238,000 because the error is below $5 \%$. This grid was selected to perform the simulations. Figure 3.5 shows the cost effectiveness of the meshes tested; the average error and the computational cost were determined for each mesh.

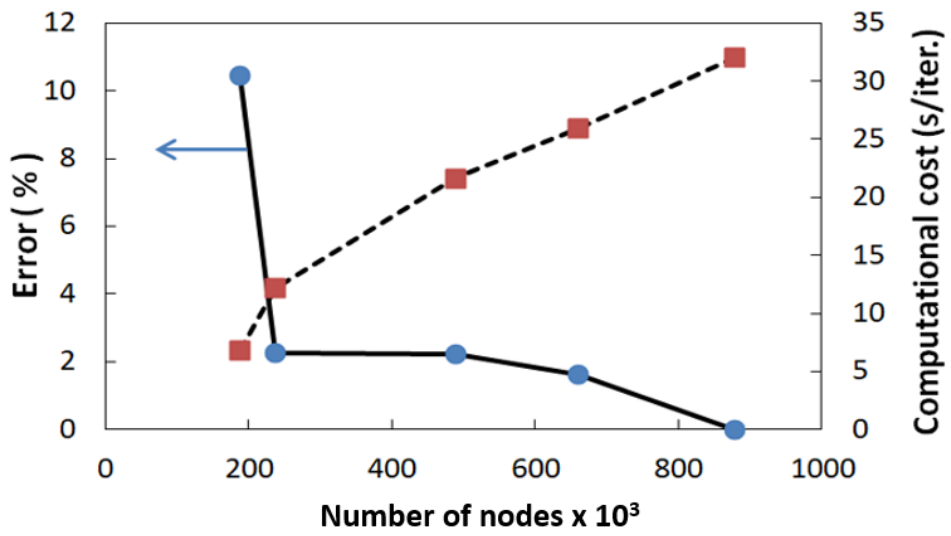

Figure 3.5. Cost effectiveness of the meshes tested

On the other hand, for the meshing of the oxidation ditch, the diffusers were drawn in detail with 3D CAD software to introduce air only through the perforated annular 
area. This increased considerably the total number of nodes of the mesh compared to the single-phase model, from 2,014,856 to 2,927,830. The modelling of the free surface made it necessary to increase the 3D domain in the vertical direction by 0.5 $\mathrm{m}$, introducing a mesh refinement to reproduce the interface liquid-gas interface. This gave a more detailed description of these two regions that is extremely important to describe the dispersed phase correctly. The meshes for the simulations were selected following the CFX Best Practices Guide for Numerical Accuracy. Tetrahedral dominant meshes were performed to calculate the simulations which guarantee the accuracy and stability of the numerical computation by the mesh quality parameters (aspect ratio and skewness). To ensure the mesh independency of the results, a three-grid GCI was computed for several quantities using the formula proposed by Roache (Roache, 1998) and the methodology of Tanaka (Tanaka, 2014; Tanaka et al., 2016).

High aspect ratio value and low skewness values are recommended, between 0.95-1 and $0-0.25$, respectively. Specifically, the parameters of the mesh quality for the single-phase and the two-phase CFD models are shown below where the parameters of reference to evaluate the mesh quality are included.

Table 3.1. Mesh quality parameters depending on the Aspect ratio value

\begin{tabular}{|l|l|l|l|l|}
\hline Excellent & Good & Acceptable & Poor & Bad \\
\hline 1 & $1-10$ & $10-50$ & $50-100$ & $>100$ \\
\hline
\end{tabular}

Table 3.2. Mesh quality parameters depending on the Skewness value

\begin{tabular}{|l|l|l|l|l|l|}
\hline Excellent & Good & Aceptable & Poor & Bad & Degenerated \\
\hline $0-0,25$ & $0,25-0.5$ & $0,5-0,8$ & $0,8-0,95$ & $0,95-0,99$ & $0,99-1$ \\
\hline
\end{tabular}

To ensure the mesh independency of the results, a three-grid GCI was computed for several quantities. In this approach, the results provided by three meshes with different number of nodes $\left(N_{1}, N_{2}\right.$ and $\left.N_{3}\right)$ are compared, being 1 the index corresponding to the finest mesh and 3 the one for the coarsest. The GCI was calculated by using the formula proposed by (Roache et al., 1998):

$$
G C I=F_{S} \frac{\left|\varepsilon_{21}\right|}{r_{21}^{p}-1} .
$$

According to the recent works of Tanaka et al. (Tanaka et. al., 2014), $F_{S}=$ 1.25 when the order of convergence, $p$, lies between 1 and 2 , and $F_{S}=3$ otherwise. 
The order of convergence can be obtained by solving iteratively the following system of equations:

$$
\begin{gathered}
p=\frac{\ln \left(\frac{\varepsilon_{32}}{\varepsilon_{21}}+q\right)}{\ln \left(r_{21}\right)}, \\
\varepsilon_{i j}=\frac{f_{i}-f_{j}}{f_{j}}, \\
r_{i j}=\sqrt[3]{\frac{N_{j}}{N_{i}}} \\
q(p)=\ln \left(\frac{r_{21}^{p}-s}{r_{32}^{p}-s}\right), \\
s=\operatorname{sign}\left(\frac{\varepsilon_{21}}{\varepsilon_{32}}\right) .
\end{gathered}
$$

In these equations, $f_{i}$ stands for the value of the variable used in the comparison calculated by using the $i$-th mesh. The results of the GCI are provided in Table 3.3 for the averaged velocity at a vertical cross-section plane containing the measurement profile P2. Finally, the finest mesh was chosen for a better description of the flow.

Table 3.3. Overview of the GCI analysis

\begin{tabular}{|c|c|c|c|c|c|c|}
\hline$i$ & $N_{i}$ & $f_{i}(\mathrm{~m} / \mathrm{s})$ & $r_{i(i-1)}$ & $\varepsilon_{i(i-1)}(\%)$ & $p$ & $G C I(\%)$ \\
\hline 1 & 2014856 & 0.2007 & 1.065 & 1.75 & 11.2 & 2.4 \\
\hline 2 & 1475654 & 0.1972 & 1.109 & 4.36 & & \\
\hline 3 & 1220855 & 0.1886 & & & & \\
\hline
\end{tabular}




\subsubsection{Discretisation Scheme}

The governing equations are solved under steady state and transient conditions. The equations are solved by the code in each cell of the computational domain. The code stores the discrete values at the centre of the cell.

For all flow conditions simulated, reliable convergence criterion based on the root mean square (RMS) residual of $1 \times 10^{-4}$ was adopted for the termination of numerical calculations. This value has been considered a good compromise between accuracy of the results and the speed-up of the calculation process.

The time step was selected to ensure that the mean Courant number in the domain was below 0.5 . Some regions exceed this value, we checked that only $2 \%$ of the volume had a $\mathrm{Co}>1(0.3 \%$ with $\mathrm{Co}>2)$. Time convergence was ensured by stopping the iterations with and RMS error of $10^{-5}$. The spatial convergence was ensured by performing a GCI.

To our understanding, the application to each location would have not much statistical importance as for most of measured locations the simulation results falls within the range of one/two sigmas, with some exceptions. In order to provide a better insight on the overall error, this RMS is generally accepted.

But this comment addresses an important point on the statistical analysis: the deviation from the trend. The plot below shows a representation of the experimental values against the simulation ones. The apparent linear relationship means that the trends in the flow behaviour are quite well captured (and the RMS error stands for it). In addition to this, we note now that the slope of this linear fit is not 1 (as should be for a perfect match between simulation and experiments), but approaches 0.75 , providing a slight overprediction of the velocities in the model. This underprediction is related to the momentum sources, and further changes into the momentum source model should be incorporated to account from this deviation (the efficiency of the propellers would be smaller than the one used). As the purpose of this work is not the accurate modelling of impellers, we prefer to keep the model as it is, with no modifications so that the results fit better. Even so, our model provided good results compared to other works of reference such us (Brannock, 2003) which compared CFD results to experimental $3 \mathrm{D}$ velocity components.

The imbalances have been calculated and monitored for the scalar transport equations to guarantee the continuity in the system.

With respect to the influence of this overprediction on the purpose of this paper, this deviation would affect the actual values for the mass exchange between the channels, but not to the trends, i.e. which configuration would provide a better hydrodynamic behaviour).

Typically, the calculation of full-scale CFD-ASM models implies high computing times. As mentioned in Section 2.3.4, simulations were run in two steps with the 
purpose to reduce computational costs, solving hydrodynamics in the first step, and kinetics in the second one. Furthermore, a timestep sensitivity analysis over the second step of the simulation was performed with the aim of obtaining a maximum value of timestep which would provide good accuracy in CFD results. In order to do that, the evolution of the state variables was solved several times by employing different timesteps for each run. All runs shared the same velocity field, as a single steady state solution was used to feed the transient with frozen hydrodynamics. The evolution of the state variable value in time for different timesteps has been plotted. It was found that there was no significant difference in the resulting state variables (lower than $0.1 \%$ ) when the timestep is kept below $1 \mathrm{~s}$. When this value is increased up to $100 \mathrm{~s}$, the simulation time is conveniently reduced, but leading to deviations of approximately 5\% at the end of the simulation. Further increase of the timestep results in faster computations but at higher deviations. It was also noted that the numerical imbalance of the partial differential equations (PDEs) increased over 5\% for some state variables, thus exceeding the aforementioned $1 \%$ maximum recommendations. Also, the initial part of the transient actually shows very different values, leading to huge errors in the computations in the early times of the simulation.

\subsubsection{Solution of multi-Phase Flow}

Within the Eulerian-Eulerian model, ANSYS CFX provides a way to model polydispersed flows using the Multiple Size Group (MUSIG) Model. In the MUSIG modelling approach, the bubbles are divided into classes and the initial bubble size distribution is defined as a boundary condition.

The free-surface approach have been used in this work to study the dispersed phase dynamics including the liquid-air interface to calculate the interfacial area density.

Based on the two-fluid model approach, different modelling concepts can be found in literature that have been proposed to obtain practical solution to the population balance model equation. MUltiple SIze Group (MUSIG) has been used as the class method which describes the spectrum of bubble size through a series of discrete bubble size classes, the dynamical changes of size distribution can thus be tracked. This case, the homogeneous MUSIG. model by Lo, (1996) was implemented which assumes that all the discrete bubble size classes move with the same velocity field. For modelling the break-up and coalescence phenomena there are several model available in the literature. 

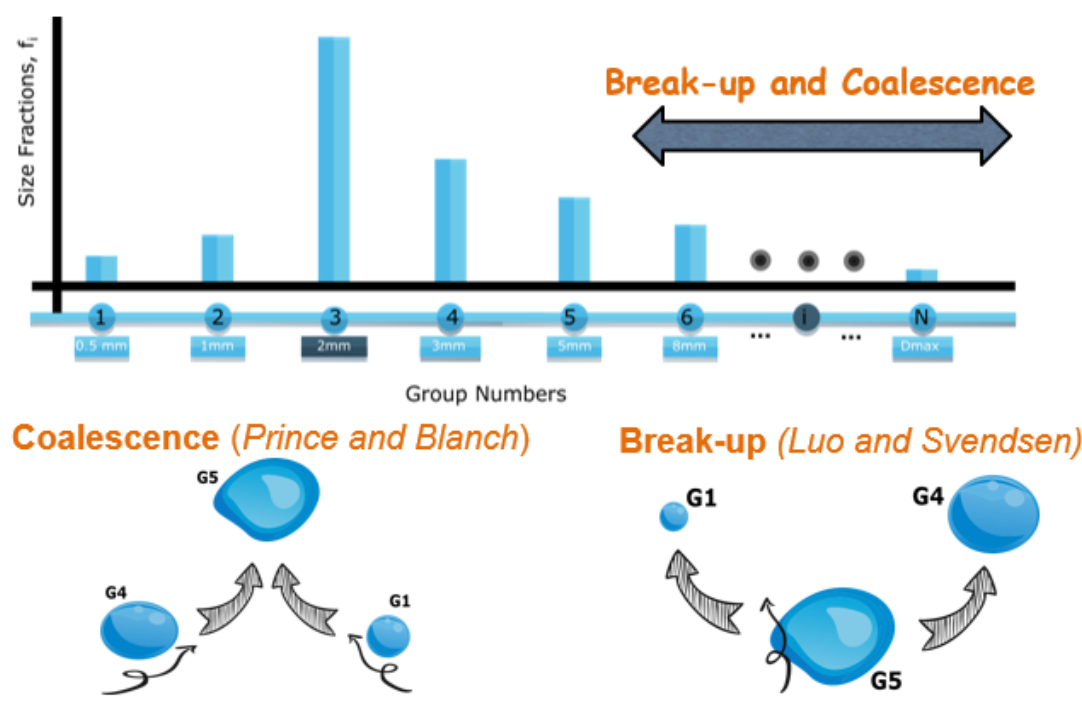

Figure 3.6. Scheme of the MUSIG model (Coalescense and Break-up models)

In this approach, the flow dynamics is determined by the mass and momentum conservation equations,

$$
\begin{gathered}
\frac{\partial}{\partial t}\left(\alpha_{r} \rho_{r}\right)+\nabla \cdot\left(\alpha_{r} \rho_{r} \vec{U}_{r}\right)=S_{r} \\
\frac{\partial}{\partial t}\left(\alpha_{r} \rho_{r} \vec{U}_{r}\right)+\nabla \cdot\left(\alpha_{r} \rho_{r} \vec{U}_{r} \vec{U}_{r}\right)= \\
=-\alpha_{r} \nabla p+\alpha_{r} \rho_{r} \vec{g}+\nabla\left\{\alpha_{r} \mu_{e, r}\left[\nabla \vec{U}_{r}+\left(\nabla \vec{U}_{r}\right)^{T}\right]\right\}+\vec{M}_{r}
\end{gathered}
$$

for each phase $r$, using the sub-index $c$ for the continuous phase and $d$ for the dispersed one. The fluids densities and effective viscosities are represented by $\rho_{r}$ and $\mu_{e, r}$, whereas flow properties as the volume fraction for each phase and the corresponding velocity vectors are given by $\alpha_{r}$ and $\vec{U}_{r}$, respectively. The pressure, $p$, and the gravity vector, $\vec{g}$, are common for both phases. The mass transfer between the phases is accounted for by the source term, $S_{r}$, and the momentum exchange between them is determined by the so-called interfacial forces, $\vec{M}_{r}$.

To model the continuous phase (wastewater), the rheological conditions from the single-phase model were preserved. Also, the SST model was used for the turbulence modelling. The same boundary conditions as in the single-phase case were used, except for the water surface. In this configuration, the water-air surface 
was modelled by means of a free-surface model (Brackbill et. al., 1992) instead of the degassing approach used in the references included in this work. The displacement of the liquid level caused by the injection of the air is thus accurately reproduced, leading to a better description of the flow in the regions surrounding the aerators. The top surface of the domain was set as an opening to the atmosphere.

The dispersed phase (air bubbles) was modelled as a polydispersed-incompressible phase by using the homogeneous MUSIG framework (Brackbill et. al., 1992). In this population balance approach, the dispersed phase is divided into $\mathrm{M}$ discrete groups, each one labelled by an index $\mathrm{m}$ and characterized by a given bubble diameter, $D_{b, m}$. The fraction of bubbles that fall into each group is named as the group size fraction, $f_{m}$. In order to develop a transport equation, the number density of group $\mathrm{m}, n_{m}$, is introduced as

$$
n_{m}=\rho_{d, m} \alpha_{d} f_{m}
$$

where $\rho_{d, m}$ is the density of the m-th group. The resulting transport equation reads as follows:

$$
\frac{\partial\left(n_{m}\right)}{\partial t}+\nabla \cdot\left(n_{m} \vec{v}_{d}\right)=S_{B, m}+S_{C, m},
$$

being $S_{B, m}$ and $S_{C, m}$ the break-up and coalescence source terms, respectively.

The break-up source term can be calculated as

$$
S_{B, m}=\sum_{m^{\prime}>m}^{M} \beta_{m^{\prime}, m^{\prime}} \Omega_{m^{\prime}} n_{m^{\prime}}-\Omega_{m} \mathrm{n}_{m}
$$

Note that the sum in the first term of the right-hand side of this equation stands for the birth of bubbles in group $m$ due to the break-up of bubbles of bigger sizes, and it depends on the break-up frequency of every group, $\Omega_{m}$, and the family probability distribution function, $\beta_{m^{\prime}, m}$. The second term accounts for the death of bubbles in group $m$ due to their break-up resulting in bubbles of group $m^{\prime}$. In order to compute the break-up frequency, the well-known model of Luo and Svendsen (Luo and Svendsen, 1996), (Liao and Lucas, 2009) was used.

The coalescence source term, $S_{C, m}$, is calculated as

$$
S_{C, m}=\sum_{m^{\prime}=1}^{m} \lambda_{m^{\prime}, m} h_{m^{\prime}, m^{\prime}} n_{m^{\prime}-m, m^{\prime}} n_{m^{\prime}}-n_{m} \sum_{m^{\prime}=1}^{M} \lambda_{m, m^{\prime}} h_{m, m^{\prime}} n_{m^{\prime}}
$$


The first term on the right hand side accounts for the birth of new bubbles in the group $m$ due to the coalescence of smaller bubbles, and depends on the coalescence frequency between groups, $\lambda_{m^{\prime}, m}$, and the collision efficiency, $h_{m^{\prime}, m}$. The second term arises from the death of members of the $m$-th group, i.e. when a bubble of the $\mathrm{m}$-th group collides with another bubble and the resulting bubble belongs to group $m^{\prime}$. In this work, the collision frequency and efficiency are modelled basing on the work of Prince and Blanch (Prince and Blach, 1990). The resulting coalescence frequency is slightly modified as suggested in (Liao and Lucas, 2010), by multiplying the resulting frequency by two factors. The first one to consider the space occupied by the bubbles themselves as proposed by $\mathrm{Wu}$ correlation $\mathrm{Wu}$ et. al., 1998):

$$
\frac{1}{\alpha_{r, \max }^{\frac{1}{3}}\left(\alpha_{r, \max }^{\frac{1}{3}}-\alpha_{r}^{\frac{1}{3}}\right)^{\prime}}
$$

being $\alpha_{r, \max }=0.8$ the maximum packing limit for a polydispersed flow. The second one is introduced to account for the finite length of the eddies that cause the bubble collisions. If these transporting eddies are much shorter than the distance between bubbles, then there will be no collisions. This can be included by using a multiplicative factor as the one proposed in Wang correlation (Wang et. al, 2005):

$$
\frac{1}{\alpha_{r, \max }^{\frac{1}{3}}\left(\alpha_{r, \max }^{\frac{1}{3}}-\alpha_{r}^{\frac{1}{3}}\right)^{\prime}}
$$

where $l_{b, m, m^{\prime}}$ stands for the mean distance between bubbles, that was approximated by

$$
l_{b, m, m^{\prime}}=\frac{\left(\frac{D_{b, m^{\prime}}+D_{b, m}}{2}\right)}{\left(\frac{3 n_{m}+3 n_{m^{\prime}}}{\pi}\right)^{\frac{1}{3}}},
$$

and $l_{e, m, m^{\prime}}$ for the mean length of the transporting eddies, that was fit as

$$
l_{e, m, m^{\prime}}=0.89\left(\frac{D_{b, m^{\prime}}+D_{b, m}}{2}\right) .
$$

In the proposed simulations, 10 groups were defined. The group bubble diameters were uniformly distributed between 1 and $10 \mathrm{~mm}$ (Group 1 corresponding to $1 \mathrm{~mm}$ bubble size and so on).

With respect to the boundary conditions, tank walls were introduced as free-slip walls for the dispersed phase, and non-slip condition for the liquid phase. Regarding the inlets, let us recall that a total air flow-rate of $990 \mathrm{Nm}^{3} / \mathrm{h}$ was injected evenly by 
the 459 disc diffusers ( 3 grids of 153 diffusers each). So each diffuser was modelled as an air inlet boundary condition, providing the specified mass flow rate. The size distribution at the inlet was approximated to a monodisperse $3 \mathrm{~mm}$ (this is the mean size provided by the manufacturer of the diffusers). To complete the boundary condition, the hold-up at the inlet was computed as

$$
\alpha=\frac{Q_{\text {gas }}}{A_{\text {in } j} v_{t}}
$$

In this equation, $v_{t}$ stands for the terminal velocity corresponding to $3 \mathrm{~mm}$ air bubbles in clean water, using Jamialahmadi correlation (Jamialahmadi et. al., 1994), this resulted in $0.25 \mathrm{~m} / \mathrm{s}$ ) and $A_{i n j}$ represents the diffuser area corresponding to $0.023 \mathrm{~m}$ and $0.050 \mathrm{~m}$ for the internal and the external diffuser diameter, respectively (resulting in an area of $0.039 \mathrm{~m}^{2}$ ). Given these conditions in the setup, the inlet hold-up resulted in a $5.65 \%$.

Note that, unlike previous works mentioned which injected air through the total surface of the diffuser, in this simulation the diffusers were drawn in detail with 3D CAD software to introduce air only through the perforated annular area. This increased considerably the total number of nodes of the mesh compared to the single-phase model, from 2,014,856 to 2,927,830. The modelling of the free surface made it necessary to increase the $3 \mathrm{D}$ domain in the vertical direction by $0.5 \mathrm{~m}$, introducing a mesh refinement to reproduce the interface liquid-gas interface. This gave a more detailed description of these two regions that is extremely important to describe the dispersed phase correctly. The meshes for the simulations were selected following the CFX Best Practices Guide for Numerical Accuracy. Tetrahedral dominant meshes were performed to calculate the simulations which guarantee the accuracy and stability of the numerical computation by the mesh quality parameters (aspect ratio and skewness). To ensure the mesh independency of the results, a three-grid GCI was computed for several quantities using the formula proposed by (Roache, 1998) and the methodology of (Tanaka, 2014) and (Tanaka, 2016).

Finally, in order to include the momentum exchange, the Ishii-Zuber correlation (Ishii and Zuber, 1979) was used to model the drag force. Two non-drag forces were included in this simulation: lift and wall-lubrication. The lateral lift force was implemented using the Tomiyama correlation, that accounts for the reversal of this force for big diameter bubbles. Wall lubrication was implemented following the baseline model stablished by (Rzehak et al, 2015). With respect to the effects of turbulence, the turbulent dispersion of bubbles was modelled by using the Favre Averaged model. Finally, the turbulence interaction between the phases was modelled according to the induced turbulent viscosity model proposed by Sato. 


\subsubsection{Interfacial forces}

Several interfacial forces have been considered as having a main influence on the dynamics of bubbly flow in aerated tanks. One is the drag force that is parallel to the flow direction; the others are non-drag forces and are perpendicular to the flow direction. The non-drag forces considered are: the lift force, the wall lubrication force, the turbulent dispersion force and the virtual mass force. This last can be neglected (Frank et al., 2008). In case of the presence of external fields, other forces could be also taken into consideration, but this feature goes beyond the scope of this work. The definition of the interfacial forces are included in this section.

\subsubsection{Drag Force}

The drag force or friction force accounts for the drag of one phase on the other. In its generic form it can be expressed as:

where $C_{D}$ is the drag coefficient, the Grace model (Grace et al. 1976) formulation was used for its definition. This model has been developed using air-water data and produces better results for air-water systems (Ansys, 2019). The Grace model for the drag coefficient considers the bubble having a distorted form similar to an ellipse. The expression for the drag coefficient is:

$$
C_{D}=\frac{4}{3} \frac{g D}{u_{r}^{2}} \frac{\Delta \rho}{\rho_{l}}
$$

Where the bubble terminal velocity is expressed as

$$
u_{r}=\frac{\mu_{l}}{\rho_{l}} M o^{-0.149}(J-0.857)
$$

The parameter $J$ is defined as it follows:

$$
\begin{gathered}
J=0.94 H^{0.751}, \text { if } 2<H<59.3 \\
J=3.24 H^{0.4411}, \text { if } H>59.3
\end{gathered}
$$

where $H$ is equal to

$$
H=\frac{4}{3} E o M o^{-0.149}\left(\frac{\mu_{g}}{\mu_{r e f}}\right)^{-0.14} u_{r}=\frac{\mu_{l}}{\rho_{l}} M o^{-0.149}(J-0.857)
$$

In the equation above $\mu_{\text {ref }}$ is the water reference viscosity and it is taken to be $0.0009 \mathrm{~kg} / \mathrm{ms}$. 
The Morton number and the Eötvös number are dimensionless numbers and are used to characterize the shape of bubbles or drops moving in a surrounding fluid or continuous phase. Their expression are:

$$
\begin{aligned}
& M o=\frac{g \mu_{l}^{4} \Delta \rho}{\rho_{l}^{2} \sigma^{3}} \\
& E o=\frac{g D^{2} \Delta \rho}{\sigma}
\end{aligned}
$$

\subsubsection{Lift Force}

If a bubble is rising in a liquid where velocity gradients are presents, the relative velocity will not be the same on all its surface. The lift force can be defined to consider the asymmetric distribution of the pressure resulting in a net force applied perpendicular to the flow motion. In general it can be expressed for spherical rigid particles as (Drew and Lahey, 1987):

$$
\vec{F}_{L}=-C_{L} \alpha \rho_{l}\left(\vec{u}_{g}-\vec{u}_{l}\right) \overrightarrow{r o t}\left(\vec{u}_{l}\right)
$$

In a pipe for example, it has been experimentally proven that smaller bubbles migrate to the near wall region, while bigger bubbles do it towards the pipe center. The parameters that affect more the lift force are the relative velocity between the phases, the velocity gradient of the continuous phase in the curl vector and the induced particle rotation. $C_{L}$ is the lift force coefficient and it takes into account the change in sign of the lift force depending on the bubble conditions. There is the possibility for the bubble to move towards the pipe center or towards the wall. because of different effects such as:

- deformation of the bubble (Tomiyama et al., 1995), (Ervin and Tryggvason, 1997)

- bubble rotation and asymmetries in the wake produced by the bubble itself (Moraga et al., 1999)

\subsubsection{Wall Lubrication Force}

In the near wall region, the velocity of the flow on the bubble surface is modified. The created velocity gradient generates a force on the bubble to displace it away from the wall. This force is only applicable in the very near wall region. The strength of this force decays exponentially and its effect is already zero a few 
millimeters away from the solid wall which means that considering lubrication force in a full-scale tank simulation will have low impact on the results.

Antal (Antal et al., 1991), derived a formula for the repulsive force that prevents bubbles attaching on the solid wall. The tests to develop his formulation have been developed for a value of the bubble Reynolds number smaller than 1500 and for a gas volume fraction less than $10 \%$. This force was modelled by (Antal et al., 1991) as follows:

$$
\vec{F}_{W L}=-C_{W L} \alpha \rho_{l} D u_{\|}^{2} \vec{n}_{w}
$$

where $u_{\|}$is the wall parallel component of the slip velocity.

The wall lubrication coefficient $C_{W L}$ in the Antal formulation (Antal et al., 1991) has the following expression:

$$
C_{W L}=\max \left(0, \frac{C_{W L 1}}{D / 2}+\frac{C_{W L 2}}{y_{w}}\right)
$$

The values used for $C_{W L 1}$ and $C_{W L 2}$ that have been used are -0.0064 and 0.016 as proposed by (Krepper et al. 2005) if the bubble induced turbulence model of Sato is used. The coefficients are -0.01 and 0.05 if the Morel model for the bubble induced turbulence is considered. Different sets of coefficient are needed if a different simulation approach is used in order to obtain these two effects: achieve a higher/lower absolute value of the wall lubrication force and extend its action not only at the near wall region.

\subsubsection{Turbulent Dispersion Force}

The turbulent dispersion force considers the phase dispersion from zones at lower concentration to those at a higher one due essentially to turbulent fluctuations. This force is due to a combination of the effects of the drag force and the turbulent eddies between the phases.

The turbulent dispersion force has been performed using The Favre Averaged Drag force (Burns et al. 2004) formulation is used for the evaluation of the turbulent dispersion force.

This force is modeled as:

$$
F_{T D}=-C_{T D} \cdot C_{c d} \cdot \frac{v_{t, c}}{S c_{t, c}}\left(\frac{\nabla \alpha}{\alpha}-\frac{\nabla(1-\alpha)}{(1-\alpha)}\right)
$$


where $C_{c d}$ is the momentum transfer coefficient for the interphase drag force. The model depends on the details of the drag correlation used. $S c_{t, c}$ is the turbulent Schmidt number for continuous phase, in general it is defined as

$$
S c=\frac{v}{D}=\frac{\text { viscous diffusion rate }}{\text { molecular diffusion rate }}
$$

It is taken to be 0.9 .

$D$ is the mass diffusion coefficient due to turbulence. $C_{T D}$ is a multiplier. Its default value is 1 in Ansys CFX, and it can be modified to increase or decrease the influence of the turbulent dispersion force.

\subsubsection{Mixers performance}

A submersible agitator will basically be used to promote agitation, homogenization and mixing, as well as to create a velocity for circulation of the fluid in the bioreactor.

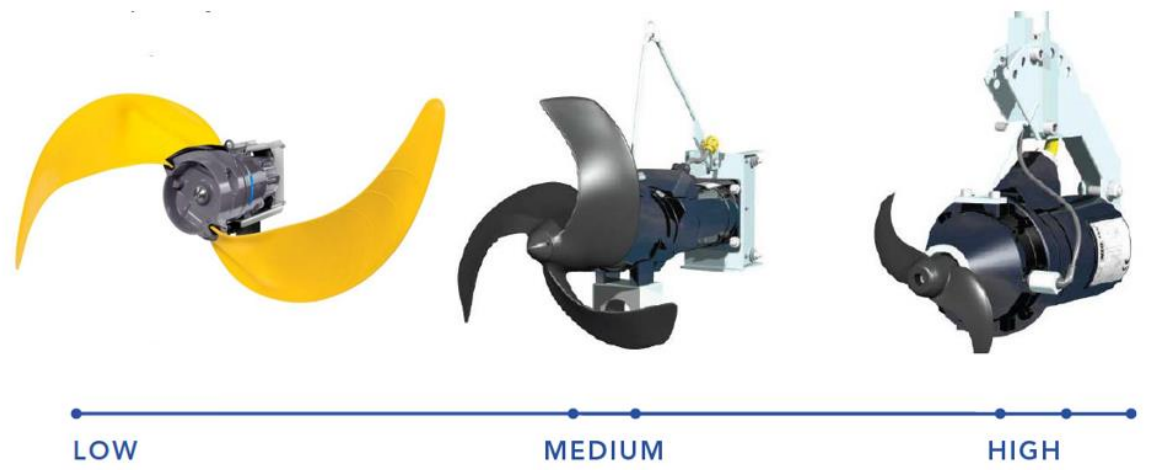

Figure 3.7. Types of horizontal axis-oriented stirrers depending on the rotational velocity (Low, Medium and High)

Good flow conditions mean that there are no unhomogenized zones, there are no direct flows from the entrance to the exit, no vortices are formed in the vicinity of the mixer, there are no large dead zones behind the curves or in the corners of the tank (Flyght). All these features must be considered to analyse the results of the CFD when modelling a mixer. There are different types of mixers used in the wastewater treatment field. The horizontal axis-oriented stirrers are most common in biological reactors of urban WWTP. Figure 3.7 shows different type of these stirrers. The higher the rotational velocity, the smaller the diameter. The CFD modelling of this type of stirrer has been studied in this work. 
Moreover, the common non-dimensional numbers can be determined to characterise the mixer: Flow number (F1), Thrust number (Th) and the Power number (P). (Uby, 2001).

$$
\begin{gathered}
F l=\frac{Q_{0}}{N D^{3}} \\
T h=\frac{F}{\rho N^{2} D^{4}} \\
P=\frac{P_{0}}{\rho N^{3} D^{5}}
\end{gathered}
$$

Where $\mathrm{N}$ is the rotational velocity; $\mathrm{D}$ is the diameter; $\rho$ is de density, $Q_{0}$ is the flowrate, $\mathrm{F}$ is the thrust and $P_{0}$ is the power of the stirrer.

From the previously defined parameters, other parameters can be defined: c parameter and the swirl number. The c parameter is a constant that stablish a relationship between the flow number and the thrust number as follows:

$$
F l=c T h^{1 / 2}
$$

The value of this parameter is usually around 0.8 (Uby, 2001).

The swirl number $(\mathrm{S})$ is the parameter used to specify how turbulent a flow is. The higher the swirl number, the more turbulent the flow is. The swirl number can be calculated from the following expression:

$$
c=F l\left(\frac{\pi S}{P_{o}}\right)^{1 / 2}
$$

Among the four approaches to model a mixer by CFD reported by (Börjesson, 2000), two different models have been studied in this work: The Sliding Mesh and the Momentum Source Model (MSM). The SM is the most complex model, CFD can calculate the performance of the mixing reproducing in detail the effect of the stirrer blades over the fluid by defining the stirrer as a rotating sub-model inside the domain (reactor). The performance of the blades rotating at a specific velocity will provide the velocity profiles along the jet from the stirrer, the pressure field, the turbulence, etc. Thus, the non-dimensional numbers can be analysed for any type of mixer. This is shown in figure 3.8. This approach has been found to be the most accurate but also the most computational power demanding. Although it is successfully used for small domains (laboratory scale reactors) (Fan et al.,2018; 
Karpinska and Bridgeman, 2017), it has been considered not feasible to perform full-scale tank reactors (Brannock, 2003).
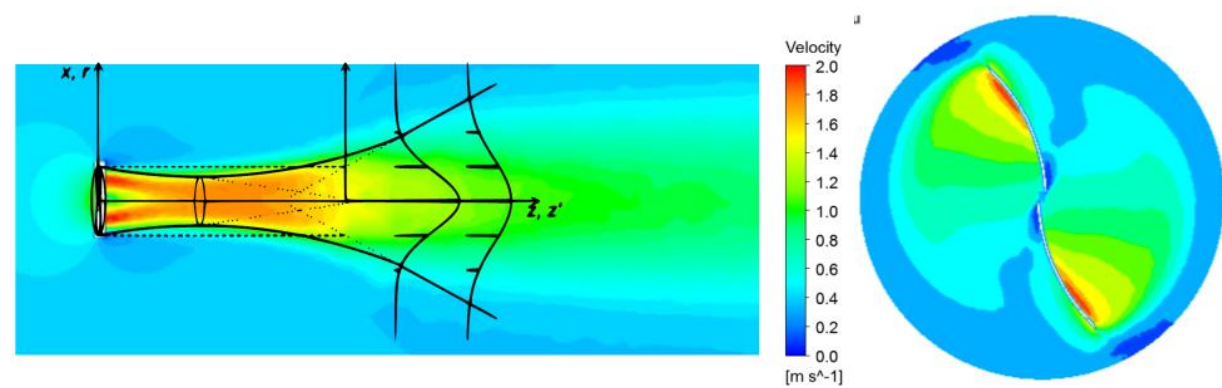

Figure 3.8. Velocity field of the jet from the two-blade horizontal axis-oriented stirrer and the velocity field inside the subdomain of the stirrer

The Momentum source model consists on defining the thrust of the stirrer using a disk shape subdomain that represent the volume occupied by the blades of the stirrer (see Figure 3.9). This is the most easy and feasible approach to perform the stirrer model in CFD.
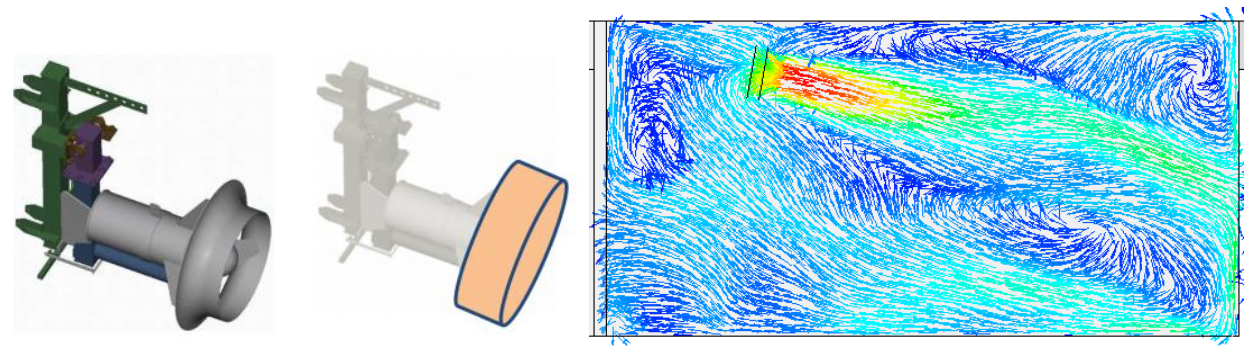

Figure 3.9. Scheme of the disc shape subdomain and its implementation in a fullscale tank in a 3D CFD model

Following this approach, the momentum source model was used to include the thrust provided by the mechanical motion of a submersible mixer. Manufacturers provide parameters $\mathrm{F}$ and $\mathrm{D}$, which were used to calculate the momentum sources in this work. Thus, the propeller geometry was replaced by a cylindrical subdomain containing a momentum source driving the fluid movement that accounts for the flow continuity through it. The corresponding volumetric momentum source, $\mathrm{M}$ ( $\mathrm{kg}$ $\mathrm{m}^{-2} \mathrm{~s}^{-2}$ ), can be calculated as:

$$
M=\frac{\rho}{V_{c y l}}\left(\frac{q}{D}\right)^{2}
$$


$D$ being the diameter of the stirrer $(\mathrm{m}), \rho$ the fluid density $\left(\mathrm{kg} \mathrm{m}^{-3}\right)$ and $V_{c y l}\left(\mathrm{~m}^{3}\right)$ the volume of the cylindrical subdomain. The flow rate propelled, $q\left(\mathrm{~m}^{3} / \mathrm{s}\right)$, can be obtained as

$$
q=C D\left(\frac{F}{\rho}\right)^{\frac{1}{2}}
$$

In this equation, $F$ stands for the thrust force $(\mathrm{N})$ and $C$ is constant parameter related to the propeller efficiency, depending on several factors such as the tank geometry or flow configuration.

Finally, as it is explained in the following section, velocity measurements must be conducted to adjust $\mathrm{C}$ more accurately in order to calibrate $\mathrm{q}$ at the outlet of the stirrer domain to fit experimental velocity.

\subsection{Experimental Validation}

CFD models were primarily used for evaluation of hydraulic problems at WWTP. Afterwards, with the implementation of biochemical models to reproduce the processes involved in WWTP, CFD evolved in a more powerful tool able to be applied to control process. A first protocol was defined (Laurent et. al, 2014) for this alternative use of CFD in process modelling, that is, to gain insight into complex systems leading to improved modelling approaches used in combination with the IWA activated sludge models and other kinetic models.

The next figure presents a schematic view of a protocol for CFD applied to WWTP process modelling where the CFD experimental validation plays an essential role and represents one of the most complex steps.

CFD models need global and, where possible, local measurements in order to become a robust simulation tool. Thus, although tracer tests is commonly used global validation technique for the CFD model (Potier et al., 2005; Gresch et al., 2010; Brannock et al., 2010) fluid velocity profile measurements are preferred because they provide a detailed and local hydrodynamic analysis in 3D. During this work, an exhaustive validation campaign was conducted by means of 3D velocity measurements. The aim of the extensive sampling campaign performed was both to obtain a comprehensive hydrodynamic analysis of a full-scale bioreactors and to validate the CFD models. 


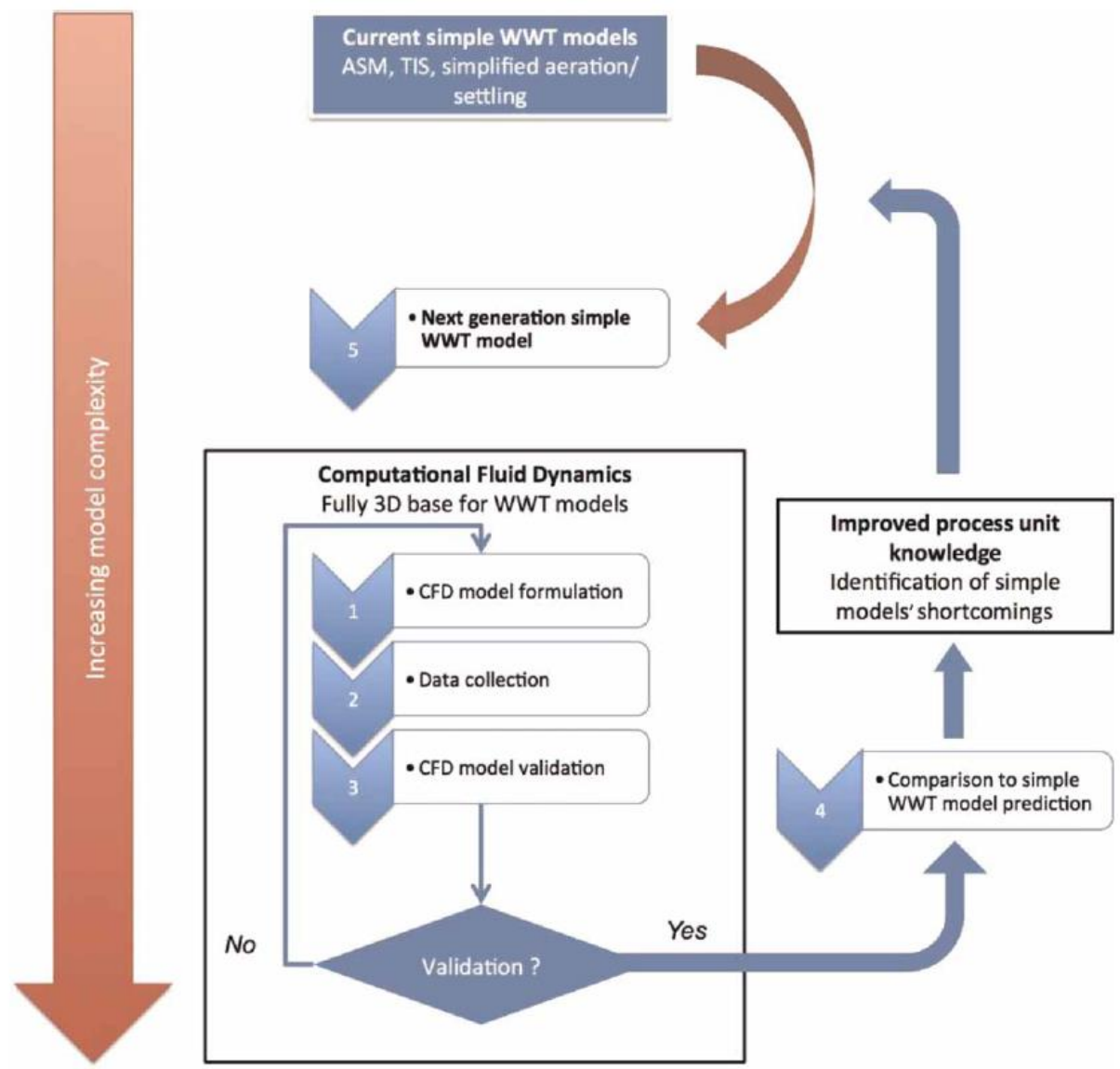

Figure 3.10. Conceptual protocol for the potential use of CFD as a supportive tool for WWT process modelling. (Laurent et al., 2014)

\subsubsection{Tracer test procedure and analysis}

The three main factors to evaluate the mixing in a reactor are: (1) Residence Time Distribution (RTD) of material which is flowing through the vessel, (2) the State of Aggregation of the flowing material, its tendency to clump and for a group of molecules to move about together, and (3) the Earliness and Lateness of mixing of material in the vessel.

Activated sludge in a bioreactor should be considered closer to Microfluid either for single-phase (liquid) or multi-phase (sol-gas-liquid) where the solid should be understood as flocs. While in some type of reactors, the Earliness of Mixing for determining the reactor behaviour can be crucial, for the normal operation of an activated sludge biological reactor, this can be ignored. The RTD is the key 
parameter used to analyse hydrodynamics and to validate CFD Modelling applied to biological reactors.
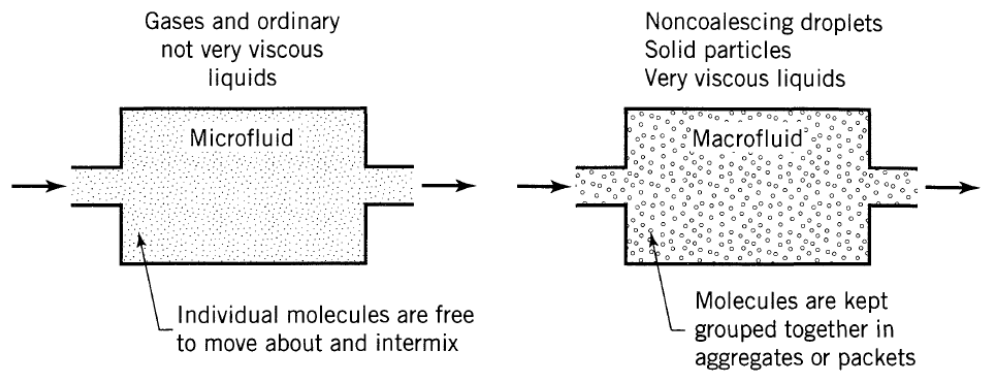

Figure 3.11. Two extrems of aggregation of fluid (Levenspiel, 1999)
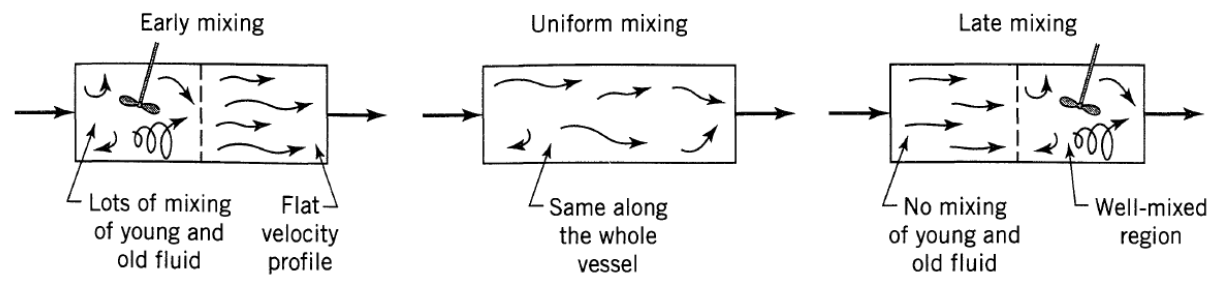

Figure 3.12. Earliness and Lateness of Mixing (Levenspiel, 1999)

The idea of using the Residence Time Distribution (RTD) in the analysis and the study of chemical reactors was proposed for the first time in a pioneering work by (MacMullin and Weber, 1934). However, the concept was not widely applied until the 1950s, when (Danckwerts, 1953) structured, organized and defined most of the distributions of interest. All subsequent works have followed and have been adjusted to their nomenclature (Wolf and Resnick, 1963).

When a fluid flows through a tank at a constant flowrate, either "piston-flow" (plug-flow reactor) or perfect mixing (completely stirred tank reactor, CSTR) is usually assumed. Thus, the residence time of a reactor is defined as the time that the material remains inside it. Apart from these two ideal reactors, in real reactors, there is a distribution of residence time of the fluid in the reactor. In this way, it is easy to find cases in which: not all molecules that pass through the reactor remain at the same time, there are dead zones where the fluid is practically not renewed, part of the feed short-circuits directly to the output, reagents/products form agglomerations do not mix well with each other, etc. In short, there is a non-ideal flow, whose study is the objective of the application of tracer techniques to this work. (Bischoff and Mccracken, 1966; Cholette and Cloutier, 1959; Levenspiel, 1999; Monteith and Stephenson, 1981). 
The problems of non-ideal flow are usually related to those of change of scale. Often, the scale change factor is the magnitude of the non-ideality of the flow, and this factor often differs drastically between large and small units. Consequently, ignorance of this factor can lead to large errors in the design and operation.

To understand the hydrodynamic behaviour of a reactor would be necessary to have a complete representation of the flow velocity distribution. In fact, for CFD modelling, local measurements of fluid velocity are required to validate the models. As it will be discussed later, this is complex and a tedious work, and depending on the process unit it is almost unfeasible (anaerobic digester tanks). In this way, Residence Time Distribution (RTD) can be less ambitious and to provide the global fluid behaviour of a system, the minimum knowledge necessary for the design and operation. The RTD guarantees the necessary information to develop a model that reflects the hydrodynamic behaviour of the fluid in the reactor and guarantees the necessary information to elaborate a model that reflects the hydrodynamic behavior of the fluid in the reactor. This information, although costly, it can be determined relatively easily through tracer tests (Rieckermann et al, 2007).

Apart of the fluorescent compounds (Rhodamine WT, Fluorescein), the salts of $\mathrm{Na}^{+}, \mathrm{Br}^{-}, \mathrm{K}^{+}, \mathrm{F}^{-}$and $\mathrm{Li}^{+}$, are the most common tracers in hydrodynamic studies for their easy handling and low cost (Monteith and Stephenson, 1981), (Dustin, J. S. and Hansen, 2012); (Smith et al., 1993); (Terashima et al., 2009), (Water Environment Federation, 2007). The selection of the tracer in a hydrodynamic study depends on the characteristics of the system, the provision of appropriate equipment for the determination of concentrations and the accessibility to the tracer itself in terms of cost and handling. The way to analyze them in the output flow will depend on the type of tracer used, methods and equipment to determine the absorbance, $\mathrm{pH}$, electrical conductivity, fluorescence, etc. (Levenspiel, 2004). The tracer must have similar physical properties to those of the reaction mixture and must be totally soluble in the mixture. In addition, it should not be absorbed in the walls or other surfaces of the reactor, as well as in any substance that contains the mixture.

By far, the most commonly-used tracer today is lithium, typically from lithium chloride, because it does not sorb to solids, is not biodegradable, is not found in high concentrations in wastewater solids and only inhibits bacterial activity at concentrations larger than $2 \mathrm{~g} \mathrm{Li}+/ 1$ (Anderson et al., 1991). However, for water treatment applications (no for sludge lane), the use of fluorescent products is widespread due to the detection techniques for $\mathrm{Li}^{+}$are expensive (ion chromatography, atomic absorption/atomic emission spectrophotometry, and inductively-coupled plasma (ICP), optical emission spectroscopy or ICP mass spectrometry). Rhodamine and Fluorescein can be monitored online with specific optical probes. The important issue to take into consideration is the sorption and the UV photodegradation of these compounds. Finally, it is well-recommended to recover about $95 \%$ of the tracer although recover less amount of tracer should not 
invalidate the tracer test performance (Chazarenc et al., 2003; Kadlec and Wallace, 2009).

These requirements are necessary so that the behavior of the tracer faithfully reflects that of the material flowing through the reactor. There are different methods to inject the tracer such as "periodic entry" or "random entry", but the most commonly used methods of injection are "by step" and "by pulse".

The most used injection method for wastewater applications is the input by pulse. When an amount $\mathrm{M}$ (moles or grams) is injected instantaneously into the inlet current in the reactor and the concentration of the tracer is measured as a function of the elapsed time, the concentration-time curve or curve $\mathrm{C}$ is obtained.

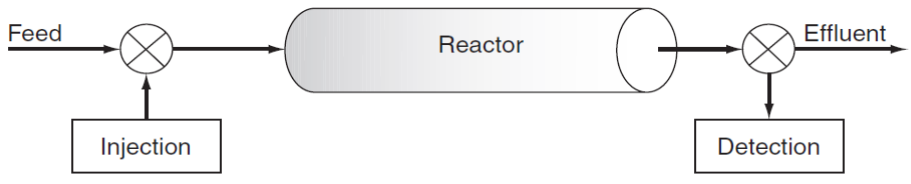

Injection method
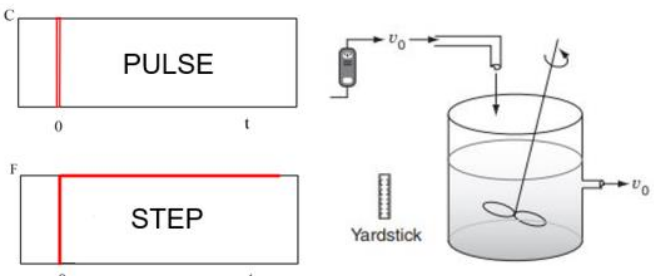

Response
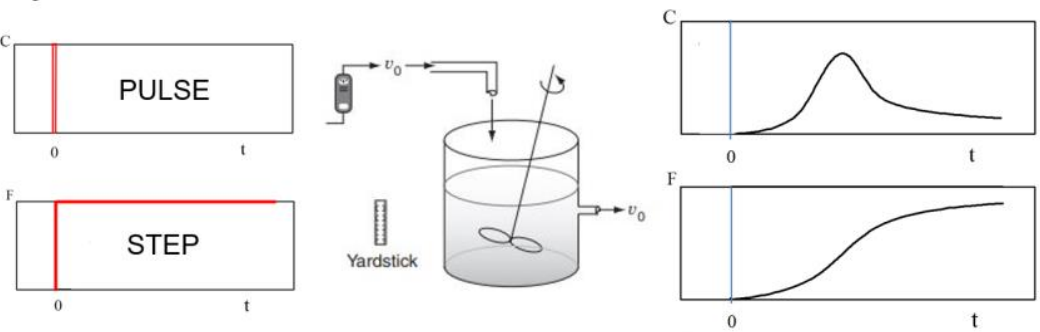

Figure 3.13. Scheme of the tracer test procedure

The tracer is usually added as a pulse and monitored until its concentration has reached zero. In the case of step injection with continuous addition the measurements will be carried out until the concentration in the effluent has stabilized. The RTD can be calculated from the concentrations obtained at the effluent, C (t) curve. The shape of the RTD can be used to determine the hydrodynamic behaviour and to detect problems of mixing. An early sharp peak of the curve reveals shortcircuting. A perfectly mixed CSTR would result in a smooth exponential decay of $\mathrm{C}(\mathrm{t})$ when an injection pulse is carried out. When the experimental mean residence time obtained from either $\mathrm{C}(\mathrm{t})$ or RTD is lower the theoretical HRT of the reactor, it indicates stagnant regions. 
Dead Volume

Cmax. initial

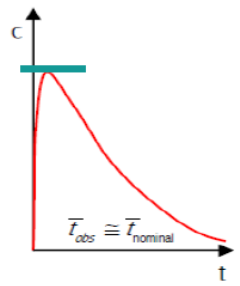

Short

circuiting

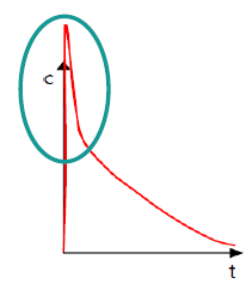

Initial time

Mixing

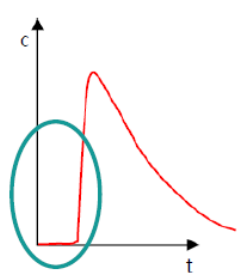

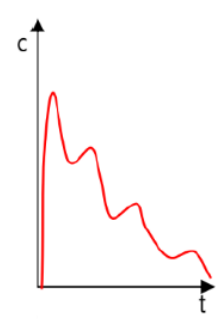

Figure 3.14. Different $\mathrm{C}(\mathrm{t})$ response curve and their analysis

If a sufficiently small time increase $\mathrm{dt}$ is taken in curve $\mathrm{C}$, the concentration of the tracer leaving between $t$ and $t+d t$ will be essentially constant. The amount of tracer that leaves the reactor in that time interval will be (being $q$ the volumetric flow):

$$
d M=C(t) q d t
$$

If it is integrated between $t=0$ and $t=\infty$, the total mass of tracer introduced in the pulse is obtained, because sooner or later it all comes out.

$$
M=\int_{0}^{\infty} d M=\int_{0}^{\infty} C(t) q d t
$$

For conditions of constant flow, it follows from the previous expression that the area under the curve $\mathrm{C}$ is equal to the quotient $\mathrm{M} / \mathrm{q}$.

$$
\frac{M}{q}=\int_{0}^{\infty} C(t) d t=\text { Area under the curve } C(t)=\sum_{i=1}^{\infty} C\left(t_{i}\right) \Delta t_{i}
$$

In this way, the mean residence time tm can be defined mathematically by the mean time that the particles remain in the reactor. Geometrically, the average residence time is in the vertical with the barycenter of the area enclosed under the DTR curve.

$$
t_{m}=\frac{V}{q}=\frac{\int_{0}^{\infty} t C(t) d t}{\int_{0}^{\infty} C(t) d t}=\frac{\sum_{i=1}^{\infty} t_{i} C\left(t_{i}\right) \Delta t_{i}}{\sum_{i=1}^{\infty} C\left(t_{i}\right) \Delta t_{i}}
$$

Thus, from curve $\mathrm{C}$ obtained experimentally we have two equations that relate three magnitudes: $\mathrm{M}, \mathrm{V}$ and $\mathrm{q}$. Therefore, if one of these magnitudes is known, the other 
two can be determined from a "stimulus-response" experiment. If more than one magnitude is known, consistency tests can be made with the results obtained.

From the curve $\mathrm{C}$, curve $\mathrm{E}$ can be elaborated dividing the values of the tracer concentration for each time, $\mathrm{C}(\mathrm{t})$, between the total area of the curve, a new quantity is obtained that will be called $\mathrm{E}(\mathrm{t})$.

Thus, the value of the curve $\mathrm{E}$ for a time $\mathrm{t}$ is defined as:

$$
E(t)=\frac{C(t)}{\int_{0}^{\infty} C(t) d t}=\frac{C(t)}{M / q}
$$

The magnitude $\mathrm{E}(\mathrm{t})$ has dimensions of time-1 and is known as the distribution of residence times. It is a distribution that has the same shape as the curve $\mathrm{C}$ but normalized, that is, the area that encloses the curve $\mathrm{E}$ is equal to the unit:

$$
\int_{0}^{\infty} E(t) d t=1
$$

The value of the curve $\mathrm{E}$ for a determined time $\mathrm{t}, \mathrm{E}(\mathrm{t})$, indicates the fraction of material that has a residence time $t$ inside the reactor. This is checked by making a quotient between the amount of tracer leaving the reactor in a range dt and the total amount of tracer introduced.

$$
E(t) d t=\frac{C(t) q d t}{M}=\frac{C(t) d t}{M / q}
$$

Thus, the fraction of material with a residence time between $\mathrm{t} 1$ and $\mathrm{t} 2$ will be equal to the integral of the function $\mathrm{E}(\mathrm{t})$ between those times:

$$
\int_{t 2}^{t 1} E(t) d t
$$

Based on a dimensionless time scale, taken as $\Theta=t / t \_m$, the dimensionless function $\mathrm{E}(\Theta)$ is defined according to:

$$
\mathrm{E}(\theta)=t_{m} E(t)=\frac{V}{q} E(t)=\frac{V}{M} C(t)
$$


Using this function, the type of flow can be directly compared in reactors of different sizes. In this way, for example, all perfect continuous ideal mix reactors will have the same numerical values of DTR using $E(\Theta)$. The average residence time in the reactor is calculated from the curve $\mathrm{E}(\mathrm{t})$ :

$$
\sigma^{2}=\int_{0}^{\infty}\left(t-t_{m}\right)^{2} E(t) d t
$$

The DTR curves are compared using their moments as a comparison criterion instead of the entire distribution. These are the average residence time and the variance with respect to the mean time, which measures the amplitude or dispersion of the distribution. Then, tank-in-series number $(\mathrm{N})$ can be calculated as follows:

$$
N=\frac{t_{m}^{2}}{\sigma^{2}}
$$

The main difficulties presented by this pulse tracer input technique consist in achieving this type of input, since the injection must be carried out homogeneously in the different segments of the reactor flow, in a very short period of time compared to the time of residence and so that the dispersion between the injection point and the entry is negligible. If all this can be achieved, the technique is simple and direct to obtain the DTR.

When the curve obtained by this technique has a long "tail", inaccuracies can be made in its analysis, mainly in the integration of the curve $C(t)$. In these cases it is usually advisable to extrapolate the tail (usually exponentially) and do the calculation analytically (Levenspiel, 1999).

There are some characteristic features which allow to quantify analytically shortcircuiting and dead-volume such us

- $\mathrm{t}_{\mathrm{i}}=$ initial time since the tracer is applied until it appears in the effluent.

- $\mathrm{t}_{10}=$ time corresponding to the step of $10 \%$ of the total amount of the tracer.

- $\mathrm{t}_{\mathrm{p}}=$ modal time, corresponding to the presentation of the maximum concentration.

- $\mathrm{t}_{\mathrm{m}}=$ mean residence time, corresponding to the $50 \%$ step of the tracer amount.

- $\mathrm{t}_{\mathrm{o}}=$ average retention time or theoretical retention time $=\mathrm{V} / \mathrm{q}$.

- $t_{90}=$ time corresponding to the passage of $90 \%$ of the total amount of the tracer.

- $\mathrm{t}_{\mathrm{f}}=$ time that elapses until it passes through the entire alreactor tracer.

- $\mathrm{C}_{\mathrm{o}}=$ initial concentration.

- $\mathrm{C}_{\mathrm{p}}=$ maximum concentration at the exit. 
There exists some characteristic index defined from these parameters such us:

a) $\frac{t_{i}}{t_{0}}$ Measure large shorts. It is equal to 1 for plug-flow and 0 for mixed flow. If the value of the ratio is $(<0.3)$, it can mean that there is a direct path of the tracer between the input and the output (hydraulic short circuit).

b) $\frac{t_{m}}{t_{0}}$ If the ratio is less than unity, there are hydraulic short circuits. If it is greater, there are experimental errors or there are areas where the tracer has been retained for a certain time (dead spaces), and then leave slowly, so that the descending branch of the curve has an elongated shape, which displaces the centroid of the area and increase the value of tm, making $\mathrm{tm}>$ to.

c) $\frac{t_{p}}{t_{0}}$ Indicates the ratio of piston flow and mixed flow. When it is equal to 1 , there is only piston flow, and when it is 0 , there is mixed flow. When the ratio tp / to approaches 1 and $\mathrm{ti} /$ to $>0.5$, it can be concluded that there is a predominance of piston flow, and when it approaches 0 , there is a predominance of mixed flow.

d) $\frac{t_{c}}{t_{0}}$ It is generally related to the diffusion due to inertial currents (turbulence). It is equal to the quotient ( $\Delta$ to / to) (injection time ratio) for the ideal stable flow and approximately of the order of 0.7 for mixed flow.

e) $\frac{t_{b}}{t_{0}}$ It is related to the turbulent inertia and large recirculation characteristics. It is equal to the ratio $\Delta$ to / to (injection time ratio) for the ideal stable flow and of the order of 2.3 for ideal mixed flow.

f) The reactor dispersion Index (MDI): the segment between $10 \%$ and $90 \%$ is the most regular and that is why is suggested the this relationship as an index of dispersion. MDI values up to 22 correspond to CSTR behaviour while MDI value less than 2 is related to an effective plug-flow reactor.

$$
\text { The reactor dispersion Index }(M D I)=\frac{t_{90}}{t_{10}}
$$

Finally, one can define non-ideal hydraulic models. This type of flow corresponds to any intermediate degree between plug-flow and complete mixing with other possible alterations such as the presence of dead zones, hydraulic short circuits, recirculation effects. It is the kind of flow that we would usually find in the treatment units in the plants and the most used is tanks in series approach. 


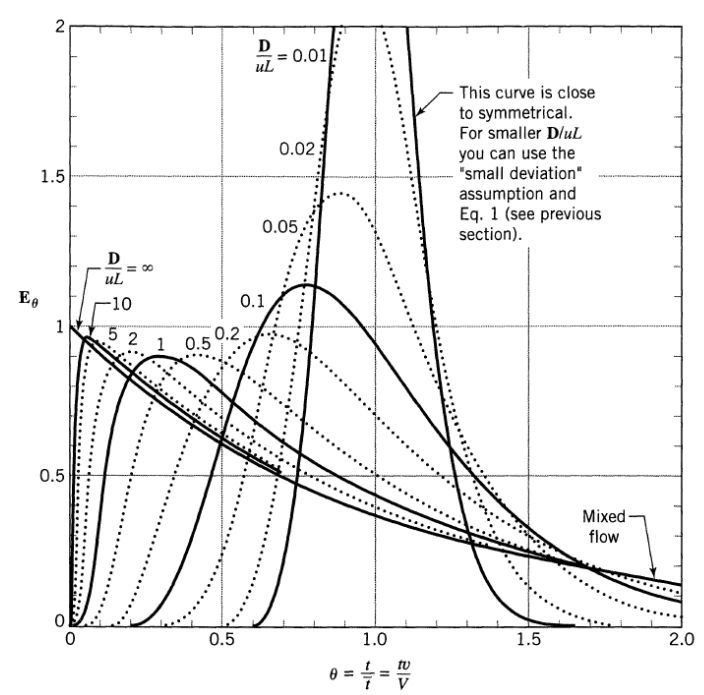

Figure 3.15. Tracer response curves for closed vessels and large deviations from plug flow (Metcalf and Eddy, 2004).

As a result of this, a tracer test will result in a diagnosis of the hydrodynamics inside the reactor through the characterization of the RTD. Problems of the mixing can be detected, and hydraulic models can be performed in order to represent a system through tanks-in-series connected with fluxes and recirculations. In this work, tracer test have been performed in order to analyze the global fluid behaviour in biological reactors and to validate the CFD model by matching a virtual tracer calculated in dynamic state to the RTD obtained experimentally.

Fluorescein sodium salt was the tracer selected to carry out the tracer tests of this study. It presents some advantages over other similar dye tracers, mainly its low sorption rate which is far better than Rhodamine $\mathrm{B}$, and comparable to Rhodamine WT. However, it is more sensitive to sunlight exposure (A Practical Guide to Flow Measurement, monograph by Turner Designs, 845 W. Maude Avenue, Sunnyvale, CA 94086).

In all tests performed in this work, the tracer was introduced at the influent following a "pulse" as the injection method. The tracer was diluted previously in tap water in a 20-50 litres bucket. The duration of the pulse was very short (neglectable compared to the duration of the test), being the ratio between the pulse time and the mean residence time $(\tau)$ about $0.58 \%$. Tracer concentration was always measured at the outlet as the key monitor point during the entire experiment, minimum $2 \tau$, (Rieger et al., 2013). Moreover, different specific monitor points along the bioreactor were analysed to obtain more information. The sampling frequency at initial time is quite high (around 2 minutes), and as the experiment advances, it decreases until hours. 
Samples were processed with a fluorescence spectrophotometer Varian Cary Eclipse set at $491.5 \mathrm{~nm}$ excitation wavelength and a sample detector PMT voltage from 680 to 820 volts. The fluorimeter was calibrated using the effluent as the zero point and as the dilutant for preparing the dilution samples to calibrate the equipment. Considering the accuracy of the instrumental equipment and the measurement, we estimate that the error in the concentration values is not higher than $4 \%$, which allowed us to provide quite reliable values for the simulation process. The configuration of the spectrophotometer Varian Eclipse was:

- Excitation: $491,5 \mathrm{~nm}$

- Emission: 513,5 nm

- Slit width in: $2,5 \mathrm{~mm}$

- Slit width out: $2,5 \mathrm{~mm}$

- Mode: FAST

- Time of excitation: $1 \mathrm{~s}$

The samples of the tracer test were settled to obtain a first separation. Subsequently, a filtration was carried out in the laboratory to avoid possible interferences caused by colloids or free bacteria in the analytical measurement. To avoid tracer sorption and its photodegradation, samples were filtered immediately after the sample collection. The samples were preserved in the fridge and their fluorescence spectrum was measured in less than $24 \mathrm{~h}$ after their recollection. Each sample was measured in triplicate, and the average value was taken as the final concentration value.

Regarding the calibration of the fluorimeter, solutions of different concentration of the probe molecule (fluorescein) were prepared with the effluent of the secondary clarifier as the solvent in order to obtain the matrix of the solutions as close as possible to the wastewater process.

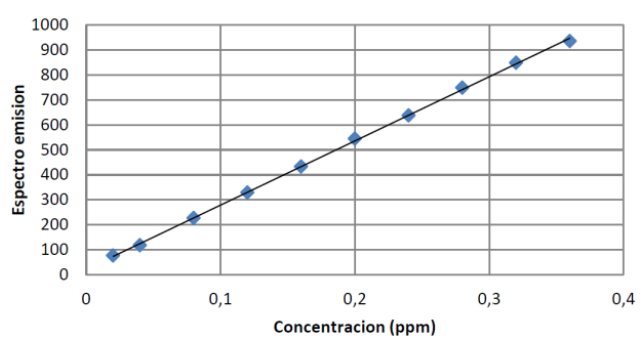

Figure 3.16. Calibration at $820 \mathrm{~V}$

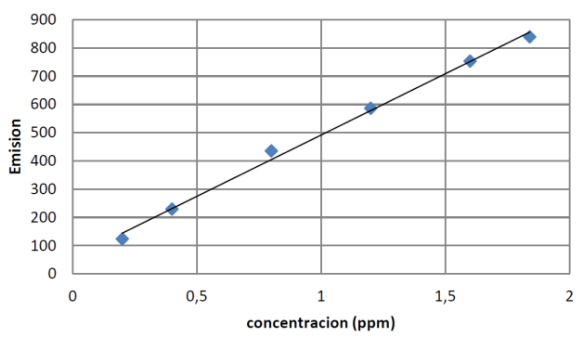

Figure 3. 17. Calibration at $680 \mathrm{~V}$

Two calibration curves were performed at different intensities of the photodetector ( $820 \mathrm{~V}$ and $680 \mathrm{~V}$, correspondingly) in order to detect accurately the concentration at different sampling points where it was expected concentration in a different range. 
It allowed covering the highest possible emissivity range (from 0 to 1000) without saturating the fluorimeter detector. A 0.987 and 0.362 zero background concentration were measured for the calibration 1 and the calibration 2, respectively.

After the tracer test, the tracer recovering is usually the first issue to address, it is calculated by a tracer mass balance (Levenspiel, 1999). Recovering almost 100\% the tracer injected is complex in a long-term real scale performance. For example, (A. Alvarado et. al, 2012) guarantee almost $90 \%$ of recovery as acceptable for a real case study. All the tracer tests performed in this work guarantee the percentage recovery acceptable and reasonable for a full-scale long-term tracer test. On the one hand, it is recommended to conduct a tracer sorption test (Borroto, 2003) to ensure the photochemical stability of the tracer as well as its low adsorptive potential at values of $\mathrm{pH}$ above 7 . On the other hand, the issues related to the loose of tracer must be identified and studied.

\subsubsection{Velocity measurements}

Devices working on the principle of the Doppler-shift effect from acoustic signals are the most used to conduct experimental measurements in wastewater treatment field. One variant of them is the high-resolution acoustic doppler velocimeter (ADV) Vectrino Nortek ${ }^{\circledR}$ which was used to measure the fluid velocity components with the following configuration:

- Measurement of 3D liquid entrained particle velocity over a range of 0 to 4 $\mathrm{m} / \mathrm{s}$

- Sampling rate of $25 \mathrm{~Hz}$ (Standard firmware, 25 samples per second)

- Accuracy of $\pm 0.5 \%$ of measured value $\pm 1 \mathrm{~mm} / \mathrm{s}$

- Sampling volume diameter of $6 \mathrm{~mm}$

- Sampling volume height from 3 to $15 \mathrm{~mm}$ (usually selected of $7 \mathrm{~mm}$ length)

The minimum time of sampling stablished for each measurement was $300 \mathrm{~s}$ to capture large eddies. Then, the raw signals acquired by the equipment were treated using a Savizky-Sgolay filter to smooth the signal. The instrument, which has an error of $\pm 1 \mathrm{~mm} / \mathrm{s}$, proved to be appropriate for aerated biological reactors, although measurements over the diffusers must be avoided due to the difficulties of the equipment to measure in bubbly flow. Therefore, measurements with gas should be carried out before and after the grids and then to apply a depickling (Birjandi and Bibeau, 2011). Figure 3.18 shows the signal of velocity component $Y$ acquired (points) and the signal filtered (line) during $180 \mathrm{~s}$ and $25 \mathrm{~s}$, correspondingly. 
Filtering of the signal acquired from the Vectrino ( $25 \mathrm{~Hz}$ sample rate)
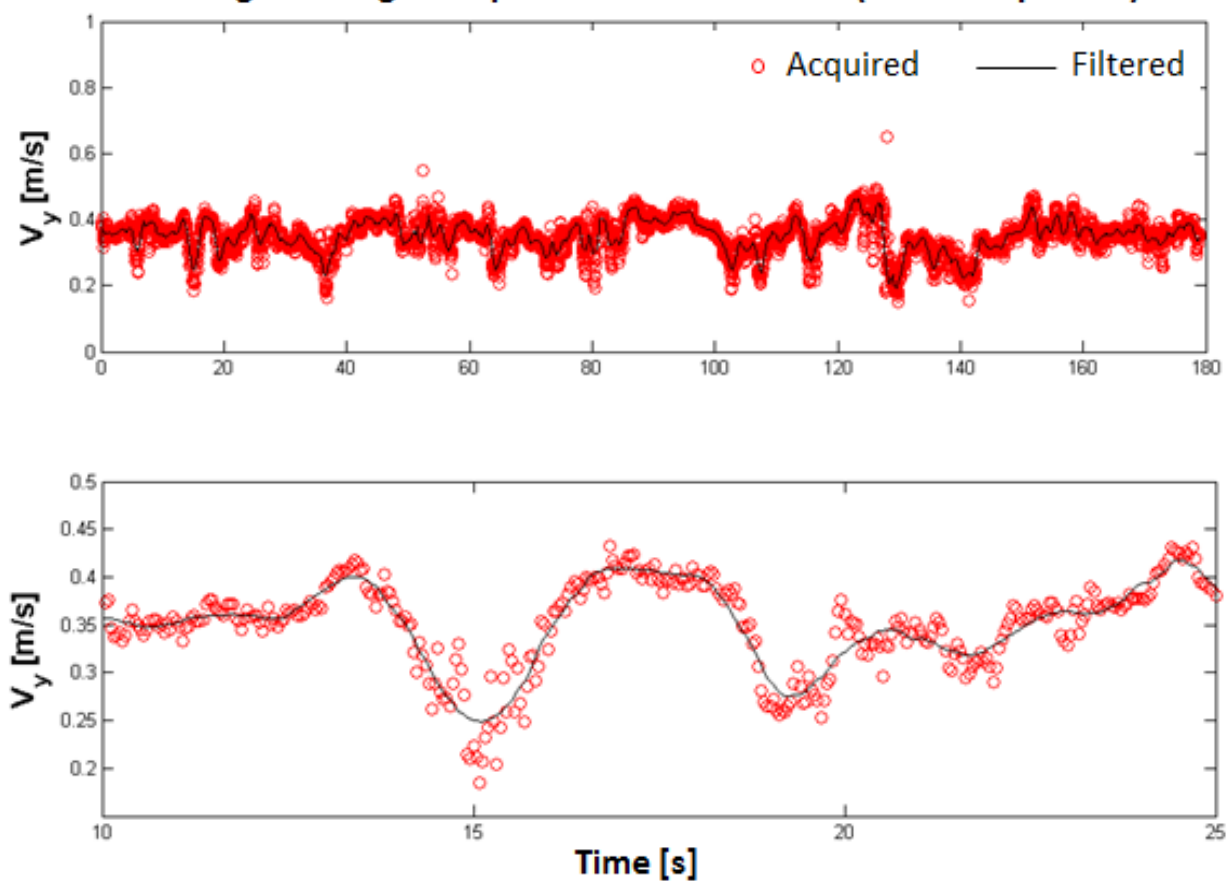

Figure 3.18. Velocity component acquired and filtered

Special efforts must be made to characterize the fluid behaviour in those regions with difficult accessibility where one can obtain crucial information about the flow activity. In order to carry out the measurements, an aluminum structure of 4.5 meters, made of four pieces of 3-point-truss of $1.5 \mathrm{~m}$ each, was anchored to the walls. A mobile wagon was made to slide over this structure driven by a pulley system in order to set the position over the surface of the tank. An aluminum profile of $9 \mathrm{~m}$ was attached vertically to the wagon as a guide for the velocimeter. Thus, the velocimeter was able to move automatically at different heights actioned by a stepper motor. This system allowed the movement of the velocimeter with enough precision inside the tank to measure 3D fluid velocity at different locations and depths. Figures 3.19 and 3.20 show the structure of aluminium built to carry out the experimental measurements of velocity. It allowed the velocimeter to be located with spatial precision. 


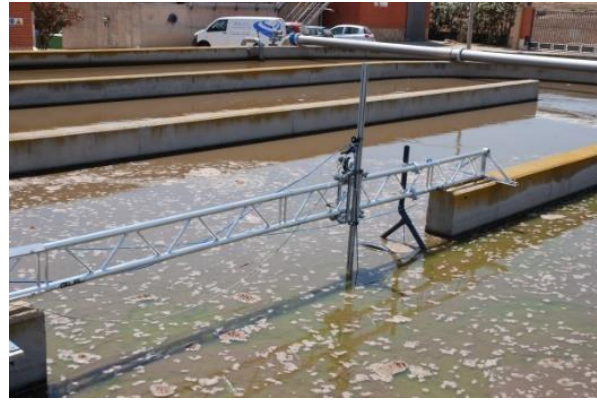

Figure 3.19. Velocity measures at the channel spacing

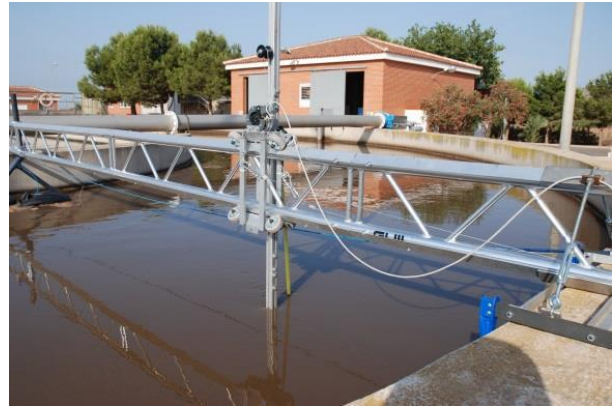

Figure 3.20. Measures at the otter channel
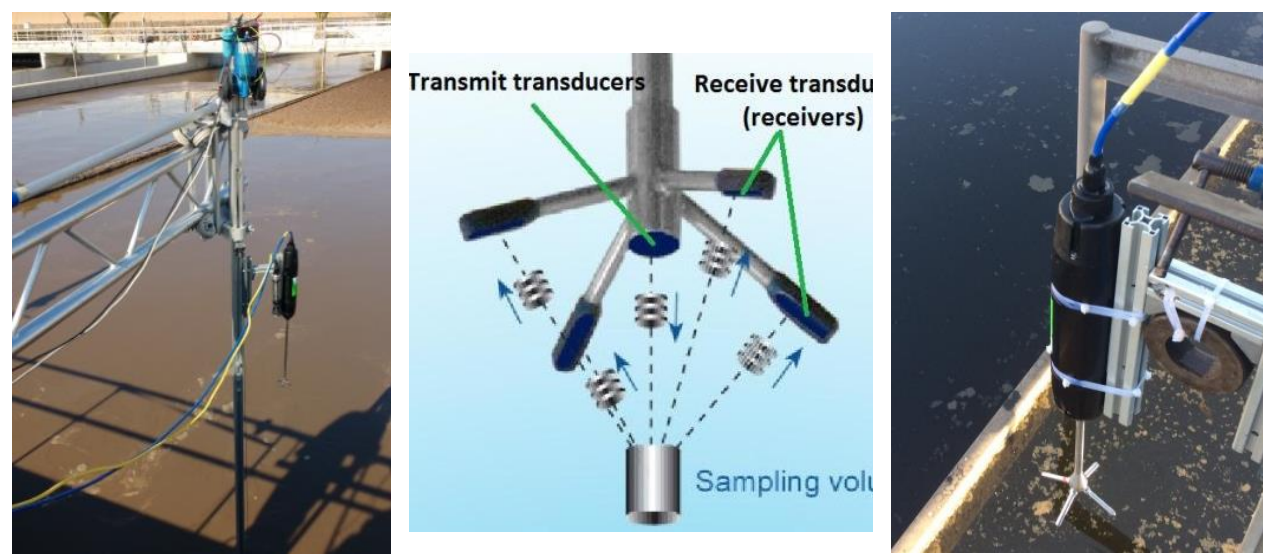

Figure 3.21. Laboratory probe (left) and field probe (right) of the Vectrino Nortek measuring in full-scale tanks and the scheme of functioning.

\section{$\underline{\text { 3.3.3 Non-Newtonian fluid performance }}$}

Newtonian fluids show a linear relation between shear rate and shear stress, i.e. the viscosity does not depend on the shear rate conditions. On the other hand, nonNewtonian fluids have an internal structure, and behave differently under different shear rate conditions. The shear rate dependent viscosity is referred to as apparent viscosity (Ramin, 2014). Activated sludge is considered to behave as a nonNewtonian fluid (Eshtiaghi et al., 2013; Ratkovich et al., 2013).

A rheological study was performed to characterize non-Newtonian behaviour of the fluid They were carried out with a BOHLIN® CVO $120 \mathrm{HG}$ (High resolution) rheometer equipment to measure physical properties of activated sludge at $18^{\circ} \mathrm{C}$ such as viscosity and yield stress. A double concentric cylinder rotational rheometer was used to obtain the flow curves, taking into account that the gap size (measuring 
gap: 1.99 and $2.73(\mathrm{~mm})$ was much larger, at least 10 times, compared to the particle size in suspension (until $0.14 \mathrm{~mm}$ ) (Eshtiaghi et al., 2013). Sensitivity tests of the sample were performed at different initial shear stress to measure viscosity with sufficient precision at low velocity gradients, and to detect the characteristic threshold stress of the pseudoplastic sample. In order to ensure a reliable experimental dataset, preliminary preparation of the sample was carried out to guarantee homogeneity of mixed liquor when measuring; a Shear Stress of $0.5 \mathrm{~Pa}$ for $30 \mathrm{~s}$ was induced and it was left to stand for another $30 \mathrm{~s}$ before to start measuring. Since the total suspended solids percentage in liquid is low $(<1 \%)$, the fluid in the CFD model was defined as a non-Newtonian single phase to reproduce changes in physical fluid properties under different velocity gradients.

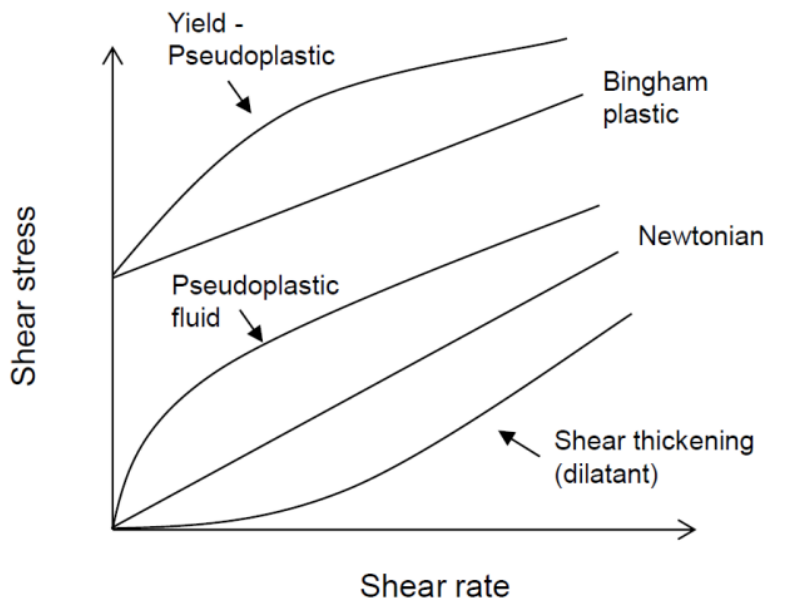

Figure 3.22. Typical rheological behaviour of fluids (Ratkovich et al., 2013).

As (Ramin et al., 2014), the Herschel-Bulkley model was selected to provide a complete description of the shear-thinning behaviour of the fluid, represented by the following equations:

$$
\begin{gathered}
\tau=\tau_{0}+K \gamma^{n} \\
\eta=\frac{\tau_{0}}{\gamma}+K \gamma^{n-1}
\end{gathered}
$$

Where $\tau$ is the shear stress $(P a), \tau_{0}$ is the yield stress $(P a), K$ is the consistency index $\left(P a s^{n}\right), \gamma$ is the shear rate $\left(s^{-1}\right), n$ is the flow behaviour index and $\eta$ is the apparent viscosity of sludge ( $\mathrm{Pa} S$ ).

The fitting parameters resulted $\tau_{0}=0.00883 \mathrm{~Pa} ; \mathrm{K}=0.01932 \mathrm{~Pa} \mathrm{~s}^{n} ; n=0.6262$. 
Herschel-Bulkley non-Newtonian fluid model was implemented to enrich the CFD model performance since viscosity variations due to velocity gradients were considered. Incorporating the rheological model does not imply a remarkable increase of the computing cost.
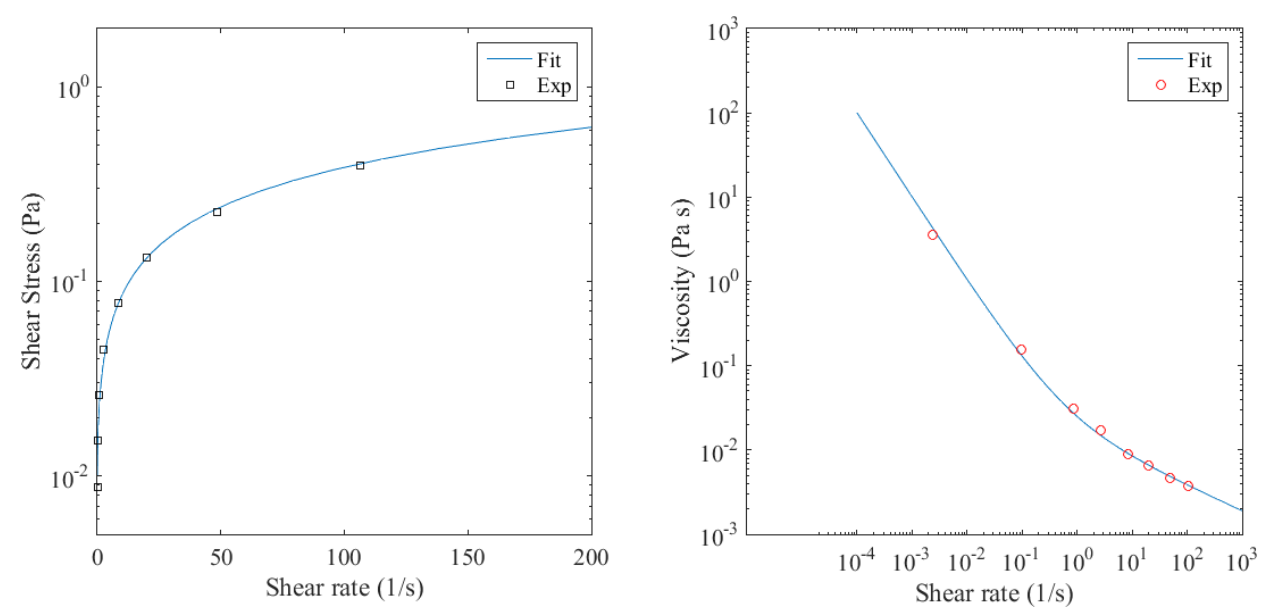

Figure 3.23. Rheological measurements at $2850 \mathrm{~g} / \mathrm{m} 3$. Shear stress (left) and viscosity (right)

\subsubsection{Physic-chemical species}

Physic-chemical analyses were carried out to measure the chemical species of interest defined in the ASM1 model at the influent flow, the internal recycling, and at some specific locations inside the tanks studied in this work. It was conducted following the Standard Methods for the Examination of Water and Wastewater (Rice et al., 2012). These analytics are essential to perform the fractioning (particulate and soluble, biodegradable and non-biodegradable) of the COD and $\mathrm{N}$ in order to define the state variables for the CFD model (Petersen, 2000).

Most of the values for the kinetic and stoichiometric coefficients of the mathematical model were defined as default values for $20^{\circ} \mathrm{C}$ (Jeppsson, 1996). Some parameters were determined by respirometry.

Moreover, to measure nitrate in different specific location inside the tanks, samples of $500 \mathrm{ml}$ were extracted from a specific depth. In order to asses denitrification performance, filtered BOD was measured following the procedure described in (Rice et al., 2012) and Hach-Lange ${ }^{\circledR}$ photometric kit was used to measure Nitrate (kit LCK339). 


\subsection{Calculation strategies}

Some calculation strategies applied to run the simulations of this work are explained in this section. On the one hand, the RTD scalar field allow calculating the residence time field of the flow in steady state which is a very useful technique to study the hydrodynamics in biological reactors. On the other hand, three different strategies were developed focused on reducing the computing cost associated to CFD-ASM models. Firstly, the Two-step solver allows to calculate hydrodynamics and kinetics separately. Secondly, an expression was defined to select a Timestep variable in to calculate biokinetics faster. Finally, the Hydroswapping approach was elaborated to run a case combining two different hydrodynamic fields previously converged for specific applications such us the On-Off aeration cycles carried out in the operation of biological reactors.

\subsubsection{RTD scalar field}

Tracer transport method (Ghirelli and Leckner, 2004) is a feasible way to perform a comparative study among different options. This implies a simple definition of residence time and can be run in steady state, which entails reducing efforts in terms of computing time and complexity of the simulations. This method was used to study and to select the best option to redesign the new biological reactor configuration.

An additional scalar variable with "time units" (s) was defined in the domain It was implemented according to transport equation for additional variables (Help System Ansys CFX-Solver Theory-Guide, ANSYS Inc.) as follows:

$$
\frac{\partial(\rho \varphi)}{\partial t}+\nabla(\rho U \varphi)=\nabla\left(\rho D_{\Phi} \nabla \varphi\right)+S_{\varphi}
$$

Mean residence time from the simulations is calculated by means of an additional scalar field, $t_{m}(\mathrm{~s})$, that is described by the following transport equation (Guirelli and Leckner, 2004)

$$
\sum_{j}\left[\frac{\partial}{\partial x_{j}}\left(U_{j} t_{m}-D_{t r} \frac{\partial t_{m}}{\partial x_{j}}\right)\right]=1
$$

where $D_{t r}\left(\mathrm{~m}^{2} \mathrm{~s}^{-1}\right)$ stands for the total diffusivity of the tracer in the fluid and $U_{j}$ the velocity components.

Simulations were carried out in steady state calculating the value of the $t_{m}$ from Equation 3.56 to obtain the field of the mean residence time in the domain. 


\subsubsection{Solver in two steps}

The solution is carried out in two steps. First, a stationary solution for the fluid with no additional variables was calculated. Then, the resulting velocity and turbulence fields are kept constant for the transient simulation. In this second step, only the transport equations for the additional variables are solved as their presences do not influence the main flow (low values of the molecular diffusivity compared to convective term).

The usual solving strategy is based on two steps; in the first step the hydrodynamics is solved, and in the second step, the ASM model is solved from the velocity field (as a known variable) as a convection-diffusion problem for a set of transport equations, one for each species, where ASM terms are included as sources. Then, as the hydrodynamics is not generally affected by biokinetics in these processes, transient simulations can be split into two steps. In the first one, hydrodynamics was calculated in steady state by using a proper time step. No biochemical reactions were allowed in this step. In the second step, the transport equations for the biokinetics were solved by using the flow fields obtained in the previous step, which remained constant, i.e., no flow equations were solved throughout this step. This strategy has an important advantage; it is possible to solve the biokinetic evolution over a long period of time with a non-expensive computational cost in scenarios where the hydrodynamic remains essentially constant.

\section{$\underline{\text { 3.4.3 Timestep variable }}$}

Typical time steps for the iterative resolution of hydrodynamics are of the order of a millisecond, depending on flow speed and mesh refinement through the Courant number. Given the RTDs corresponding for MLEs and the slowest reaction times for the biochemical processes involved take place at time scales way over the hydrodynamic timescale, their resolution would require a huge number of time steps. In order to reduce the number of time steps needed for the calculations, one can isolate both phenomena and resolve the corresponding equations separately. In practice, the number of iterations required for a proper resolution, and therefore in computational time, has been reduced by using a two-fold solving strategy, it is convenient to isolate both phenomena and resolve the corresponding equations separately.

As a first proposal for the reduction of the calculation time, we noted that the fluid pattern in the anoxic tanks could be considered constant as there was no aeration (the hydrodynamics only depended on the stirrers' momentum and incoming streams flow rates, which are both set constant in normal working conditions). These tanks have a strong fixed recycling stream, then the effect of the influent flow temporal evolution is quite limited. We could assume the hydrodynamic variables are constant over a long period of time. 
Then, as the hydrodynamics is not generally affected by biokinetics in these processes, transient simulations can be split into two steps. In the first one, hydrodynamics was calculated in steady state by using a proper time step. No biochemical reactions were allowed in this step. In the second step, the transport equations for the biokinetics were solved by using the flow fields obtained in the previous step, which remained constant, i.e., no flow equations were solved throughout this step. This strategy has an important advantage; it is possible to solve the biokinetic evolution over a long period of time with a non-expensive computational cost in scenarios where the hydrodynamic remains essentially constant.

A second proposal for the reduction of computation time is based on the use of a variable timestep that changes as the simulation advances. Given the structure of the biokinetics source terms (Makinia, 2010), one can expect that the reactions take place faster in the beginning and their speed reduces as the reactions advance until they reach equilibrium. Consequently, the solver was fed with a time step increasing with the iteration number, providing more accuracy and shorter timesteps at the initial timesteps, to ensure a proper convergence and prevent from overflow errors.

The variable timestepping proposed follows a geometric series, $t_{s}=t_{o} r^{s}$, where $s$ stands for the iteration number, $t_{o}$ the initial time step and $r$ the time common ratio. Then, the total simulation time is given by the expression:

$$
T=\sum_{s=1}^{S} t_{s}=t_{o} \frac{1-r^{S}}{1-r}
$$

Where $\mathrm{S}$ and $\mathrm{T}$ stand for the total iteration number and total time, respectively. In practice, the initial timestep is set to be equal to that of the hydrodynamic part. Then, the common ratio is calculated according to the desired number of iterations (or computational time).

Minimizing numerical error is a common cause of model error is numerical error. This is an unphysical loss of accuracy due to the way the CFD package solves and governing equations, and is especially dangerous near mesh boundaries. Numerical errors that reduce the result accuracy without crashing the simulation can be introduced by the following sources (Hirsch 2007): the discretization of space and time, unconverged implicit solutions, especially pressure, $\cdot$ loss of precision due to rounding, - inaccurate or inexact topography and geometry, incorrect or incompatible boundary conditions, - user error in solver parameters such as relaxation and iteration coefficients, $\cdot$ simplifications and approximations in models, especially relating to turbulence closures and multiphase flows, and bugs (errors) in the software code itself. 
Typically, the calculation of full-scale CFD-ASM models implies high computing times. As mentioned in Section 2.3.4, simulations were run in two steps with the purpose to reduce computational costs, solving hydrodynamics in the first step, and kinetics in the second one. Furthermore, a timestep sensitivity analysis over the second step of the simulation was performed with the aim of obtaining a maximum value of timestep which would provide good accuracy in CFD results. In order to do that, the evolution of the state variables was solved several times by employing different timesteps for each run. All runs shared the same velocity field, as a single steady state solution was used to feed the transient with frozen hydrodynamics. The evolution of the state variable value in time for different timesteps has been plotted. It was found that there was no significant difference in the resulting state variables (lower than $0.1 \%$ ) when the timestep is kept below $1 \mathrm{~s}$. When this value is increased up to $100 \mathrm{~s}$, the simulation time is conveniently reduced, but leading to deviations of approximately $5 \%$ at the end of the simulation. Further increase of the timestep results in faster computations but at higher deviations. It was also noted that the numerical imbalance of the partial differential equations (PDEs) increased over 5\% for some state variables, thus exceeding the aforementioned $1 \%$ maximum recommendations. Also, the initial part of the transient actually shows very different values, leading to huge errors in the computations in the early times of the simulation.

Given that the value of the state variable tends to similar values for every timestep studied (within a range of $10 \%$ ), but the differences in the earlier steps of the simulations can be huge, it makes sense to use the variable timestepping procedure provided by (Eq. 3.57). Moreover, the resulting timestep evolution when an initial timestep of 1 second is used for the first iteration, a total simulation time of 2 hours is desired, and a total number of 724 iterations is set. This strategy of calculation was successfully applied to this case and was especially useful for transient simulations with constant inlet conditions, but its application should be studied carefully for simulations with dynamic influent conditions.

Table 3.4 contains the parameters of interest from the feasibility of running simulations with the following PC features: Intel ${ }^{\circledR}$ Cores $^{\mathrm{TM}}$ i7-3770 CPU $3.40 \mathrm{GHz}$ 32.0GB RAM. The variable timestep provided highest accuracy in a reasonable computing time.

Table 3.4. Comparison of the main features of simulation depending on the timestep

\begin{tabular}{|l|l|l|l|}
\hline Timestep value & Number iterations & Total time $(\mathrm{h})$ & Error steady state $(\%)$ \\
\hline $1 \mathrm{~s}$ & 7200 & 28.24 & reference \\
\hline $100 \mathrm{~s}$ & 72 & 0.39 & 4.68 \\
\hline $900 \mathrm{~s}$ & 8 & 0.06 & 10.15 \\
\hline variable & 726 & 2.86 & 0.003 \\
\hline
\end{tabular}


Figure 3.24 shows the value of a state variable in time from its initial value to the converged solution value.

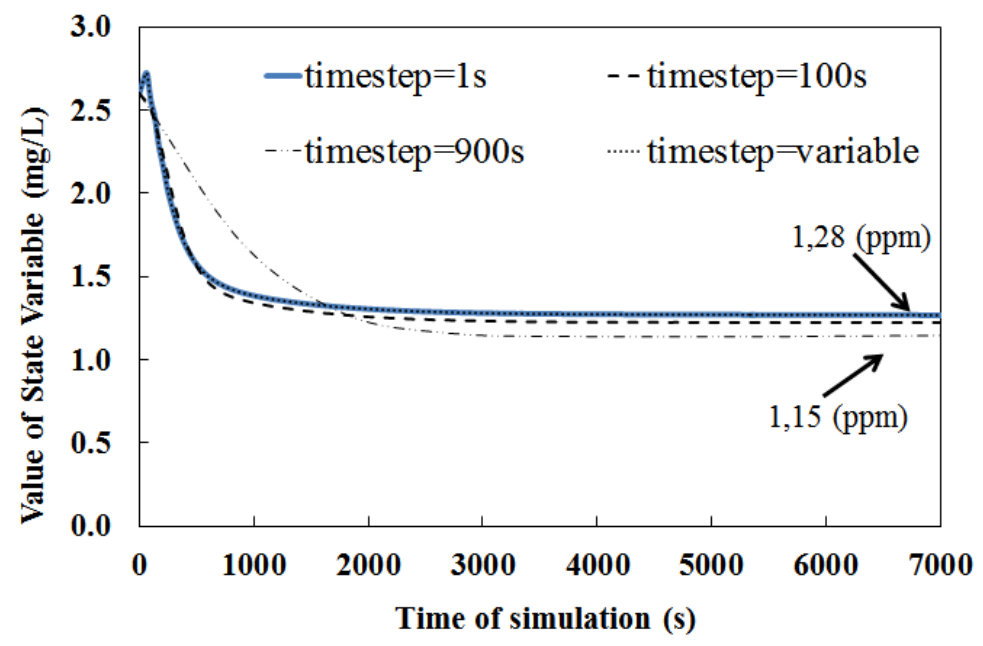

Figure 3.24. Evolution of the state variable value in steady state for different timesteps.

Figure 3.25 shows the resulting timestep evolution with a maximum of timestep value of 37 second when an initial timestep of 1 second is used for the first iteration, total simulation time of 2 hours is desired, and a total number of 724 iterations is set.

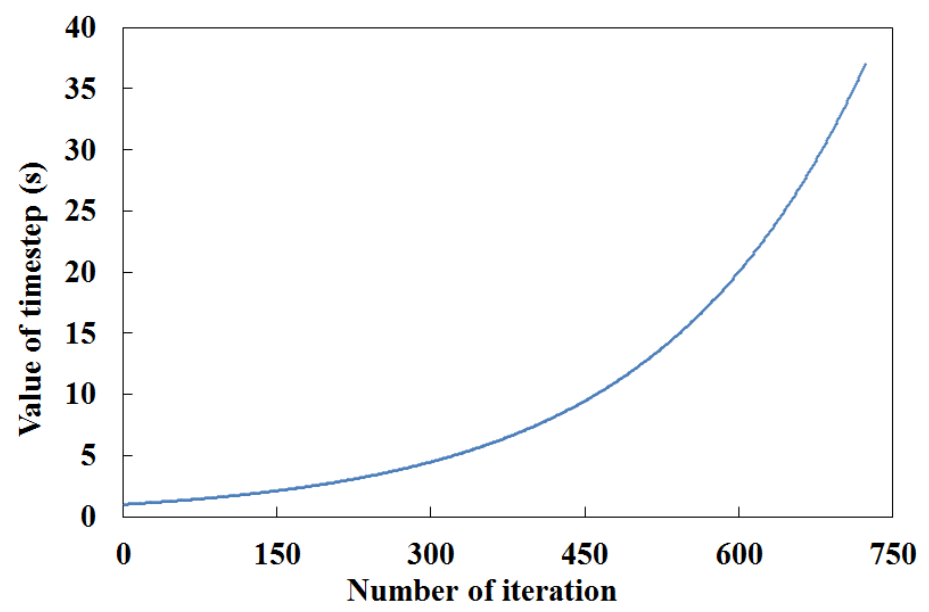

Figure 3.25. Value of timestep depending on number of iteration. 


\subsubsection{Hydroswapping formulation}

Hydroswapping is an innovative switching approach formulated to combine different hydrodynamics maintaining the transient evolution of state variables. It results useful to reproduce nitrification-denitrification in a bioreactor when aeration is provided by means of cycles.

The transport equation will see the speed with which the domain has been initialized. As the transport equation has the form

$$
\frac{d \varphi}{d t}+\nabla\left(\vec{u}_{1} \varphi\right)=\nabla(D \nabla(\varphi))+S_{1}
$$

where $\vec{u}_{1}$ is the initialization velocity field. It is about rewriting it so that it has the form

$$
\frac{d \varphi}{d t}+\nabla\left(\vec{u}_{\text {real }} \varphi\right)=\nabla(D \nabla(\varphi))+S_{2}
$$

where $\vec{u}_{\text {real }}$ is the field of velocities that we want to act, that is, that will be $\vec{u}_{1}$ in some moments and $\vec{u}_{2}$ in others. To convert the Eq. 3.58 into the Eq. 3.59 one must put a source term such that:

$$
S_{2}=\nabla\left(\left[\vec{u}_{1}-\vec{u}_{r e a l}\right] \varphi\right)+S_{1}
$$

In practice, a source domain is created with a source called Total_Source, and that results from the sum of two subsources: the named Implicit_Source, and that is equal to the term of the divergence, and another named Real_Source, which is the rate of the reaction:

$$
\begin{gathered}
S_{\text {implicit }}=\nabla\left(\left[\vec{u}_{1}-\vec{u}_{\text {real }}\right] \varphi\right) \\
S_{\text {real }}=S_{1} \\
S_{\text {total }}=S_{\text {implicita }}+S_{\text {real }}
\end{gathered}
$$


To implement the divergence, the associative property is used:

$$
S_{\text {implicit }}=\varphi \nabla\left(\vec{u}_{1}-\vec{u}_{\text {real }}\right)+\left[\vec{u}_{1}-\vec{u}_{\text {real }}\right] \nabla \varphi
$$

Note that to perform the operation in the first term, it is necessary to have previously saved the velocity gradients. 


\section{Chapter 4}

\section{Analysis of results}

The main results achieved in this work are presented in this section. CFD Modelling applied to biological reactors have been performed over three different configurations. Firstly, the main results of the MLE biological configuration are shown. It is part of the Article A, which has been included entirely in the Appendix A. Secondly, a full-scale performance over an Orbal configuration is presented. As in the previous, hydrodynamics and biokinetics were analysed compared to experimental measurements. Finally, the main results of the oxidation ditch configuration study are analysed which corresponds to the main results of the Article B, included entirely in the Appendix B.

\subsection{Modified Lutzack Ettinger configuration}

A CFD-ASM has been used to evaluate the operation of a full-scale AS system and optimize its performance through changes in the biological reactor anoxic zone. The original configuration has been retrofitted and modified after detecting problems in the fluid behaviour within the tank.
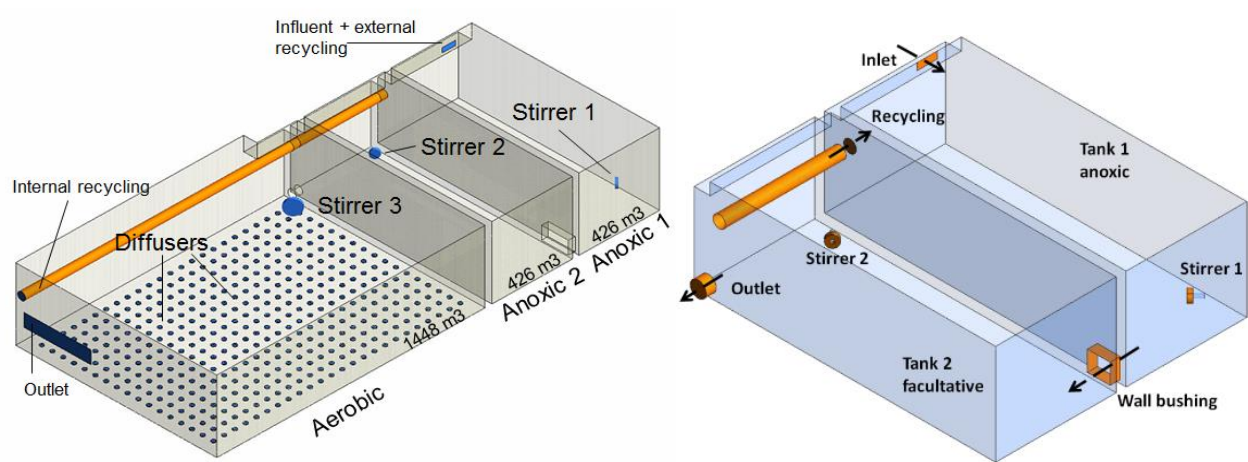

Figure 4.1. 3D model of biological reactor LEM configuration (left) and the two first anoxic tanks retroffited (right) 


\subsubsection{Hydrodynamic analysis using CFD Modelling}

RTD simulations were run in steady state to calculate mean residence time, $t_{m}$, by means of additional scalar field. As shown, a 3D comparison between both configurations for a specific interval of mean residence time, represented by the portion of fluid volume which contained values of $t_{m}$ between 500s and the time when the fluid escapes from the anoxic zone at the original configuration, $680 \mathrm{~s}$. The Modified configuration removed the short-circuiting (Figure 4.2)

a)

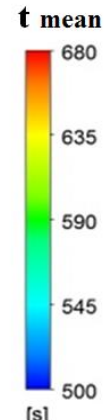

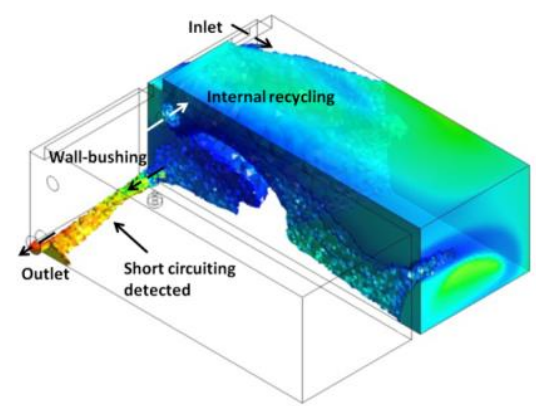

b)

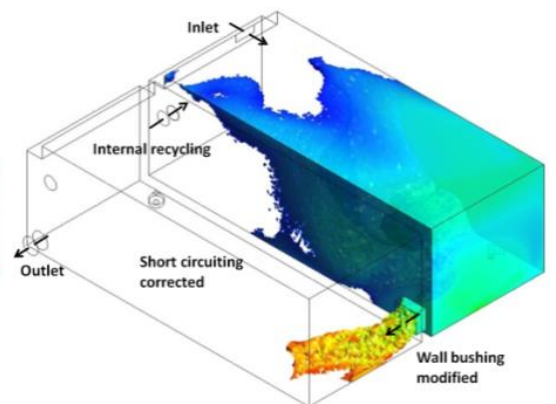

Figure 4. 2. Short-circuiting a) detected at Original configuration and b) corrected at Modified configuration.

Figure 4.3 shows the streamlines revealing the faulty hydrodynamics performance and the improvement in the Modified configuration.

Therefore, it is apparent that the existence of the short-circuiting in the Original configuration was not consequence of the poor mixing degree but because of the design configuration.

a)

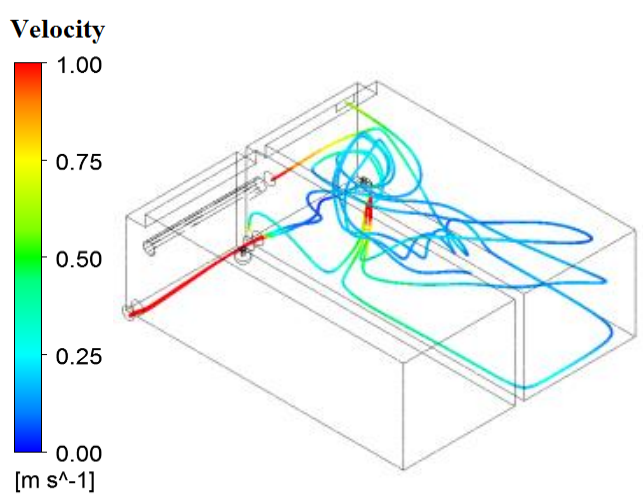

b)

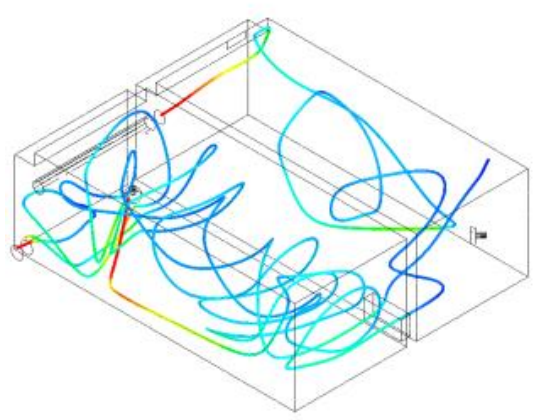

Figure 4.3. Streamline of a) short-circuiting at Original b) Modified configuration 


\subsubsection{Retrofitting of the configuration using CFD Modelling}

To optimize the performance of the configuration, a virtual study was developed, consisting of several simulations. First, the influence of wall-bushing crossing section area (between 0.5 and $4 \mathrm{~m}^{2}$ ) and shape (circular and rectangular) on the residence time and velocity field homogeneity was studied (see Figure 4.4). Then, the optimal crossing-area and shape combination is used as a basis for a study on the stirrer positioning at 6 positions and its influence on the mixing efficiency of the tank. Finally, the optimal position is used as a basis for a study on the orientation of stirrer ( 3 angles). The angular orientation providing better mixing performance is then chosen as the optimal one.

The optimization of the Modified configuration was based on maximizing $t_{m}$ and the fluid velocity homogeneity. As an example, figure 4.4 shows $t_{m}$ variable represented over a plane located at $0.60 \mathrm{~m}$ height (wall-bushing crossing section). Slightly differences can be appreciated among the configurations.

Table 4.1. Description of the configurations tested to optimized the wall-bushing

\begin{tabular}{|c|c|c|c|}
\hline Configuration & Geometrical shape & $\begin{array}{c}\text { Crossing } \\
\text { section }\left(\mathrm{m}^{2}\right)\end{array}$ & Parameter $(\mathrm{mm})$ \\
\hline 1 & circular & 0.50 & $\varnothing 800$ \\
\hline 2 & circular & 1.13 & $\varnothing 1200$ \\
\hline 3 & rectangular & 1.13 & $1130 \times 1000$ \\
\hline 4 & circular & 2 & $\varnothing 1600$ \\
\hline 5 & rectangular & 2 & $2000 \times 1000$ \\
\hline 6 & rectangular & 2 & $2 \times(1000 \times 1000)$ \\
\hline 7 & rectangular & 3 & $2500 \times 1200$ \\
\hline 8 & rectangular & 4 & $2500 \times 1600$ \\
\hline
\end{tabular}

A hardly noticeable difference can be appreciated between different crossing section shapes enclosing the same flow area (4.4c and $4.4 \mathrm{~d})$. A gradual increase of the crossing section was tested showing that there was an optimum configuration, since above $2 \mathrm{~m}^{2}$ crossing section a $t_{m}$ variable field was worsening instead of getting better (4.4e and 4.4f). The latter shows an undesirable effect of the fluid induced by the wall bushing. It consisted of zones with upper $t_{m}$ values, which would correspond to be closer to the Outlet, located behind zones with lower $t_{m}$ values. 
a)

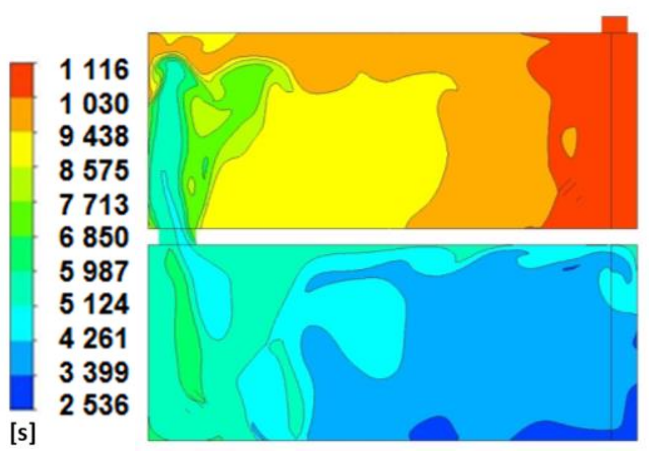

c)

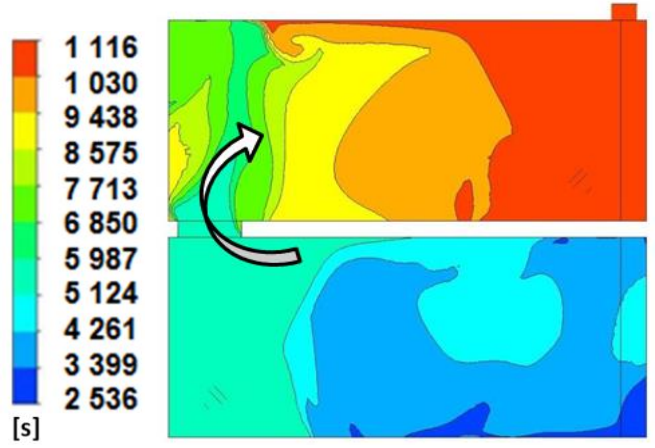

e)
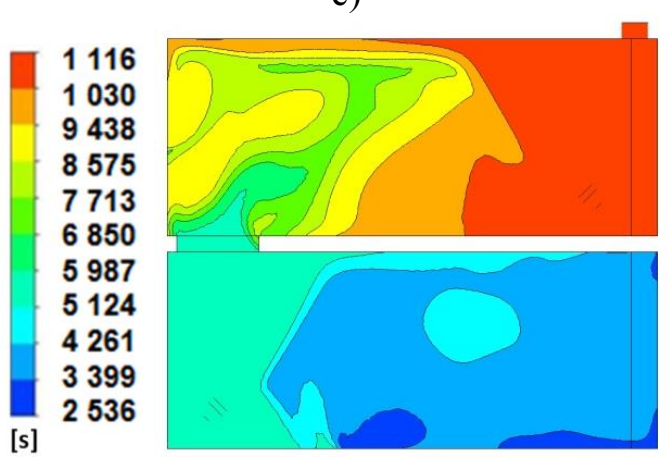

[s]

b)

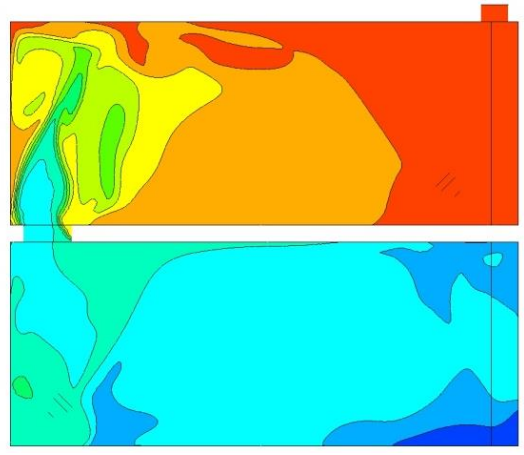

d)

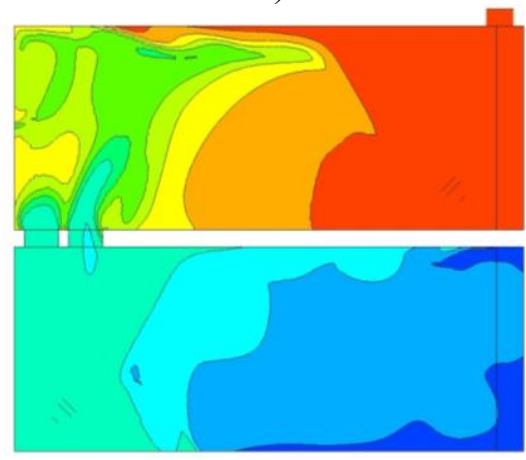

f)

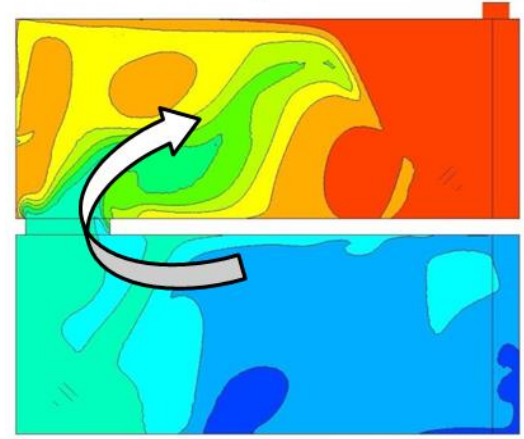

Figure 4.4. Horizontal cross-sections for $t_{m}$ variable in a) configuration $1, b$ ) configuration 2 , c) configuration 5 , d) configuration 6 , e) configuration 7 and f) configuration 8 
Comparative fluid velocity profiles between configurations have been plotted over the dashed lines drawn in figure 4.5 and figure 4.6. They show that there is a noticeable local reduction of fluid velocity when the crossing section increased from $0.5 \mathrm{~m}^{2}$ to $1.13 \mathrm{~m}^{2}$ (Figure 4.5) and also up to $2 \mathrm{~m}^{2}$ (Figure 4.6), and no substantial differences has been found depending on the number of wall-bushings (one or two) for $2 \mathrm{~m}^{2}$ configuration (Figure 4.6).

After the steady state simulations, an optimal crossing section of $2 \mathrm{~m}^{2}$ with a rectangular wall-bushing shape (configuration 5) was selected. This configuration improved hydraulic efficiency indicating that more effective use of available tank volume was occurring (maximizing $t_{m}$ variable). Also, the resulting local velocity after the wall-bushing is reduced leading to an enhanced homogeneity of the fluid velocity field.

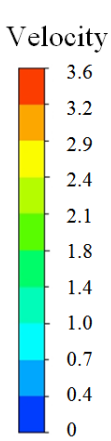

a)

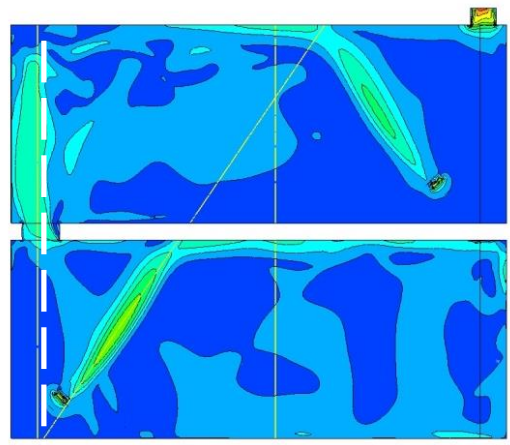

b)

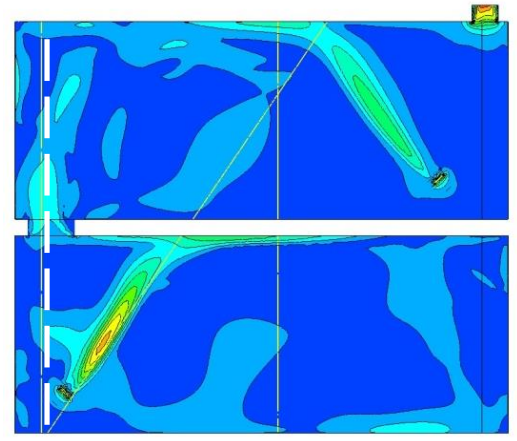

Figure 4.5. Fluid velocity field in a) configuration 1 and b) configuration 2

a)

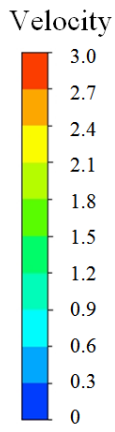

$[\mathrm{m} / \mathrm{s}]$

\section{)}

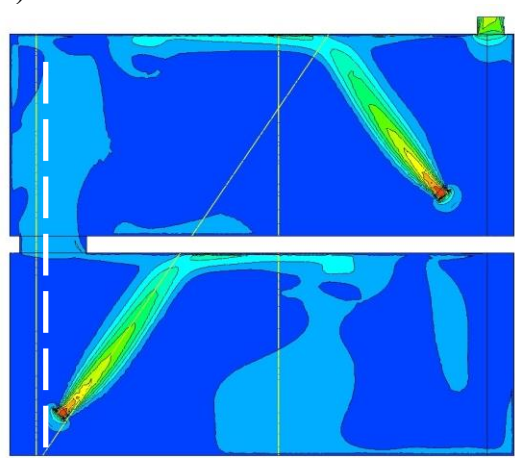

b)

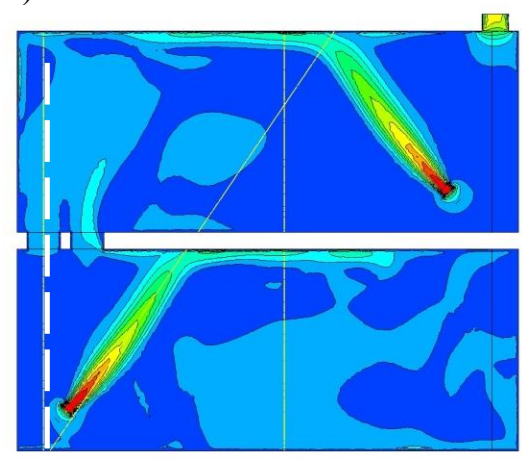

Figure 4.6. Fluid velocity field in a) configuration 5 and b) configuration 6 
A comparative study was conducted to relocate the stirrer of the first tank according to its position and its angle. Transient simulations were performed for 5 positions and 3 different angles. The purpose was to evaluate the stirrer mixing efficiency by means of the tracer concentration through the wall-bushing depending on these two factors. Tracer concentration was calculated as an average of the crossing section in time and it was used as the main indicator for the following approach: the higher mixing efficiency, the lower the tracer concentration exiting the first tank.

We have defined the Reference configuration under the assumption that the proper location for the stirrer (Modified stirrer) should be symmetrical from the initial one (Original stirrer). An explanatory figure has been included. The stirrer in the Reference case is therefore located at $0.70 \mathrm{~m}$ from the main wall (X direction), 1.5 $\mathrm{m}$ from the side wall (Y direction), and $1.2 \mathrm{~m}$ from the bottom ( $\mathrm{Z}$ direction). Then, in order to study variations around this reference, 5 additional locations were proposed. Table 4.2 summarizes the relative locations of these new positions.

Table 4.2. Description of the different locations tested

\begin{tabular}{|c|c|c|c|}
\hline Location & $\begin{array}{c}\text { Relative position } \\
\text { X }(\mathrm{m})\end{array}$ & $\begin{array}{c}\text { Relative position } \\
\mathrm{Y}(\mathrm{m})\end{array}$ & $\begin{array}{c}\text { Relative position } \\
\mathrm{Z}(\mathrm{m})\end{array}$ \\
\hline Reference & 0 & 0 & 0 \\
\hline Ahead & 0.5 & 0 & 0 \\
\hline Up & 0 & 0 & 0.3 \\
\hline Down & 0 & 0 & -0.3 \\
\hline Right & 0 & 0.6 & 0 \\
\hline Left & 0 & -0.6 & 0 \\
\hline
\end{tabular}
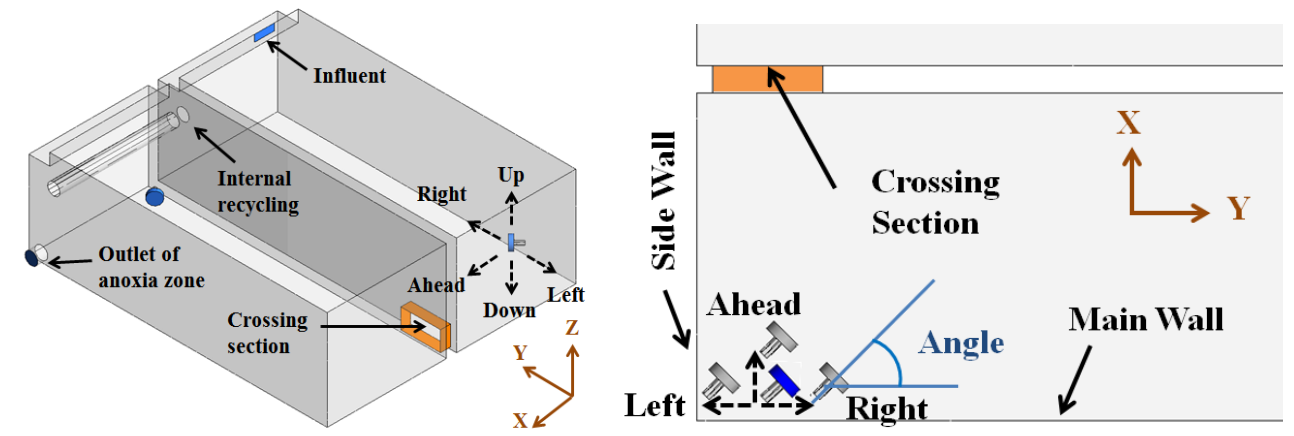

Figure 4.7. Positioning of the stirrer depending on its location (left) and the angle (right)

Figure 4.8a shows the evolution of tracer concentration over time calculated at the crossing section for the different spatial locations. It is appreciated the different 
tracer performance obtained through the wall-busing after the pulse of mass tracer at the inlet. All cases presented a similar initial time, defined as the time from which tracer starts exiting the first tank. The maximum tracer concentration values are achieved for Up and Left relative positions of the stirrer which correspond to a reduced efficiency in terms of mixing. On the other hand, a much better mixing performance is achieved by Down and Right relative positions since lower tracer concentration values escaping the first tank are obtained. The Right position was finally chosen because it presented low values of tracer concentration and the maximum value of the initial time.

a)

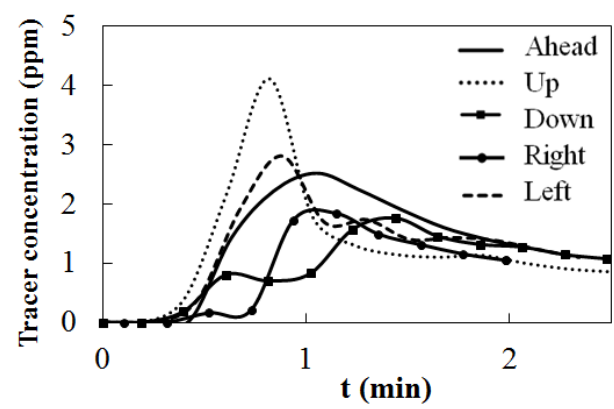

b)

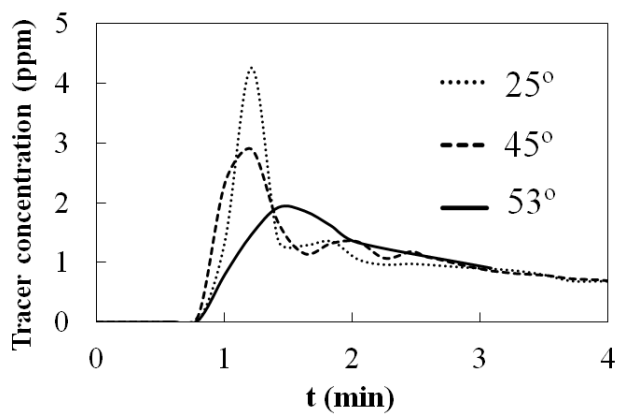

Figure 4.8. Tracer concentration calculated at the crossing section for different a) positions and $b$ ) angle

Figure $4.8 \mathrm{~b}$ exhibits the importance of the angle when relocating the stirrer. The most acute angle provided a sharp peak related to an unintended high tracer concentration exiting the first tank. This peak was reduced when opening the angle of the stirrer respect to the Main wall. Note that real angles were tested since the mast of the stirrer in the real plant had limited positions. It was concluded that the angle of $53^{\circ}$ provided the lowest peak being potentially a good option to provide a much better mixing performance.

To conclude with the retrofitting study, figure 4.9 shows the comparison of the fluid velocity field between the Original and the Modified configuration after the optimization study. The wall-bushing was retrofitted removing the short circuiting and providing a homogeneous fluid velocity field; the $2 \mathrm{~m}^{2}$ rectangular shape option was selected. Moreover, the optimal configuration, corresponding to the stirrer placed in Right position at an angle of $53^{\circ}$, provided a mean residence time increased by $38 \%$ over the original anoxic zone. Also, maximum tracer concentration was reduced by $30 \%$. This optimal configuration will be referred to as Modified configuration from now on. 

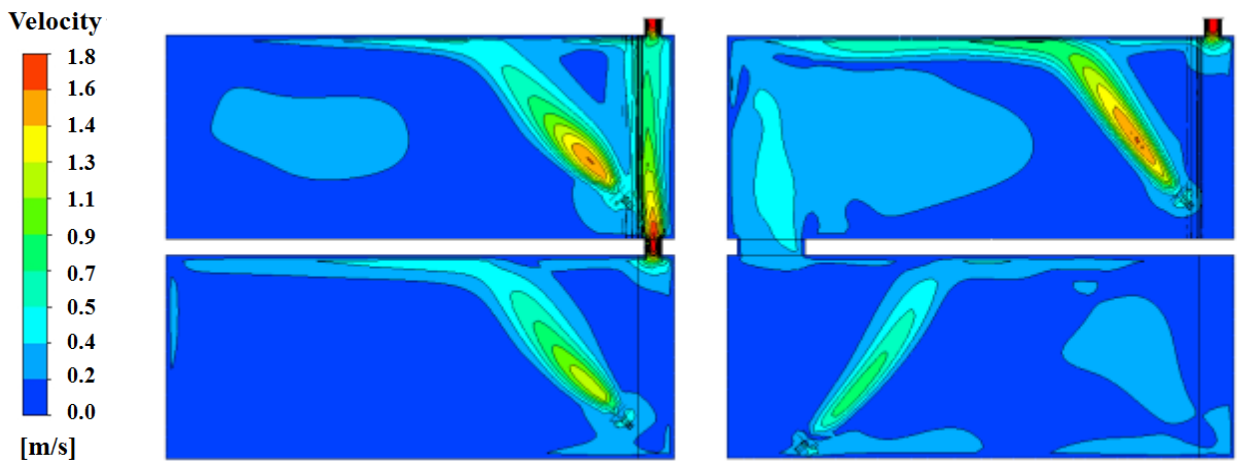

Figure 4.9. Comparison of the fluid velocity field between the Original configuration (left) and the Modified configuration (right)

\subsubsection{Tracer tests in dynamic state}

Figure 4.10 shows the residence-time distribution function $\mathrm{E}(\mathrm{t})$ at $\mathrm{P} 4$ for both the Original and Modified configurations compared to the distribution of ideal fluid behaviour of one completely stirred tank reactor (1CSTR). CFD model provided good results and fitting well with experimental data obtained from "short tracer tests". As expected, note that the CFD and experimental data start to differ significantly after minute 30 , as the CFD model does not include recycling of tracer concentration. The RTD of the Original configuration shows a pronounced spike, meaning that a significant part of the inflowing tracer exited the tank in a time much shorter than the mean residence time, compared to 1CSTR indicates the presence of a short-circuit. The curve corresponding to the Modified configuration indicates that there is no longer short-circuiting. Also, the full curve is displaced to the right and smoothed out, leading to an increased mean residence time. Thus, this configuration provides an improvement of the global fluid behaviour in the tank.

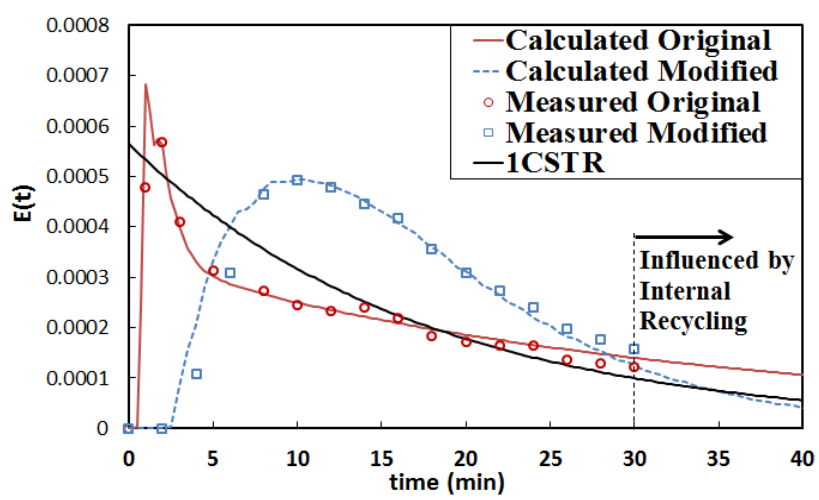

Figure 4.10. Comparison and validation of both RTD obtained in WWWT1 configurations: Original and Modified. 
The Modified configuration provided overall better hydraulic conditions than Original configuration since mean residence time increased by $38 \%$ approximately and the value of dead volume calculated decreased significantly.

Table 4.3. Main parameters of experimental RTD analysis

\begin{tabular}{|l|c|c|c|c|c|c|}
\hline Case & $\tau(\min )$ & $t_{m}(\min )$ & $t_{m} / \tau$ & $V_{d}(\% V)$ & $\theta_{\max }$ & $\mathrm{N}$ \\
\hline Original & 17.3 & 12.4 & 0.71 & 28.3 & 0.08 & 1.09 \\
\hline Modified & 17.3 & 17.1 & 0.99 & 1.15 & 0.59 & 2.42 \\
\hline
\end{tabular}

\subsubsection{Validation of the CFD-ASM model}

After the full-scale modification in WWTL1, permanent unbalanced denitrification efficiency was observed between both lanes; Modified WWTL1 was favoured over the Original WWTL2 in terms of effluent quality due to its better hydrodynamics performance. Figure 4.11 shows the comparison between both WWTLs obtained for an equal continuous operational regime taking samples in time at the outlet of the aerobic tanks.

Nitrate concentration of the Modified WWTL1 presented lower values than the Original WWTL 2 being the average difference by $17 \%$, with a maximum difference of $60 \%$.

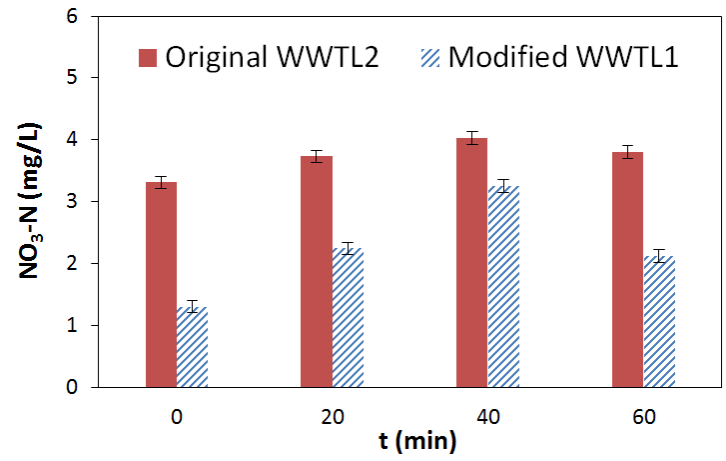

Figure 4.11. Comparison of Nitrate measured at different times at outlet of both WWTLs

Moreover, experimental measurements were conducted within both anoxic zones in order to validate the CFD-ASM model and comparing both WWTLs. On the one hand, a representative sampling volume was taken at four different control points located at $2.5 \mathrm{~m}$ height inside both anoxic zones (P1, P2, P3 and P4). On the other hand, CFD-ASM1 results were calculated as an average concentration integrated over a specific bulk defined around each control point. Assuming the same 
distribution and composition of influent flow for both WWTLs, CFD-ASM1 models were performed defining the boundary conditions on equal terms for both configurations, except for the nitrate concentration at the internal recycling, which was adjusted because of the unbalanced state of the Modified WWTL1 being reduced by $17 \%$. CFD results reproduced correctly main trends of pollutant concentrations within the tank (Figure 4.12) and (Figure 4.13). In general, the tendencies provided by CFD-ASM1 models can be considered acceptable for both species, albeit some absolute values, particularly in P1, presented marked deviations. The difference for each measuring point between the Original and the Modified configurations should be less pronounced than calculated as the experimental data suggested.

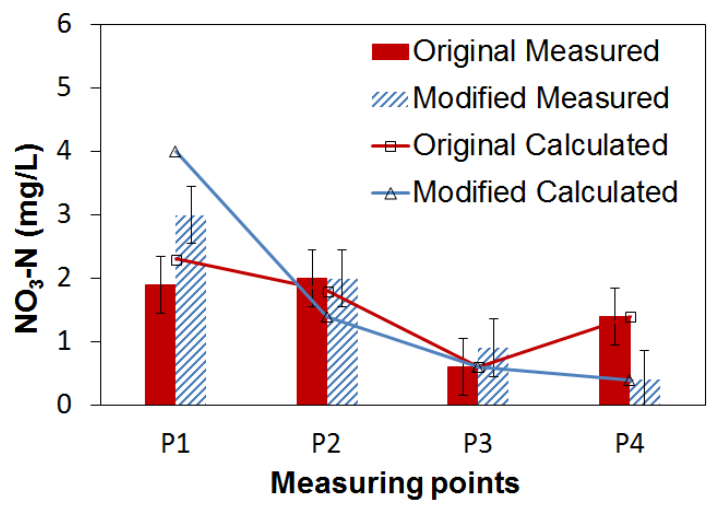

Figure 4.12. Comparison between nitrate concentration measured and calculated

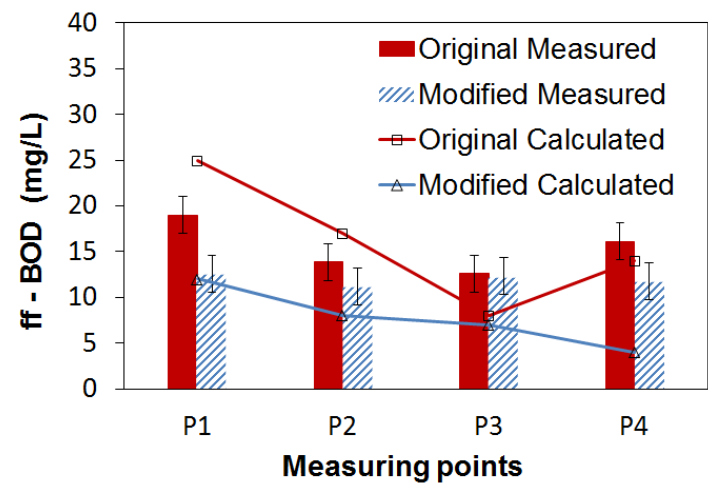

Figure 4.13. Comparison between filtered BOD measured and readily biodegradable substrate concentrations calculated at both configurations 
Fitting full-scale sampling results obtained in a discrete way resulted particularly difficult. The majority of parameters for the biokinetic model were taken from ASM1 default at $20^{\circ}$ (Jeppsson, 1996), but some of them such as the maximum specific growth rate and the decay coefficient for heterotrophic biomass, $\mu_{\mathrm{H}}$ and $b_{\mathrm{H}}$, were determined by respirometry with the objective to provide further information of the anoxic growth of heterotrophs resulting of 6.9 day $^{-1}$ and 0.22 day $^{-1}$ respectively.

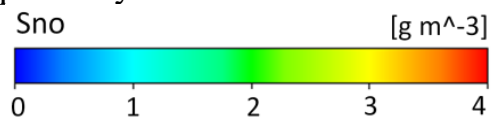
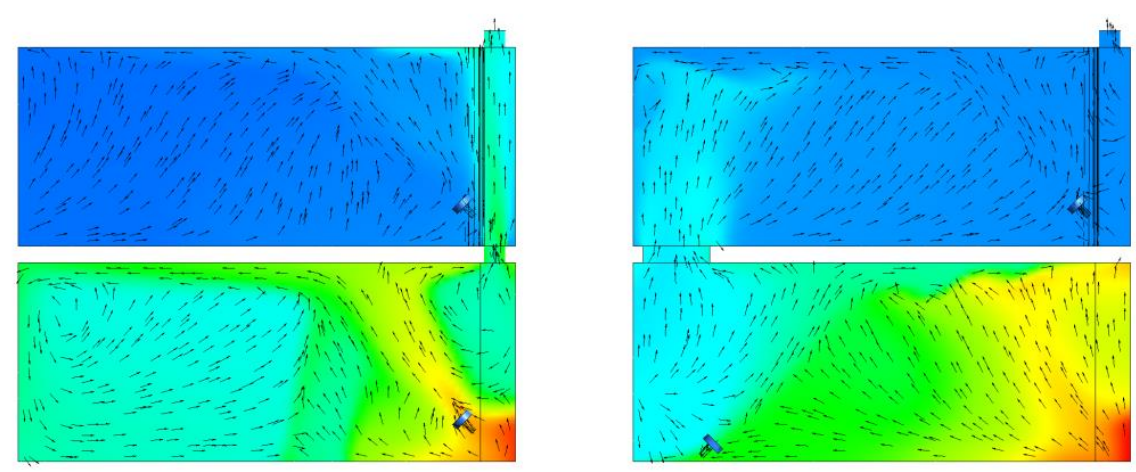

Figure 4.14. Nitrate (Sno) at Original configuration (left) and at Modified configuration (right)
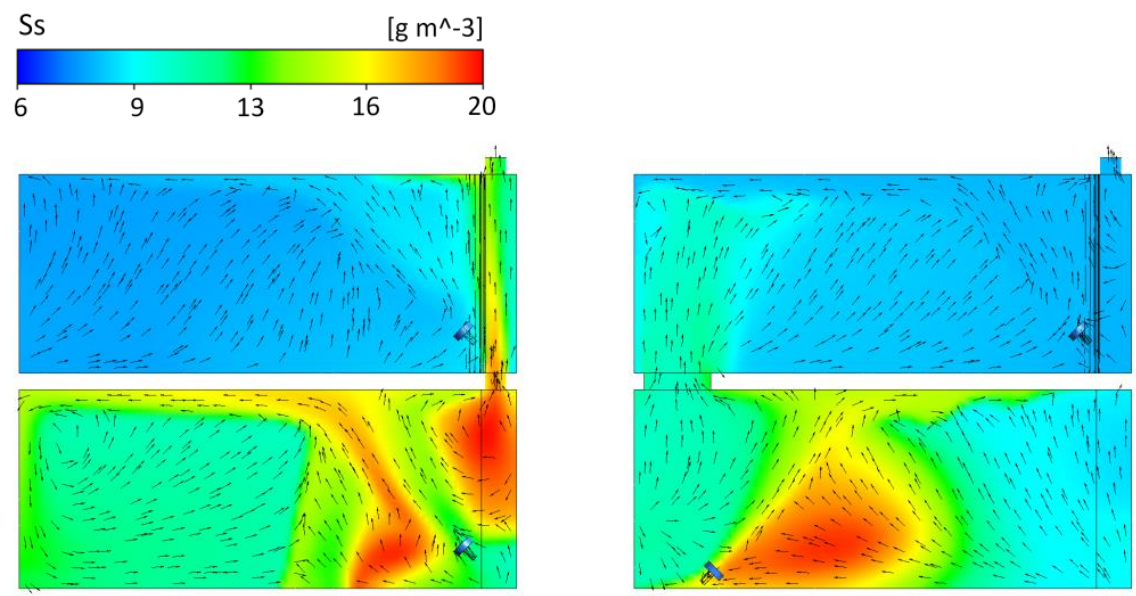

Figure 4.15. Readily biodegradable substrate (Ss) at Original configuration (left) and at Modified configuration (right) 
Moreover, the half-saturation coefficient for heterotrophic biomass Ks $=4.9 \mathrm{gCOD}$ $\mathrm{m}^{-3}$ was measured since it is the main parameter influencing growth rate (Arnaldos et. al., 2015) and it presents a wider experimental value range compared with the other half-saturation default coefficients of Monod equations (Jeppsson, 1996). Yield for heterotrophic biomass $\left(\mathrm{Y}_{\mathrm{H}}\right)$ resulted in $0.68 \mathrm{COD}$ formed/COD oxidized. Dissolved oxygen concentration was measured continuously at different locations ensuring values below $0.1 \mathrm{mg} / \mathrm{L}$ within the anoxic zone.

Figure 4.14 and Figure 4.15 show the comparison of nitrate and readily biodegradable substrate concentration distributions for the same scenario. The influence of the short-circuiting over the nutrient removal process can be noticed. Results show the improvement of the Modified configuration which provided lower nitrate concentration at the outcoming from the anoxic zone due to a better utilization of the organic matter for denitrification.

Following the evaluation of CFD-ASM1 results and taking into account the complexity to show the CFD performances in $3 \mathrm{D}$, the entire volume was divided into six virtual control cubicles. This analysis has been included providing biokinetic results from average values integrated in each subvolume. Results are shown by means of comparative histograms between both configurations.

Figure 4.16 shows a noticeable improvement of the Sno performance for the Modified configuration which ensures low concentration at the outcoming anoxic flow and a better use of the available anoxic volume. The more plug-flow hydrodynamic behaviour from the retrofitting can be appreciated following the Sno value. The Original configuration showed the effect of the short-circuiting providing an undesirable high concentration at the outlet. Moreover, it exhibited locally high Ss values along the short-circuiting (Figure 4.17). Because of the different hydrodynamics performance, consumption rates in the Original configuration offered the maximum values nearby the outlet which tended to worsen denitrification efficiency within the entire anoxic zone.

The other nitrogen compounds remained practically unchanged between configurations. The Snd, Snh and Xnd state variables concentration were calculated within the tank, showing average differences between cases (Original and Modified) lower than 5\%. 


\begin{tabular}{lllll|} 
Sno & & & \multicolumn{2}{r|}{$\left[\mathrm{g} \mathrm{m}^{\wedge}-3\right]$} \\
\hline 0 & 1 & 2 & 3 & 4
\end{tabular}
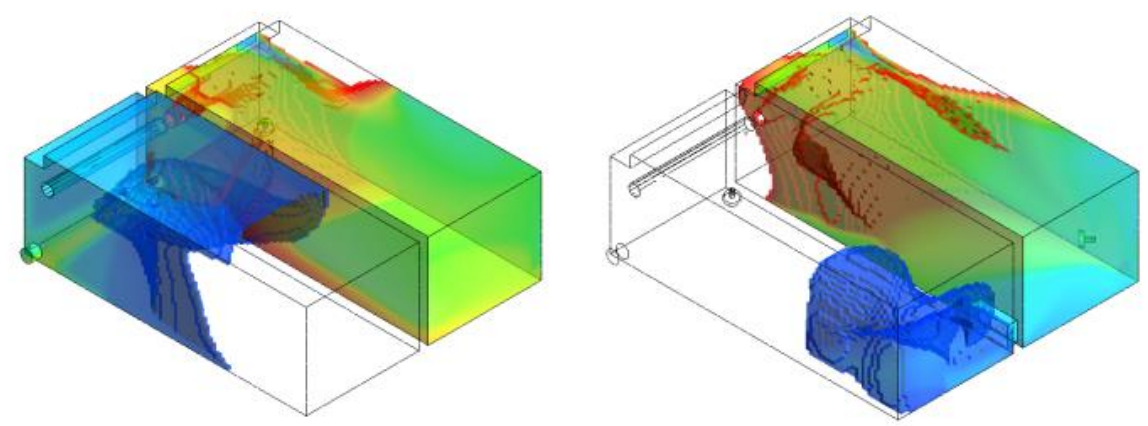

Figure 4.16. Nitrate (Sno) at Original configuration (left) and at Modified configuration (right)

\begin{tabular}{lllll|} 
Ss & & & \multicolumn{2}{c}{ [g m-3] } \\
\hline 6 & 9 & 13 & 16 & 20
\end{tabular}
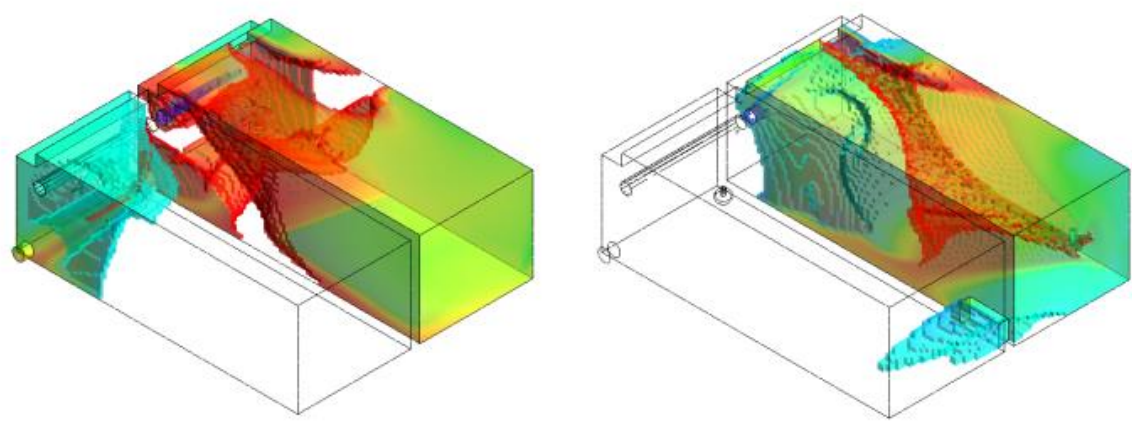

Figure 4.17. Readily biodegradable substrate (Ss) at Original configuration (left) and at Modified configuration (right) 

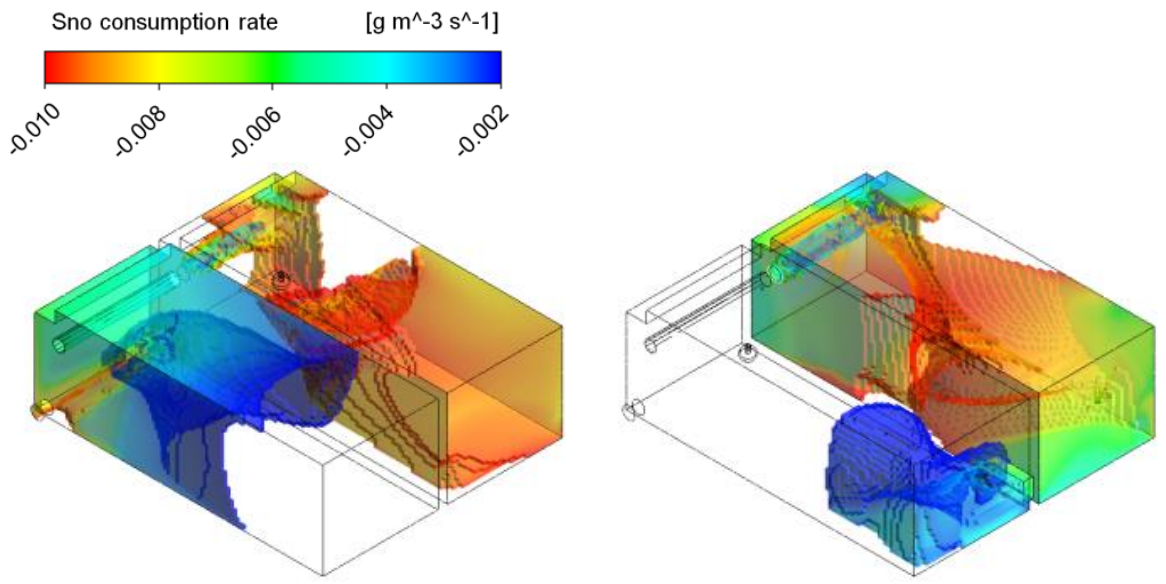

Figure 4.18. Nitrate consumption rate (g m-3 s-1) at Original configuration (left) and at Modified configuration (right)
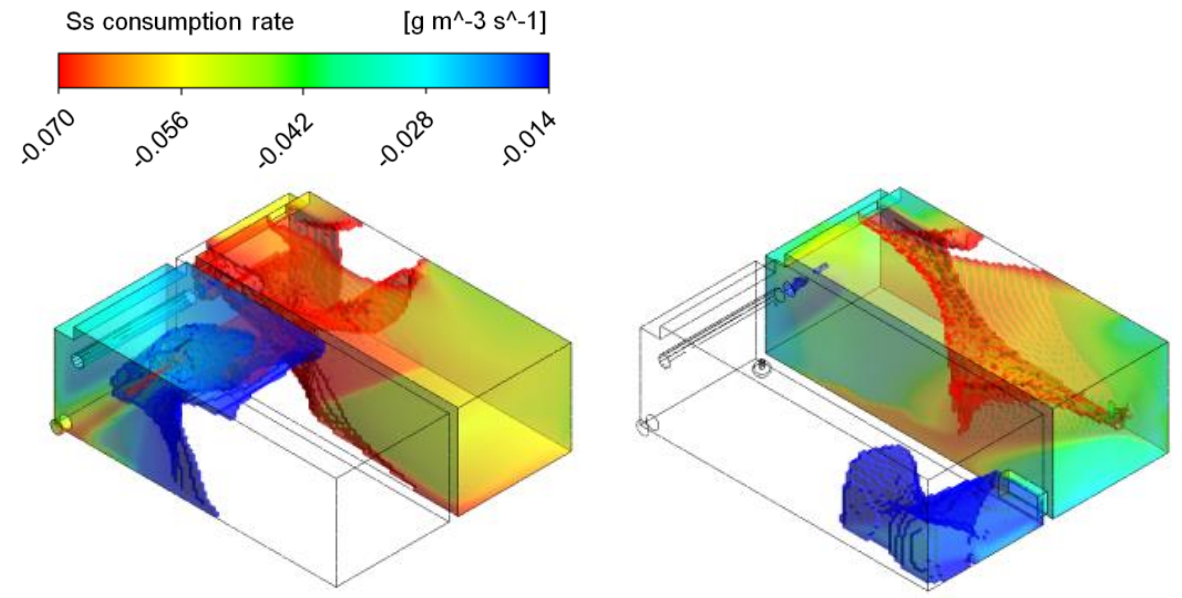

Figure 4.19. Readily biodegradable substrate consumption rate $(\mathrm{g} \mathrm{m}-3 \mathrm{~s}-1)$ at Original configuration (left) and at Modified configuration (right) 


\subsubsection{Hydroswapping}

The results show the maximum potential of the CFD tools applied WWTP operation by means of a novel full-scale ASM-CFD biological reactor model, which reproduces kinetics by means of two-phase flow simulations. The main aim is to perform the aeration cycles carrying out the actual control strategy in a real plant.

A CFD full description of a full-scale bioreactor has been calculated in dynamic state. Hydro-swapping approach allows:

- Combining different hydrodynamics (with aeration ad without aeration)

- Reproducing aeration cycles (real control loops)

- Calculating the evolution of the state variables in transient state

- Performing nutrient removal process

- CFD can be used as a decision-making tool

Hydrodynamics have been calculated in steady state considering these 4 combinations:

- with aeration (the stirrer in the aerobic tank is OFF)

- without aeration (the stirrer in the aerobic tank is $\mathrm{ON}$ )

- $200 \%$ of the internal recycling ratio (Ri) respect to the influent flow rate.

- $400 \%$ of the internal recycling ratio (Ri) respect to the influent flow rate

Simulations in this work have been run in two steps, calculating hydrodynamics and ASM1 separately. Following this, assuming that hydrodynamics in the tanks can be considered constant during the aerobic and the anoxic periods, the innovative swapping approach, which changes hydrodynamics among these 4 combinations, allows calculating kinetics reproducing accurately the fluid behaviour.

Hydrodynamics has been reproduced in detail in two-phase flow for 2 operation modes in steady state:

- Hydro 1: consists of the biological reactor with aeration and $\mathrm{Ri}=400 \%$ (Figure 4.20) where nitrification takes places in the third tank (Fig. 4.22)

- Hydro 2: consists of the biological reactor without aeration and $\mathrm{Ri}=400 \%$ (Figure 4.21) where denitrification takes place in the whole system (Figure 4.23)

Then, the state variables of ASM1 can be calculated dynamically meanwhile HYDRO 1 and HYDRO 2 swaps them alternatively based on Ammonia set point between $[1-4,5]$ ppm calculated at the Outlet (Figure 4.24). 


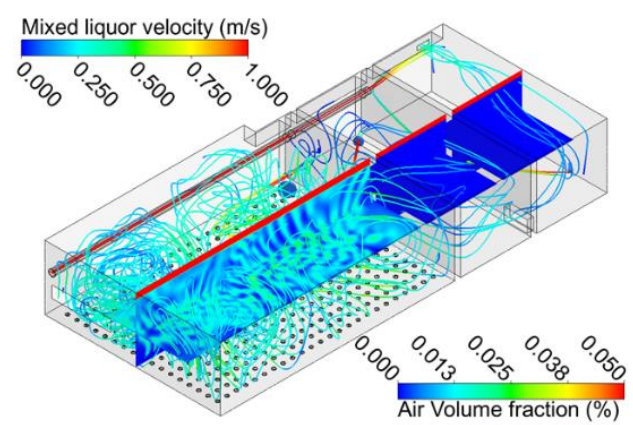

Figure 4.20. Streamlines velocity and void fraction. Configuration of $\mathrm{Ri}=$ $400 \%$ with aeration. Hydrodynamics 1

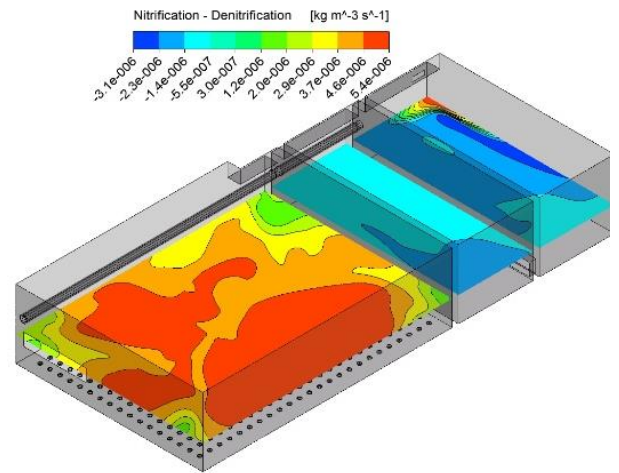

Figure 4.22. Nitrification-denitrification rate with aeration

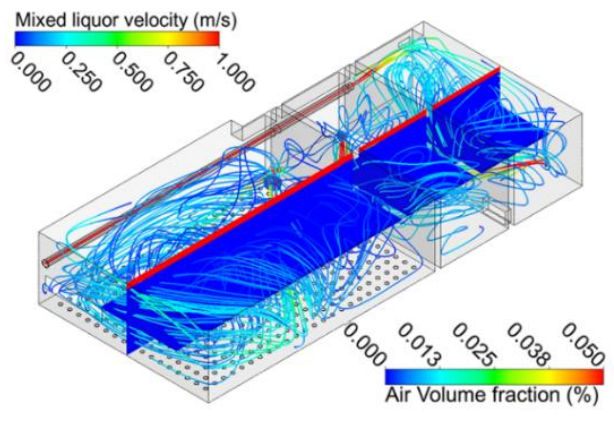

Figure 4.21. Streamlines velocity and void fraction. Configuration of $\mathrm{Ri}=$ $400 \%$ without aeration. Hydrodynamics 2

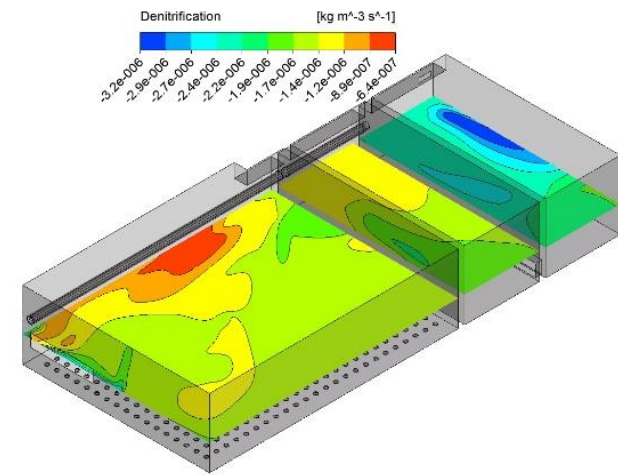

Figure 4.23. Denitrification rate without aeration

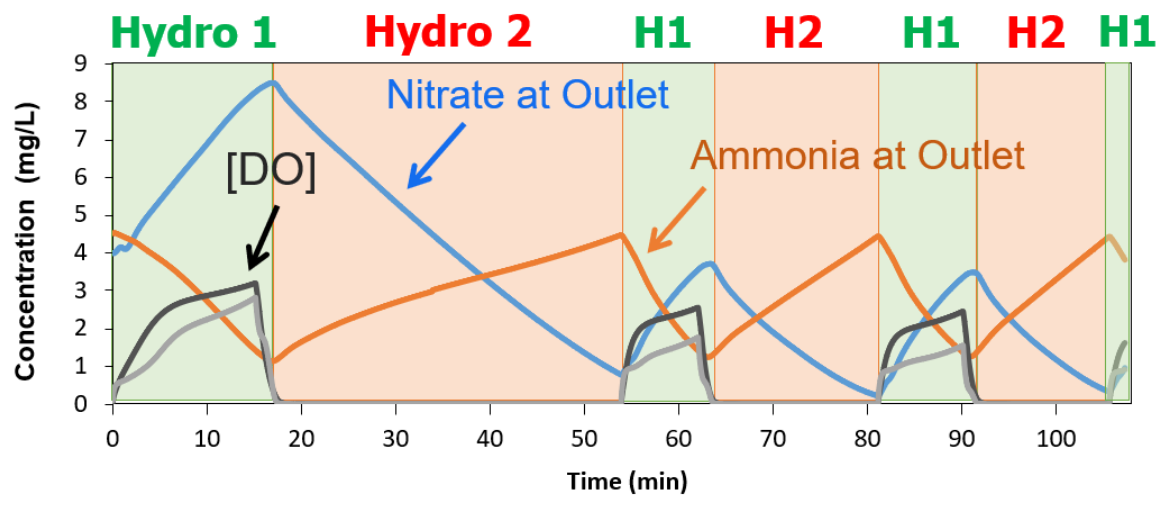

Figure 4.24. Nitrification-denitrification rate with aeration 
Results show the hydrodynamics performance in detail inside the tanks. It allows analysing fluid behaviour in two-phase flow under aerobic and anoxic conditions. Figure 4.25 to 4.27 show the increase of dissolved oxygen concentration in time inside the aerobic tank. Moreover, the distribution of bubble diameter can be calculated.

This paper presents a successful case study based on CFD modelling applied to real WWTP unit process. It shows the CFD as a decision-making tool to support the adjustment of essential control parameters such us the internal recycling ratio.

It must be emphasized the challenge in CFD modelling to develop multiphase flow systems to reproduce phenomena in detail reducing time computing coupled with biokinetic model as ASM.

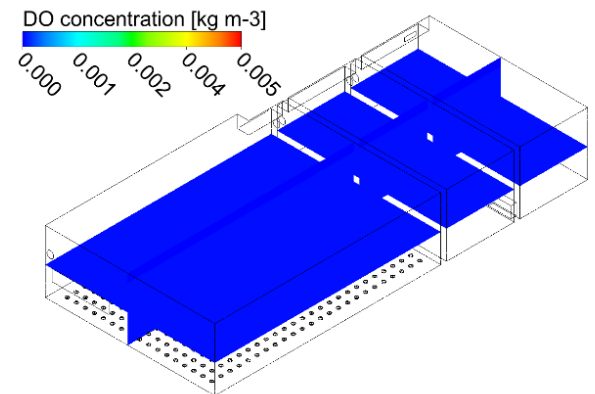

Figure 4.25. DO concentration at $\mathrm{t}=0 \mathrm{~s}$

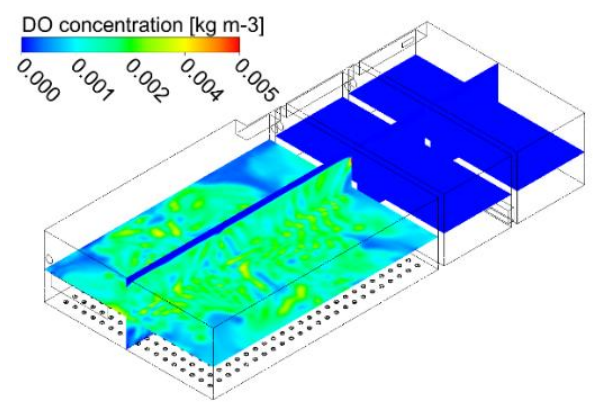

Figure 4.27. DO concentration at $\mathrm{t}=20 \mathrm{~s}$

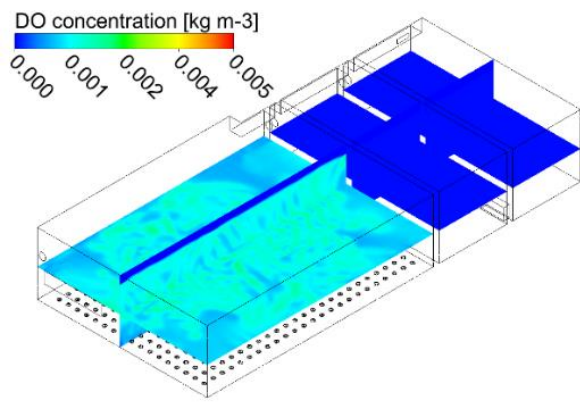

Figure 4.26. $\mathrm{DO}$ concentration at $\mathrm{t}=10 \mathrm{~s}$

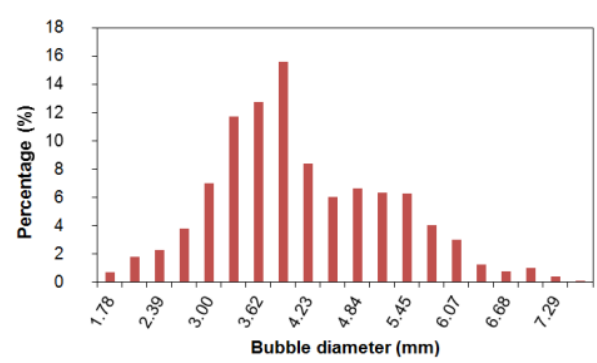

Figure 4.28. Distribution of bubble diameter for the Configuration of $\mathrm{Ri}=$ $400 \%$ with aeration $(\mathrm{t}=20 \mathrm{~s})$ 


\subsection{Orbal configuration}

This study is focused on an Orbal reactor designed to treat an average daily flow of $528 \mathrm{~m}^{3}$. The mean daily recycled flow is $260 \mathrm{~m}^{3}$. This biological reactor is formed by two channels of $1184 \mathrm{~m}^{3}$ and $705 \mathrm{~m}^{3}$, both of $4.75 \mathrm{~m}$ wide and $3 \mathrm{~m}$ height (Figure 4.29). The aeration system is provided by horizontal rotator disks. Hence, the energy used for aeration is enough to provide mixing in a system with a relatively long hydraulic time. When the WWTP operates in continuous regime limiting the aeration rate, nitrification and denitrification process is carried out.

It is possible to study hydrodynamics inside the tank comparing several forms of operation process depending on aeration system and pollutant loads. It will be determined nitrification/denitrification zones around the two channels.
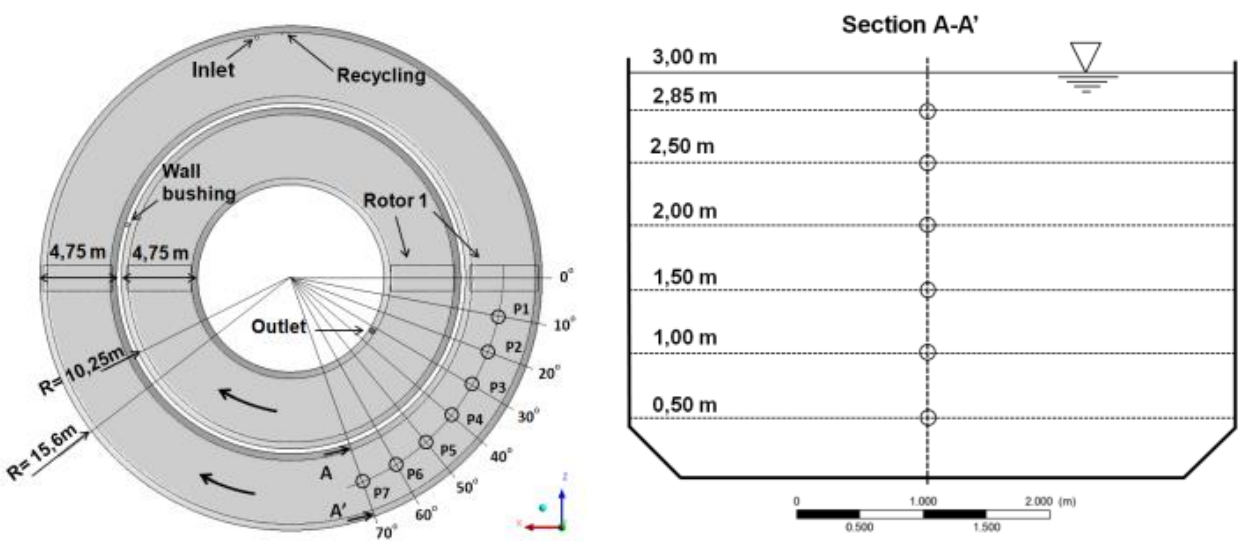

Figure 4.29. Description of the orbal oxidation ditch (left), and experimental data measurement points (right)

\subsubsection{Hydrodynamic analysis using CFD Modelling}

Both rotors were run at $35 \mathrm{rpm}$ resulting higher velocities around $0.40(\mathrm{~m} / \mathrm{s})$. In both cases, circular flow is achieved inside the channels being velocities at inner slightly higher than outer channel, (see figure 4.30). Moreover, more homogeneous flux is reached when two rotors are running. On the other hand, CFD model was validated by means of:

- Tracer tests: to validate the global hydrodynamic behaviour in the tank

- Velocity measurements: to characterize the rotors with local data

- ASM1 model: DO and physic-chemical measurements 

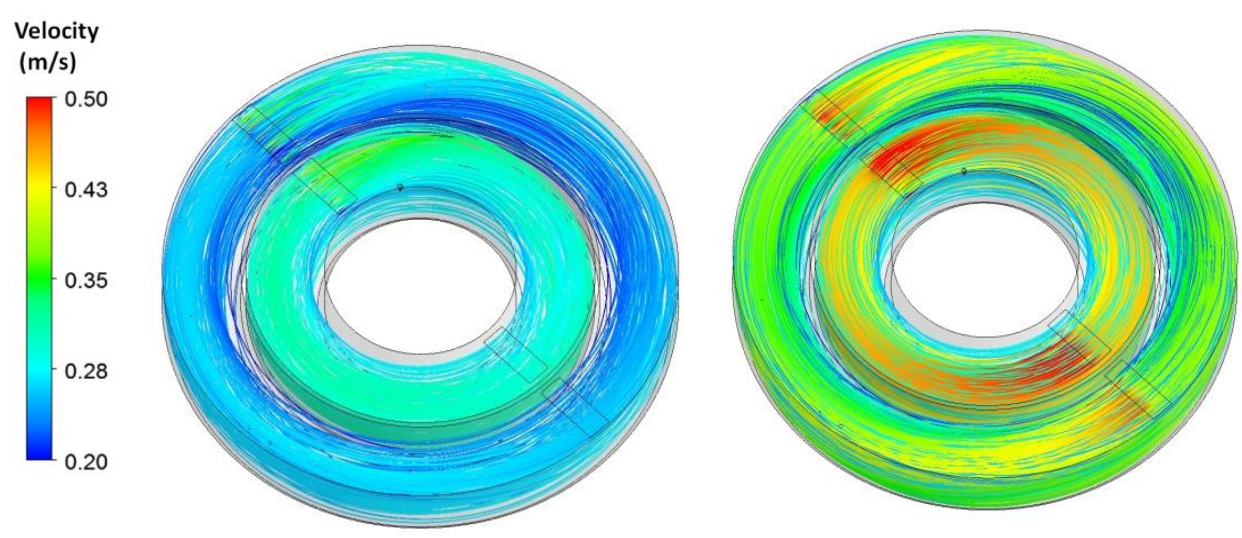

Figure 4.30. Streamlines with one rotor (left) and two rotors (right)

\subsubsection{Tracer tests and velocity measurements}

Velocity profiles were measured at seven points at six different heights from the rotor 1 (see Figure 4.29) in order validate the CFD model results by comparing velocity calculated with experimental data at the specific locations, given by the Vectrino. Figure 4.31 shows the velocity profile measured at position 2 from $0.25 \mathrm{~m}$ to $2.85 \mathrm{~m}$ height. CFD model matches quite good the velocity distribution as a function of the height.

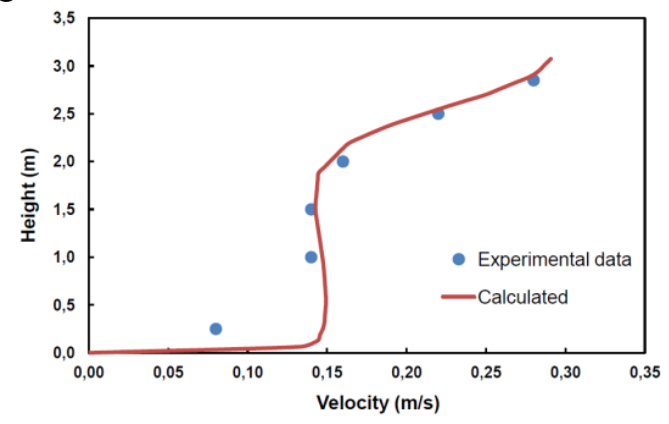

Figure 4.31. Velocity profile at position 2

On the other hand, tracer tests were performed. Both $\mathrm{E}(\mathrm{t})$ curves were represented and analysed, figures 4.32 and 4.33. As a result of that, high mean residence time of 3,02 days was obtained for the complete reactor. Moreover, it was possible to calculate mean residence time of each channel separately (Zhang et al, 2007), expression (3). It was calculated a mean residence time of 1.73 day for the outer channel. 


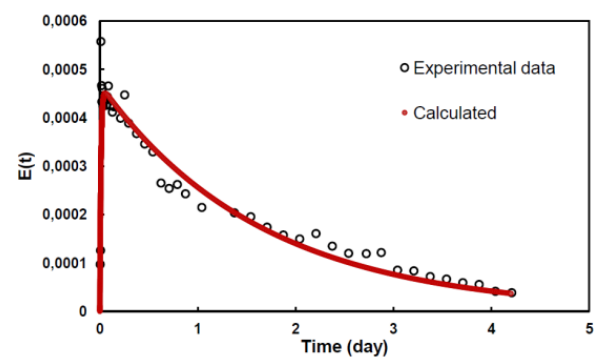

Figure 4.32. RTD at Point 1

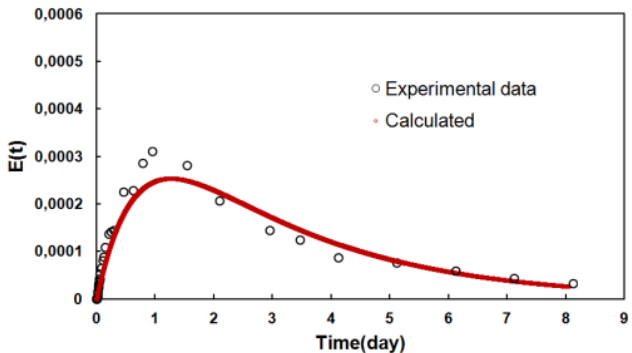

Figure 4.33. RTD at Point 2

As we can see at figure 4.32 and 4.33 , CFD model reproduces correctly the experimental data obtained. There is a low initial short-circuiting detected in experimental data that can be consequence of the process due to the two aerators work alternatively. In this way, reactor hydrodynamics is equivalent to 1.3 continuous stirred tank in series, even if its behaviour was a plug flow inside of each channel (Byung et al. 2004).

\subsubsection{Validation of the CFD-ASM model}

In terms of DO concentration, CFD results allow to reproduce the trend and distribution in a good way. Results are shown in figures 4.34 and 4.35, where basic characteristics are noted: higher concentration in a surface layer $(2.85 \mathrm{~m}$ height $)$ than those that are below; also, they tend to decrease the further from rotor they are (Guo, 2013). In addition, it is worth to notice that there is virtually no DO under $1,5 \mathrm{~m}$ height.

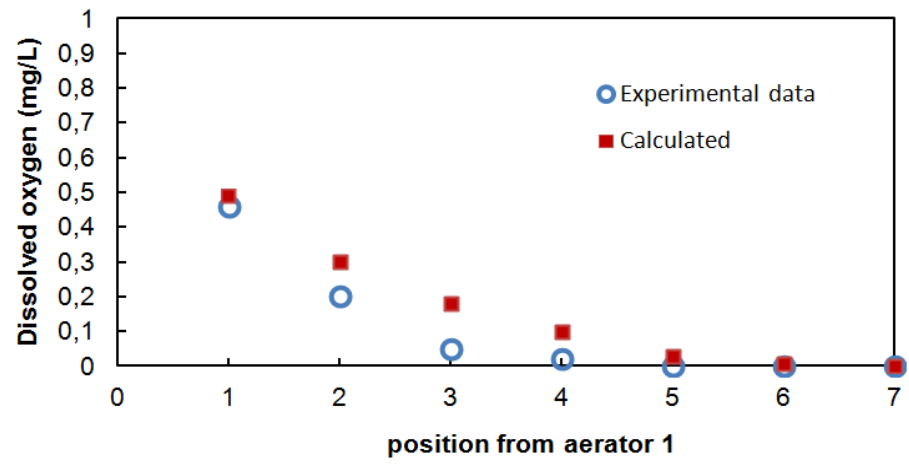

Figure 4.34. Dissolved oxygen concentration distribution at different positions 


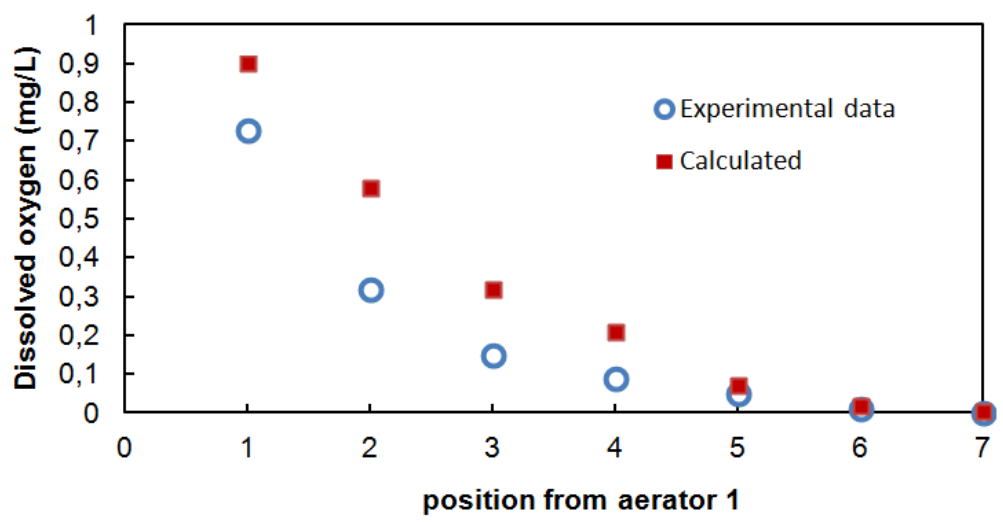

Figure 4.35. Dissolved oxygen concentration distributions at $2.85 \mathrm{~m}$ height (left) and $2.50 \mathrm{~m}$ height (right)

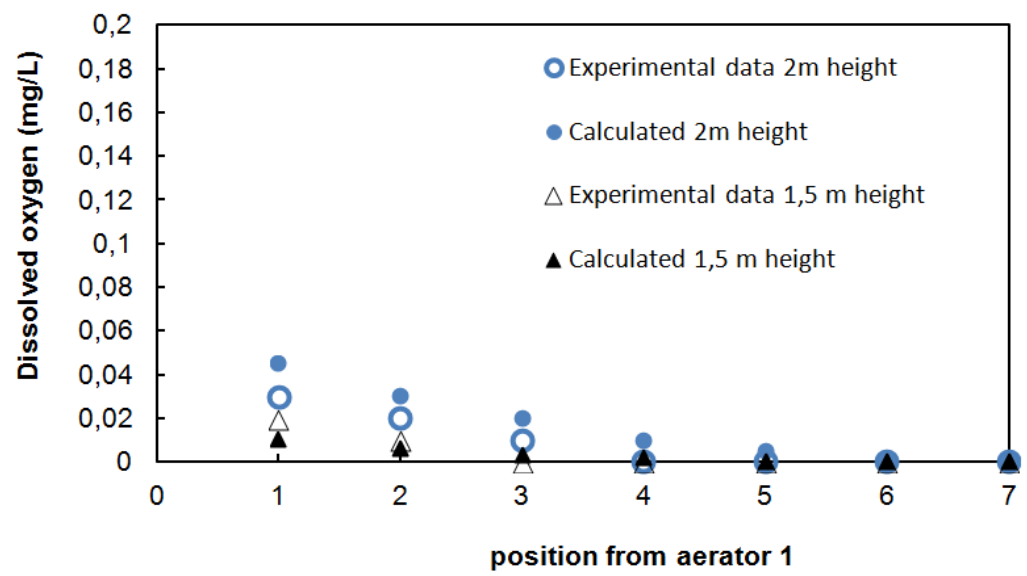

Figure 4.36. Dissolved oxygen concentration distributions at $2 \mathrm{~m}$ and $1.5 \mathrm{~m}$ height.

Aerobic and anoxic zones inside the Orbal biological reactor were calculated in steady state determining different percentages of aerobic volume depending on the configuration. Consequently, DO is considered the main variable which determines nitrification and denitrification process due to there is limiting oxygen conditions in the tank. When flow passes through the aerators, DO increases dramatically and then, it decreases rapidly as it moves forward the channel (Figure 4.37). 

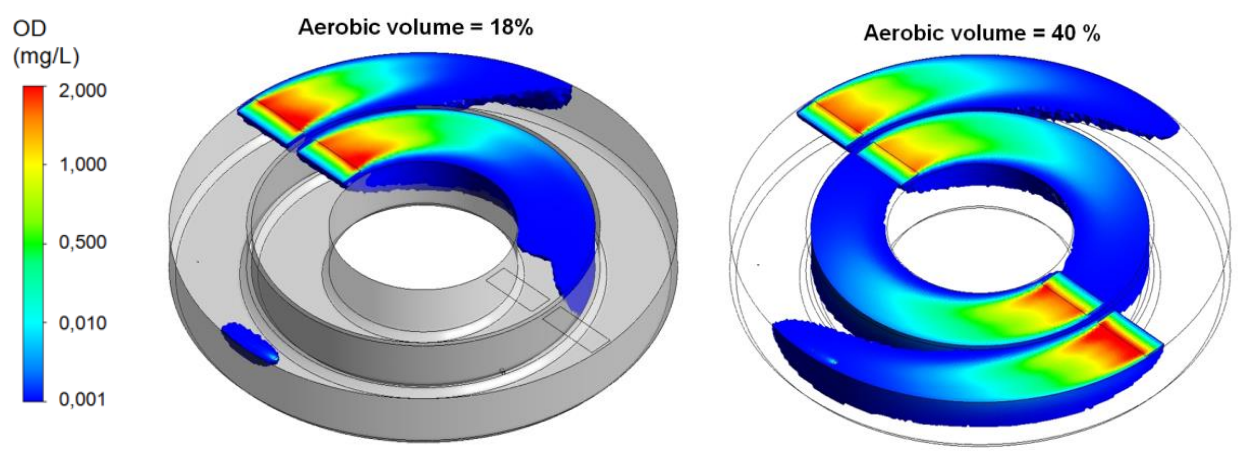

Figure 4.37. Dissolved oxygen and percentage of aerobic volume for one rotor (left) and two rotor (right)

Finally, it was studied the COD, ammonia and nitrates removal in order to predict the water quality. Inlet conditions were selected following experimental data measured: $350(\mathrm{mg} / \mathrm{L})$ of COD, $30(\mathrm{mg} / \mathrm{L})$ of ammonia and $0(\mathrm{mg} / \mathrm{L})$ of nitrate. It was calculated a steady simulation to reproduce the global behaviour of the variables from an actual inlet (Nelson, 2009) and using the parameter values based on those given by (Henze et al., 2000). Several chemical analyses at five measuring points were carried out in both channels and were compared with those calculated. The 5 points (P1, P2, P3, P4 and P5) are sorted following the flow stream.
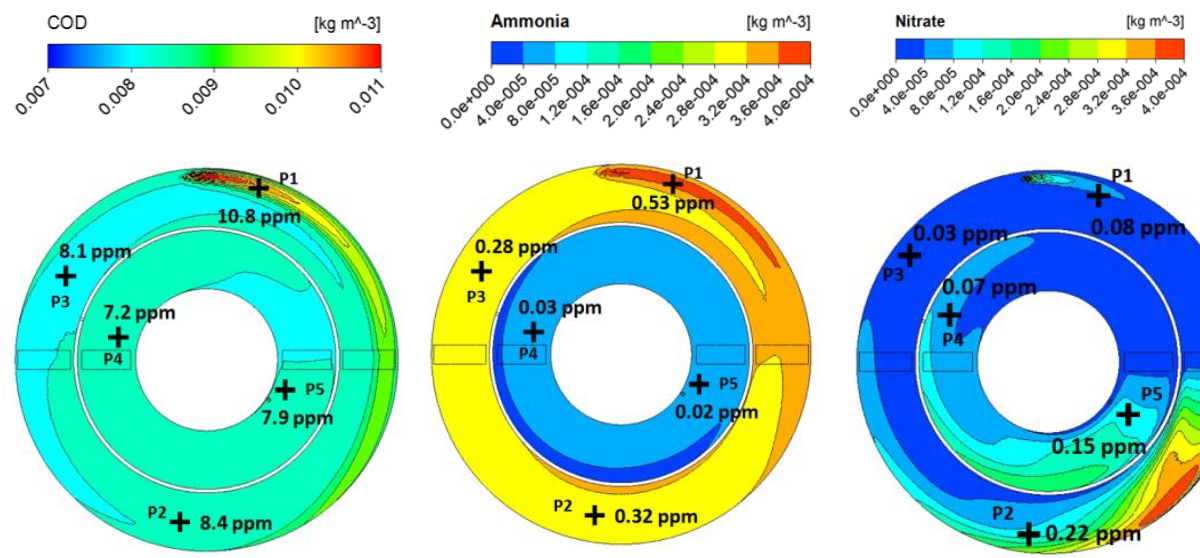

Figure 4.38. COD, Ammonia and nitrates distribution calculated 
The calculated values are shown in figure 4.38 and are compared with experimental data in figure 4.39. In this way, proposed CFD model provides COD and ammonia results in good agreement with experimental data. However, there is a "poor" estimation of nitrates (Sno). Hence, nitrate concentration is very dependent on autotrophic biomass (Xba) which was estimated as $8 \%$ of total biomass. Moreover, kinetic parameters should be obtained experimentally in order to achieve accuracy on the yield of the autotrophic biomass and nitrification rate.
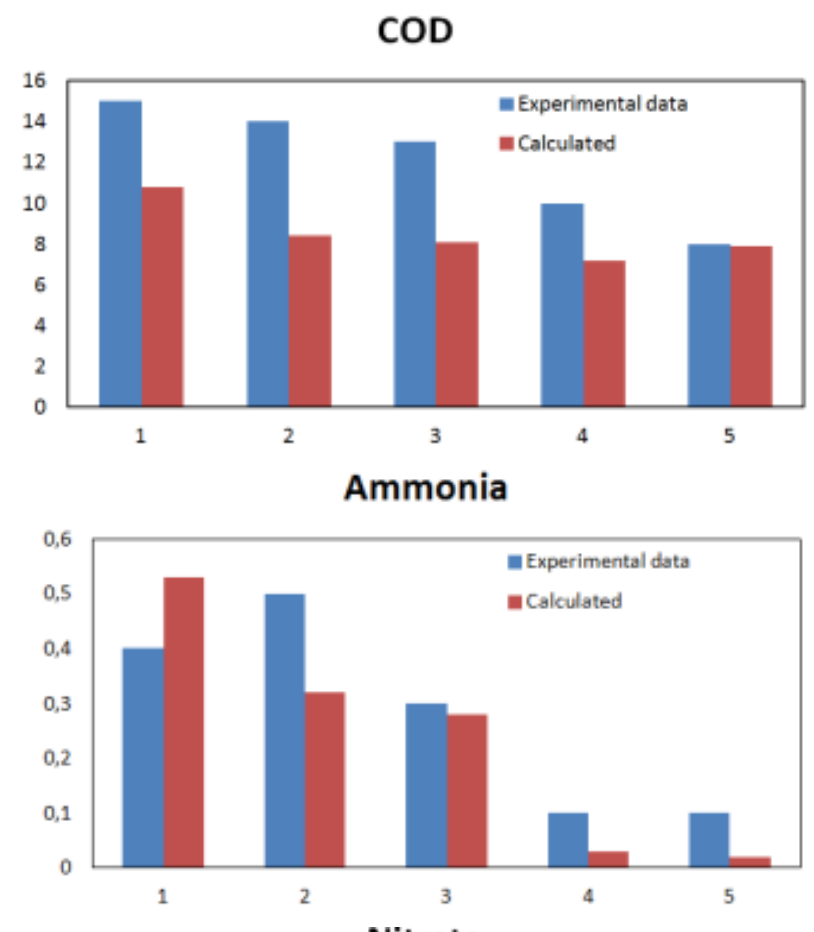

Nitrate

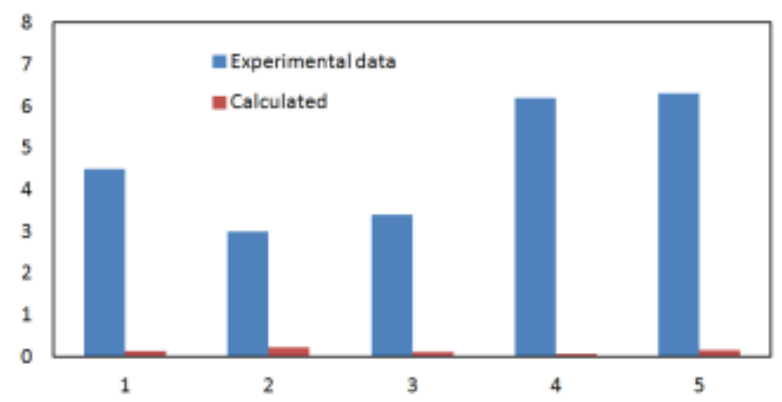

Figure 4.39. Comparison of COD, ammonia and nitrates 
In the present work we made a maximum use of the potential of CFD to reproduce the detailed hydrodynamic behaviour of the studied tank, for the purpose of implementing the biological reactions from ASM models, in order to characterize the biochemical behaviour. An Orbal oxidation ditch was taken as scenario to check capabilities of this modelling tool. Previously, a field study was carried out in order to have experimental data to test and calibrate the model. It was necessary to study hydrodynamics effect caused by horizontal contactor disks, the aeration system.

Moreover, tracer studies were carried out in order to validate hydrodynamics. The main parameters of the CFD model were tested, and an assessment process was followed in order to be confidence with the CFD hydrodynamic results, regarding to the experimental data. Mean residence time was calculated in both channels resulting in good agreement with experimental data; also, the velocity distribution matches quite good with the experimental results. The completed set of ASM1 model equations was implemented in the CFD code as transport equations, including a convective term and neglecting the diffusion process. The new set of differential equations could be solved at each time step if necessary, taking into account the hydraulic behaviour. This new capability of the CFD, the biochemical parameters modelled through the introduction of ASM1 model, were tested. Oxygen consumption was performed, so that, it allows determining anoxic and aerobic zones around the tank which determines the efficiency of the process. Thus, an Orbal reactor was performed where nitrification and denitrification take place in both reactors due to limiting dissolved oxygen concentration rates. ASM1 variables were calculated in order to obtain water quality. Hence, the COD and ammonia variables present good results in relation to experimental data; however, there is a "poor" estimation of nitrates. It may be corrected with a good estimation of parameters involving autotrophic biomass (Xba). 


\subsection{Oxidation ditch configuration}

\subsubsection{Hydrodynamic analysis using CFD}

Figure 4.40 shows the velocity field within the tank by means of the streamlines. In general, a more homogeneous fluid velocity distribution and a higher average fluid velocity resulted for the configuration without air. Even so, the maximum fluid velocity corresponded to the regions over the diffuser grids for the configuration with air, specifically, the region placed at the top and located immediately behind the third grid following the fluid direction at the outer channel. In both cases, the lowest velocity zones took place in the inner channels.
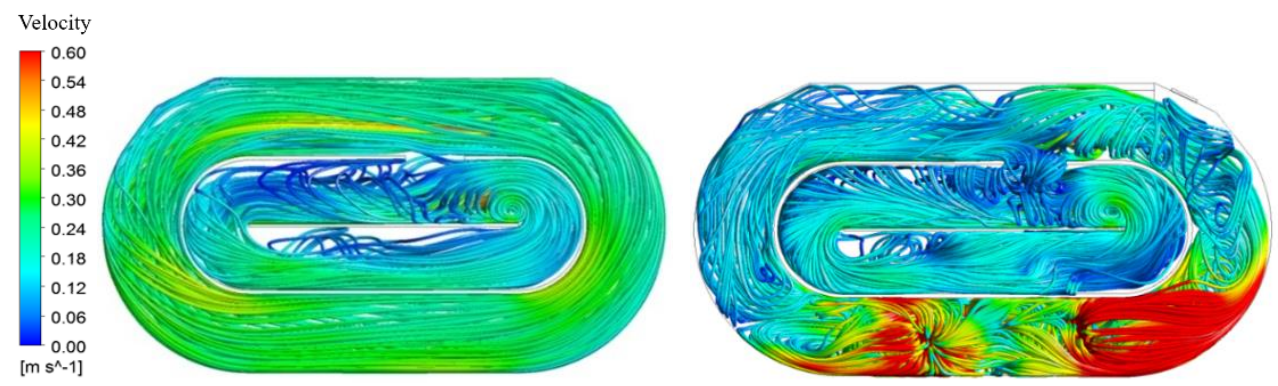

Figure 4.40. Velocity of the streamlines without air (left) and with air (right)

This was caused by the faulty positioning of the propeller, placed too close to the internal curved wall. Thus, the curved wall guided the current round, which cannot be impelled perpendicularly by the internal propeller, deflecting the plume driven by the propeller. Consequently, a considerable reflux was introduced from the outer to the inner channel through the channel spacing, causing the malfunctioning of the inner channel. This can be appreciated in Figure 4.41. It shows the velocity field contours plotted at five different height cross sections. Comparing the effect of the plumes induced by the propellers at the $1.5 \mathrm{~m}$ and the $2.5 \mathrm{~m}$ high velocity contours, the external propeller exhibited a favourable performance while the internal propeller did not operate as expected. As described previously, its plume was altered, and the flux was guided to the centre wall, generating regions with slow internal circulation of the flux and recirculation effect. This can be appreciated by the direction of some vectors plotted over the low velocity regions. For the case with air, the velocity field was more inhomogeneous, especially after the grids in the direction of the fluid flow, which was mainly influenced by the air injection. Thus, the leading role of the external propeller over the hydrodynamics in the outer channel decreased considerably. The air injected generates a convective cell of fluid, providing the maximum fluid velocity over the diffusers and contributing notably in the reduction of the average axial fluid velocity along the outer channel. 
Moreover, the convective cell generates an appreciable recirculation flow effect in the curved region after the diffuser grids, over the full height, reinforced by the effect of the fluid meeting the external curved wall at maximum velocity.
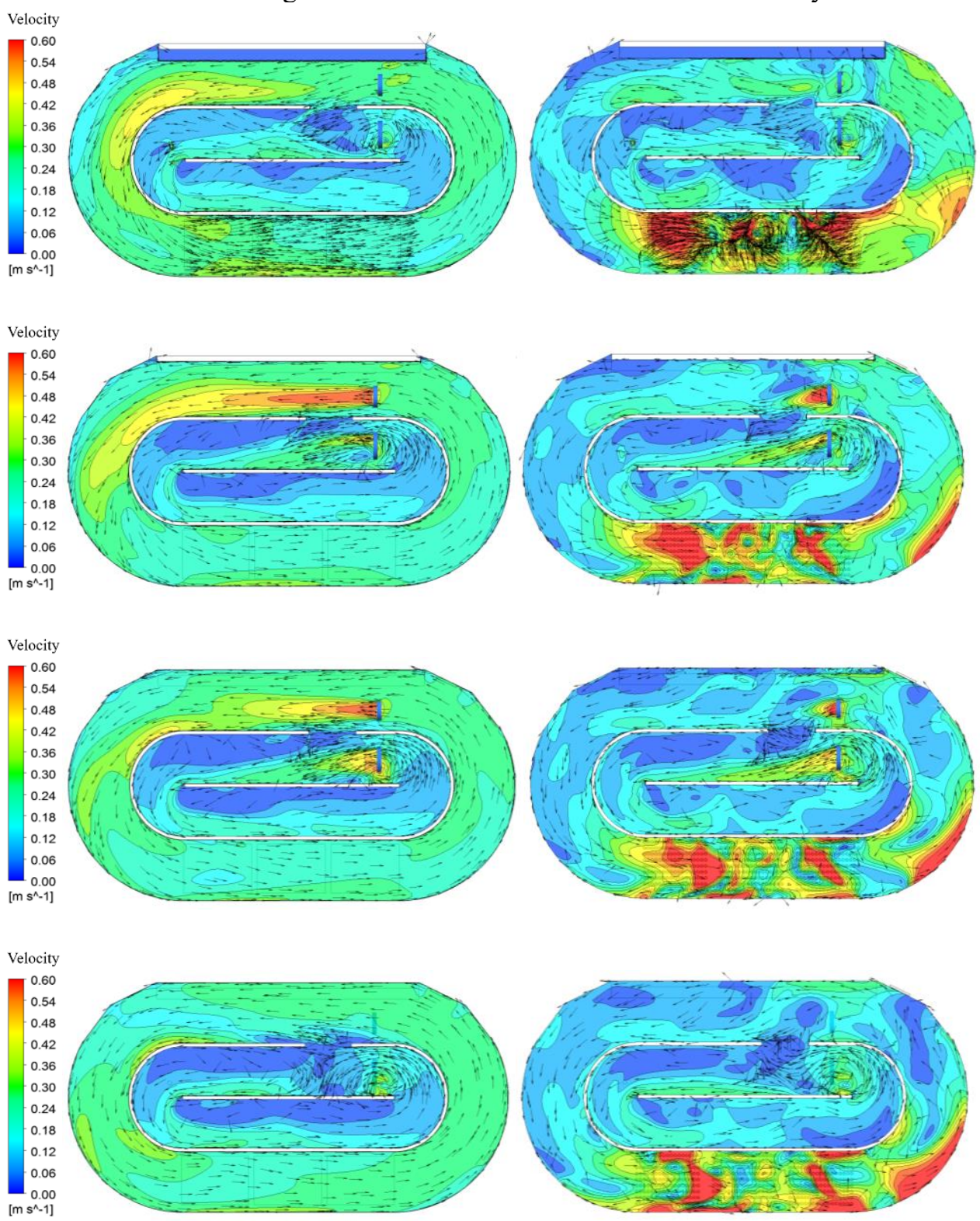


\subsection{Oxidation ditch configuration}

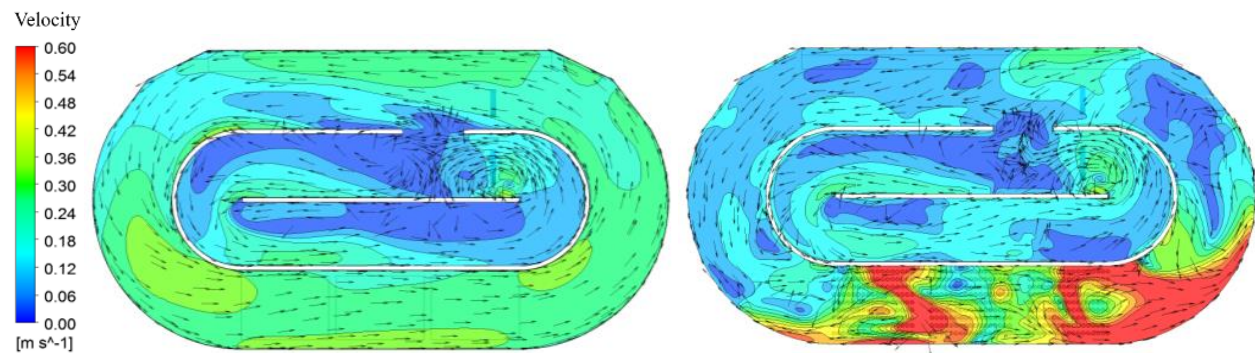

Figure 4.41. Velocity contour at $0.5 \mathrm{~m}, 1.5 \mathrm{~m}, 2.5 \mathrm{~m}, 3.5 \mathrm{~m}$ and $4.5 \mathrm{~m}$ high (from top to bottom) without air (left) and with air (right)

Figure 4.42 shows the five vertical fluid velocity profiles (P1, P2, P3, P4 and P5) selected to explain graphically the functioning of the hydrodynamics around the outer channel together with figure 4.41 .
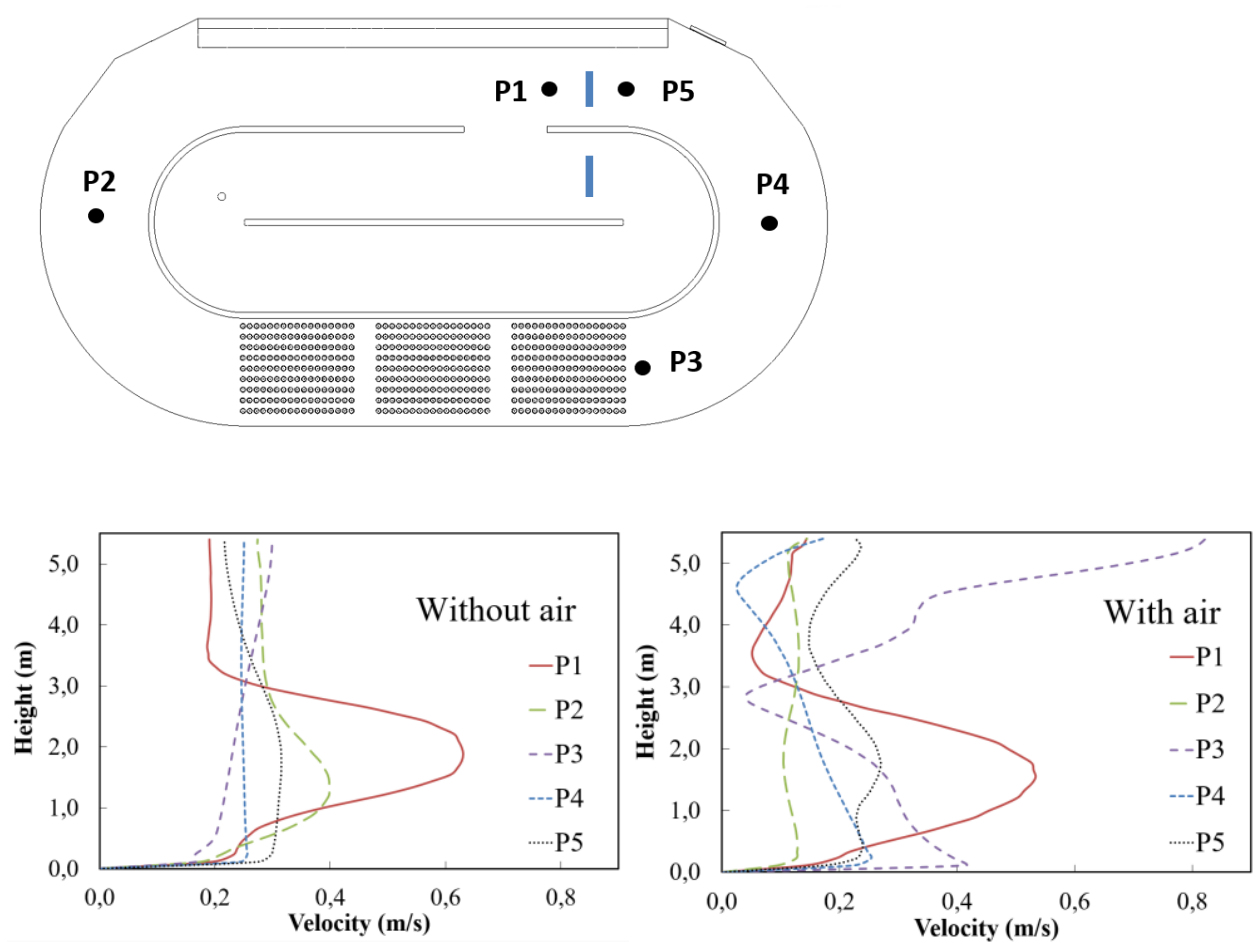

Figure 4.42. Vertical velocity profiles around the outer channel (P1 - P5) without and with air 
As shown, they were positioned in the centre of the outer channel and distributed along the direction of the current flow from the external propeller. Importantly, for a given vertical section of the outer channel (5.54 m wide and $5.4 \mathrm{~m}$ high), the vertical fluid velocity profile changes in $3 \mathrm{D}$ across the width as will be shown in sections 3.2.2 and 3.2.3. That said, the five fluid velocity profiles corresponded to the modulus of the fluid velocity; they were considered enough representative of their sections to carry out the following flow analysis. Figure 4.42 shows the flow pattern along the channel. For the case without air, the closer the fluid was to the propeller, the more pronounced was the vertical fluid velocity profile. Thus, P1 showed the maximum velocity values around $2 \mathrm{~m}$ high, where the external propeller was located. Since the flowrate is conservative along the outer channel and the section is constant, the fluid velocity profile must be balanced inside each section. According to this, at the top, P1 also presents the minimum fluid velocity values. Subsequently, the velocity profiles flatten as they move away from the external propeller. Thus, $\mathrm{P} 4$ exhibited a total flat vertical velocity profile while the suction effect of the propeller was appreciated through P5, located behind it. As expected from figure 4.41 , figure 4.42 showed a more inhomogeneous vertical velocity profiles for the case with air, where $\mathrm{P} 3$ presented the maximum velocity values at the top and P1 was less pronounced compared to the case without air.

The average flowrate through the outer channel was evaluated at five sections corresponding to P1 - P5 (Fig. 4.42). The same value resulted for each section, with an error less than $0.25 \%$, validating the conservation of the mass. Comparing both cases simulated, without and with air, the average velocity calculated was $0.249 \mathrm{~m} / \mathrm{s}$ and $0.098 \mathrm{~m} / \mathrm{s}$ correspondingly. Hence, the average flowrate circulating inside the outer channel reduced by $60 \%$ when the aeration was supplied. Furthermore, it is important to highlight that the hydraulic influence of the influent over the internal fluid behaviour can be neglected since the influent flowrate entering the tank was compared with the flowrate circulating internally in the channel, representing less than $1 \%$.

\subsubsection{Velocity measurements in single-phase}

Figure 4.43 shows the experimental measurements performed to validate the singlephase simulations. It shows the ( $\mathrm{x}, \mathrm{y}$ and $\mathrm{z})$ velocity components compared to the CFD simulation results. The figure includes the graphical scheme in the $\mathrm{X}, \mathrm{Y}$ plan view and the legend of the velocity components. The 14 positions of the measuring points were spread all over covering each of the critical zones of the tank and the width dimension of the channel. Thus, 3 different heights were measured in each position which gives a total of 42 measurements. The left axis of the figures shows the height (m) from the bottom to the top, which corresponds to the $\mathrm{Z}$ axis. 

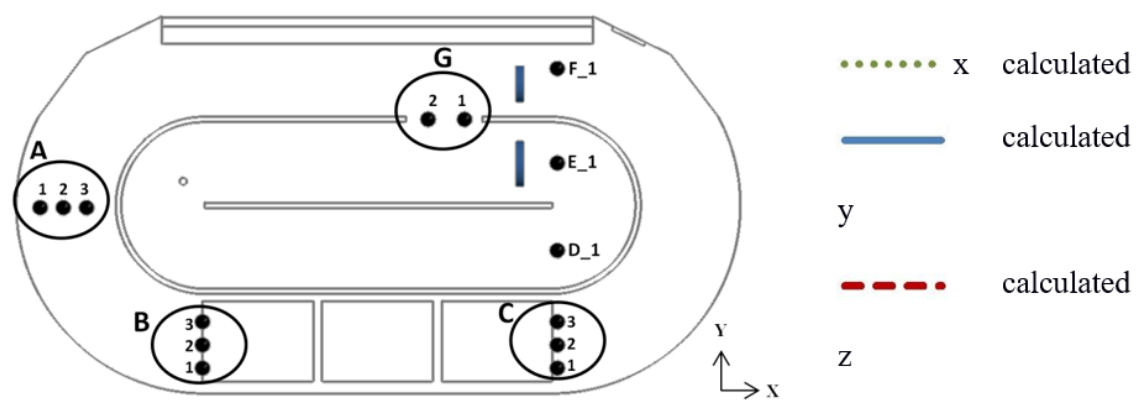
$\Delta \quad \mathrm{x}$ experimental
- y experimental
ㅁ $\mathrm{z}$ experimental
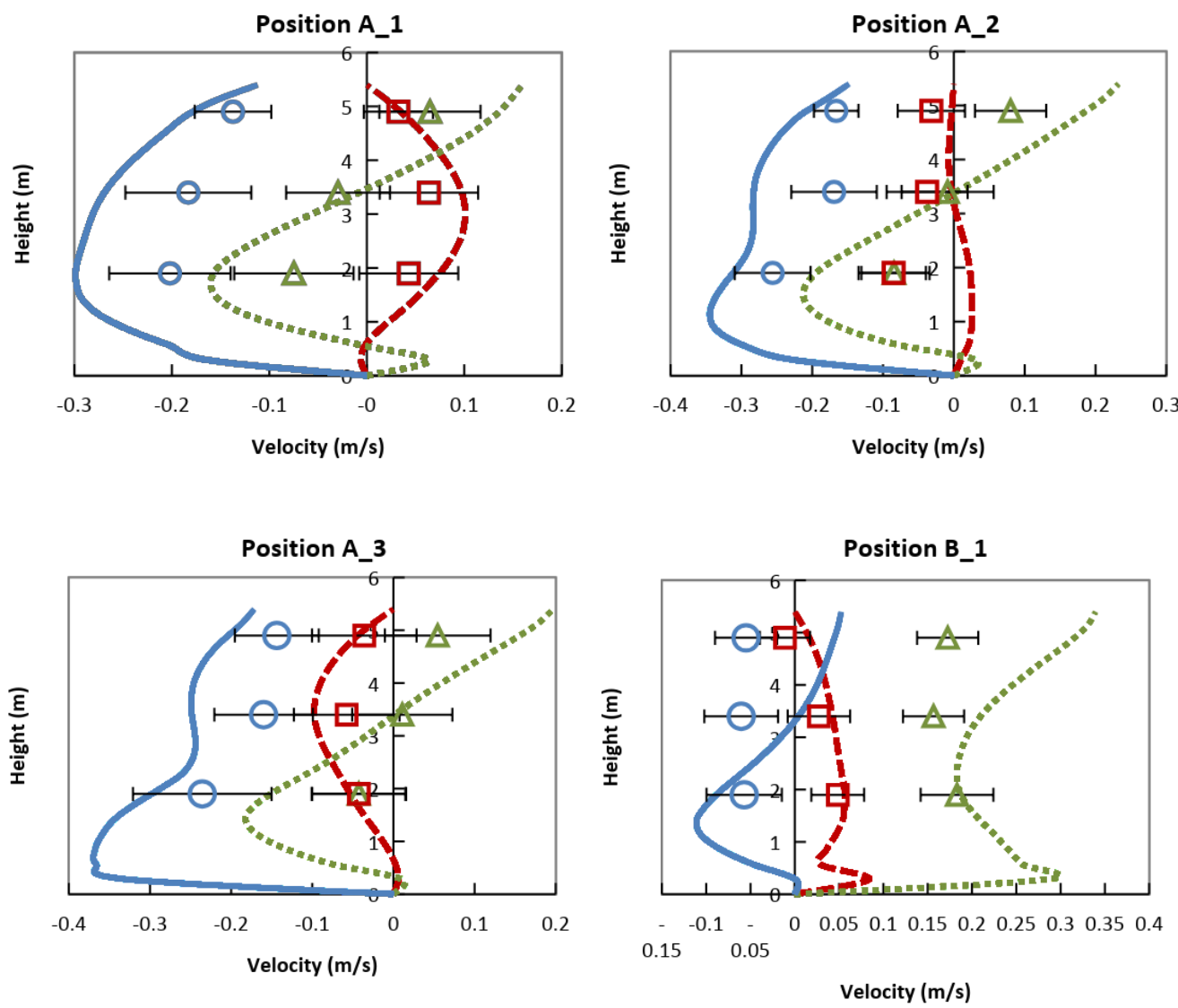

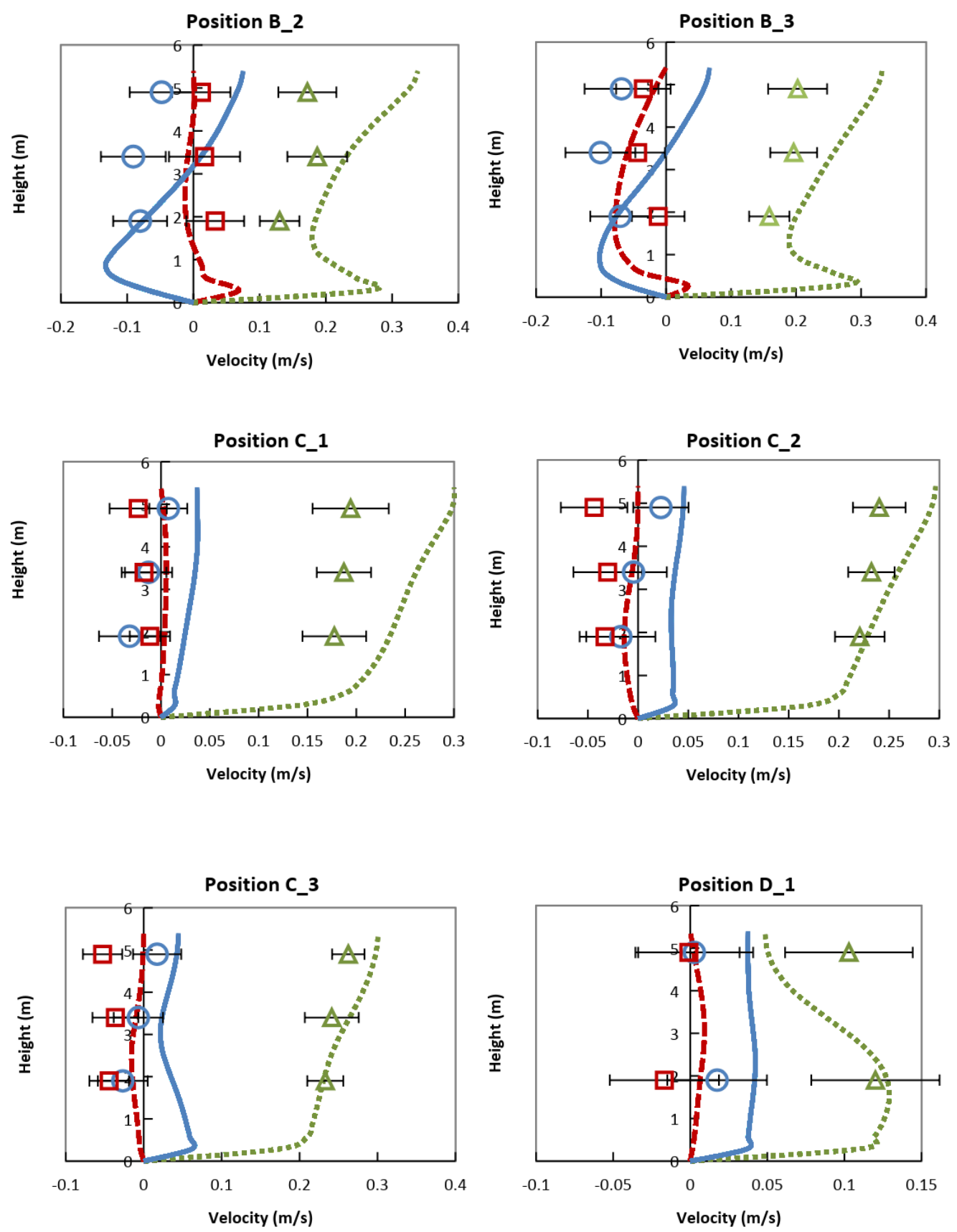

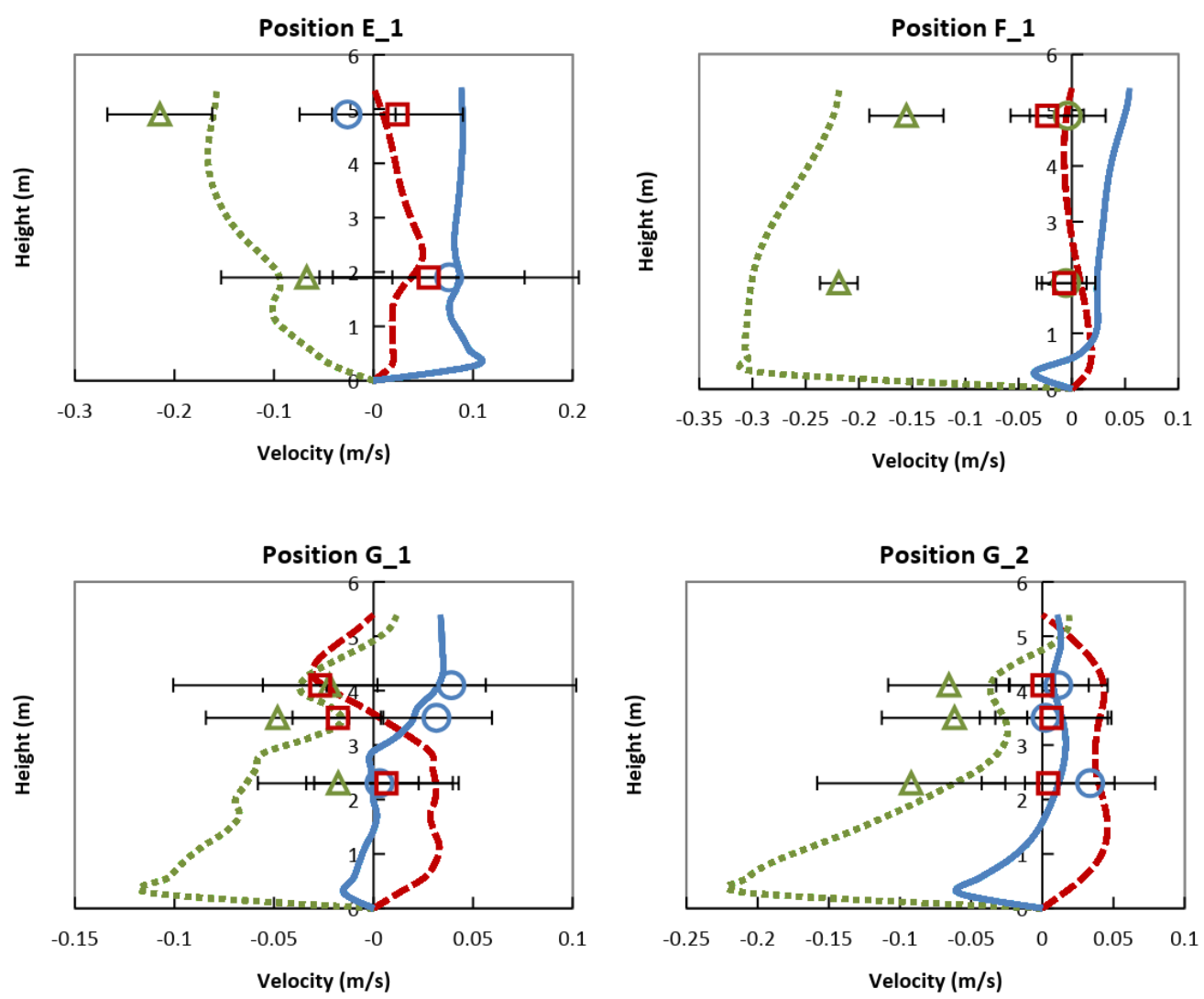

Figure 4.43. Comparison of the fluid velocity components calculated and measured without air.

The distribution of the fluid velocity components for the single-phase model depended considerably on the geometry of the tank and as previously analysed, on the relative distance of the position from the propellers. Thus, the 3 positions located in A and B presented the velocity components distributed in the directions $\mathrm{X}$ and $\mathrm{Y}$ due to the influence of the curved wall of the tank. Hence, Position $\mathrm{A}$ showed the maximum velocity values in $\mathrm{Y}$ while position $\mathrm{B}$ in $\mathrm{X}$. In both positions, the fluid velocity profiles are more pronounced at $2 \mathrm{~m}$ height where the propeller is located. Conversely, position $\mathrm{C}$ presented only one velocity component as the predominant, in theX direction, due to the straighter layout of the cannel which influences the flow stream. As previously explained, the suction effect of the propeller can be appreciated in position $\mathrm{F}$ comparing the velocity component in $\mathrm{X}$ to the position $\mathrm{C}$. Although the diameter of the internal propeller is higher, and the section of the inner channel is lower than the outer channel, the experimental 
measurements performed in the positions $\mathrm{D}$ and $\mathrm{E}$ reveals lower fluid velocity. It was reproduced with high accuracy by the CFD model. Finally, it is important to highlight the difficulty of performing the velocity measurements in position $G$ and to describe the fluid behaviour in 3D through the channel spacing.

It can be said that the CFD model performs to a satisfactory degree in each of the velocity components. Nevertheless, we note that the calibration procedure led to an average over-prediction of flow velocities about $25 \%$, i.e. the momentum source should be smaller, so further improvements need to be done in the modelling of impellers as volumetric sources to make the model more general.

\subsubsection{Velocity measurements in two-phase flow}

As in the previous section, figure 4.44 shows the experimental measurements with air performed in 7 positions to validate the two-phase CFD simulations. Following the same procedure of the single-phase measurements, 3 different heights were evaluated which gave a total of 21 measurements. It was also included a graphical scheme in the X, Y plan view and the legend of the velocity components. The left axis of the figures shows the height $(\mathrm{m})$ from the bottom to the top, which corresponds to the $\mathrm{Z}$ axis.

The plumes of air increase the free surface height which induces the acceleration of the flux at the top and causes the recirculation of the current flow before the grid zone. The backflow was observed along the free surface. Position B showed a marked profile of velocity component $\mathrm{X}$, which changed drastically from negative values at the top to positive velocity values at the bottom. Conversely, position $\mathrm{C}$ showed high values of the $\mathrm{x}$ component in the direction of the current flow at the top, and negative values at the bottom, caused by the convective cell induced by the raising bubble columns.
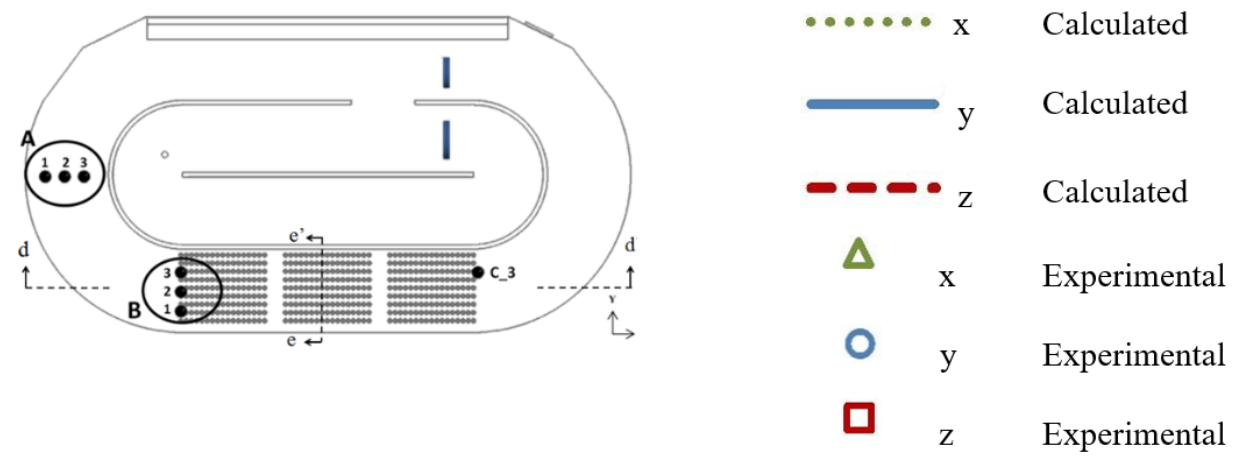

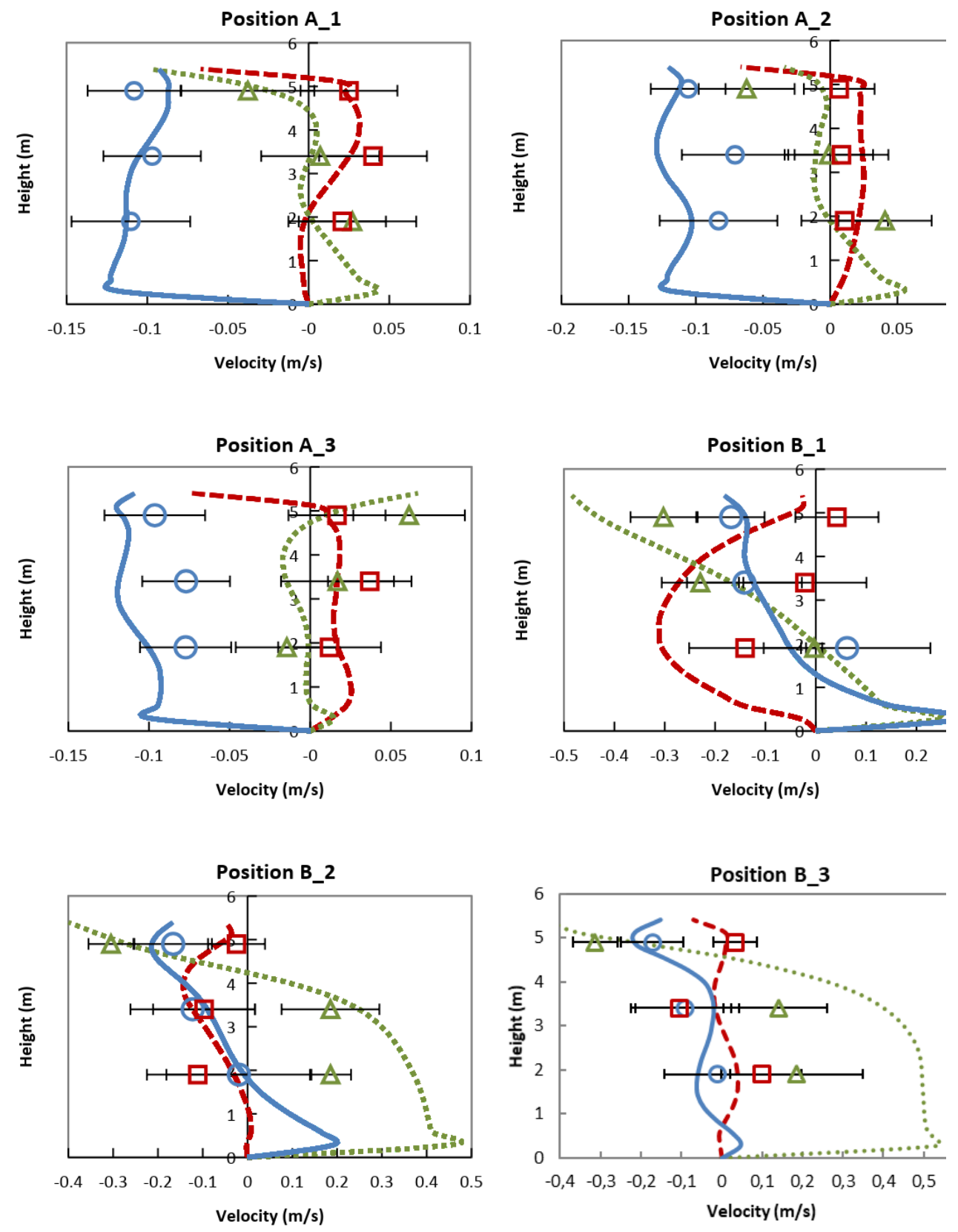


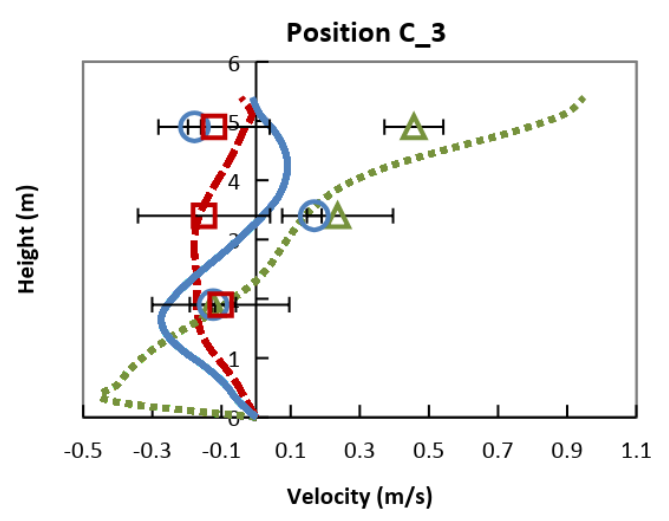

Figure 4.44. Comparison of fluid velocity components calculated and measured with air.

\subsubsection{Two-phase flow performance using PBM}

The three main plumes of air bubbles, corresponding to the three diffusers grids, showed good stability for the steady state calculation. Once achieved a certain height, they merged into one due to the layout of the grids which maintain them close enough to produce this phenomenon.

Moreover, the free surface approach used, allowed the increase of the mixed liquor level to be analysed. This contributed to induce the convective flux cell: a backflow in the first half region over the grids, and an increase of the flux velocity in the second half part alongside the free surface. Figure 4.45 shows also the vortex core regions displaying the turbulent structures over the mixed liquor beyond the grid region.

To analyse the results from the PBM, one must distinguish between the hold-up provided by the dispersed phase, $\alpha_{g}$, and the i-th group hold-up provided, $\alpha_{i}$, defined as $\alpha_{i}=s_{i} \alpha_{g}$, being the size fraction of the i-th group. As the sum of the size fractions for all the groups must sum unity, the sum of the group hold-ups must equal the hold-up. 

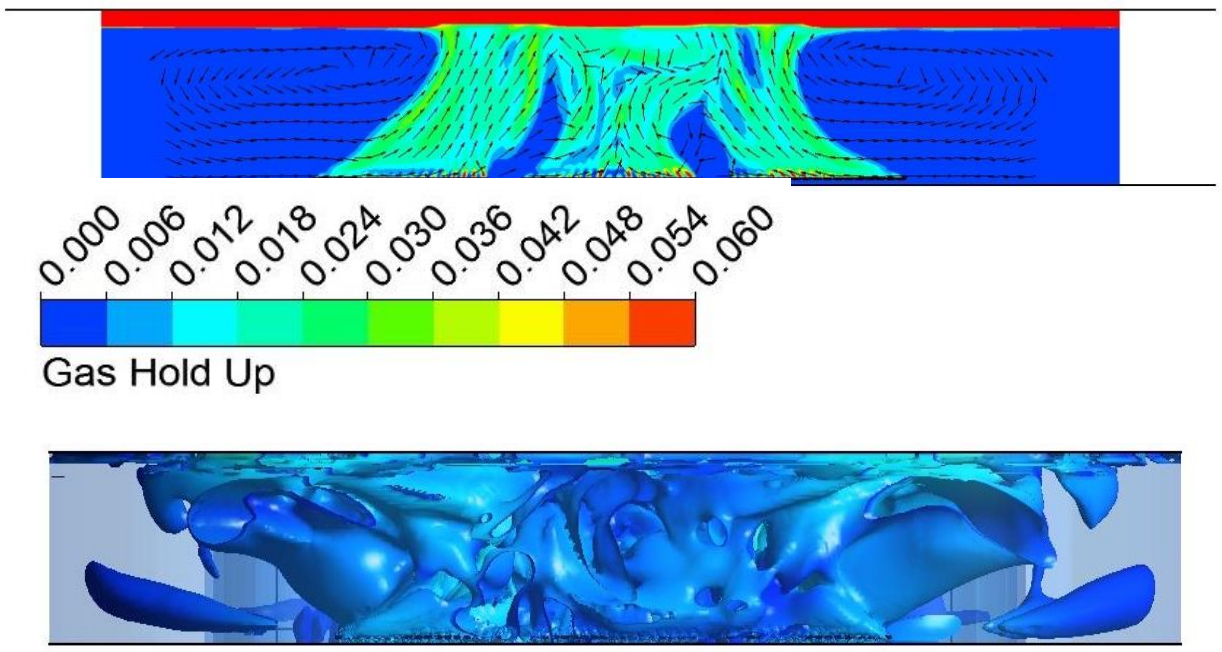

Figure 4.45. Contour of gas hold-up air bubble plumes (above) and the vortex core regions in 3D (below) both plotted in section d-d' (figure 4.44).
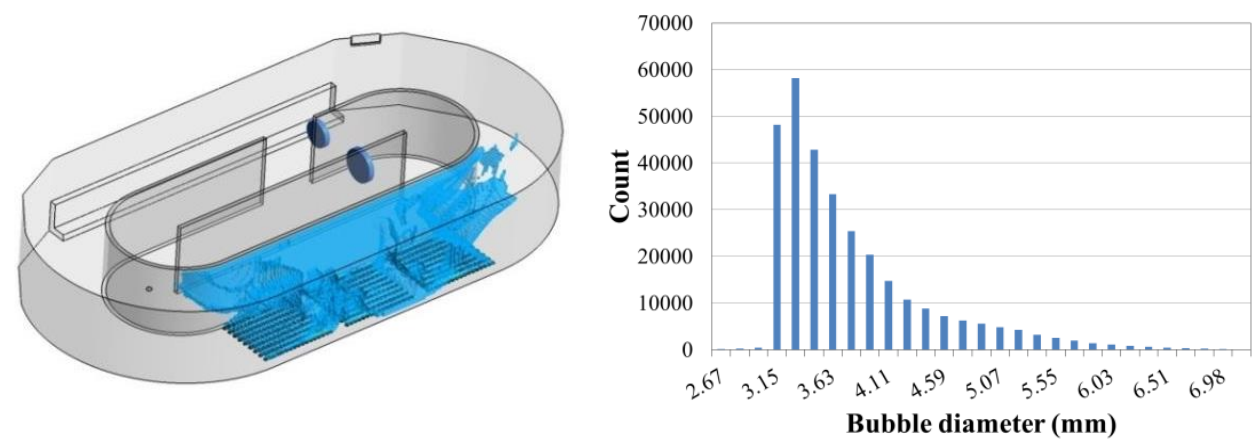

Figure 4.46. Isovolume of all the groups of bubbles (left) and its bubble size distribution (right)

We start the analysis by isolating the volume in the domain where the hold-up exceeds $0.05 \%$ for all the groups (Fig. 4.46). The histogram in figure 4.46 shows the diameter distribution of the bubbles in this region. The effects of bubble coalescence can be clearly noticed given that diameters lower than $3 \mathrm{~mm}$ (size of the injected 
bubbles) can be neglected. Also, note that bubbles with diameters between 3 and 4 $\mathrm{mm}$ represented $75 \%$ of the volume while bubble diameters greater than $4 \mathrm{~mm}$ occupied about $25 \%$ of the volume. The highest diameter calculated corresponded to $7.46 \mathrm{~mm}$. From this histogram, one can finally conclude that bubble break-up is negligible.

Figure 4.47 left shows the volume where there is presence of large bubbles represented by Groups 7 to 10 . These regions are located mainly in the sides of the channel. This is caused by the increased turbulence in the limits of the bubble plume close to the walls. The bubble plume raises the liquid, whereas the non-slip condition at the wall prevents its movement. The resulting high-shear and turbulence level enhances the bubble collisions, thus increasing the bubble coalescence. Moreover, it was determined that the coalescence in these regions is so high due to there are no bubbles with diameters below $4 \mathrm{~mm}$.

To get a better insight into the break-up, a third volume was selected corresponding to regions where there is presence of the Groups 1 and 2 (Fig. 4.47 right). Again, these regions are located near the walls, as the main mechanism for the bubble break-up consists of the shearing-off of large bubbles. Only $1 \%$ of this volume is occupied by bubbles smaller than $3 \mathrm{~mm}$. This result can be interpreted given the shearing-off mechanism that produces the small bubbles. Big bubbles are sheared by high velocity gradients near the wall and rarely split into two equal volume smaller bubbles (Lasheras et al, 2002), but rather into one big and one small bubble.
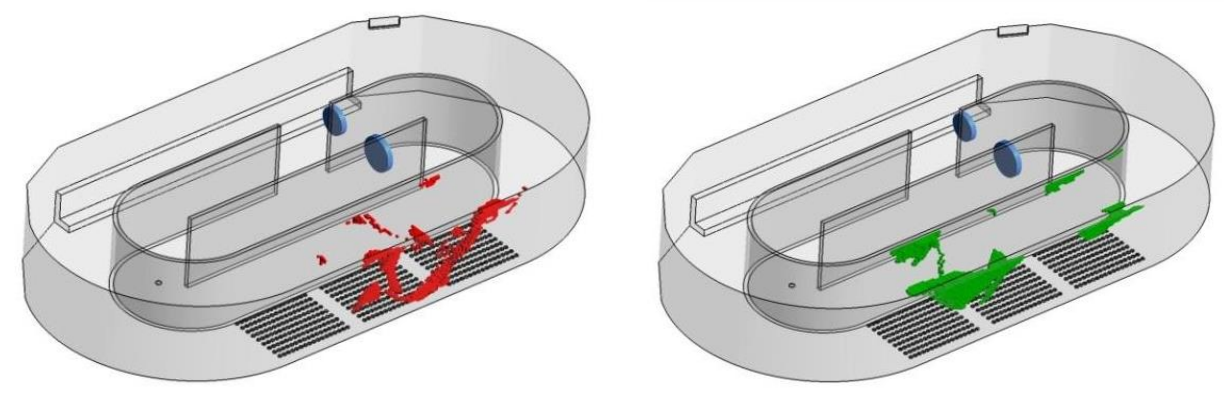

Figure 4.47. Isovolume of bubbles of groups 7 to 108 (left), and Isovolume of bubbles of groups 1 and 2 (right)

Figure 4.48 represents the interfacial area density calculated by the PBM inside a volume of air. This was defined by selecting the hold-up below to $3.5 \%$ in order to exclude the free-surface contribution. The two highest bars of the histogram were concentrated around $15 \mathrm{~m}^{-1}$. Values between 30 and $60 \mathrm{~m}^{-1}$ represented an important contribution of $42 \%$ of the volume, while values under $10 \mathrm{~m}^{-1}$ and above $60 \mathrm{~m}^{-1}$ represented about $7 \%$ in each case. 

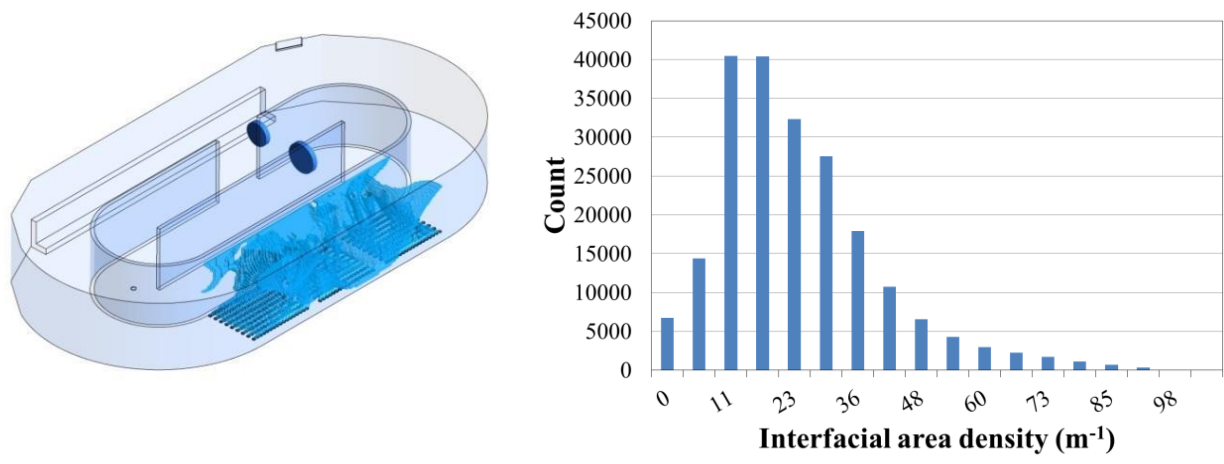

Figure 4.48. Isovolume of holdup represented up to $3.5 \%$ (left), and its corresponding interfacial area density (right)

Figure 4.49 shows the plumes across the width of the channel by means of the holdup, section e-e' (indicated in Fig. 4.44). It can be considered a representative performance of the dispersed phase. Note that the air bubbles are injected through the diffusers vertically, but every column gets attracted by the one that is placed next to it towards the interior of the channel. Consequently, bubble columns tend to group/collide (see figure 4.45 for a similar effect).
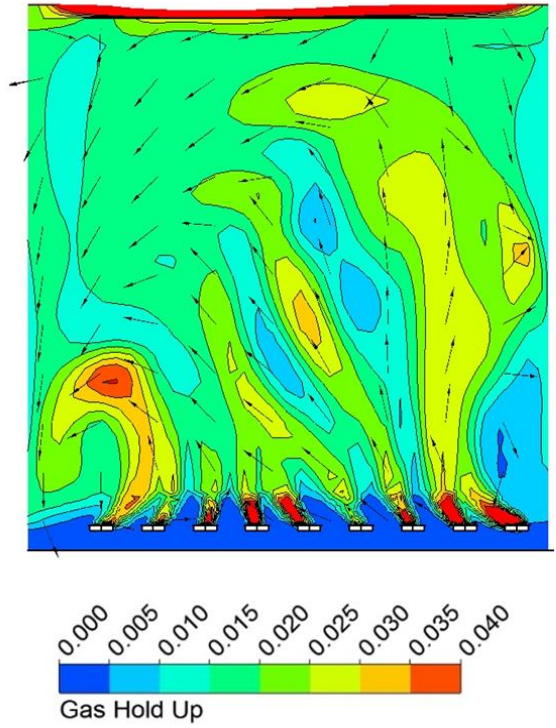
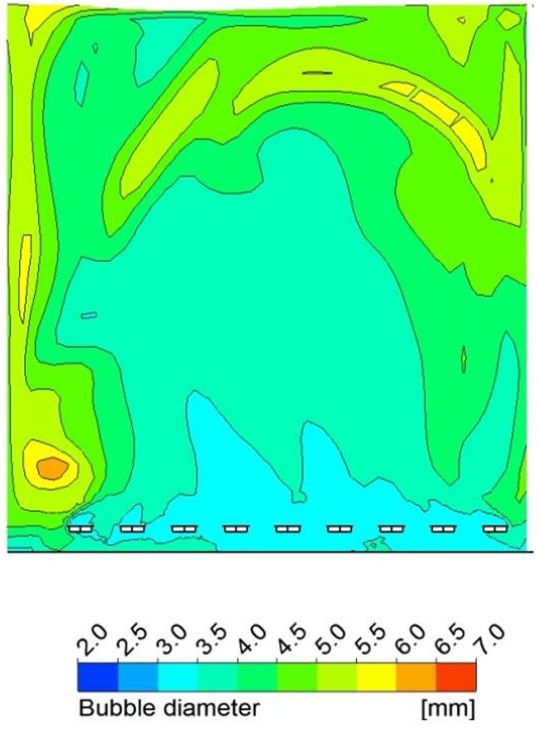

Figure 4.49. Hold-up (left) and bubble diameter (right) both in section e-e' 
Also, near to the walls recirculation vortexes do appear. In this case, the asymmetry of the diffuser distribution along the width of the tank enhances this effect, which is especially noticeable over the recirculation formed in the bottom left corner. Note that the larger bubbles tend to go near the walls. This is caused by two phenomena: first, the lift tends to direct them towards the walls; second, bubble coalescence is driven by turbulent collisions, matching the regions with higher turbulence levels with higher bubble diameters. Also, turbulent impact of eddies against big bubbles can lead to breakup, which can lead to regions with smaller diameters near regions with large bubbles and turbulence, as for example near the air-liquid interface. In addition, ascending bubbles act as a source of turbulence, so the turbulence level increases with the height over the channel ground. Hence, a certain trend can be observed where the larger bubbles take place at the upper region and close to the walls, while the medium sizes are located at the central and the bottom zone.

To sum up, the multiphase modelling depicts a scenario where the bubble plumes generated by the diffusers collide leading to coalescence. This is an undesired effect, as the aeration efficiency is reduced. Given the difficulties to measure the actual sizes of the bubbles in real tanks, CFD simulations can be used as a tool for the optimization of the air flow injected through the diffusers, taking into account the influence of both increase in turbulence and bubble sizes onto the mass transfer. Also, the multiphase simulation shows that a bubble column filling the width of the channel significantly reduces the flow velocity in the whole tank, as it generates a drag that tends to stop the flow. This might be considered a faulty hydrodynamic design, and might be of interest for future studies.

\subsubsection{Optimization study using CFD}

Several configurations were tested modifying the position of the two propellers for minimizing the incoming flow through the channel spacing, which affected negatively the hydrodynamic behaviour in the inner channel.

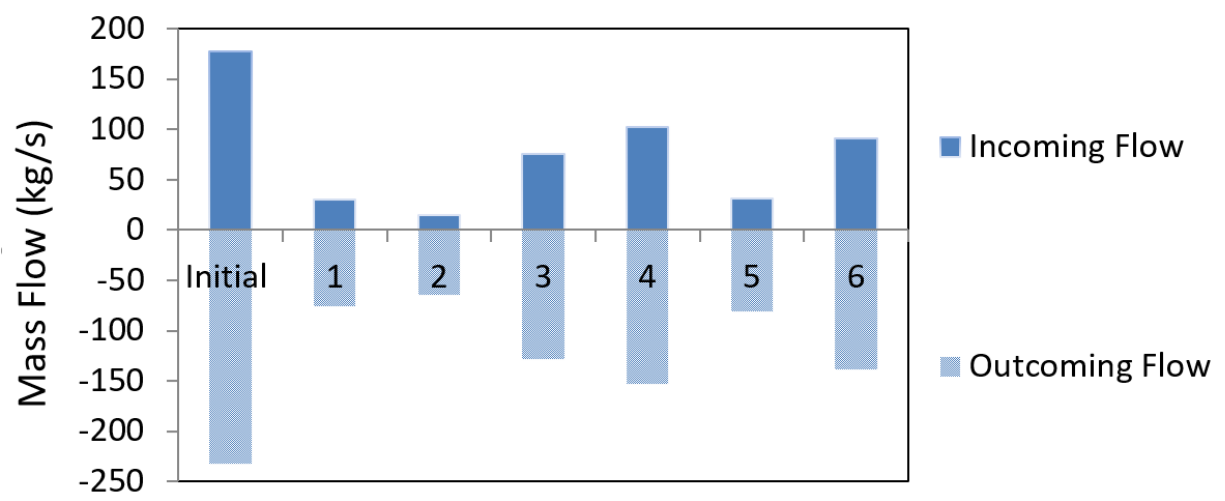

Figure 4.50. Mass flow rate incoming and outcoming through the channel spacing 
Figure 4.50 shows the results of the calculations of the 6 configurations simulated. They were analysed considering these two requirements: (1) minimizing the incoming flux entering from the outer to the inner channel and (2) the accomplishment of the distance to the wall. As a result, a modified configuration was proposed. Firstly, a detailed study of fluid flow was performed in the channel spacing. This zone was considered one of the most critical because of the coexistence of both the incoming and the outcoming flow. Based on the criteria explained above, the configuration 2 was selected as the optimal proposal which minimized the mass flow entering from the outer to the inner channel drastically, improving the fluid behaviour inside the inner channel.

Figure 4.51 shows the optimal configuration selected which improves the mixing in the inner channel, reducing the low velocity zones and minimizes the reflux of the fluid from the outer to the inner channel by $92 \%$. This configuration maintained the average fluid velocity along the outer channel increasing the average fluid velocity in the inner channel due to the internal propeller, and inducing a more stable plume of fluid.
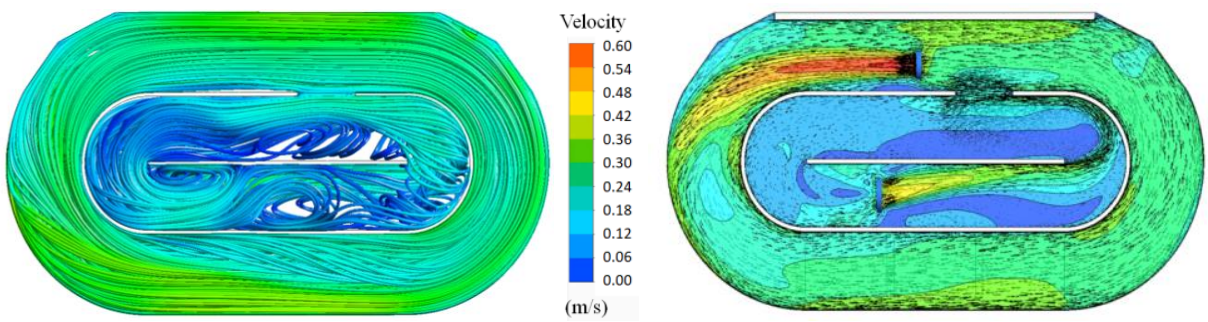

Figure 4.51. Velocity of the streamlines at the optimum configuration

\subsubsection{Nutrient removal performance using CFD-ASM}

A single phase CFD simulation was successfully run in transient state based on a real control strategy which consists of switching on the aeration when ammonia concentration was under $4,5 \mathrm{ppm}$ at the outlet, and to switching off the aeration when the set point achieves 1,5 ppm. This is the real control strategy used to operate the real biological reactor in order to ensure the water quality at the outlet. This is the way to maintain total nitrogen under control.

Detailed information was obtained in transient state by plotting ammonia contours and monitoring DO and N-nitric (nitrate + Nitrite) during 1day (Figure 4.52). Despite the fact that the influent was constant (flowrate and ASM1 state variables), and it is difficult to validate this type of transient simulations, nitrificationdenitrification process was reproduced in detail inside the domain during 24 hours. 


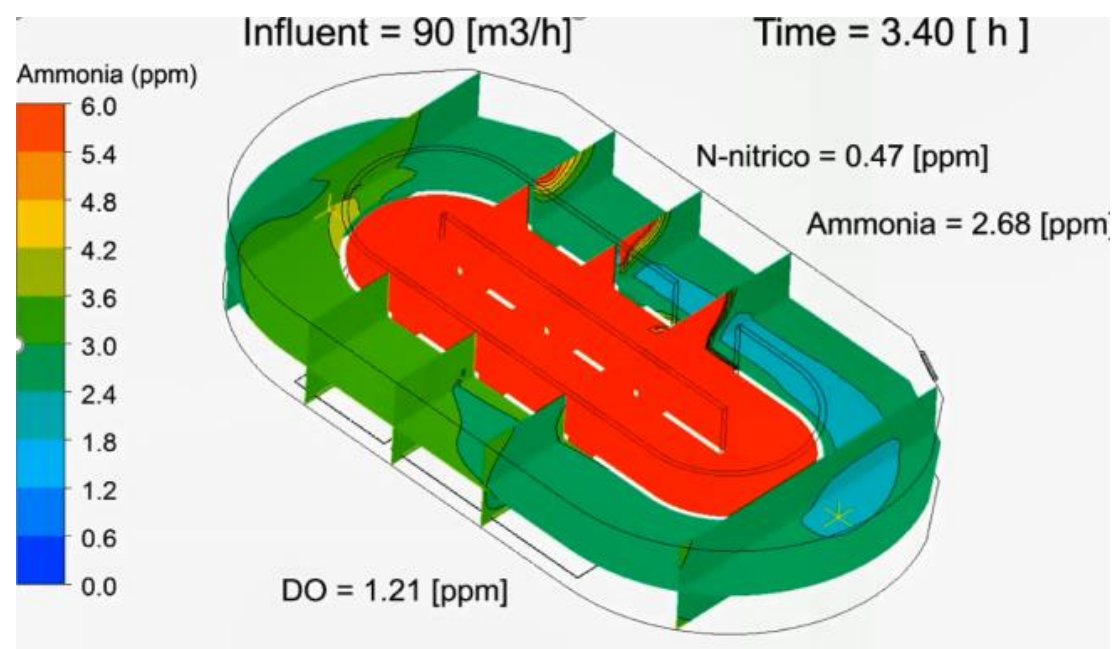

Figure 4.52. Ammonia contours inside the tank

The values of the most important state variables was monitored as shown below. Ammonia values show the typical trend monitored in real performance oslitating between the set point values [ 1,5-4,5] ppm. Aeration cycles can be appreaciated following the DO concentration. It shows a quick increase of the concentration since it is introduced directly dissolved (not using two-phase flow appoach). The DO concentration was calibrated achieving values up to $2,5 \mathrm{ppm}$ as monitored in real operation. Finally, it can be appreciated how the initial value of nitrate decrease as a consequence of denitrification process when the aeration is Off until reaching stable values.

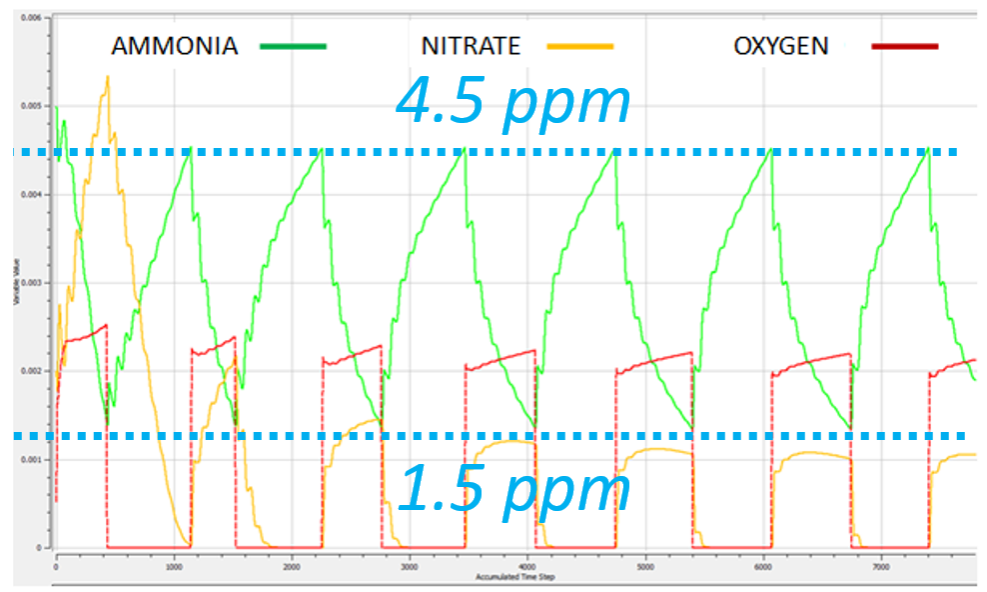

Figure 4.53. Transient calculation of State Variables 


\section{Chapter 5}

\section{Conclusions}

In this study, an analysis of behaviour of CFD models applied to WWTP biological reactors is presented. To this end, different full-scale tank configurations have been investigated. The objectives of this research were to:

- To evaluate changes in full-scale configurations by CFD-ASM modelling.

- To define strategies for reducing the computational cost of CFD-ASMmodels

- To implement a PBM to study an aerated bioreactor through a two-phase flow approach

- To study the influence of the two most common internal elements over the hydrodynamics in real tanks (stirrers and submerged diffusers)

- To better understand the validation of full-scale configurations and their limitations, especially in two-phase flow

The objectives have been successfully achieved with a thorough study of the previous CFD works related this topic, the learning of CFD codes and its verification, the use of a methodology to implement submodels in the CFX software, the development of strategies to reduce computing time, and the validation of the case studies at real scale.

It has been demonstrated the use of the CFD for retrofitting of existing facilities in WWTP through comprehensive studies, from the initial evaluation of hydraulic problems and optimization to the final experimental validation. Moreover, an additional use of CFD coupled with biochemical reactions confirmed the useful assessment of activated sludge modelling and pollutant removal efficiency through CFD-ASM models.

One of the basic needs for the development of CFD tools is the validation of the models developed by means of experimental data of the system. For this, a measurement campaign is always necessary to define, at least partially, the hydrodynamics of the different phases of the system to be analyzed. The experimental technique of tracer test has been successfully applied to assess the 
performance of biological reactors of this study in order to evaluate the hydrodynamics of the tank from a global point of view. The mean residence time and the detection of problems on the fluid behaviour were the most relevant information extracted as well as the comparison between lanes working in parallel and the evaluation of each channel separately for specific tank configurations.

Additionally, tracer tests allowed the verification of the CFD hydrodynamics when RTD is compared with a virtual tracer performance. Nevertheless, since high accuracy CFD results provide a detailed performance of the $3 \mathrm{D}$ domain, specific experimental measurements by means of 3D acoustic doppler velocimeter are preferred rather than tracer tests. An exhaustive validation campaign with accurate measurements in $x$-, $y$-, and $z$-direction point velocities was successfully conducted in this research with the aim of both obtaining a comprehensive hydrodynamic analysis of a full-scale bioreactors and validating the CFD models. ADV is an appropriate technology to measure the flow current in WWT which has been widely used to characterize hydrodynamics inside the tanks. However, it presented limitations when measuring directly over the diffuser grids, where it only can provide a poor signal. It was necessary to acquire the data before or after the grids and apply a filter to smooth the signal afterwards.

Finally, the major complexity of validation can be found in the transported species, the validation of the state variables in a real performance presented important limitations. On the one hand, the calibration of the ASM model is based on simpler hydraulic assumptions, which difficulties the verification of the CFD ASM model. On the other hand, the validation of the CFD model in a real performance strongly depended on the accuracy of the sampling, both at spatial and temporal scale.

The liquid phase described as a non-Newtonian continuous fluid was successfully applied. In addition to the modelling of dispersion phenomena and reaction of chemical components transported, multiphase fluid simulations were performed in CFD. The dynamics of these systems are extremely complex since, in addition to having to solve the equations for each fluid, one must resolve the mechanisms of interaction between the different phases. The description of the solid and gaseous phases can be carried out in different ways according to the degree of accuracy required. The most complete formulation is trying to solve the interface of each particle (solid or bubble) and allow to solve both superficial phenomena of erosion and the internal flow of gas in the bubbles. This type of simulations calls upon, however, a high computational cost that prevents their application even in pilot plant type systems, so their use is limited to fundamental research. In this research, the Eulerian formulation was used to study two-phase flow. It is the most widespread approach in the field of simulation for industrial systems which is based on statistical averages on the particles that are dispersed in the main flow. In this type of simulations, it is especially complicated to describe the impacts between particles, since all information about their location is lost. To model this type of 
phenomena it is necessary to introduce population balance techniques with adequate models for coalescence and particle rupture.

The use of PBM integrated in CFD modelling may be considered relatively complex but allows to deepen in the operation of the processes e.g. aeration, reproducing in greater detail the $3 \mathrm{D}$ hydraulic behaviour in biological reactors. This research allowed to study the influence of the submerged propellers over the air plumes stability, and the analysis of the bubble size and the interfacial area density, which revealed that the coalescence is predominant, and the break-up can be neglected. Although with a high cost of computing time, this type of simulation presents a breakthrough with high potential for the understanding of the performance of the internal elements within biological reactors.

Different strategies focused on reducing the computing cost associated to CFDASM models were applied satisfactorily. On the one hand, assuming that biokinetics does not influence hydrodynamics (one-way coupling), simulations were run in two-steps, calculating hydrodynamics first and then the biochemical reactions. On the other hand, the timestep variable allowed defining an increasing timestep to run the simulation faster.

A specific strategy named Hydroswapping, which allowed swapping between two hydrodynamics previously converged to solve the ASM in transient state was developed. Thus, it was possible to reproduce the real behaviour of a biological reactor with a control strategy consisting in aeration cycles based on an ammonia setpoint and to monitor the key state variables for the nitrification-denitrification process: ammonia, nitrates and dissolved oxygen. All this is necessary to boost CFD for control strategy applications for the real operation of biological reactors. This opens new perspectives to boost the transformation of the paradigm of the CFD applied to wastewater treatment, which comes from the well-stablished applications based on the design, and head towards the decision support tool based on control of the process.

In summary, CFD simulation applied to biological reactors is highly mature as design or troubleshooting tool. The potential of the multiphase flow offers clear opportunities to further develop the value of CFD in wastewater process assessment. For this, it is necessary to continue studying CFD models coupled with biokinetics through multiphase fluid approach. Moreover, it is important to simplify the models and to develop strategies of calculation to deal with the simulation of large and complex tanks with a relatively low computational cost. 


\subsection{Future work}

The main limitations of CFD to address in order to better reproduce the real operation of full-scale bioreactors are:

- The bio-kinetic models, which were not intended to be applied to CFD and therefore, the verification of the CFD-ASM is limited. The calibration of the half saturation constants is not linked to hydrodynamics. As a consequence, the reaction rates only depend on the concentration of reactants (in the case of first-order reactions) but not on the mixing conditions. Moreover, CFD-ASM multiphase fluid approach need further research to better couple the state variables, particulate and soluble, into each phase.

- Multiphase flow modelling: the interaction between solid-liquid-gas can be reproduced accurately according to complex models which can consider all the interfacial forces in more complex CFD formulations as Lagrangian. Then, Eulerian formulation can reproduce the dispersed phases (solid and gas) using complex submodels as PBM to reproduce flocculation and breakage. The main issue is to balance the accuracy and the computing cost vs the number of phases and submodels that a CFD model is prepared to bear, all depending on the objective.

- The global mass transfer coefficient $\mathrm{k}_{\mathrm{L}} \mathrm{a}$ : CFD modelling is able to implement the film-penetration theory (based on the two-film theory) in order to study in depth $\mathrm{k}_{\mathrm{L}}$ models related to turbulence flow, and to study the interfacial area density (a) separately.

- Strategies for run simulations: it is essential to improve knowledge of the mechanisms of the biological reactor performance to simplify the submodels correctly, reducing their complexity to calculate faster the scenarios in full-scale tanks.

- Rheological conditions: viscosity plays an important role not only in biological reactors but also in secondary settling, and to a greater extent, in anaerobic digester tanks. The presence of solids influences the rheological conditions which, in addition to temperature and shear rate, should be considered in the model.

- Internal elements: the performance of mixers, superficial aerators, and diffusers is essential to reproduce correctly hydrodynamics. The better formulation of the approaches to include them as internal elements in a 
CFD model can be improved by means of calibration through experimental data: velocity measurements, void fraction, suspended solids, DO, etc.

- Investigate new control strategies of the process based on CFD. From an exhaustively validated CFD model using on-line probes combined with more powerful calculus resources, it may possible to base the control of a biological reactors on CFD simulation.

- Errors and uncertainty of CFD models validation applied to large tanks: first, it is difficult to validate a 3D domain spatially by means of monitor points. There are existing zones with significant gradients, with an error directly related to the positioning of the sensor in the tank, increased when it is compared with the variables calculated in a certain node of the CFD model. This is largely compounded for the validation of the biochemical species. Second, the hydrodynamic performance of a real tank, although operating in steady state conditions with a constant flowrate, presents a pseudo-dynamic state. The fluid flow evolves periodically producing and dissipating macrostructures of fluid, which can be appreciated locally and are extremely complex to reproduce either with steady state model or transient state CFD model. 



\section{Appendices}





\section{Appendix A}

\section{Biological reactor retrofitting using CFD- ASM modelling.}

\section{Article A}

J.Climent, L.Basiero, R.Martínez-Cuenca, J.G.Berlanga, B.Julián-López and S.Chiva (2018). Biological reactor retrofitting using CFD-ASM modelling. Chemical Engineering Journal. 348, 1 - 14. 



\begin{abstract}
In recent years, the interest in modelling activated sludge (AS) systems by means of Computational Fluid Dynamics (CFD) techniques has significantly increased. This work shows a successful case study combining CFD hydrodynamics and biokinetic modelling. The hydrodynamics is analysed by using the Reynoldsaveraged Navier-Stokes equation for incompressible non-Newtonian fluids and SST turbulence model. Biokinetics has been included in the CFD as transport equations with source and sink terms defined by the Activated Sludge Model $\mathrm{n}^{\circ} 1$ (ASM1). Furthermore, a strategy for reducing the computational cost while maintaining accuracy of the results of these calculations has been proposed. This strategy is based on a two-step solver configuration and the definition of a variable timestep scheme. The resulting CFD-ASM approach permits a proper evaluation of denitrification in the anoxic tanks as well as the reproduction of nitrate and readily biodegradable substrate distributions. To demonstrate the strength of the proposed CFD-ASM, it has been used to evaluate the operation of a full-scale AS system and optimize its performance through changes in the biological reactor anoxic zone. The original configuration has been retrofitted and modified after detecting intrinsic defects in the fluid behaviour within the tank. This study has been assessed by analysing hydrodynamics in detail and validating the simulation results with tracer tests and flow velocity measurements. Substantial variations on the Residence Time Distribution have been confirmed when modifying the internal elements of the tank configuration: the wall-bushing and the stirrer positioning. As a result of this work, an influential short circuiting was corrected improving hydrodynamics and increasing mean residence time, all favouring denitrification efficiency. Outcomes of this study show the benefit of CFD when applied to AS tanks.
\end{abstract}

\title{
Highlights
}

- CFD models were used to retrofit a full-scale tank being validated experimentally

- A CFD virtual study was conducted to optimize the modified configuration proposed

- RTD was demonstrated to be strongly influenced by modifications over the internal elements within the tank

- A strategy of calculation was implemented to reduce computing time of simulations

- CFD-ASM models allowed to evaluate the improvement of fluid behaviour and denitrification efficiency to be evaluated 


\section{Graphical Abstract}

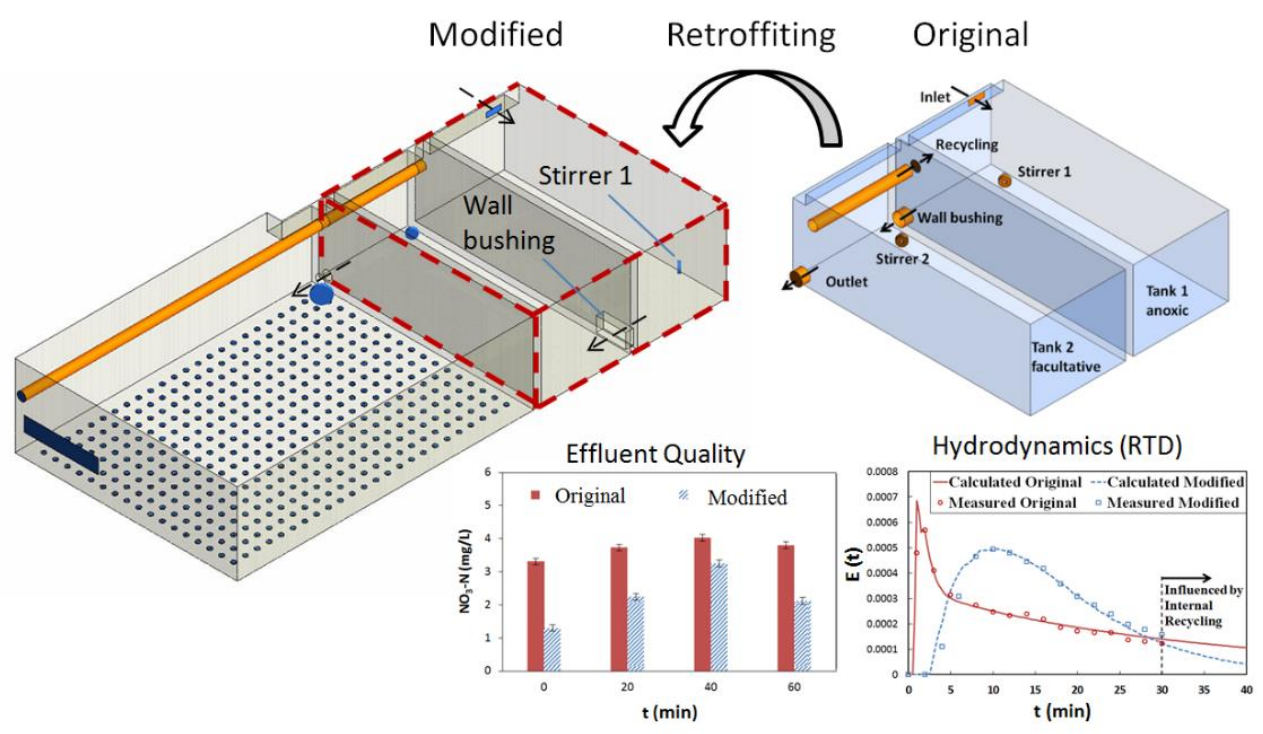

Keywords: CFD; ASM1; Denitrification; RTD; Anoxic; Full-scale

\section{A.1 Introduction}

The Modified Ludzack-Ettinger (MLE) biological reactor is a commonly used nutrient removal configuration, typical of municipal wastewater treatment (WWT) plants, composed of anoxic and aerobic tanks. As known, this system represents one of the simplest configurations to provide nitrification-denitrification with greater efficiency (Haandel and Lubbe, 2012). This increase in efficiency comes from two main factors: recovering lost oxygen, potentially up to $63 \%$ of the energy expended in nitrification, and alkalinity, about half of the lost through the nitrification is recovered when nitrate is used as electron acceptor of readily biodegradable organic substrate (Metcalf \& Eddy et al., 2004). Denitrifying bacteria prefer to use molecular oxygen, but if the environment contains less than 0.3 to $0.5 \mathrm{mg} / \mathrm{L}$ of dissolved oxygen (DO), they will use the oxygen from nitrate-N molecules to oxidise carbon compounds (e.g., BOD) (Grady et al., 2011). Hence, sufficient amounts of substrate must be ensured in anoxic conditions to carry out the denitrification process and thereby saving aeration energy consumption of the activated sludge (AS) system.

The main disadvantage of the MLE reactor configuration is that the effluent will always contain appreciable quantities of nitrate- $\mathrm{N}$ because nitrification occurs in the 
last bioreactor (Water Environment Federation, 2006). Consequently, the adjustment of the internal recycling ratio, which provides nitrate to the anoxic zone, is a critical operational parameter. In this case study, a common mode of operation consists of setting relatively a high internal recirculation rate in order to maintain the effluent under control. But, a high recycling ratio will strongly influence the retention time of the anoxic tank, decreasing the denitrification efficiency. Accordingly, if the mean residence time of the anoxic tank is not enough, the aerobic tank must often be controlled stopping aeration to provide (sufficient) further anoxic volume.

Mean residence time is a variable of paramount importance which should be wellknown, and not assumed as the theoretical hydraulic retention time which frequently entails a poor approach. In this regard, the Residence Time Distribution (RTD) that describes the amount of time a fluid element can spend inside the reactor is commonly used as an experimental source of knowledge giving useful information about hydrodynamics and mean residence time. Though it is costly to obtain and not all RTD analytical methods provide information about shortcircuiting flow or dead zones when large-volume tanks are examined (Burrows et al., 1999), RTD allows quantitative measurement of mixing, and what is more important the determination of the potential for pollutant removal (Brannock et al., 2010). It is possible to obtain crucial hydrodynamic information of AS systems from Computational Fluid Dynamics CFD tools provide deep knowledge of the fluid behavior (Howes et al., 2003). As shown in this study, CFD techniques , CFD techniques allow the shape of the RTD curve to be analysed and modified, changing the internal elements within the tank (Brannock, 2003). The literature offers numerous examples of CFD tracer studies to reproduce the fluid pattern and calculate mean residence time, dead volume, mixing, short-circuiting, etc., which must be validated experimentally mainly by means of RTD, fluid velocity profiles (Brannock et al., 2010; Howes et al., 2003; Brannock, 2003; Le Moullec et al., 2010), and even with reactive tracers (Gresch et al., 2011).

Several commercial packages with different level of complexity are available for modelling WWT processes. Design and operation are frequently based on ASM (Henze et al., 2000) which are generally implemented with ideal hydraulic tank-inseries models. Nevertheless, the hydrodynamics definitely effects the efficiency of the pollution abatement (Dudley, 1995; Le Moullec et al., 2011). In order to obtain a more accurate approach, hydrodynamic effects can be modelled by means of CFD, and ASM can be maintained to reproduce the nutrient removal process. Thus, to perform the simulations, it is possible to incorporate the ASM equations in the CFD code (Rehman, 2016). The usual solving strategy is based on two steps; in the first step the hydrodynamics is solved, and in the second step, the ASM model is solved from the velocity field (as a known variable) as a convection-diffusion problem for a set of transport equations, one for each species, where ASM terms are 
included as sources (Le Moullec et al., 2011; Glover et al., 2006; Karpinska and Bridgeman, 2016; Essemiani et al., 2004).

Authors agreed that successful modelling of the hydrodynamics facilitates the development of a complete model (Glover et al., 2006; Essemiani et al., 2004). The most powerful use of the CFD is to simulate integrated physical, chemical and/or biological processes involved in WWT design and operation, but to date, it should be understood as a supportive tool for unit process design and troubleshooting (Samstag et al., 2016; Wicklein et al., 2016).

In this paper, the authors want to exhibit the use of CFD to model a real bioreactor with malfunctions and its validation against experimental measurements. The results obtained by the validated model have been analysed and a new improved design has been developed using CFD. That new design was performed in the real WWTP, and further and more detailed experimental data were obtained to check the proposed modification and the CFD model itself.

This study deals with a faulty hydrodynamic performance of the biological reactor, which is the consequence of an influential short-circuiting detected in its design configuration (Original configuration). This direct flow between the wall-bushings, which were located facing each other, short-circuited the current flux in the second anoxic tank. In order to improve the performance, a new configuration (Modified configuration) was proposed by changing the locations of the wall-bushing and the stirrer as indicated in Figure A.2.

The outline of this work was divided into three different steps (Figure A.1). The two symmetrical wastewater treatment lanes (WWTL1, WWTL2) of the MLE bioreactor (Figure A.2) were used to carry out this study. Firstly, a CFD model (L1CFDo) was developed to study hydrodynamics in the Original configuration of WWTL1 (WWTL1o), validated experimentally by means of tracer tests (I). Secondly, the CFD model was used to perform improvements in the fluid behaviour over WWTL1 (L1CFDmod), which was eventually retrofitted. After the full-scale modifications in WWTL1, the modified configuration (WWTL1mod) was validated using tracer tests and velocity measurements (II). Finally, the CFD-ASM1 model for each configuration was developed calculating differences in denitrification performance, which were validated experimentally comparing WWTL1mod and WWTL2 (Original) (III).

As a result from this study, we demonstrate that the retrofitted configuration WWTL1 (WWTL1mod) provides an effluent with higher quality compared with the unchanged WWTL2. 


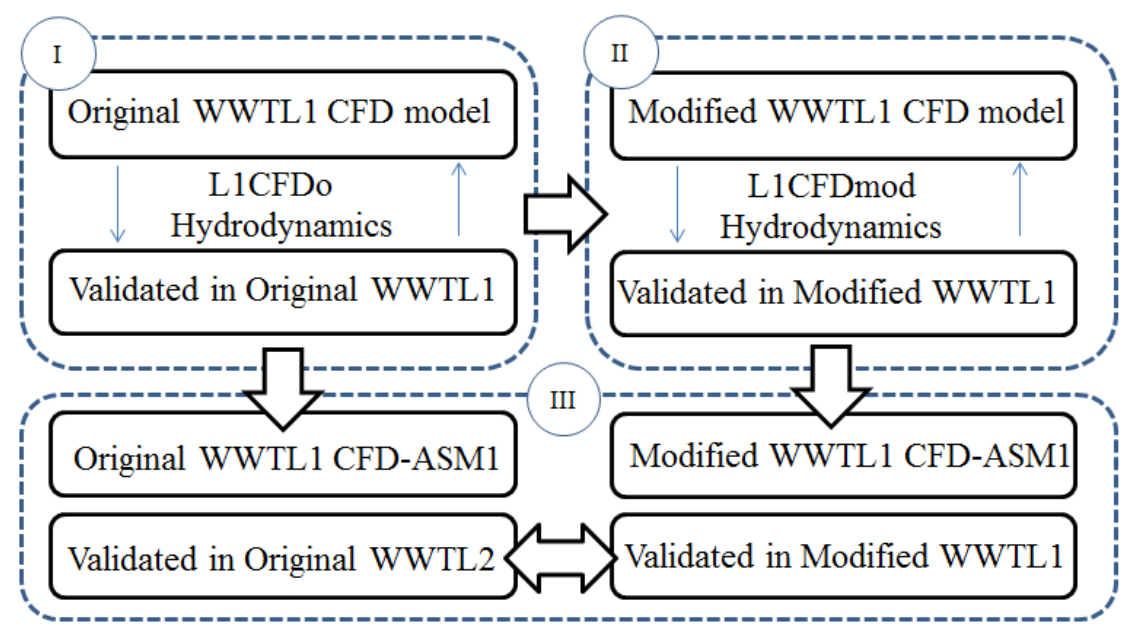

Figure A.1: General outline of the study.

\section{A.2 Materials \& methods}

The description of the reactor has a critical importance to obtain representative process dynamics when modelling the effect of local hydrodynamic phenomena on biochemical reactions (Glover et al., 2006). This section starts with a full description of the biological reactor under inspection and introduces the proposed retrofitting configuration. Then, the experimental techniques used for model validations are presented along with the various locations at which data were acquired. Finally, the (novel) implementation of the combined CFD-ASM1 model is briefly described.

\section{A.2.1 Description and operation of the biological reactor}

This study has been conducted in a full-scale biological reactor of a WWT plant located in Vila-real (Spain). It was designed to treat a flow of 22486 (m3/day) (50 786 equivalent inhabitants). As shown in Figure A.2, its configuration consisted in a MLE activated sludge process composed by two symmetrical and separated WWTLs (WWTL1, WWTL2), set in parallel, each one composed of 3 tanks in a row. Each tank was communicated to the next one by just one wall-bushing and equipped with one stirrer. Influent flow and external recycling from secondary settlers were previously mixed and equally distributed into the two WWTLs, feeding the first anoxic tanks where the DO is maintained lower than $0.1(\mathrm{mg} / \mathrm{L})$. The third tank was the only one able to form nitrate when operating under aerobic conditions. The internal recirculation stream for each WWTL returned mixed liquor from the Outlet, located after the third tanks, providing nitrate-N to the first tanks. 


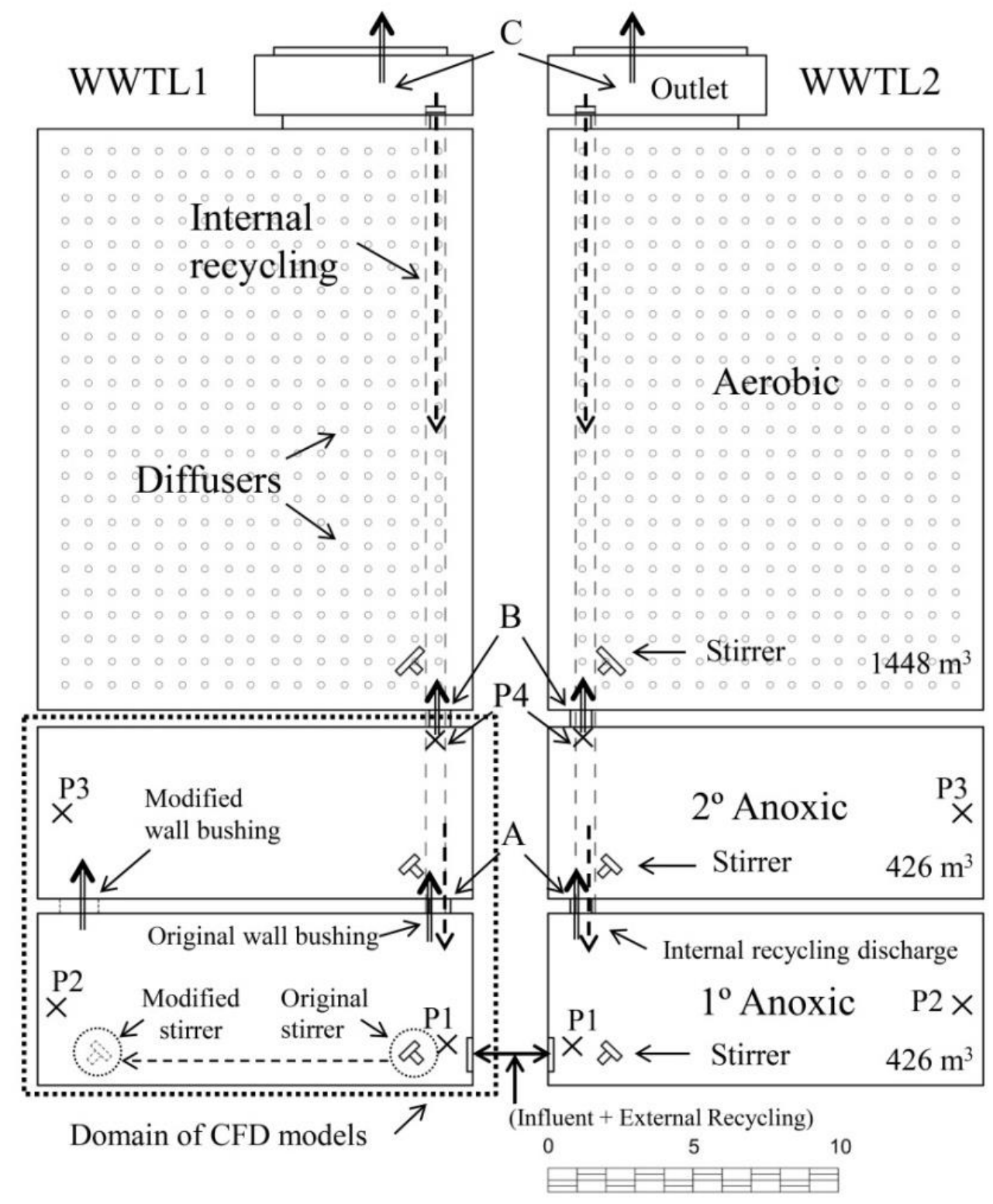

Figure A.2: Plan view of the MLE biological reactor including both WWTLs. 
The discharge point of the internal recycling within the first tanks was located $2.5 \mathrm{~m}$ above the wall bushing between anoxic tanks (Original wall-bushing), whereas the following wall bushing, which communicated to the aerobic tank, was located in front of it causing a significant short-circuiting which induced hydrodynamics malfunctioning within both second tanks.

The biological reactor operates using intermittent aeration to promote both nitrification-denitrification in the aerobic tanks due to a high unintended accumulation of nitrates. This raises the difficulty in setting up the optimal aeration cycle time in order to guarantee reasonable concentration of nitrogen compounds in the effluent. That is why the third reactor is often needed to increase the denitrification volume added up to the anoxic tanks. The CFD study was focused on the first two tanks of the WWTL1, facultative tanks which always operated in anoxic conditions due to the poor denitrification efficiency achieved. As mentioned above and shown in Figure A.2, the modification consisted on retrofitting the wallbushing and relocating the stirrer (Original to Modified).

\section{A.2.2 Experimental measurements for CFD validation}

This study started carrying out a first tracer test in the entire biological reactor, taking samples at different critical zones within each tank of both WWTLs for 24 hours, in order to acquire broad knowledge about the fluid behaviour inside the tanks. Fluorescein sodium salt was selected as a dye tracer due to its advantageous performance, particularly for extensive sampling campaigns. From these experiments, the RTDs were obtained at the outlet of each tank $(A, B$, and $C$ in Figure A.2) and at the sidestreams (internal and external recirculation), with the aim of analysing the flow pattern and quantifying the influence of the internal recycling over the mean residence time of the anoxic zone. In addition, as other authors suggested (Borroto et al., 2003), a tracer sorption test was conducted to ensure its photochemical stability as well as its low adsorptive potential at values of $\mathrm{pH}$ above 7.

A dye tracer was introduced at the influent following a "pulse" as the injection method. The tracer was diluted in tap water in a 20 litres bucket. The duration of the pulse was about 6 seconds (as it is considered in for simulation). The ratio between the pulse time and the mean residence time $(\tau)$ was about $0.58 \%$. Tracer concentration at the outlet point of the second anoxic tank (P4 in Figure A.2) was measured with a sampling interval of 2 min. Samples were processed with a fluorescence spectrophotometer Varian Cary Eclipse set at $491.5 \mathrm{~nm}$ excitation wavelength and a sample detector PMT voltage of 820 volts. The fluorimeter was calibrated using the effluent as the zero point and as the dilutant for preparing the dilution samples to calibrate the equipment. Taking into account the accuracy of the instrumental equipment and the measurement, we estimate that the error in the concentration values is not higher than $4 \%$, which allowed us to provide quite reliable values for the simulation process. 
A high-resolution acoustic Doppler velocimeter Vectrino Nortek ${ }^{\circledR}$ was used to measure velocity in the first anoxic tank after the retrofitting. An aluminium structure of 4.5 meters, made of four pieces of 3-point-truss of $1.5 \mathrm{~m}$ each, was anchored to the walls. A mobile wagon was made to slide over this structure driven by a pulley system in order to set the position over the surface of the tank. An aluminium profile of $9 \mathrm{~m}$ was attached vertically to the wagon as a guide for the velocimeter. Thus, the velocimeter was able to move automatically at different height actioned by a stepper motor. This system allowed the movement of the velocimeter with enough precision inside the tank to measure 3D fluid velocity at different locations and depths. Velocity at the second anoxic tank was not measured because of its more complex accessibility.

Rheological tests were carried out with a BOHLIN® CVO 120 HG (High resolution) rheometer equipment to measure physical properties of activated sludge at $18^{\circ} \mathrm{C}$ such as viscosity and yield stress. A double concentric cylinder rotational rheometer was used to obtain the flow curves, taking into account that the gap size (measuring gap: 1.99 and $2.73(\mathrm{~mm})$ was much larger, at least 10 times, compared to the particle size in suspension (until $0.14 \mathrm{~mm}$ ) (Eshtiaghi et al., 2013). Sensitivity tests of the sample were performed at different initial shear stress to measure viscosity with sufficient precision at low velocity gradients, and to detect the characteristic threshold stress of the pseudoplastic sample.

Finally, physico-chemical analyses were carried out to characterise the influent flow, the internal recycling and to determine state variables at four different locations (P1, P2, P3 and P4) for comparing both WWTLs and validating CFD models, not only for global predictions but also for more local estimation of the concentrations (Le Moullec et al., 2011). Samples of $500 \mathrm{ml}$ were extracted from a specific depth $(2.5 \mathrm{~m}$ for P1, P2 and P3 and $4.5 \mathrm{~m}$ for P4 corresponding to the wallbushing). In order to asses denitrification performance, filtered BOD was measured following the procedure described in (Rice et al., 2012) while Hach-Lange ${ }^{\circledR}$ photometric kit was used to measure Nitrate (kit LCK339).

\section{A.2.3 CFD Modelling}

A combined CFD-ASM three-dimensional non-Newtonian single-phase approach was performed with the purpose of evaluating the influence of the two different geometries over hydrodynamics and its impact on the kinetic model. ANSYS ${ }^{\circledR}$ Academic Research Release 16.2 software was used to perform the CFD model. Different simulations which are described in this section, were run on ANSYS-CFX for the Original and Modified configurations to accomplish these aims.

ANSYS- CFX is a cell-vertex finite volume, coupled implicit, pressure based solution technique, solving pressure and velocity at the same time in the same matrix. This code uses a co-located (non-staggered) grid layout such that the control volumes are identical for all transport equations, using the discretization proposed 
by the Rhie-Chow approach. ANSYS-CFX uses an unstructured Finite Element based Finite Volume method, using shape functions, common in FE techniques, to describe the way a variable changes across each element. It is also a node based code, where the solution variables are solved and stored at the centres of the finite volumes, or the vertices of the mesh.

The resulting mesh for the simulations was selected after carrying out a grid dependence procedure and discretization schemes which have been included; finally, a hexahedral dominant mesh with 238730 nodes was performed to calculate the simulations by means of hexahedral elements with an edge of approximately 17 $\mathrm{cm}$. The guidelines detailed in CFX Best Practices Guide for Numerical Accuracy (ANSYS ${ }^{\circledR}$, 2015) were taken into account, testing mesh dependence and discretization schemes. Then, a sensitivity analysis of the mesh confirmed the null impact of the mesh size element on the simulation results. In addition, mesh quality parameters (orthogonal quality and skewness) were checked for the defined mesh. High orthogonal quality and low skewness values are recommended, 0.95-1 and 00.25 , respectively. Specifically, an orthogonal quality average of 0.95761 and a skewness average of 0.19593 were obtained.

The Shear Stress Transport turbulence model developed by Menter (Menter, 1994) was selected. This model is widely used and very robust. It is a two-equation eddyviscosity turbulence model that combines the $\mathrm{k}-\omega$ turbulence model near the wall when the inner region of the boundary layer has a dominant effect and k- $\varepsilon$ turbulence model in the free shear flow.

Mixed liquor transport properties were defined as a non-Newtonian fluid using the Herschel-Bulkley submodel (Eqs. A1 and A2) (Ramin, 2014) which enriched the performance since viscosity variations due to velocity gradients were taken into account.

$$
\begin{aligned}
& \tau=\tau_{0}+K \gamma^{n} \\
& \eta=\frac{\tau_{0}}{\gamma}+K \gamma^{n-1}
\end{aligned}
$$

Where $\tau$ is the shear stress $(P a), \tau_{0}$ is the yield stress $(P a), K$ is the consistency index $\left(P a s^{n}\right), \gamma$ is the shear rate $\left(s^{-1}\right), n$ is the flow behaviour index and $\eta$ is the apparent viscosity of sludge ( $P a s)$. 
Inlet and outlet boundary conditions were defined with mass flow rates whereas the free surface of the fluid was established as a free-slip wall.

Submersible mixers used for flow controlled mixing in large volumes, and the single performance parameter thrust (F) is commonly known to be the basis for mixing system design, along with a set of mixer positioning principles. The submersible mixers could be modelled in a detailed way using CFD, but it is too complex to be included in a plant wide model, instead, a simile is used to include as a momentum source, $\mathrm{M}\left(\mathrm{kg} \mathrm{m}^{-2} \mathrm{~s}^{-2}\right)$ (Brannock, 2003), the mechanical momentum added by the mixer in the system, in the same mixer geometrical location.

The following expressions from the technical sheet of the manufacturers, which provide parameters $\mathrm{F}$ and $\mathrm{D}$, were used to calculate the momentum sources. Subsequently, velocity measurements were conducted to adjust $\mathrm{C}$ more accurately in order to calibrate $\mathrm{q}$ at the outlet of the stirrer domain to fit experimental velocity.

$$
\begin{gathered}
q=C D\left(\frac{F}{\rho}\right)^{1 / 2} \\
M=\rho\left(\frac{q}{D}\right)^{2}
\end{gathered}
$$

Where $q$ is the fluid flow propelled $\left(\mathrm{m}^{3} / \mathrm{s}\right), C$ is a constant parameter, $D$ is the diameter of the stirrer $(\mathrm{m}), F$ is the thrust force $(\mathrm{N})$ and $\rho$ is fluid density $\left(\mathrm{kg} \mathrm{m}^{-3}\right)$.

The ASM model was implemented including an extra transport equation for each additional variable:

$$
\frac{\partial}{\partial t}\left(\rho \cdot \varphi_{i}\right)+\nabla \cdot\left(\rho . U \cdot \varphi_{i}\right)=\nabla \cdot\left[\left(\rho . D_{\Phi} \cdot+\frac{\mu_{t}}{S c_{t}}\right) \nabla \varphi_{i}\right]+S_{\varphi_{i}}
$$

Where $U$ is the fluid velocity $\left(\mathrm{m} \mathrm{s}^{-1}\right), \rho$ is the mixture density $\left(\mathrm{kg} \mathrm{m}^{-3}\right), \Phi$ is the concentration of the $i$ variable $\left(\mathrm{kg} \mathrm{m}^{-3}\right), \varphi=\Phi / \rho$ is the conserved quantity of $\mathrm{i}$ variable per unit mass of fluid, $S c_{t}$ is the turbulence Schmidt number, $\mu_{t}$ is the turbulence viscosity term in $\mathrm{Pa} \mathrm{s}, D_{\Phi}$ is the kinematic diffusivity $\left(\mathrm{m}^{2} \mathrm{~s}^{-1}\right)$ and $S_{\varphi_{i}}$ is a volumetric source term $\left(\mathrm{kg} \mathrm{m}^{-3} \mathrm{~s}^{-1}\right)$ that embeds the biochemical reactions. 
Manifold simulations with different aims described below were performed over several configurations of the anoxic tanks with the objective to improve hydrodynamics and, consequently, nutrient removal efficiency.

\section{A.2.3.1 Tracer runs in transient state}

Dynamic simulations were run for 30 min where the mass flow rates are defined as constants (Table A.1). This assumption was made because the influent flow represented about the $15 \%$ of the total mass flow rate entering the domain and it presented a low variation $(<5 \%)$ during the experimental measurements period. RTD was calculated following the tracer concentration at the outlet of the anoxic zone (P4), and compared with experimental results for both configurations (Potier et al., 2005).

Table A.1: Main parameters of CFD validation by means of "short tracer tests"

\begin{tabular}{|l|l|}
\hline Mass tracer $(\mathrm{g})$ & 500 \\
\hline Q influent $\left(\mathrm{m}^{3} / \mathrm{h}\right)$ & 417 \\
\hline R internal $\left(\mathrm{m}^{3} / \mathrm{h}\right)$ & 1570 \\
\hline R external $\left(\mathrm{m}^{3} / \mathrm{h}\right)$ & 541 \\
\hline
\end{tabular}

The tracer was defined as an additional scalar field by means of a transport equation setting the tracer molecular diffusivity of $5.110^{-9} \mathrm{~m}^{2} \mathrm{~s}^{-1}$ (Casalini et al., 2011). The Schmidt number was set of 0.9 as it provided good agreement with experimental results. The selection of a proper Sch is related to the turbulence level provided by the simulation and the actual turbulence in the flow; this parameter is typically ranging between 0.7 and 1 (Brannock, 2003; De Clercq, 2003). The pulse of mass tracer at the inlet was modelled by properly using step functions.

\section{A.2.3.2 RTD calculation in steady state}

Tracer transport method (Ghirelli and Leckner, 2004) is a feasible way to perform a comparative study among different options. This implies a simple definition of residence time and can be run in steady state, which entails reducing efforts in terms of computing time and complexity of the simulations. This method was used to study and to select the optimal Modified configuration.

Mean residence time from the simulations is calculated by means of an additional scalar field, $t_{m}(\mathrm{~s})$, that is described by the following transport Equation: 


$$
\sum_{j}\left[\frac{\partial}{\partial x_{j}}\left(U_{j} t_{m}-D_{t r} \frac{\partial t_{m}}{\partial x_{j}}\right)\right]=1
$$

where $D_{t r}\left(\mathrm{~m}^{2} \mathrm{~s}^{-1}\right)$ stands for the total diffusivity of the tracer in the fluid and $U_{j}$ the velocity components.

Simulations were carried out in steady state calculating the value of the $t_{m}$ from Equation A.6 to obtain the field of the mean residence time in the domain. Several wall-bushing features were studied depending on its shape and its flow cross section size. Hence, a criterion based on the fluid behaviour consisting of maximizing the mean residence time was defined. From this comparative analysis, the optimum performance to carry out the full-scale modification of WWTL1 was selected.

\section{A.2.3.3 CFD-ASM runs}

ASM1 equations were taken from (Henze et al., 2000). Therefore, 8 processes and 13 state variables were introduced as volumetric scalar fields.

Most of the values for the kinetic and stoichiometric coefficients of the mathematical model were defined as default values for $20^{\circ} \mathrm{C}$ (Jeppsson, 1996). Even so, some parameters were determined by respirometry.

Table A.2: State variables at initial and boundary conditions. (mol/m3)*

\begin{tabular}{|l|l|l|l|}
\hline $\begin{array}{l}\text { State } \\
\text { variable }\end{array}$ & $\begin{array}{l}\text { Inlet (influent }+ \\
\text { External recycling) } \\
\left(\mathrm{g} / \mathrm{m}^{3}\right)\end{array}$ & $\begin{array}{l}\text { Internal Recycling } \\
\left(\mathrm{g} / \mathrm{m}^{3}\right)\end{array}$ & $\begin{array}{l}\text { Initial Conditions } \\
\left(\mathrm{g} / \mathrm{m}^{3}\right)\end{array}$ \\
\hline $\mathrm{S}_{\mathrm{I}}$ & 20 & 20 & 20 \\
\hline $\mathrm{S}_{\mathrm{S}}$ & 172.4 & 38 & 12 \\
\hline $\mathrm{X}_{\mathrm{I}}$ & 152.8 & 152.8 & 152.8 \\
\hline $\mathrm{X}_{\mathrm{S}}$ & 207.4 & 68 & 52 \\
\hline $\mathrm{X}_{\mathrm{B}, \mathrm{H}}$ & 2745 & 2745 & 2745 \\
\hline $\mathrm{X}_{\mathrm{B}, \mathrm{A}}$ & 305.6 & 305.6 & 305.6 \\
\hline $\mathrm{X}_{\mathrm{P}}$ & 562 & 562 & 562 \\
\hline $\mathrm{S}_{\mathrm{O}}$ & 0.5 & 0.8 & 0.01 \\
\hline $\mathrm{S}_{\mathrm{NO}}$ & 2.1 & 7.2 & 4 \\
\hline $\mathrm{S}_{\mathrm{NH}}$ & 51.6 & 3.7 & 7.6 \\
\hline $\mathrm{S}_{\mathrm{ND}}$ & 7.4 & 1 & 2 \\
\hline $\mathrm{X}_{\mathrm{ND}}$ & 2 & 2 & 2 \\
\hline $\mathrm{S}_{\mathrm{ALK}}$ & 4.4 & 4.4 & 4.4 \\
\hline
\end{tabular}

Table A.2 shows the values of the state variables used as boundary conditions and for the initialization of the transients; they were experimentally measured from the 
settled influent and both recycling streams. Despite the fact that state variables were not defined with dynamic boundary conditions, they were calculated in transient state in order to study their time evolution. Moreover, with the goal of ensuring that global balances were met after the simulation, a target imbalance about $0.3 \%$ was established for the conservation of each state variable, giving results lower than typical default value recommended of $1 \%$ (ANSYS $\AA, 2015)$.

\section{A.2.3.4 Saving computational time}

Typical time steps for the iterative resolution of hydrodynamics are of the order of a millisecond, depending on flow speed and mesh refinement through the Courant number. Given the RTDs corresponding for MLEs and the slowest reaction times for the biochemical processes involved take place at time scales way over the hydrodynamic timescale, their resolution would require a huge number of time steps. In order to reduce the number of time steps needed for the calculations, one can isolate both phenomena and resolve the corresponding equations separately. In practice, the number of iterations required for a proper resolution, and therefore in computational time, has been reduced by using a two-fold solving strategy, it is convenient to isolate both phenomena and resolve the corresponding equations separately.

As a first proposal for the reduction of the calculation time, we noted that the fluid pattern in the anoxic tanks could be considered constant as there was no aeration (the hydrodynamics only depended on the stirrers' momentum and incoming streams flow rates, which are both set constant in normal working conditions). These tanks have a strong fixed recycling stream, then the effect of the influent flow temporal evolution is quite limited. We could assume the hydrodynamic variables are constant over a long period of time.

Then, as the hydrodynamics is not generally affected by biokinetics in these processes, transient simulations can be split into two steps. In the first one, hydrodynamics was calculated in steady state by using a proper time step. No biochemical reactions were allowed in this step. In the second step, the transport equations for the biokinetics were solved by using the flow fields obtained in the previous step, which remained constant, i.e., no flow equations were solved throughout this step. This strategy has an important advantage; it is possible to solve the biokinetic evolution over a long period of time with a non-expensive computational cost in scenarios where the hydrodynamic remains essentially constant.

A second proposal for the reduction of computation time is based on the use of a variable timestep that changes as the simulation advances. Given the structure of the biokinetics source terms (Makinia, 2010), one can expect that the reactions take place faster in the beginning and their speed reduces as the reactions advance until they reach equilibrium. Consequently, the solver was fed with a time step 
increasing with the iteration number, providing more accuracy and shorter timesteps at the initial timesteps, to ensure a proper convergence and prevent from overflow errors.

The variable timestepping proposed follows a geometric series, $t_{s}=t_{o} r^{s}$, where $s$ stands for the iteration number, $t_{0}$ the initial time step and $r$ the time common ratio. Then, the total simulation time is given by the expression:

$$
T=\sum_{s=1}^{S} t_{s}=t_{o} \frac{1-r^{S}}{1-r}
$$

Where $\mathrm{S}$ and $\mathrm{T}$ stand for the total iteration number and total time, respectively. In practice, the initial timestep is set to be equal to that of the hydrodynamic part. Then, the common ratio is calculated according to the desired number of iterations (or computational time). The performance of this new approach will be tested and compared to constant timestepping schemes.

\section{A.2.3.5. Rheological properties}

The mixed liquor has a non-Newtonian behaviour, and a rheological study was performed to characterize the fluid (ANSYS $\left.{ }^{\circledR}, 2015\right)$. From this, the HerschelBulkley model was selected to provide a complete description of the pseudo-plastic behaviour of the fluid (Ramin, 2014). The fitting parameters resulted $\tau_{0}=0.00883$ $P a ; \mathrm{K}=0.01932$ Pa $s^{n} ; n=0.6262$.

In order to ensure a reliable experimental dataset, preliminary preparation of the sample was carried out to guarantee homogeneity of mixed liquor when measuring; a Shear Stress of $0.5 \mathrm{~Pa}$ for $30 \mathrm{~s}$ was induced and it was left to stand for another 30 $\mathrm{s}$ before to start measuring. Since the total suspended solids percentage in liquid is low $(<1 \%)$, the fluid in the CFD model was defined as a non-Newtonian single phase to reproduce changes in physical fluid properties under different velocity gradients. 


\section{A.3. Results \& Discussion}

\section{A.3.1 Hydrodynamics}

\section{A.3.1.1 Tracer tests and simulations}

The tracer concentration-time curves, $\mathrm{C}(\mathrm{t})$, obtained from the first tracer test are shown in figure A.3. On the one hand, $\mathrm{C}(\mathrm{t})$ curves measured at the outlet of each WWTL (point C in Figure A.2) showed that overall both lanes corresponded to a similar hydrodynamic performance noticing that the maximum concentration of tracer was achieved at the same time. The marked peaks indicate short-circuiting, as will be discussed later; the mixing degree provided by intermittent aeration of the third tank is not enough to eliminate the short-circuiting, whilst the shape of the curves for long times suggests that the flow pattern can be understood as completely mixed. On the other hand, $\mathrm{C}(\mathrm{t})$ obtained at recycling streams provided the performance of mass tracer returned to the first anoxic tank, thereby the peaks revealed the time that takes the maximum concentration flow to return through the sidestreams. From this, it was observed the strong influence of the mass tracer recycled by internal recirculation over the tracer concentration measured at the outlet point (P4) of the anoxic zone. According to this, it was considered that mass tracer recirculated may not have impact on the tracer concentration measured at P4 until after 30 minutes. Thus, it was possible to define a total time of 30 minutes for the "short tracer tests" with the purpose to avoid recycling tracer material as boundary condition in the CFD simulations.

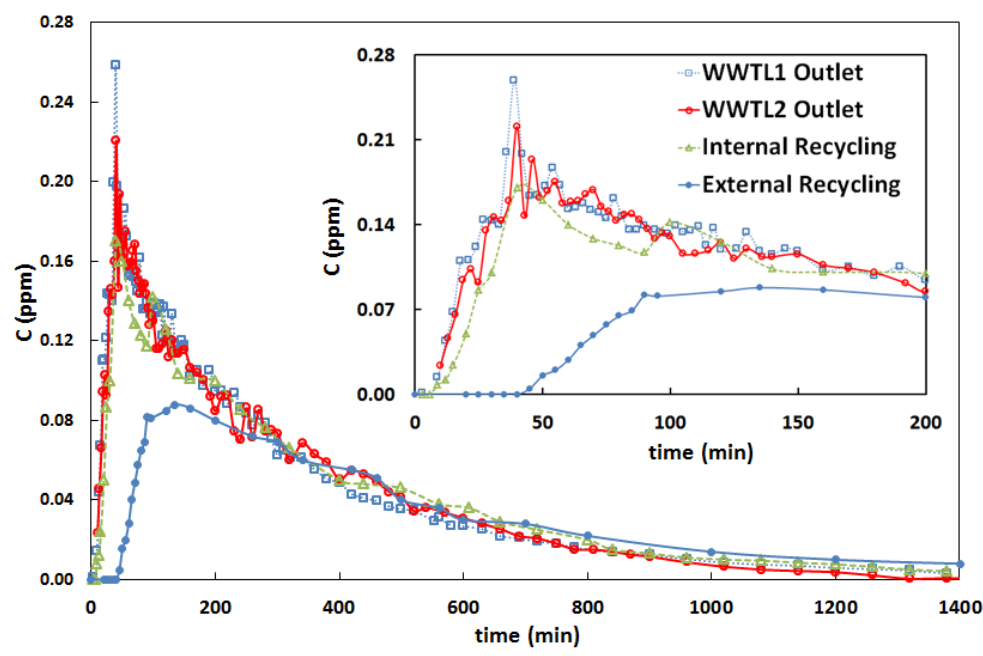

Figure A.3: Comparison of $\mathrm{C}(\mathrm{t})$ curves measured at the outlet and at the sidestreams for the full test and detail of the initial part of the dataset 


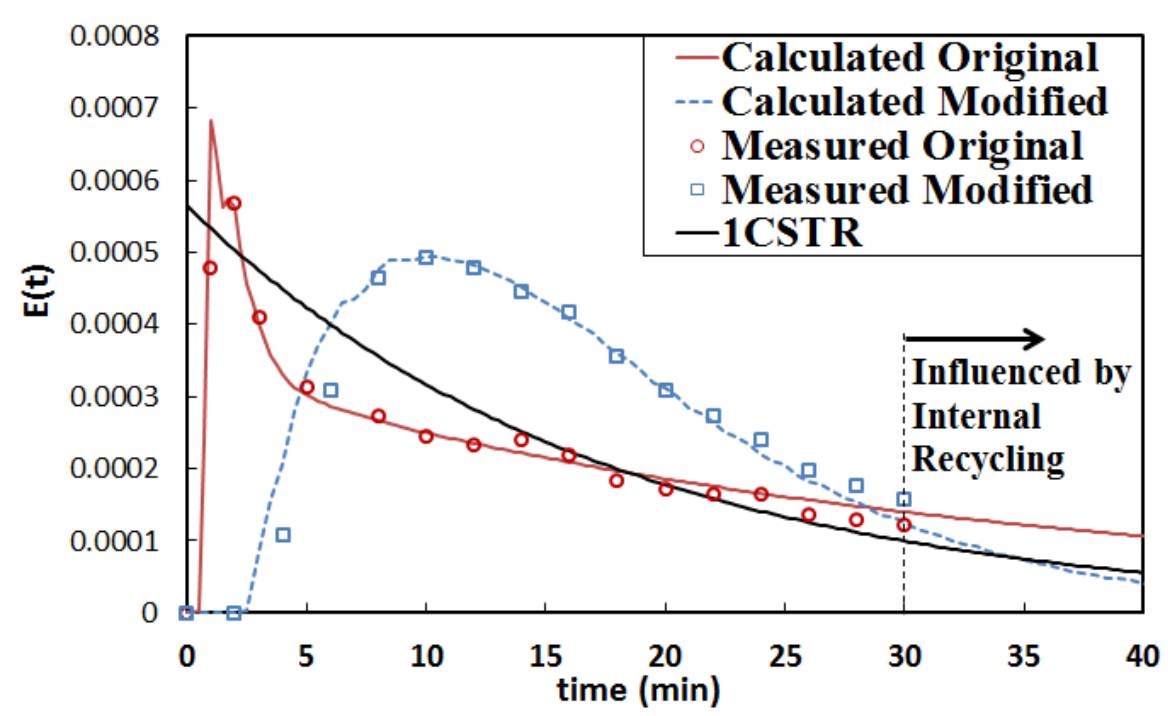

Figure A.4: Comparison and validation of both RTD obtained in WWWT1 configurations: Original and Modified

Figure A.3 shows the residence-time distribution function $\mathrm{E}(\mathrm{t})$ at $\mathrm{P} 4$ for both the Original and Modified configurations compared to the distribution of ideal fluid behaviour of one completely stirred tank reactor (1CSTR). CFD model provided good results and fitting well with experimental data obtained from "short tracer tests". As expected, note that the CFD and experimental data start to differ significantly after minute 30 , as the CFD model does not include recycling of tracer concentration. The RTD of the Original configuration shows a pronounced spike, meaning that a significant part of the inflowing tracer exited the tank in a time much shorter than the mean residence time, compared to 1CSTR indicates the presence of a short-circuit. The curve corresponding to the Modified configuration indicates that there is no longer short-circuiting. Also, the full curve is displaced to the right and smoothed out, leading to an increased mean residence time. Thus, this configuration provides an improvement of the global fluid behaviour in the tank.

Besides the visual inspection of short-circuiting and mixing from the shape of RTD curves in Figure A.4, where the improvement of the fluid behaviour is quite apparent, a quantitative criterion is often desired to better establish a comparison. There are different methods available for analysing the results of tracer studies based on Levenspiel work (Levenspiel, 1972); each of them is more appropriate according to a certain purpose, for example, to parameterise dead-volume and shortcircuiting (Burrows et al., 1999). 
Table A.3 shows the main parameters used to compare analytically both configurations reporting the improvements provided by the retrofitting. Mean residence time was calculated as

$$
t_{m}=\int_{0}^{\infty} t E(t) d t
$$

being

$$
E(t)=\frac{C(t)}{\int_{0}^{\infty} C(t) d t}
$$

In order to calculate the number of tanks-in-series $(\mathrm{N})$, one can start by defining the Normalised RTD Function $\mathrm{E}(\theta)$ as

$$
E(\theta)=t_{m} E(t)
$$

where $\theta$ is the normalized time $\theta=\left(t / t_{m}\right)$. In this approach, $\mathrm{N}$ is related to the normalized time at which the Normalised RTD is maximum, $\theta_{\max }$, by the relationship (Burrows et al., 1999).

$$
\theta_{\max }=(N-1) / N
$$

The parameters analysed are the theoretical hydraulic retention time, $\tau$, the mean hydraulic residence time, $t_{m}$, the effective volume ratio (average retention time) calculated as $t_{m} / \tau$, the reactor dead space volume, $V_{d}$, calculated as $V_{d}=1-$ $\left(t_{m} / \tau\right)$, the dimensionless time evaluated at maximum concentration, $\theta_{\max }$, and the number of tank in series, $\mathrm{N}$. Note that $\mathrm{N}$ has been calculated from the maximum value of the concentration on the RTD curve (Burrows et al., 1999).

Table A.3: Main parameters of experimental RTD analysis

\begin{tabular}{|l|c|c|c|c|c|c|}
\hline Case & $\tau(\min )$ & $t_{m}(\min )$ & $t_{m} / \tau$ & $V_{d}(\% V)$ & $\theta_{\max }$ & $\mathrm{N}$ \\
\hline Original & 17.3 & 12.4 & 0.71 & 28.3 & 0.08 & 1.09 \\
\hline Modified & 17.3 & 17.1 & 0.99 & 1.15 & 0.59 & 2.42 \\
\hline
\end{tabular}


Modified configuration provided overall better hydraulic conditions than Original configuration since mean residence time increased by $38 \%$ approximately and the value of dead volume calculated decreased significantly. This dead volume calculated for the Original configuration should be interpreted as a rough indicator referred to a portion of volume partially isolated in the second anoxic tank consequence of the effect of the short-circuiting; it remained semi-stagnant with low turnover time.

Results showed that the flow pattern of the Modified configuration provided more plug fluid behaviour than the Original configuration. That said, it is important to point out that calculations in Figure A.4 were made from experimental data values not beyond approximately than $2 \theta$, therefore, without considering the entire tail of the RTD. The differences calculated between both configurations based on these parameters would have been lower if RTD tails had been taken into account (Rieger et al., 2013).

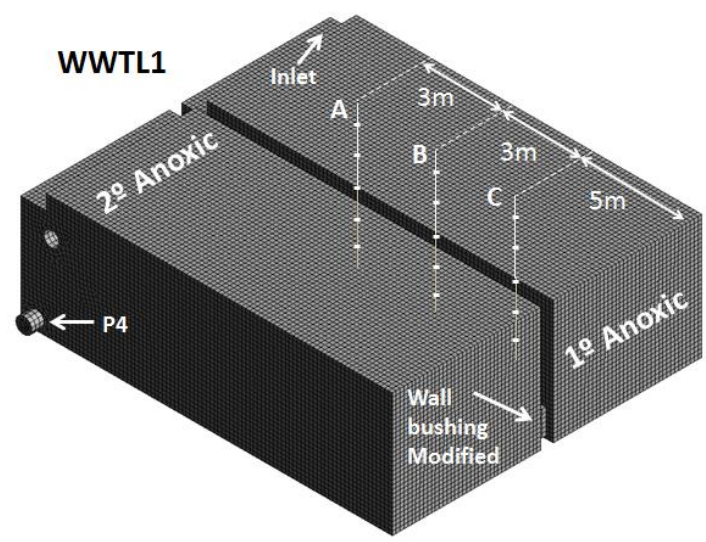

Figure A.5: Mesh of anoxic zone and points of velocity measurements (A, B, C)

In addition to the validation through global data, velocity profiles were measured at three points at five different heights of the first tank of the Modified configuration (Figure A.5) in order to reproduce hydrodynamics in detail. CFD model was validated by comparing, at the specific locations offered in Figure A.5, the velocity provided by the simulation to the velocity calculated from the experimental $3 \mathrm{D}$ velocity components given by the Vectrino. Velocity profiles calculated showed good agreement with experimental data; velocity profiles measured exhibited a smoother behaviour than calculated. Velocity values were in the range $0.10-0.30$ $\mathrm{m} / \mathrm{s}$ depending mainly on the distance from the stirrer and the internal recycling. The most important issue in velocity calibration was to assess the parameter $M$ in (Eq. A.4) for the momentum of the stirrers and their location inside the tank. Both parameters governed the fluid behaviour along with internal recirculation flow in a second term. 

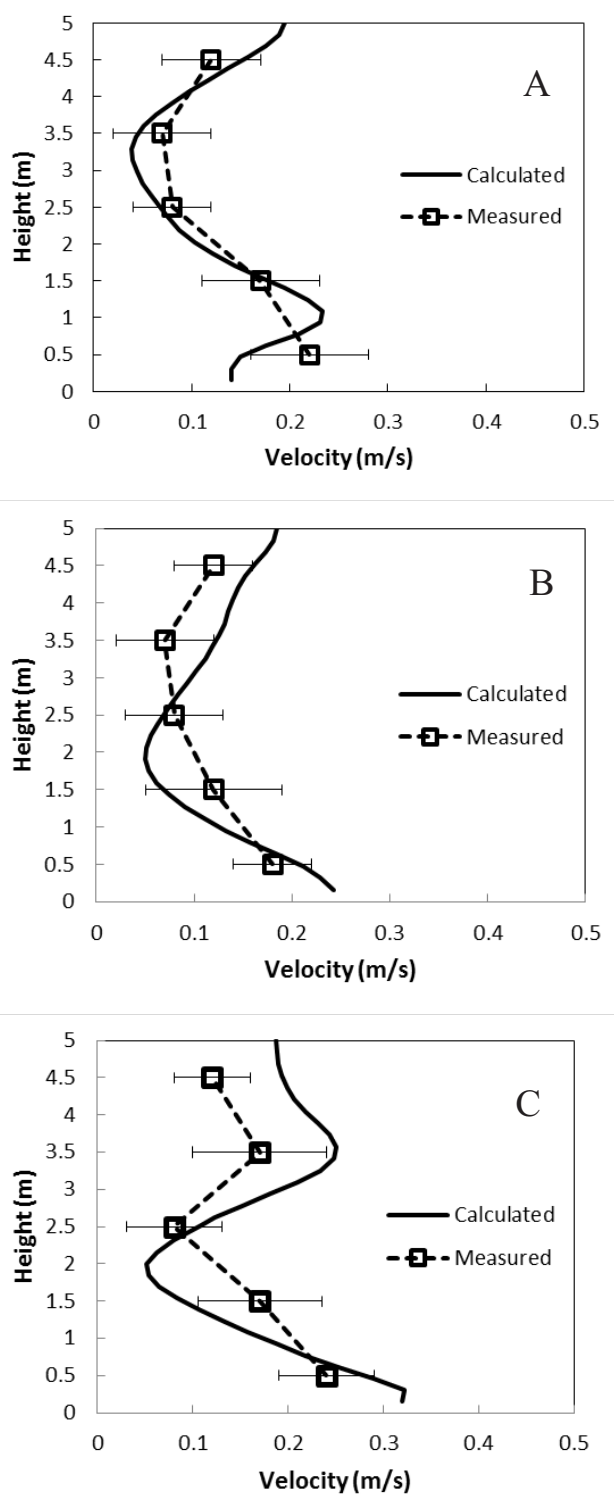

Figure A.6: Velocity profile at a) position $\mathrm{A} \mathrm{b}$ ) position $\mathrm{B}$ c) position $\mathrm{C}$

Each measurement was registered for 5 minutes in order to minimize the influence of rapid variations in flow velocities and to obtain representative hydrodynamic behaviour. It is important to mention that the raw signals acquired by the 
velocimeter should be treated using a filter, in this case type Savizky-Sgolay (polynomial least-squares adjustment).

Streamlines and velocity of the fluid were calculated to describe the fluid behaviour. Figure A.7 shows the streamlines revealing the faulty hydrodynamics performance (Figure A.7a) as long as the improvement in the Modified configuration (Figure A.7b). Therefore, it is apparent that the existence of the shortcircuiting in the Original configuration was not consequence of the poor mixing degree but because of the design configuration which provided the semi-stagnant portion of volume mentioned above.

a)

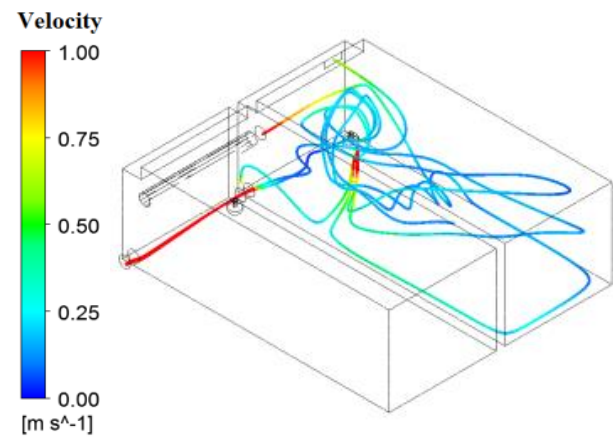

b)

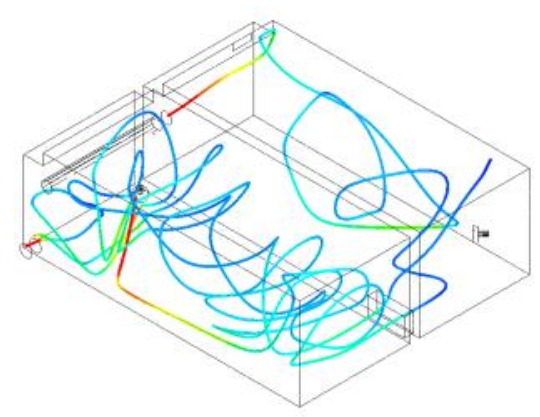

Figure A.7: Streamline of a) short-circuiting at Original configuration. b) improved at Modified configuration

\section{A.3.1.2 Optimization study}

Once Original configuration CFD model was validated, and the problem detected, and a possible solution proposed, several configurations were carried out in order to improve hydrodynamics. Assuming that an improvement in the fluid behaviour will provide a better performance of the biological nutrient removal process, biokinetics were not included to optimize the configuration proposed.

Besides tracer simulations run in transient state, RTD simulations were run in steady state. As explained previously, an additional scalar field representing mean residence time, $t_{m}$, was included to study spatially this the mean residence time field (Ghirelli and Leckner, 2004). An explanatory figure has been included representing the portion of fluid volume which contained values of $t_{m}$ between $500 \mathrm{~s}$ and the 
time when the fluid escapes from the anoxic zone at the original configuration, 680 s.

In order to optimize the performance of the Modified configuration, a virtual study is developed, consisting of several simulations. First, the influence of wall-bushing crossing section area (between 0.5 and $4 \mathrm{~m}^{2}$ ) and shape (circular and rectangular) on the residence time and velocity field homogeneity is studied. Then, the optimal crossing-area and shape combination is used as a basis for a study on the stirrer positioning and its influence on the mixing efficiency of the tank. Finally, the optimal position is used as a basis for a study on the orientation of stirrer ( 3 angles). The angular orientation providing better mixing performance is then chosen as the optimal one.

Table A.4: Description of the configurations tested to optimized the wall-bushing

\begin{tabular}{|c|c|c|c|}
\hline Configuration & Geometrical shape & $\begin{array}{c}\text { Crossing section } \\
\left(\mathrm{m}^{2}\right)\end{array}$ & Parameter $(\mathrm{mm})$ \\
\hline 1 & circular & 0.50 & $\varnothing 800$ \\
\hline 2 & circular & 1.13 & $\varnothing 1200$ \\
\hline 3 & rectangular & 1.13 & $1130 \times 1000$ \\
\hline 4 & circular & 2 & $\varnothing 1600$ \\
\hline 5 & rectangular & 2 & $2000 \times 1000$ \\
\hline 6 & rectangular & 2 & $2 \times(1000 \times 1$ \\
& rectangular & 3 & $2500 \times 1200$ \\
\hline 7 & rectangular & 4 & $2500 \times 1600$ \\
\hline 8 &
\end{tabular}

The optimization of the Modified configuration was based on maximizing $t_{m}$ and the fluid velocity homogeneity. As an example, Figure A.8 shows $t_{m}$ variable represented over a plane located at $0.60 \mathrm{~m}$ height (wall-bushing crossing section). Slightly differences can be appreciated among the configurations. Thus, Figure A.8a and A.8b show the improvement when increasing the crossing section. A hardly noticeable difference can be appreciated between different crossing section shapes enclosing the same flow area (Figure A.8c and A.8d). A gradual increase of the crossing section was tested showing that there was an optimum configuration, since above $2 \mathrm{~m}^{2}$ crossing section a $t_{m}$ variable field was worsening instead of getting better (Figure A.8e and A.8f). The latter shows an undesirable effect of the fluid induced by the wall bushing. It consisted of zones with upper $t_{m}$ values, which would correspond to be closer to the Outlet, located behind zones with lower $t_{m}$ values. 
a)

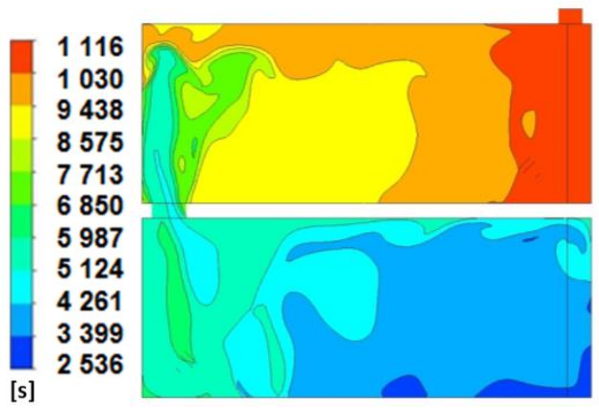

c)

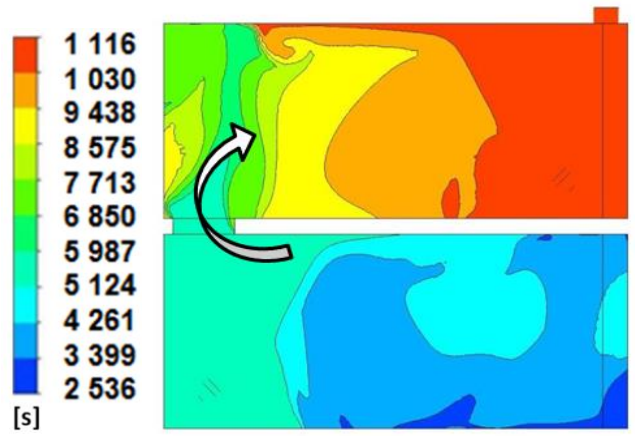

e)

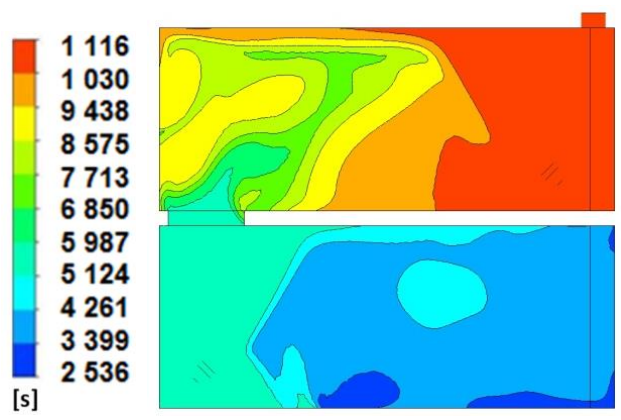

b)

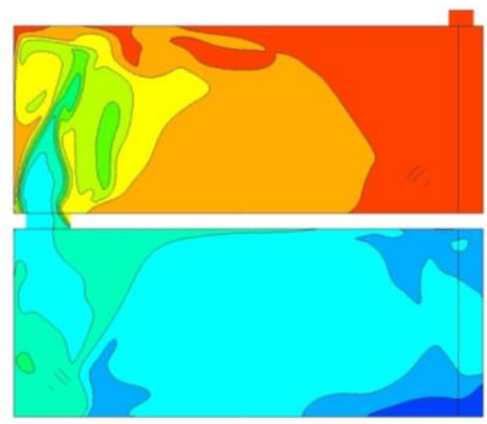

d)

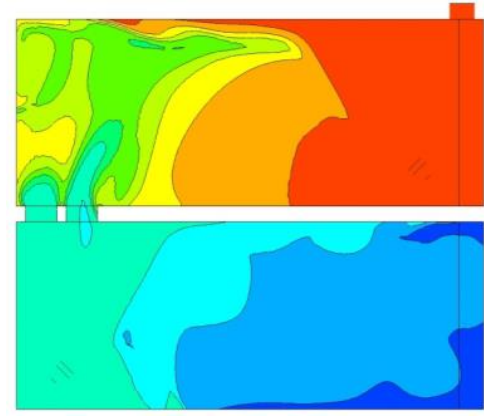

f)

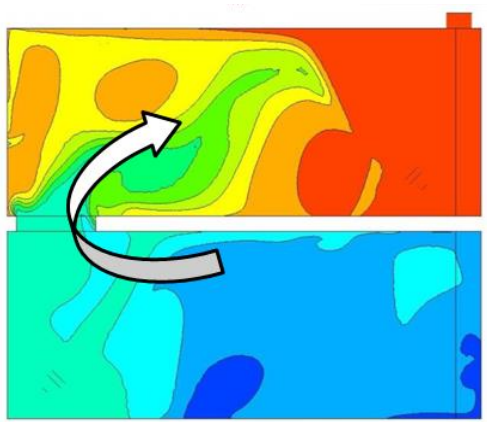

Figure A.8: Horizontal cross-sections for $t_{m}$ variable in a) configuration $1, b$ ) configuration 2, c) configuration 5, d) configuration 6 , e) configuration 7 and f) configuration 8 
In order to provide a more detailed description of the hydrodynamics inside the tanks, fluid velocity fields are shown for the different configurations. It will be noticed that a more homogeneous velocity field is achieved as the crossing section increased. Comparative fluid velocity profiles between configurations have been plotted over the dashed lines drawn in Figure A.9 and A.10. They show that there is a noticeable local reduction of fluid velocity when the crossing section increased from $0.5 \mathrm{~m}^{2}$ to $1.13 \mathrm{~m}^{2}$ (Figure A.9) and also up to $2 \mathrm{~m}^{2}$ (Figure A.10), and no substantial differences has been found depending on the number of wall-bushings (one or two) for $2 \mathrm{~m}^{2}$ configuration (Figure A.10).

a)

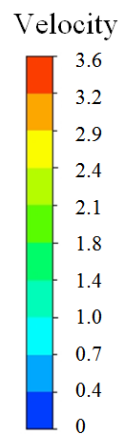

$[\mathrm{m} / \mathrm{s}]$

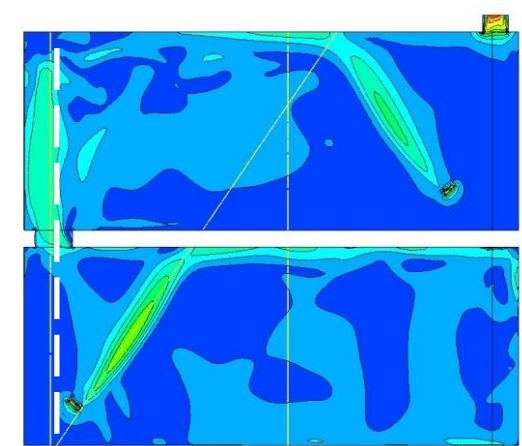

b)

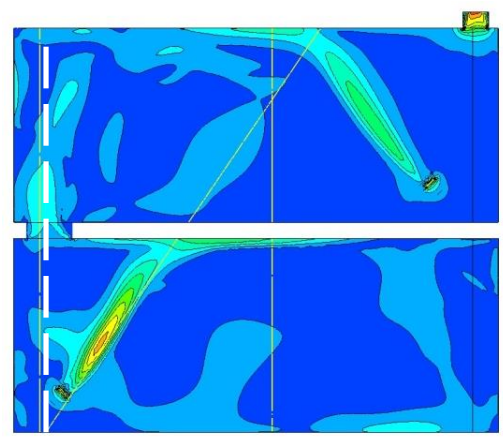

Figure A.9: Fluid velocity field in a) configuration 1 and b) configuration 2.

a)

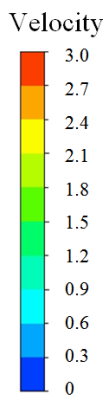

$[\mathrm{m} / \mathrm{s}]$

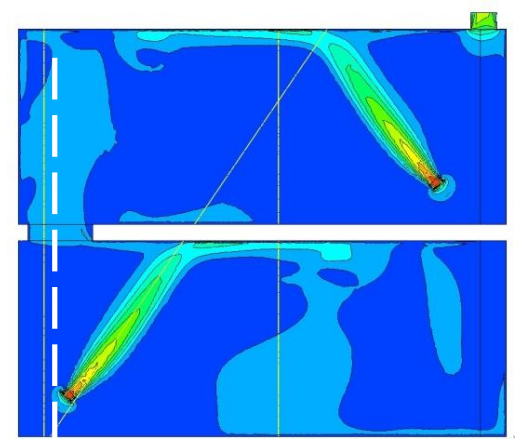

b)

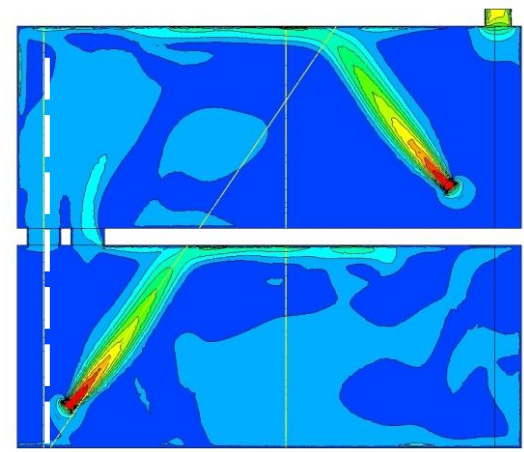

Figure A.10: Fluid velocity field in a) configuration 5 and b) configuration 6 .

After the steady state simulations, an optimal crossing section of $2 \mathrm{~m}^{2}$ with a rectangular wall-bushing shape (configuration 5) was selected. This configuration 
improved hydraulic efficiency indicating that more effective use of available tank volume was occurring (maximizing $t_{m}$ variable). Also, the resulting local velocity after the wall-bushing is reduced leading to an enhanced homogeneity of the fluid velocity field.

A comparative study was conducted to relocate the stirrer of the first tank according to its position and its angle. Transient simulations were performed reproducing the same procedure of the "short tracer tests" for 5 positions and 3 different angles. The purpose was to evaluate the stirrer mixing efficiency by means of the tracer concentration through the wall-bushing depending on these two factors. Tracer concentration was calculated as an average of the crossing section in time and it was used as the main indicator for the following approach: the higher mixing efficiency, the lower the tracer concentration exiting the first tank.

We have defined the Reference configuration under the assumption that the proper location for the stirrer (Modified stirrer) should be symmetrical from the initial one (Original stirrer).

The stirrer in the Reference case is therefore located at $0.70 \mathrm{~m}$ from the main wall (X direction), $1.5 \mathrm{~m}$ from the side wall (Y direction), and $1.2 \mathrm{~m}$ from the bottom ( $\mathrm{Z}$ direction). Then, in order to study variations around this reference, 5 additional locations were proposed. Table 5 summarizes the relative locations of these new positions.

Table A.5: Description of the different locations tested

\begin{tabular}{|c|c|c|c|}
\hline Location & $\begin{array}{c}\text { Relative position } \\
\text { X }(\mathrm{m})\end{array}$ & $\begin{array}{c}\text { Relative position } \\
\mathrm{Y}(\mathrm{m})\end{array}$ & $\begin{array}{c}\text { Relative position } \\
\mathrm{Z}(\mathrm{m})\end{array}$ \\
\hline Reference & 0 & 0 & 0 \\
\hline Ahead & 0.5 & 0 & 0 \\
\hline Up & 0 & 0 & 0.3 \\
\hline Down & 0 & 0 & -0.3 \\
\hline Right & 0 & 0.6 & 0 \\
\hline Left & 0 & -0.6 & 0 \\
\hline
\end{tabular}

Figure A11a shows the evolution of tracer concentration over time calculated at the crossing section for the different spatial locations. It is appreciated the different tracer performance obtained through the wall-busing after the pulse of mass tracer at the inlet. All cases presented a similar initial time, defined as the time from which tracer starts exiting the first tank. The maximum tracer concentration values are achieved for Up and Left relative positions of the stirrer which correspond to a reduced efficiency in terms of mixing. On the other hand, a much better mixing performance is achieved by Down and Right relative positions since lower tracer concentration values escaping the first tank are obtained. The Right position was finally chosen because it presented low values of tracer concentration and the maximum value of the initial time. 
a)

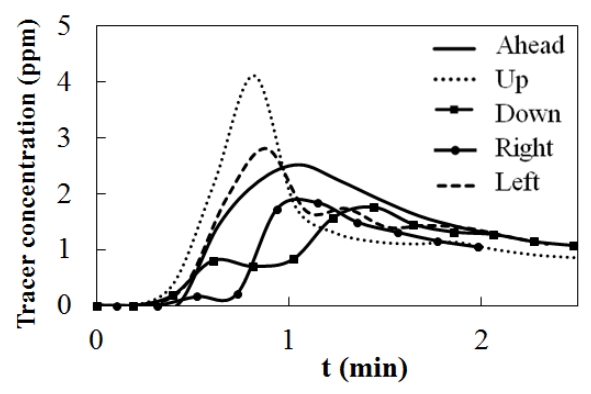

b)

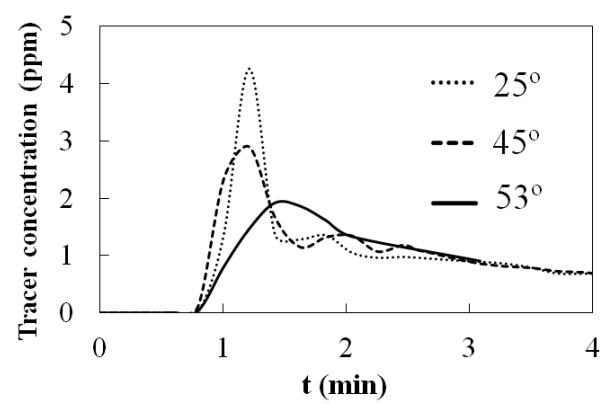

Figure A.11: Tracer concentration calculated at the crossing section for different a) positions and $b$ ) angle

Figure A.11b exhibits the importance of the angle when relocating the stirrer. The most acute angle provided a sharp peak related to an unintended high tracer concentration exiting the first tank. This peak was reduced when opening the angle of the stirrer respect to the Main wall. Note that real angles were tested since the mast of the stirrer in the real plant had limited positions. It was concluded that the angle of $53^{\circ}$ provided the lowest peak being potentially a good option to provide a much better mixing performance.

To conclude with the optimization study, Figure A.12 shows the comparison of the fluid velocity field between the Original and the Modified configuration after the optimization study. The wall-bushing was retrofitted removing the short circuiting and providing a homogeneous fluid velocity field; the $2 \mathrm{~m}^{2}$ rectangular shape option was selected. Moreover, the optimal configuration, corresponding to the stirrer placed in Right position at an angle of $53^{\circ}$, provided a mean residence time increased by $38 \%$ over the original anoxic zone. Also, maximum tracer concentration was reduced by $30 \%$. This optimal configuration will be referred to as Modified configuration from now on. 

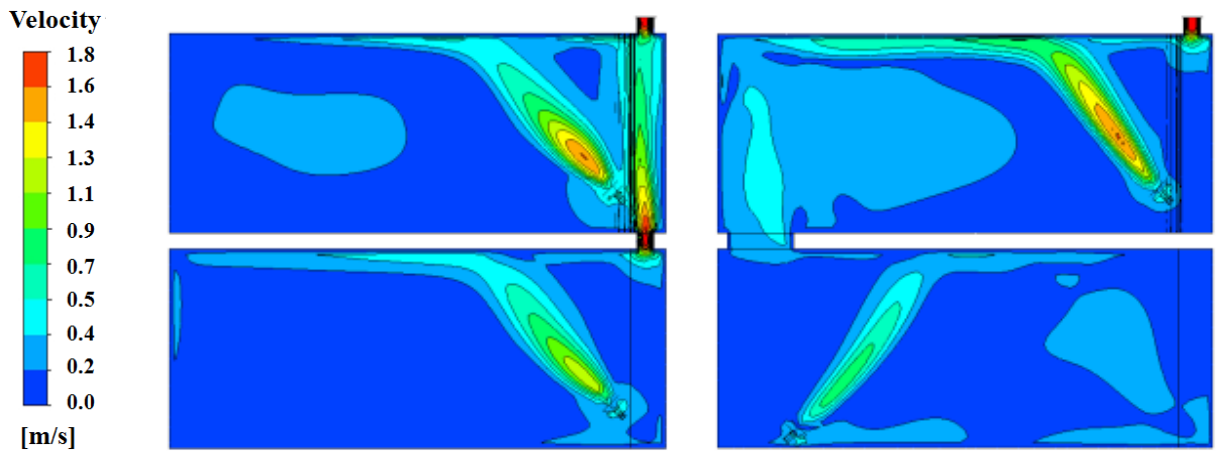

Figure A.12: Comparison of the fluid velocity field between the Original configuration (left) and the Modified configuration (right)

\section{A.3.2 Study of the denitrification process}

The CFD-ASM model was used to calculate and compare the denitrification performance for both configurations. Nitrate (Sno) and readily biodegradable organic substrate $(\mathrm{Ss})$ concentrations and their consumption rates were selected to evaluate denitrification process.

After the full-scale modification in WWTL1, permanent unbalanced denitrification efficiency was observed between both lanes; Modified WWTL1 was favoured over the Original WWTL2 in terms of effluent quality due to its better hydrodynamics performance. Figure A.13 shows the comparison between both WWTLs obtained for an equal continuous operational regime taking samples in time at the outlet of the aerobic tanks (point $\mathrm{C}$ in Figure A.2). Nitrate concentration of the Modified WWTL1 presented lower values than the Original WWTL2 being the average difference by $17 \%$, with a maximum difference of $60 \%$.

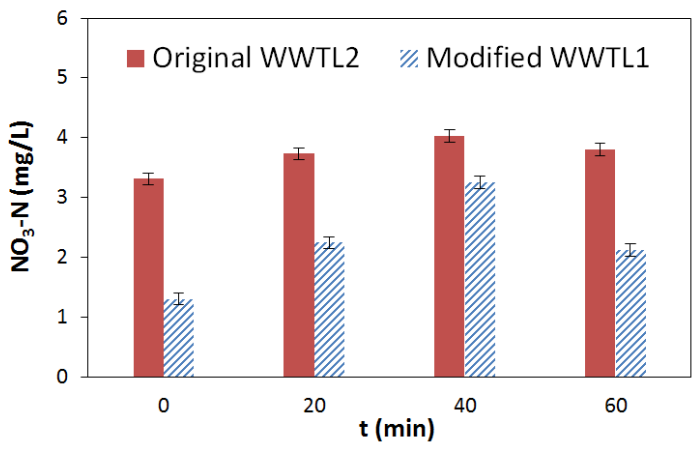

Figure A.13: Comparison of Nitrate measured at different times at outlet of both WWTLs 
Moreover, experimental measurements were conducted within both anoxic zones in order to validate the CFD-ASM model and comparing both WWTLs. On the one hand, a representative sampling volume was taken at four different control points located at 2.5m height inside both anoxic zones (P1, P2, P3 and P4 of Figure A.2). On the other hand, CFD-ASM1 results were calculated as an average concentration integrated over a specific bulk defined around each control point. Assuming the same distribution and composition of influent flow for both WWTLs, CFD-ASM1 models were performed defining the boundary conditions on equal terms for both configurations, except for the nitrate concentration at the internal recycling, which was adjusted because of the unbalanced state of the Modified WWTL1 being reduced by $17 \%$. CFD results reproduced correctly main trends of pollutant concentrations within the tank (Figure A.14) and (Figure A.15). In general, the tendencies provided by CFD-ASM1 models can be considered acceptable for both species, albeit some absolute values, particularly in P1, presented marked deviations. The difference for each measuring point between the Original and the Modified configurations should be less pronounced than calculated as the experimental data suggested.

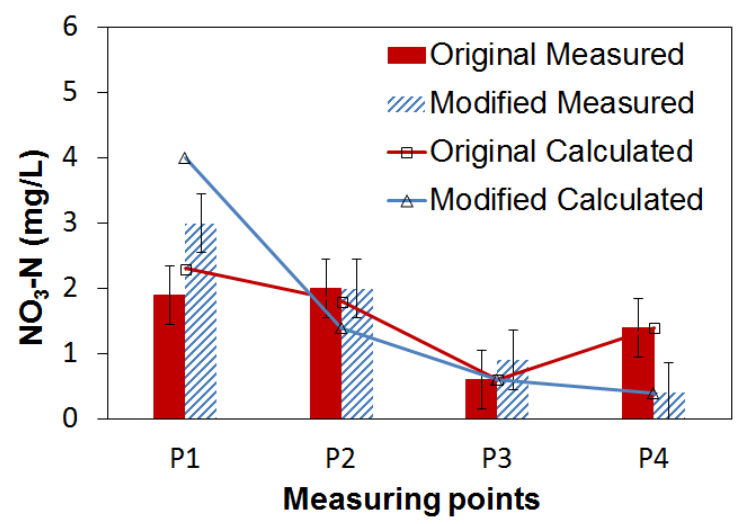

Figure A.14: Comparison between nitrate concentration measured and calculated at both configurations

Fitting full-scale sampling results obtained in a discrete way resulted particularly difficult. The majority of parameters for the biokinetic model were taken from ASM1 default at $20^{\circ} \mathrm{C}$ (Henze et al., 2000), but some of them such as the maximum specific growth rate and the decay coefficient for heterotrophic biomass, $\mu_{\mathrm{H}}$ and $\mathrm{b}_{\mathrm{H}}$, were determined by respirometry with the objective to provide further information of the anoxic growth of heterotrophs resulting of $6.9 \mathrm{day}^{-1}$ and $0.22 \mathrm{day}^{-1}$ respectively. Moreover, the half-saturation coefficient for heterotrophic biomass Ks $=4.9 \mathrm{gCOD} \mathrm{m}^{-3}$ was measured since it is the main parameter influencing growth 
rate (Arnaldos et al., 2015) and it presents a wider experimental value range compared with the other half-saturation default coefficients of Monod equations (Jeppsson, 1996). Yield for heterotrophic biomass $\left(\mathrm{Y}_{\mathrm{H}}\right)$ resulted in 0.68 COD formed/COD oxidized. Dissolved oxygen concentration was measured continuously at different locations ensuring values below $0.1 \mathrm{mg} / \mathrm{L}$ within the anoxic zone.

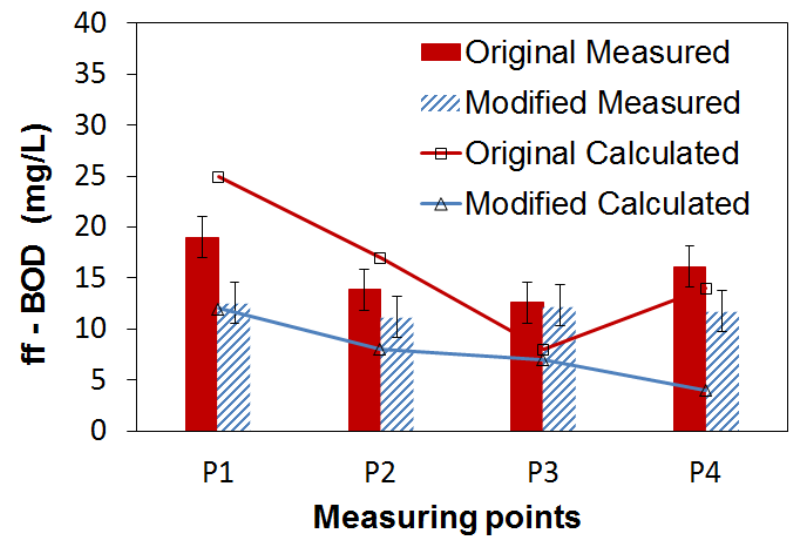

Figure A.15: Comparison between filtered BOD measured and readily biodegradable substrate concentrations calculated at both configurations
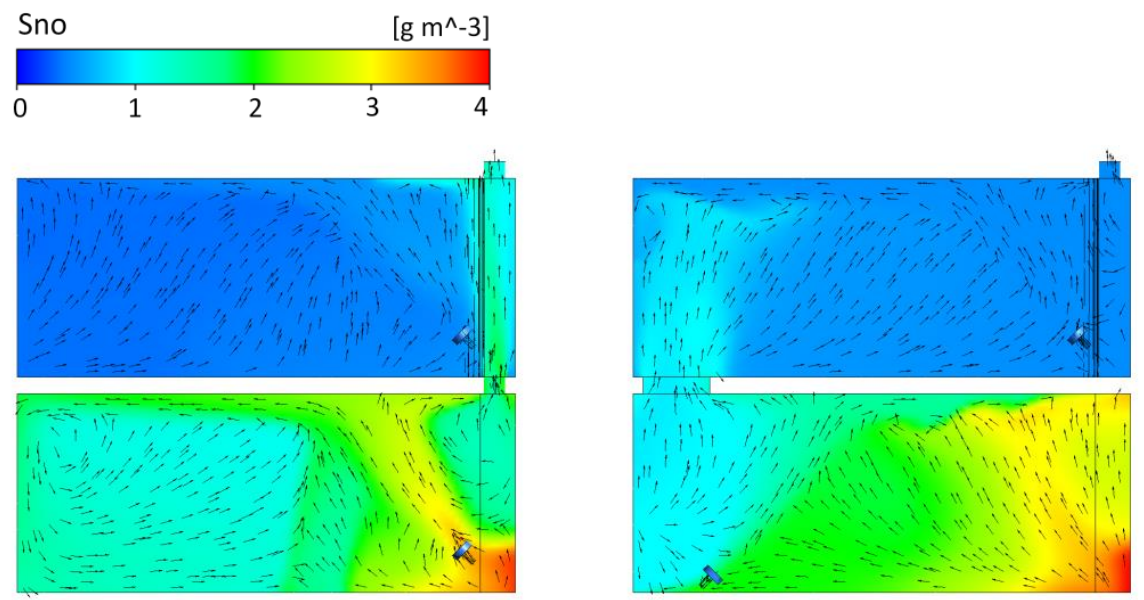

Figure A.16: Nitrate (Sno) at Original configuration (left) and at Modified configuration (right) 
Figure A.16 and A.17 show the comparison of nitrate and readily biodegradable substrate concentration distributions for the same scenario. The influence of the short-circuiting over the nutrient removal process can be noticed. Results show the improvement of the Modified configuration which provided lower nitrate concentration at the outcoming from the anoxic zone due to a better utilization of the organic matter for denitrification.
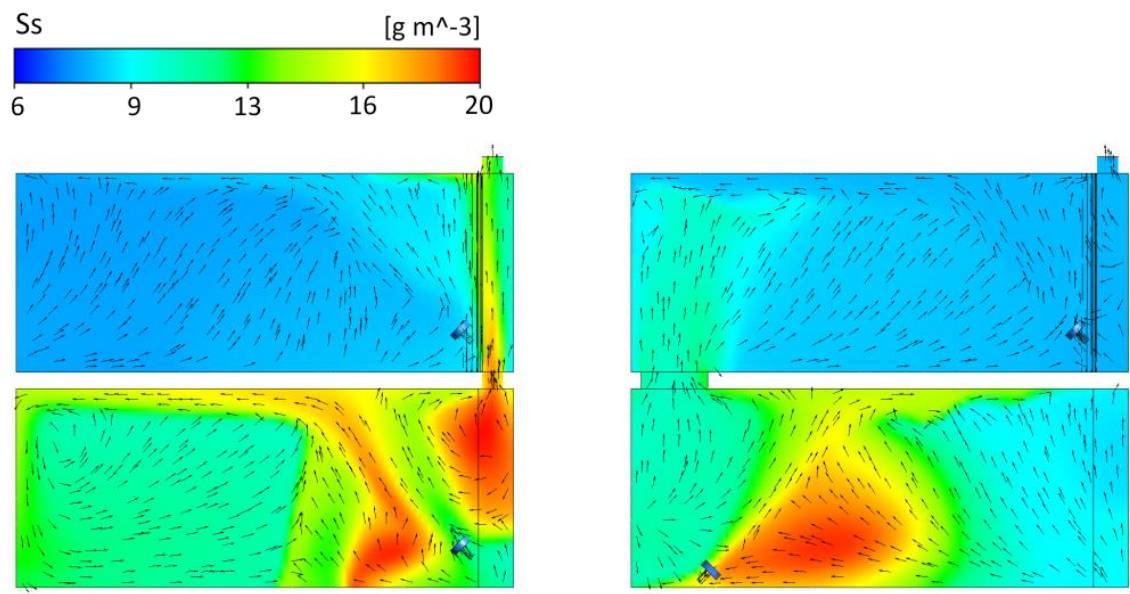

Figure A.17: Readily biodegradable substrate (Ss) at Original configuration (left) and at Modified configuration (right)

Following the evaluation of CFD-ASM1 results and taking into account the complexity to show the CFD performances in $3 \mathrm{D}$, the entire volume was divided into six virtual control cubicles. This analysis has been included providing biokinetic results from average values integrated in each subvolume. Results are shown by means of comparative histograms between both configurations.

Figure A.18 shows a noticeable improvement of the Sno performance for the Modified configuration which ensures low concentration at the outcoming anoxic flow and a better use of the available anoxic volume. The more plug-flow hydrodynamic behaviour from the retrofitting can be appreciated following the Sno value. The Original configuration showed the effect of the short-circuiting providing an undesirable high concentration at the outlet. Moreover, it exhibited locally high Ss values along the short-circuiting (Figure A.19). Because of the different hydrodynamics performance, consumption rates in the Original configuration offered the maximum values nearby the outlet (Figure A.20) and (Figure A.21) which tended to worsen denitrification efficiency within the entire anoxic zone. The other nitrogen compounds remained practically unchanged 
between configurations. The Snd, Snh and Xnd state variables concentration were calculated within the tank, showing average differences between cases (Original and Modified) lower than 5\%.

\begin{tabular}{|lllrr} 
Sno & & & \multicolumn{2}{r}{$\left[\mathrm{g} \mathrm{m}^{\wedge}-3\right]$} \\
\hline 0 & 1 & 2 & 3 & 4
\end{tabular}
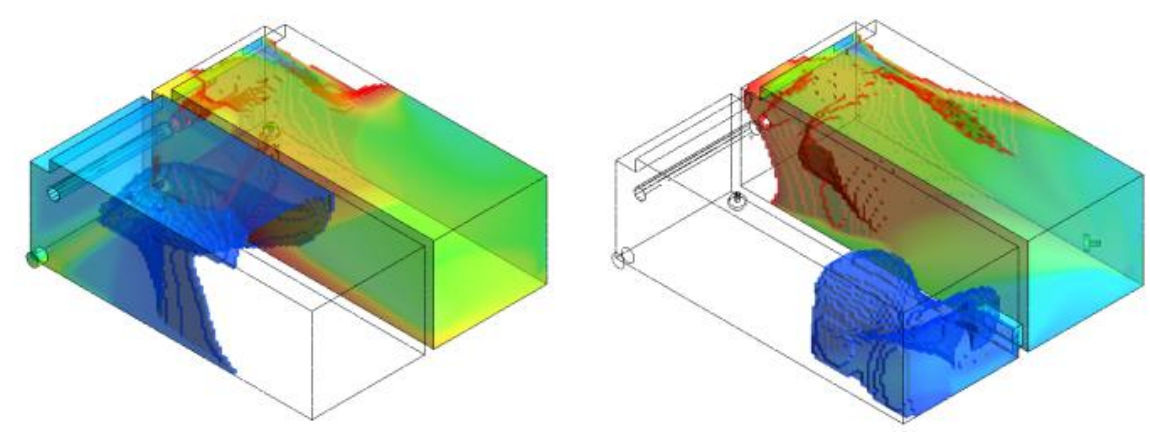

Figure A.18: Nitrate (Sno) at Original configuration (left) and at Modified configuration (right)
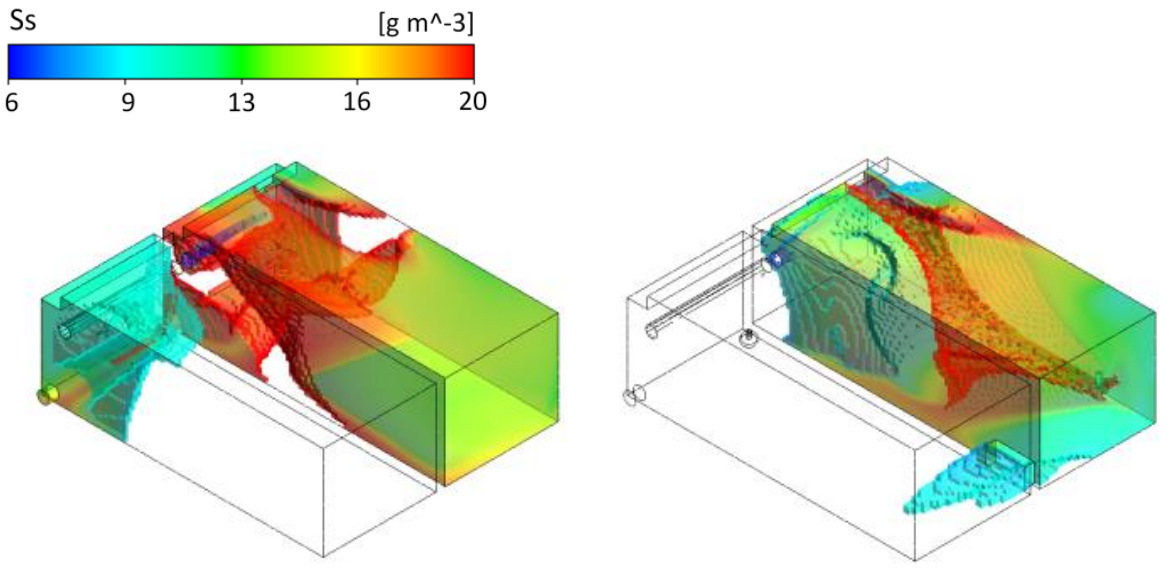

Figure A.19: Readily biodegradable substrate (Ss) at Original configuration (left) and at Modified configuration (right) 

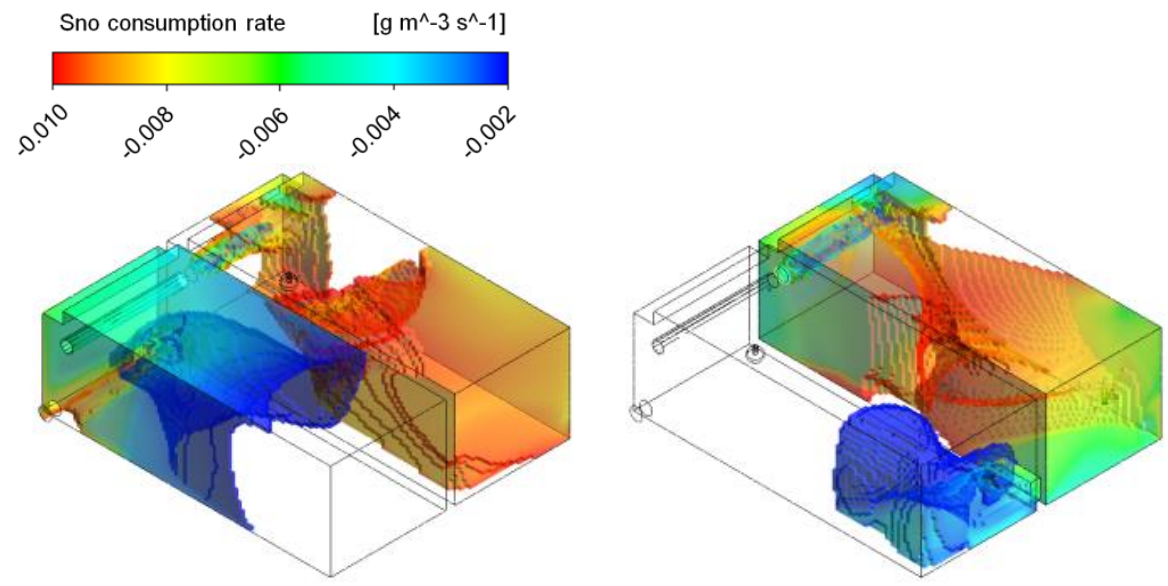

Figure A.20: Nitrate consumption rate (g m-3 s-1) at Original configuration (left) and at Modified configuration (right)
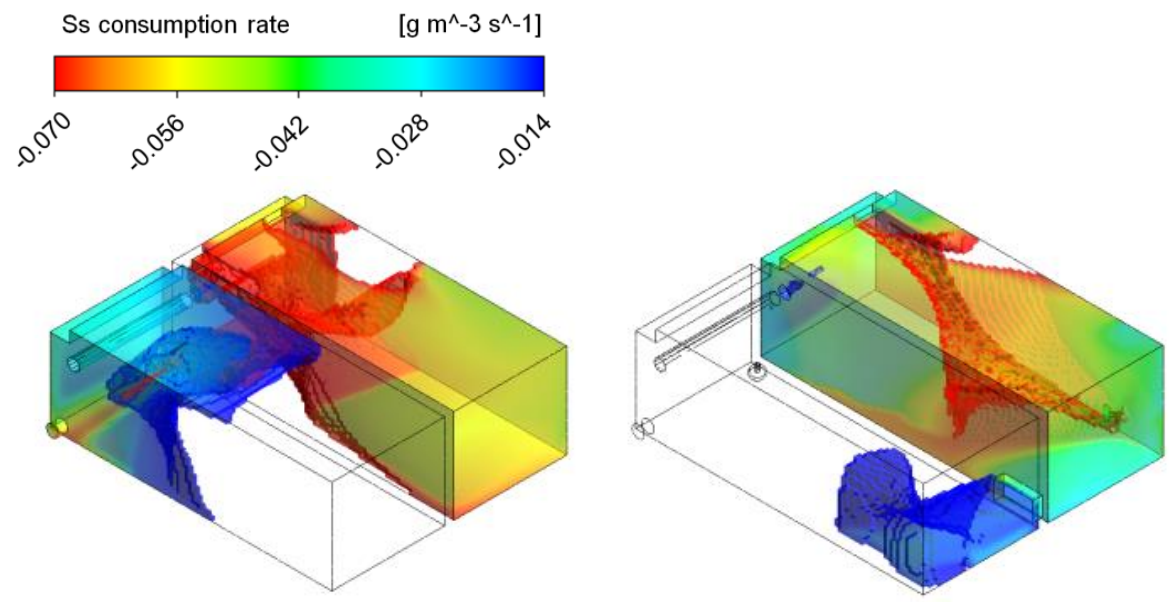

Figure A.21: Readily biodegradable substrate consumption rate (g m-3 s-1) at Original configuration (left) and at Modified configuration (right)

It is clear that CFD-ASM can provide a more faithful representation of the process, but as (Le Moullec et al., 2011) pointed out, the complexity of the factors which depend on the reactor biomass-wastewater characteristics may provide more intricacy to adapt to a local approach such as CFD. Even so, results from CFD- 
ASM1 allowed the evaluation of changes in configuration in full-scale tanks, reproducing pollutant removal based on hydrodynamic performance.

\section{A.4. Conclusions}

CFD techniques can be successfully coupled with kinetic models as the ASM1 in order to provide a full description of the process within biological reactors. This coupling CFD-ASM permits to obtain detailed 3D velocity fields and biochemical compounds distributions. It is also possible to analyse the time evolution of these compounds distributions once they entry the reactor.

This work presents a case study using CFD-ASM1 to optimize the performance of a full-scale MLE biological reactor. The analysis of the reactor hydrodynamics revealed the strong influence of a short-circuiting in the anoxic zone on the overall behaviour. An alternative setup named Modified configuration, was proposed to avoid the short-circuiting. This configuration performance is based on the relocation of the wall-bushing and the stirrer. The CFD-ASM1 was used to optimize the shape and size of the wall-bushing and the location and the orientation of the stirrers in order to increase both the mean residence time and flow homogeneity, leading to an enhanced pollutant removal. The model was validated with experimental results for both Original and Modified configuration. Furthermore, a novel resolving scheme was proposed in order to significantly reduce the computational cost of the CFDASM simulations. The proposed approach consists of the solution of the steady state hydrodynamics followed by a transient simulation of compound transport that uses a specific time-stepping scheme. Several simulations were performed to show that this procedure provides accurate results at a reduced time cost.

\section{Acknowledgements}

The authors would like to gratefully acknowledge the support provided by Entidad Pública de Saneamiento de Aguas Residuales (EPSAR). 


\section{Appendix B}

\section{A comprehensive hydrodynamic analysis of a full-scale oxidation ditch using CFD simulation}

\section{Article B}

J. Climent, R. Martínez-Cuenca, P. Carratalà, M. J. González-Ortega, G., M. Abellán, Monrós and S. Chiva (2018). A comprehensive hydrodynamic analysis of a full-scale oxidation ditch using Population Balance Modelling in CFD simulation. Chemical Engineering Journal. 374, 760-775. 



\begin{abstract}
This work exhibits the importance of the experimental validation when full-scale computational fluid dynamics (CFD) models are developed to provide a detailed analysis of the spatial variations in 3D of the fluid flow inside aerated tanks. Singlephase and two-phase CFD models were performed to study the fluid behaviour carefully by means of the velocity profiles and the aeration pattern in a full-scale oxidation ditch. Air hold-up, bubble size distribution and interfacial area density were calculated by polydisperse models where Population Balance Model (PBM) was governed by break-up and coalescence; the free-surface approach allowed the CFD model to describe the three-dimensional effect of bubbly plumes in large scales in detail. Tracer tests were carried out to obtain the flow pattern and the hydraulic distribution of the flow into two wastewater treatment lanes in order to define the boundary conditions for the model correctly. Despite the difficulty of performing velocity measurements of the fluid in $3 \mathrm{D}$, with and without air bubbles, these provided essential information to validate the CFD model. From this analysis, several simulations were performed to improve the hydrodynamics and the operation of the process by relocating the propellers.
\end{abstract}

Keywords: CFD; Hydrodynamics; Oxidation ditch; Population Balance Model; RTD; Two-phase flow

\title{
Higlights
}

- The CFD model predicted a reduction of $60 \%$ in the axial fluid velocity within the outer channel when air was supplied.

- The PBM analysis revealed the predominance of the coalescence

- A very detailed hydraulic validation was carried out by 3D velocity measurements.

- The optimal configuration proposed provided a significant process improvement.

\section{B.1 Introduction}

In recent years, there has been a noticeable increase in the scientific production related to wastewater treatment (WWT) modelling performed with Computational Fluid Dynamics (CFD) techniques. As occurred in other industries, it has evolved into a robust and precise technique for design and optimization of Activated Sludge (AS) systems. Reactors in wastewater treatment plants (WWTP) are typically designed as mixed or as plug flow configurations. However, real reactors often show more complex macroscopic flow structures with negative effects on plant performance and control (Gresch et al., 2010). A considerable number of CFD studies showed the importance of hydrodynamics for the process and modelling of 
biological reactors (Karpinska and Bridgeman, 2016), the WWT efficiency is influenced not only by the bio-reaction of activated sludge, but also by the fluid behaviour including the bubble/liquid flows. This is the scope of the present study. The CFD techniques may provide valuable hydrodynamic information of an AS bioreactor in order to apply this understanding to the process (Glover et al., 2006), especially when the tank has a non-standard design, such as the atypical oxidation ditch configuration studied in this work.

Mixing is provided by propellers and aerators in oxidation ditch configurations. The objective of the propellers is to keep the biomass suspended and provide velocity to the flow across the channels, while aeration, which is the oxygen source for the process, also provides the mixing energy by creating turbulence in the system (Metcalf \& Eddy, 2004). In the studies of submerged aeration systems using CFD, authors have mostly investigated the mixing pattern of the aeration tanks from the point of view of the aeration efficiency, e.g. pointing out both the influence of the diffuser layout and the axial liquid velocity on the oxygen mass transfer coefficient (Gresch et al., 2010; Hreiz et al., 2018; Cockx et al., 2001; Fayolle et al., 2007; Fayolle et al., 2010). Unlike other works in this field, this study aims to obtain a deeper understanding of the CFD liquid-gas approach as well as the experimental validation to reproduce hydrodynamics more faithfully in $3 \mathrm{D}$ to be applied to the aeration process in full-scale biological reactors.

To date, CFD models have been primarily used for evaluation of hydraulic problems in different process units of WWTPs in order to optimize the design and operation. Dynamic simulation of a whole WWTP is still not feasible and it would not be cost-effective. Authors agree that one of the major bottlenecks of using CFD is its high computational requirement (Laurent et al., 2014). On the one hand, CFD modelling of full-scale biological reactors defined as single-phase modelling is the most widespread approach because it takes less calculation time than multiphase fluid models to reproduce suspended solids in liquid systems. Good predictions of concentrated solid-liquid systems can be achieved in a short computing time using the single-phase non-Newtonian fluid models (Eshtiaghi et al., 2013; Brannock et al., 2010).

Although the sedimentation of the solids in the mixed liquor can be taken into account by implementing the drift-flux model (Xie et al., 2014), single-phase CFD models can be considered the most feasible approach to keep computing time low provided that the minimum velocity of the mixed liquor to keep the solids suspended is ensured (Aubin et al., 2004; Le Moullec et al., 2011). In this study, the mixed liquor has been defined as a single-phase non-Newtonian fluid.

On the other hand, the Eulerian approach is the most commonly used in multiphase gas-liquid flow in full-scale aeration tanks. Comparing workability of different 
options in multiphase modelling, the other approaches available (Lagrangian particle tracking or Volume Of Fluid), despite being more accurate, are exceedingly expensive in terms of computing time and memory (Samstag et al., 2016). Population Balance Models (PBMs) represent a powerful modelling framework for the description of the dynamics of the properties that are characterised by statistical distributions (Nopens et al., 2012). CFD models reproduce the dispersed phase motion more correctly when PBM is applied, it can define the presence and the interaction of bubbles, based on break-up and coalescence models (Wang et al., 2011; Marchisio and Fox, 2005; Karpinska and Bridgeman, 2017).

Several two-phase flow (gas-liquid) CFD models have been developed over the last years focused on aeration of full-scale oxidation ditch configurations (Karpinska and Bridgeman, 2016; Karpinska and Bridgeman, 2018). Multiphase modelling of AS tanks based on gas-liquid neutral density resulted in an overestimation of the mixing degree and its applicability to study bubbly bioreactors is still uncertain (Samstag et al., 2012). The bubble size and the air hold-up are the parameters of paramount importance that govern the interfacial area. The degassing approach and a fixed bubble diameter definition are commonly used as an input in the model, but the code does not calculate the interfacial area density during the simulation (Gresch et al., 2010; Hreiz et al., 2018; Fayolle et al., 2007; Fayolle et al., 2010; Brannock et al., 2010; Le Moullec et al., 2008; Potier et al., 2005). Unlike the other works mentioned and despite the high computational cost, the PBM and the freesurface approach have been used in this work to study the dispersed phase dynamics including the liquid-air interface to calculate the interfacial area density.

Usually, experimental data supplied to validate CFD models is relatively scarce due to the conflicting interests in terms of economics, time and complexity, especially in full-scale tank studies. In addition to the determination of the global fluid behaviour by tracer tests, very accurate results can be obtained using specific instrumentation to provide local measurements that CFD predictions require (Brannock et al., 2010; Wicklein et al., 2016). This paper shows a remarkable CFD modelling contribution through a comprehensive hydrodynamic analysis of an aerated tank, validated with local velocity measurements in $3 \mathrm{D}$.

The outline of this work was divided in three parts. Firstly, tracer tests are analysed to describe the global fluid behaviour. Subsequently, tracer results are related to the detailed description of the hydrodynamics provided by the CFD results. These were obtained for single-phase and two-phase flow models, depending on whether the air is supplied or not. A valuable comparison of the two hydrodynamic regimes is shown in this section. Secondly, the experimental validation for both cases is discussed and then, the PBM results are analysed. Finally, the improvement of the hydraulic behaviour carried out using CFD modelling is shown. 


\section{B.2 Materials \& methods}

\section{B.2.1 Description of the biological reactor}

A full-scale biological reactor (WWTP La Union, Spain) of $7800 \mathrm{~m}^{3}$ has been chosen for this study. This is composed of two symmetrical oxidation ditch units which consist of two wastewater treatment lanes (WWTLs) set in parallel. The CFD model was only elaborated in one of the tanks. The influent flow, about 1300 $\mathrm{m}^{3} /$ day, and the external recycling arrive previously mixed into the inner channel (through the inlet), which is expected to operate in anoxic conditions. Subsequently, fluid flow passes through the channel spacing (Fig. B.1), which communicates both channels to the outer channel, leaving afterwards the biological reactor (outlet) and going to the secondary settler tanks.

Mixing is provided by two submerged impellers (propellers) and the aeration diffuser system. The aeration area is divided in three grids of 153 diffusers ( 9 rows and 17 columns) located in the outer channel and installed at a height of $22 \mathrm{~cm}$ (Fig. B.1). The aeration is supplied following on-off cycles set by the ammonia concentration which is measured by a probe located at the outlet. As in the previously mentioned works conducted in oxidation ditch configurations previously mentioned, the hydrodynamic and mixing conditions of the tank become even more important because simultaneous nitrification and denitrification is desired, as this case, at the outer channel, where both aerobic and anoxic conditions are present.

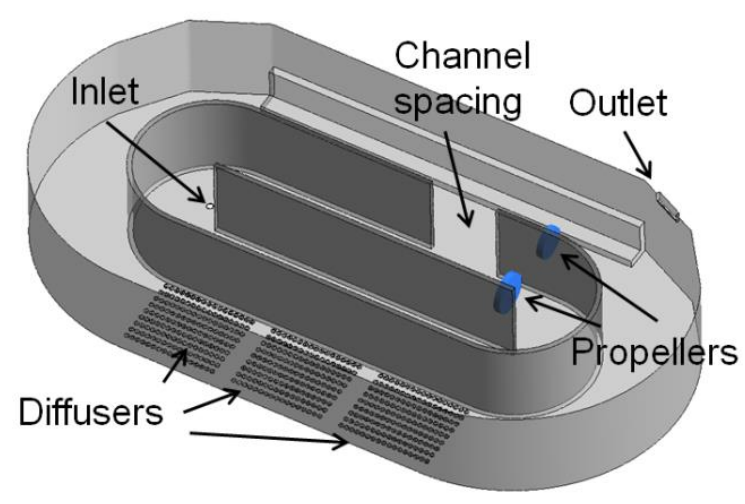

Figure B.1: 3D view of the full-scale model corresponding to WWTL1 


\section{B.2.2 CFD Modelling}

The CFD models elaborated in this study have been implemented by using the ANSYS ${ }^{\circledR}$ Academic Research Release 16.2. Two steady-state models have been implemented: a single-phase model representing the hydrodynamic conditions when the aeration is off, and a two-phase model to represent the flow hydrodynamic conditions when the aeration is on. To ensure a good quality of the simulation results, the time step was selected to keep the mean Courant number below 0.5. Time convergence was ensured by stopping the iterative solver with a mean RMS of $10^{-5}$. Spatial convergence (grid independency) was checked by conducting a GCI test.

Tracer tests were mainly used to define the influent flow rate entering the 3D domain. Then, after the calibration of the thrust of the propellers, the CFD models were extensively validated through the comparison of the experimental data using 3D fluid velocity profiles. Finally, different configurations were studied through alternative CFD models, based on changing the position of the propellers, to obtain an improved hydraulic configuration.

\section{B.2.2.1 Single-phase}

During the non-aeration stage, the flow within the aeration tank can be accurately described by a single-phase model. The mixed liquor was modelled as an incompressible non-Newtonian Herschel-Bulkley fluid based on rheological measurements; the fitting parameters (Climent et al., 2018) were $\tau_{0}=0.00883 \mathrm{~Pa}$; $\mathrm{K}=0.01932 \mathrm{~Pa} \mathrm{~s}^{n} ; n=0.6262$. Turbulence was modelled by using the Shear Stress Transport model (Menter, 1994) with automatic near-wall treatment. On the one hand, the SST turbulence model used consists on a two-equation eddy-viscosity turbulence model that combines the k- $\omega$ turbulence model near the wall when the inner region of the boundary layer has a dominant effect and $k-\varepsilon$ turbulence model in the free shear flow. On the other hand, the automatic near-wall treatment implemented permits a consistent transition between regions with coarse meshes, where the viscous sublayer is modelled using the scalable wall functions developed by ANSYS ${ }^{\circledR}$, to regions with fine meshes, where the viscous sublayer can be fully resolved as long as 10 nodal points fall within it.

The tank walls were set as smooth non-slip walls, whereas the water surface was set as a free-slip wall. Inlet condition was set from the influent mass flow rate entering the domain normal to the inlet surface. The mass flow rate at the outlet boundary condition was set to the same value. The reference pressure was set to atmospheric pressure at the air water interface.

Regarding the implementation of the propellers, the momentum source approach was used. Here, the propeller geometry is replaced by a cylindrical subdomain 
containing a momentum source driving the fluid movement that accounts for the flow continuity though it. The corresponding volumetric momentum source, $\mathrm{M}(\mathrm{kg}$ $\mathrm{m}^{-2} \mathrm{~s}^{-2}$ ), can be calculated as

$$
M=\frac{\rho}{V_{c y l}}\left(\frac{q}{D}\right)^{2},
$$

$D$ being the diameter of the stirrer $(\mathrm{m}), \rho$ the fluid density $\left(\mathrm{kg} \mathrm{m}^{-3}\right)$ and $V_{c y l}\left(\mathrm{~m}^{3}\right)$ the volume of the cylindrical subdomain. The flow rate propelled, $q\left(\mathrm{~m}^{3} / \mathrm{s}\right)$, can be obtained as

$$
q=C D\left(\frac{F}{\rho}\right)^{\frac{1}{2}} .
$$

In this equation, $F$ stands for the thrust force $(\mathrm{N})$ and $C$ is constant parameter related to the propeller efficiency, depending on several factors such as the tank geometry or flow configuration.

In practice, technical sheets provided by propeller manufacturers include values for the stirrer diameter and thrust force, whereas the parameter $C$ must be adjusted in the model so that the flow rate in the tank matches the experimental one. In the present case, the parameter $\mathrm{C}$ was calibrated for each propeller, fitting the average velocity calculated at two sections of the channels of the tank with the experimental data. Unlike other authors (Rehman, 2016), the swirling flow effect was not implemented separately, it was assumed to be included implicitly in the calibration of the momentum source of the propeller. As a result, the internal propeller was represented by a thrust force of $1750 \mathrm{~N}$, a blade diameter of $2.5 \mathrm{~m}$, and $\mathrm{C}=0.875$. With respect to the outer diameter, the force was $1750 \mathrm{~N}$, with a blade of $2 \mathrm{~m}$ and $\mathrm{C}=0.875$. As subdomains, the cylinder diameters were set equal to the corresponding blade diameters, with a cylinder length of $0.4 \mathrm{~m}$. The momentum sources resulted in 300 and $440 \mathrm{~kg} \mathrm{~m}^{-2} \mathrm{~s}^{-2}$, respectively.

\section{B.2.2.2 Two-phase flow}

The effects of the air injection significantly change the hydrodynamics flow when the aeration is applied. Momentum transfer from bubble swarms have a clear influence on the velocity field of the mixed liquor, especially in the region located right on the top of the aerators. This simulation has been set up accurately to account for these hydrodynamic changes focusing on the modelling of the diffusers and the free surface. Also, the oxygen in the air bubbles is transferred to the mixed liquor. Given the dimensions of the domain and the huge number of bubbles to be implemented, the two-phase Eulerian-Eulerian framework was selected to account for these two effects in the CFD model.

In this approach, the flow dynamics is determined by the mass and momentum conservation equations, 


$$
\frac{\partial}{\partial t}\left(\alpha_{r} \rho_{r}\right)+\nabla \cdot\left(\alpha_{r} \rho_{r} \vec{U}_{r}\right)=S_{r}
$$

and

$$
\begin{aligned}
& \frac{\partial}{\partial t}\left(\alpha_{r} \rho_{r} \vec{U}_{r}\right)+\nabla \cdot\left(\alpha_{r} \rho_{r} \vec{U}_{r} \vec{U}_{r}\right)= \\
= & -\alpha_{r} \nabla p+\alpha_{r} \rho_{r} \vec{g}+\nabla\left\{\alpha_{r} \mu_{e, r}\left[\nabla \vec{U}_{r}+\left(\nabla \vec{U}_{r}\right)^{T}\right]\right\}+\vec{M}_{r},
\end{aligned}
$$

for each phase $r$, using the sub-index $c$ for the continuous phase and $d$ for the dispersed one. The fluids densities and effective viscosities are represented by $\rho_{r}$ and $\mu_{e, r}$, whereas flow properties as the volume fraction for each phase and the corresponding velocity vectors are given by $\alpha_{r}$ and $\vec{U}_{r}$, respectively. The pressure, $p$, and the gravity vector, $\vec{g}$, are common for both phases. The mass transfer between the phases is accounted for by the source term, $S_{r}$, and the momentum exchange between them is determined by the so-called interfacial forces, $\vec{M}_{r}$.

To model the continuous phase (wastewater), the rheological conditions from the single-phase model were preserved. Also, the SST model was used for the turbulence modelling. The same boundary conditions as in the single-phase case were used, except for the water surface. In this configuration, the water-air surface was modelled by means of a free-surface model (Brackbill et al., 1992) instead of the degassing approach used in the references included in this work. The displacement of the liquid level caused by the injection of the air is thus accurately reproduced, leading to a better description of the flow in the regions surrounding the aerators. The top surface of the domain was set as an opening to the atmosphere.

The dispersed phase (air bubbles) was modelled as a polydispersed-incompressible phase by using the homogeneous MUSIG framework (Brackbill et al., 1992). In this population balance approach, the dispersed phase is divided into $\mathrm{M}$ discrete groups, each one labelled by an index $\mathrm{m}$ and characterized by a given bubble diameter, $D_{b, m}$. The fraction of bubbles that fall into each group is named as the group size fraction, $f_{m}$. In order to develop a transport equation, the number density of group $\mathrm{m}, n_{m}$, is introduced as

$$
n_{m}=\rho_{d, m} \alpha_{d} f_{m}
$$

where $\rho_{d, m}$ is the density of the m-th group. The resulting transport equation reads as follows:

$$
\frac{\partial\left(n_{m}\right)}{\partial t}+\nabla \cdot\left(n_{m} \vec{v}_{d}\right)=S_{B, m}+S_{C, m},
$$

being $S_{B, m}$ and $S_{C, m}$ the break-up and coalescence source terms, respectively.

The break-up source term can be calculated as 


$$
S_{B, m}=\sum_{m^{\prime}>m}^{M} \beta_{m^{\prime}, m^{\prime}} \Omega_{m^{\prime}} n_{m^{\prime}}-\Omega_{m} \mathrm{n}_{m} .
$$

Note that the sum in the first term of the right-hand side of this equation stands for the birth of bubbles in group $m$ due to the break-up of bubbles of bigger sizes, and it depends on the break-up frequency of every group, $\Omega_{m}$, and the family probability distribution function, $\beta_{m^{\prime}, m}$. The second term accounts for the death of bubbles in group $m$ due to their break-up resulting in bubbles of group $\mathrm{m}^{\prime}$. In order to compute the break-up frequency, the well-known model of Luo and Svendsen (Luo and Svendsen, 1996; Liao and Lucas, 2009) was used.

The coalescence source term, $S_{C, m}$, is calculated as

$$
S_{C, m}=\sum_{m^{\prime}=1}^{m} \lambda_{m^{\prime}, m} h_{m^{\prime}, m} n_{m^{\prime}-m, m} n_{m^{\prime}}-n_{m} \sum_{m^{\prime}=1}^{M} \lambda_{m, m^{\prime}} h_{m, m^{\prime}} n_{m^{\prime}} .
$$

The first term on the right hand side accounts for the birth of new bubbles in the group $m$ due to the coalescence of smaller bubbles, and depends on the coalescence frequency between groups, $\lambda_{m^{\prime}, m}$, and the collision efficiency, $h_{m^{\prime}, m}$. The second term arises from the death of members of the m-th group, i.e. when a bubble of the $\mathrm{m}$-th group collides with another bubble and the resulting bubble belongs to group $m^{\prime}$. In this work, the collision frequency and efficiency are modelled basing on the work of Prince and Blanch (Prince and Blanch, 1990). The resulting coalescence frequency is slightly modified as suggested in (Liao and Lucas, 2010), by multiplying the resulting frequency by two factors. The first one to take into account the space occupied by the bubbles themselves as proposed by $\mathrm{Wu}$ correlation (Wu et al., 1998),

$$
\frac{1}{\alpha_{r, \max }^{\frac{1}{3}}\left(\alpha_{r, \max }^{\frac{1}{3}}-\alpha_{r}^{\frac{1}{3}}\right)^{\prime}}
$$

being $\alpha_{r, \max }=0.8$ the maximum packing limit for a polydispersed flow. The second one is introduced to account for the finite length of the eddies that cause the bubble collisions. If these transporting eddies are much shorter than the distance between bubbles, then there will be no collisions. This can be included by using a multiplicative factor as the one proposed in Wang correlation (Wang et al., 2005; Wang et al., 2005),

$$
\Pi=\exp \left[-\left(\frac{l_{b, m, m^{\prime}}}{l_{e, m, m^{\prime}}}\right)^{6}\right],
$$

where $l_{b, m, m^{\prime}}$ stands for the mean distance between bubbles, that was approximated by 


$$
l_{b, m, m^{\prime}}=\frac{\left(\frac{D_{b, m^{\prime}}+D_{b, m}}{2}\right)}{\left(\frac{3 n_{m}+3 n_{m^{\prime}}}{\pi}\right)^{\frac{1}{3}}},
$$

and $l_{e, m, m^{\prime}}$ for the mean length of the transporting eddies, that was fit as

$$
l_{e, m, m^{\prime}}=0.89\left(\frac{D_{b, m^{\prime}}+D_{b, m}}{2}\right) \text {. }
$$

In the proposed simulations, 10 groups were defined. The group bubble diameters were uniformly distributed between 1 and $10 \mathrm{~mm}$ (Group 1 corresponding to $1 \mathrm{~mm}$ bubble size and so on).

With respect to the boundary conditions, tank walls were introduced as free-slip walls for the dispersed phase, and non-slip condition for the liquid phase. Regarding the inlets, let us recall that a total air flow-rate of $990 \mathrm{Nm}^{3} / \mathrm{h}$ was injected evenly by the 459 disc diffusers ( 3 grids of 153 diffusers each). So each diffuser was modelled as an air inlet boundary condition, providing the specified mass flow rate. The size distribution at the inlet was approximated to a monodisperse $3 \mathrm{~mm}$ (this is the mean size provided by the manufacturer of the diffusers). To complete the boundary condition, the hold-up at the inlet was computed as

$$
\alpha=\frac{Q_{\text {gas }}}{A_{\text {inj } v_{t}}} .
$$

In this equation, $v_{t}$ stands for the terminal velocity corresponding to $3 \mathrm{~mm}$ air bubbles in clean water (using Jamialahmadi correlation (Jamialahmadi et al., 1994), this resulted in $0.25 \mathrm{~m} / \mathrm{s}$ ) and $A_{\text {inj }}$ represents the diffuser area corresponding to $0.023 \mathrm{~m}$ and $0.050 \mathrm{~m}$ for the internal and the external diffuser diameter, respectively (resulting in an area of $0.039 \mathrm{~m}^{2}$ ). Given these conditions in the setup, the inlet hold-up resulted in a $5.65 \%$.

Note that, unlike previous works mentioned which injected air through the total surface of the diffuser, in this simulation the diffusers were drawn in detail with 3D CAD software to introduce air only through the perforated annular area. This increased considerably the total number of nodes of the mesh compared to the single-phase model, from 2,014,856 to $2,927,830$. The modelling of the free surface made it necessary to increase the 3D domain in the vertical direction by $0.5 \mathrm{~m}$, introducing a mesh refinement to reproduce the interface liquid-gas interface. This gave a more detailed description of these two regions that is extremely important to describe the dispersed phase correctly. The meshes for the simulations were selected following the CFX Best Practices Guide for Numerical Accuracy. Tetrahedral dominant meshes were performed to calculate the simulations which guarantee the accuracy and stability of the numerical computation by the mesh quality parameters (aspect ratio and skewness). To ensure the mesh independency of the results, a three-grid GCI was computed for several quantities using the 
formula proposed by Roache (Roache, 1998) and the methodology of Tanaka (Tanaka, 2014; Tanaka et al., 2016).

Finally, in order to include the momentum exchange, the Ishii-Zuber correlation (Ishii and Zuber, 1979) was used to model the drag force. Two non-drag forces were included in this simulation: lift and wall-lubrication. The lateral lift force was implemented using the Tomiyama correlation, that accounts for the reversal of this force for big diameter bubbles (Tomiyama et al., 2002). Wall lubrication was implemented following the baseline model stablished by Rzehak et al. (Rzehak et al., 2015). With respect to the effects of turbulence, the turbulent dispersion of bubbles was modelled by using the Favre Averaged model (Burns et al., 2004). Finally, the turbulence interaction between the phases was modelled according to the induced turbulent viscosity model proposed by Sato (Sato and Sekoguchi, 1975).

\section{B.2.3 Experimental measurements}

CFD models need global and, where possible, local measurements in order to become a robust simulation tool. An exhaustive validation campaign was conducted by means of 3D velocity measurements. Moreover, tracer tests were carried out to understand the global fluid behaviour, to identify the fluid pattern and to define the influent flowrate of the CFD models.

\section{B.2.3.1 Tracer test}

The main purpose of the tracer test carried out in this study was to obtain the flow pattern and define the hydraulic distribution of the flow entering the two lanes (WWTL1 and WWTL2). This allowed the influent flowrate to be defined for the one-tank CFD model correctly (WWTL1). Since the flow meters are located after the secondary treatment and there was no fine control of the flow entering each lane, a comparative study between both oxidation ditch lanes allowed the distribution of the flow to be quantified. Moreover, the mean residence time and the number of tanks-in-series was calculated, and the absence of mixing problems of the fluid was verified through the indicators of short-circuiting and dead-zones (Levenspiel, 1972). Additionally, some typical features of the tracer response curves analysis were discussed. Finally, some singularities of the mixing observed in the inner channel were analysed and compared with the CFD results.

The tracer technique was carried out obtaining the tracer response curve in several points during 10 days (about $2 * \tau$ ) (Rieger et al., 2013) where 225 samples were taken over the course of the secondary treatment. The tracer was diluted in 50 litres of tap water and added using a "pulse" injection of 18 seconds. Fluorescein sodium salt was selected as the dye tracer and the samples were processed with a fluorescence spectrophotometer Varian Cary Eclipse. Finally, the tracer test was validated satisfactorily by means of a tracer mass balance, which showed a 
deviation within an acceptable range considering the complexity of performing this experimental technique at full-scale. From the accuracy of the instrumental equipment and the measurements, we estimated that the error in the concentration values is not higher than $5 \%$, which allowed us to provide reliable values for the results.

\section{B.2.3.2 Fluid velocity profiles}

Although tracer tests can be used as a global validation technique for the CFD model, fluid velocity profile measurements are preferred because they provide a detailed and local hydrodynamic analysis in 3D.

The aim of the extensive sampling campaign was to obtain a comprehensive hydrodynamic analysis of a full-scale oxidation ditch and validate the CFD models. Special efforts were made to characterise the fluid behaviour within the channel spacing due to the tank's difficult accessibility. This was considered the most important critical zone, the zone from which one can obtain crucial information about the fluid behaviour due to the magnitude of the flow activity. 3D fluid velocity profiles were determined experimentally at several points along the tank at 14 positions and 3 heights without aeration, and 7 positions and 3 heights with aeration on.

A high-resolution acoustic doppler velocimeter Vectrino Nortek ${ }^{\circledR}$ was used to measure the fluid velocity components at $25 \mathrm{~Hz}$ within a sampling volume of $7 \mathrm{~mm}$ length. The total time of sampling for each measurement was $300 \mathrm{~s}$ to capture large eddies. Then, the raw signals acquired by the equipment were treated using a Savizky-Sgolay filter to smooth the signal. The instrument, which has an error of \pm 1 $\mathrm{mm} / \mathrm{s}$, proved to be appropriate for this purpose although measurements over the diffusers were avoided due to the difficulties of the equipment to measure in bubbly flow. Therefore, measurements with gas had to be carried out before and after the grids and then to apply a depickling (Birjandi and Bibeau, 2011).

An aluminium structure of 4.5 meters, made of four pieces of 3-point-truss of $1.5 \mathrm{~m}$ each, was anchored to the walls. A mobile wagon was made to slide over this structure driven by a pulley system in order to set the position over the surface of the tank. An aluminium profile of $9 \mathrm{~m}$ was attached vertically to the wagon as a guide for the velocimeter. Thus, the velocimeter was able to move automatically at different heights actioned by a stepper motor. This system allowed the movement of the velocimeter with enough precision inside the tank to measure 3D fluid velocity at different locations and depths. 


\section{B.3. Results \& Discussion}

\section{B.3.1 Tracer test}

Analytical methods related to the residence time distribution are very useful to characterize the hydraulics and macroscopic mixing, in an integrated way with no spatial information but can determine reactor malfunctioning flows such us shortcircuiting or dead volume (Burrows et al., 1999), which is especially important in large-volume tanks.

Figure B.2 shows the tracer concentration-time experimental data, $\mathrm{C}(\mathrm{t})$, obtained at the outlet (Outlet 1 and Outlet 2) corresponding to both WWTLs working in aeration cycles for 10 days. This showed that in general, both lanes corresponded to a similar hydrodynamic performance noticing that the global flow behaviour is related to a mixed flow, and the maximum concentration of tracer was achieved in a similar time (4h and $6 \mathrm{~h}$, for WWTL1 and WWTL2, respectively). It showed an exponential decay of $\mathrm{C}(\mathrm{t})$ which corresponded to completely stirred tank reactor (CSTR) with a reasonably good flow where an adequate mixing can be assumed (Levenspiel, 1972). Even though we know the path the flux must travel from the inlet to the outlet, the time lag (initial time) can be neglected. Although the global hydrodynamic behaviour of the fluid was favourable, some problems in the homogeneity (detailed below) were detected, especially after achieving the time of the maximum tracer concentration. The separate flow analysis of the inner channel allows to better understand the fluid behaviour of the whole tank.

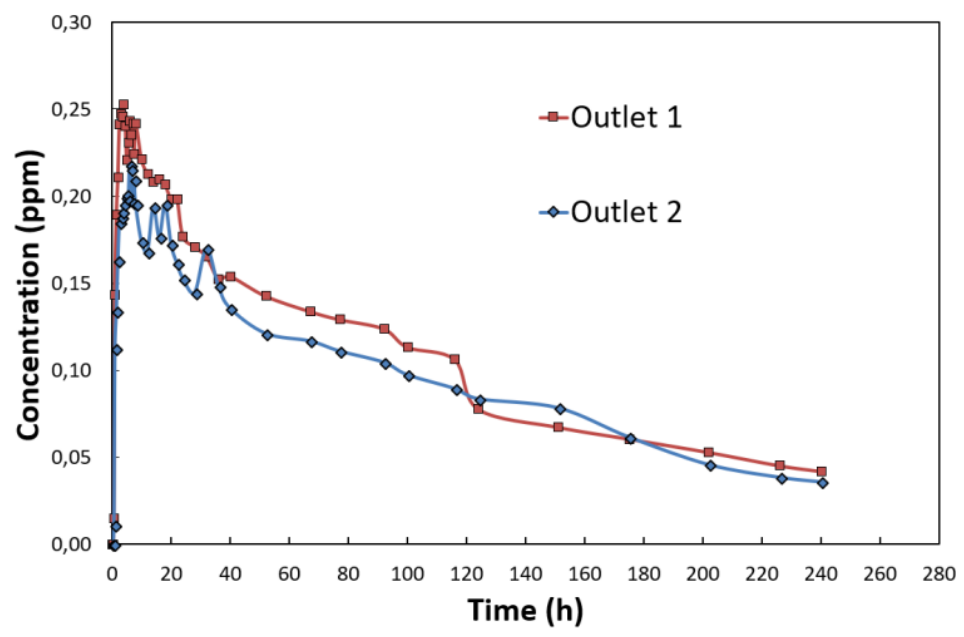

Figure B.2: Concentration vs time tracer response curves obtained at the outlet 


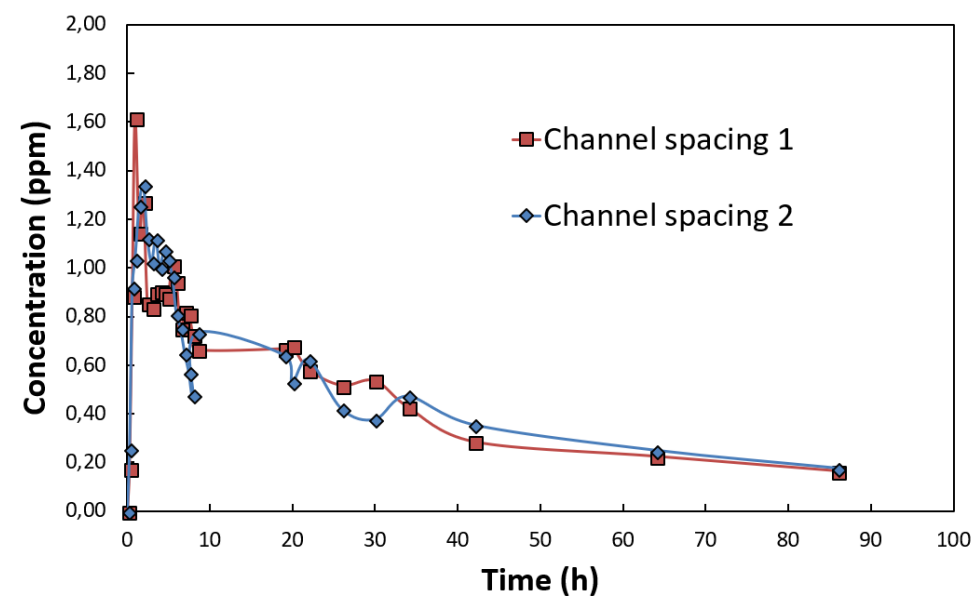

Figure B.3: Concentration vs time tracer response curves at the channel spacing

Figure B.3 shows the tracer concentrations measured at the channel spacing of both lanes, which allows the inner channels to be analysed separately. The tracer concentrations revealed a slow internal circulation within the inner channel of both lanes which suggested inadequate mixing where portions of reactor contents may not mix with the incoming water (Metcalf \& Eddy, 2004). This was caused by the faulty propeller positioning in the inner channel. This caused some singularities of the fluid behaviour which were analysed in depth and compared to the CFD model.

Mean residence time $\left(t_{m}\right)$ can be calculated either from $C(t)$ or residence time distribution $\mathrm{E}(\mathrm{t})$ following the equation 1 . To do this, the $\mathrm{C}(\mathrm{t})$ curve was fitted with a single-term exponential function. Since the distributions pointed out the flux behaviour corresponded to a CSTR, the number of tanks-in-series (N) was calculated for both WWTLs using the variance $\sigma^{2}$ from the equation 3 (Jamialahmadi et al., 1994) as well as some indices to characterise the flux (Levenspiel, 1972):

$$
\begin{aligned}
& t_{m}=\frac{\int_{0}^{\infty} t C(t) d t}{\int_{0}^{\infty} C(t) d t}=\int_{0}^{\infty} t E(t) d t \\
& \sigma^{2}=\int_{0}^{\infty}\left(t-t_{m}\right)^{2} E(t) d t
\end{aligned}
$$




$$
N=\frac{t_{m}^{2}}{\sigma^{2}}
$$

Both bioreactors showed the $t_{m}$ value close to the theoretical hydraulic retention time, $\tau$, did not present significant problems of the fluid behaviour. On the one hand, both $\mathrm{C}(\mathrm{t})$ curves measured at the outlet did not show presence of shortcircuiting since the expected initial concentration of $0.25 \mathrm{mg} / 1$ matched with the maximum concentration measured. On the other hand, an indicator of dead volume percentage, $V_{d}$, was calculated as the deviation of $t_{m}$ from $\tau$, as $V_{d}=\left(1-t_{m} / \tau\right)$. Table B.1 shows the other indices calculated. The reactor dispersion Index (MDI), was calculated as the ratio of $t_{90} / t_{10}$, relating the passage of $10 \%\left(t_{10}\right)$ and $90 \%\left(t_{90}\right)$ of the mass through the outlet. It confirmed that the global fluid behaviour corresponded to a completely mixed flow rather than plug flow (MDI values up to 22 correspond to CSTR behaviour while MDI value less than 2 is related to an effective plug-flow reactor). The number of tanks in series resulted less than 2 for each WWTL. Moreover, a slightly unequal distribution of the flowrate entering the WWTLs was determined based on the total mass tracer concentration measured in both $\mathrm{C}(\mathrm{t})$. Thus, a deviation of $5 \%$ in the ratio of both $t_{m}$ was calculated, which can be understood as the WWTL1 processed a slightly higher flowrate than WWTL2. This assumption was also supported in that the maximum concentration was detected earlier in WWTL1 at both $\mathrm{C}(\mathrm{t})$ curves. It also justifies the high $V_{d}$ value obtained for WWTL1 since its calculation was based on the $\tau$.

Table B.1: Indices calculated in $\mathrm{C}(\mathrm{t})$ tracer response curves obtained at the outlet

\begin{tabular}{|l|l|l|l|l|l|l|l|l|}
\hline Case & $\tau$ (day) & $\begin{array}{c}t_{m} \\
(\text { day })\end{array}$ & $\begin{array}{c}V_{d} \\
(\%)\end{array}$ & $\begin{array}{c}t_{10} \\
(\mathrm{~h})\end{array}$ & $\begin{array}{c}t_{90} \\
(\mathrm{~h})\end{array}$ & $M D I$ & $\begin{array}{c}\sigma^{2} \\
\left(\text { day }^{2}\right)\end{array}$ & $\mathrm{N}$ \\
\hline WWTL1 & 6.16 & 5.69 & 7.63 & 11 & 175 & 15.91 & 17.78 & 1.82 \\
\hline WWTL2 & 6.16 & 5.98 & 2.92 & 12 & 175 & 14.56 & 18,43 & 1.94 \\
\hline
\end{tabular}


The oxidation ditch configuration studied avoids the presence of short-circuiting due to the path the fluid must travel from the inlet to the outlet. Although this configuration seems to be more plug-flow because of its geometry distributed in two channels, the hydraulic behaviour indices indicate a marked CSTR behaviour, which will be increased as $t_{\mathrm{m}}$ increases.

\section{B.3.2 CFD models}

This section shows the results of the different CFD models performed to investigate the hydrodynamic behaviour of this oxidation ditch configuration. Firstly, the hydrodynamics will be analysed through CFD results. Secondly, the single-phase CFD model will be validated by comparing the 3D fluid velocity profiles calculated with the experimental data. Finally, in the same way, the two-phase flow CFD model results will be validated, and the PBM results will be used to study the aeration performance in greater detail.

\section{B.3.2.1 Hydrodynamic performance of the oxidation ditch}

Figure B.4 shows the velocity field within the tank by means of the streamlines. In general, a more homogeneous fluid velocity distribution and a higher average fluid velocity resulted for the configuration without air. Even so, the maximum fluid velocity corresponded to the regions over the diffuser grids for the configuration with air, specifically, the region placed at the top and located immediately behind the third grid following the fluid direction at the outer channel. In both cases, the lowest velocity zones took place in the inner channels. This was caused by the faulty positioning of the propeller, placed too close to the internal curved wall. Thus, the curved wall guided the current round, which cannot be impelled perpendicularly by the internal propeller, deflecting the plume driven by the propeller. Consequently, a considerable reflux was introduced from the outer to the inner channel through the channel spacing, causing the malfunctioning of the inner channel. This can be appreciated in Figure B.5.
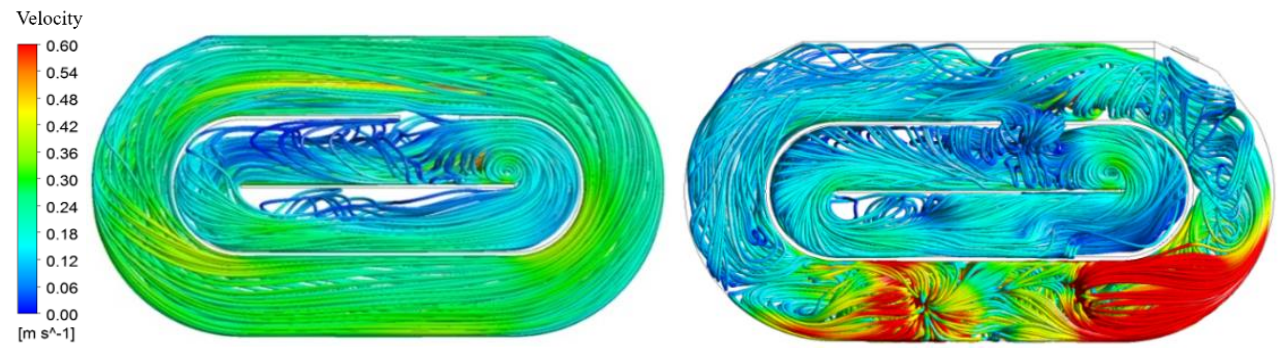

Figure B.4: Velocity of the streamlines without air (left) and with air (right) 
Figure B.5 shows the velocity field contours plotted at five different height cross sections. Some vectors, equally spaced, were added to better understand the fluid direction. The case without air showed a more homogeneous velocity field, well balanced throughout the domain, and strongly governed by the driving force of the propellers. Comparing the effect of the plumes induced by the propellers at the 1.5 $\mathrm{m}$ and the $2.5 \mathrm{~m}$ high velocity contours, the external propeller exhibited a favourable performance while the internal propeller did not operate as expected. As described previously, its plume was altered, and the flux was guided to the centre wall, generating regions with slow internal circulation of the flux and recirculation effect. This can be appreciated by the direction of some vectors plotted over the low velocity regions. For the case with air, the velocity field was more inhomogeneous, especially after the grids in the direction of the fluid flow, which was mainly influenced by the air injection. Thus, the leading role of the external propeller over the hydrodynamics in the outer channel decreased considerably. The air injected generates a convective cell of fluid, providing the maximum fluid velocity over the diffusers and contributing notably in the reduction of the average axial fluid velocity along the outer channel. Moreover, the convective cell generates an appreciable recirculation flow effect in the curved region after the diffuser grids, over the full height, reinforced by the effect of the fluid meeting the external curved wall at maximum velocity. The convective cell induced by the raising bubble columns will be analysed in depth in section B.3.2.4.

In both cases, there was an unintended high flow exchange between channels. Hence, the way to reduce the flow entering through the channel spacing will be calculated in section B.3.3.

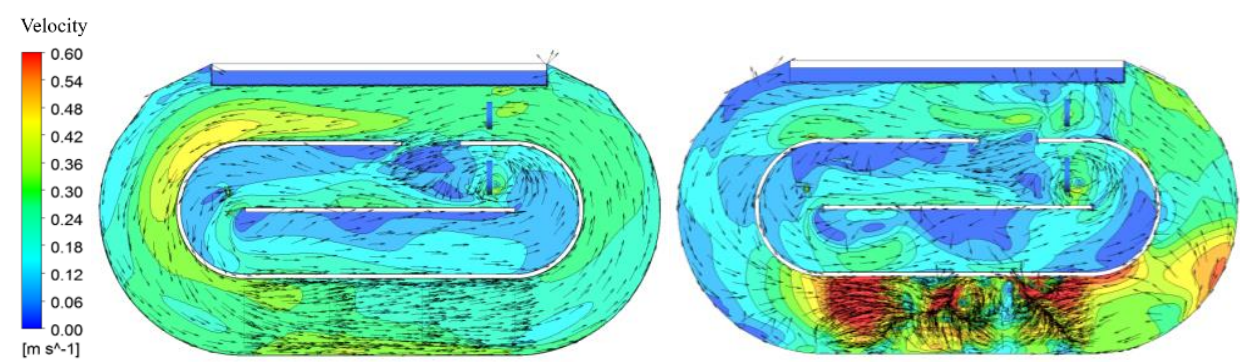



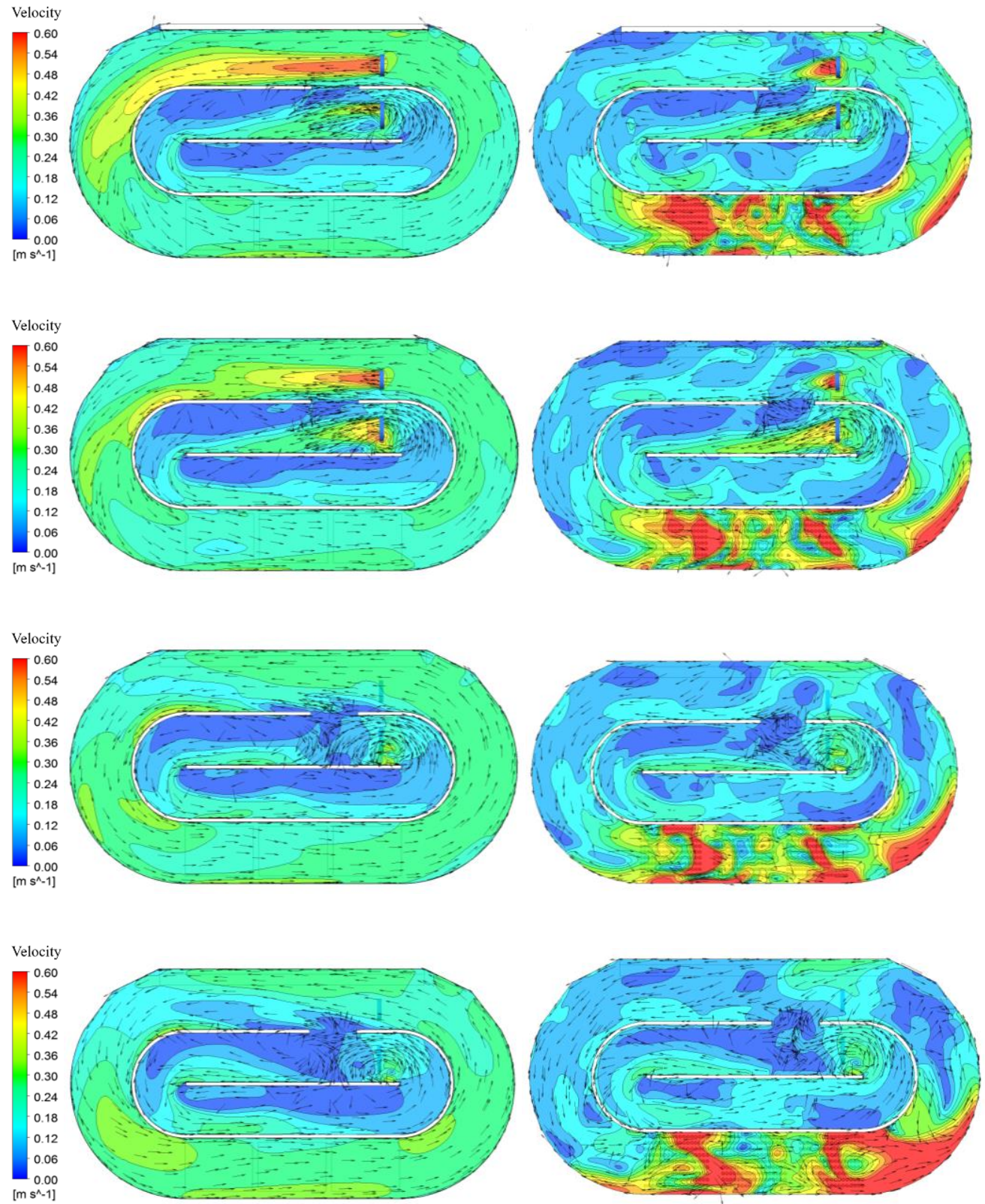

Figure B.5: Velocity contour at $0.5 \mathrm{~m}, 1.5 \mathrm{~m}, 2.5 \mathrm{~m}, 3.5 \mathrm{~m}$ and $4.5 \mathrm{~m}$ high (from top to bottom) without air (left) and with air (right) 
Figure B.6 shows the five vertical fluid velocity profiles (P1, P2, P3, P4 and P5) selected to explain graphically the functioning of the hydrodynamics around the outer channel together with figure B.5. As shown, they were positioned in the centre of the outer channel and distributed along the direction of the current flow from the external propeller. Importantly, for a given vertical section of the outer channel (5.54 m wide and $5.4 \mathrm{~m}$ high), the vertical fluid velocity profile changes in 3D across the width as will be shown in sections B.3.2.2 and B.3.2.3. That said, the five fluid velocity profiles corresponded to the modulus of the fluid velocity; they were considered enough representative of their sections to carry out the following flow analysis. Figure B.6 shows the flow pattern along the channel. For the case without air, the closer the fluid was to the propeller, the more pronounced was the vertical fluid velocity profile. Thus, P1 showed the maximum velocity values around $2 \mathrm{~m}$ high, where the external propeller was located. Since the flowrate is conservative along the outer channel and the section is constant, the fluid velocity profile must be balanced inside each section. According to this, at the top, P1 also presents the minimum fluid velocity values. Subsequently, the velocity profiles flatten as they move away from the external propeller. Thus, P4 exhibited a total flat vertical velocity profile while the suction effect of the propeller was appreciated through P5, located behind it. As expected from figure B.5, figure B.6 showed a more inhomogeneous vertical velocity profiles for the case with air, where P3 presented the maximum velocity values at the top and P1 was less pronounced compared to the case without air.

The average flowrate through the outer channel was evaluated at five sections corresponding to P1 - P5 (Fig. B.6). The same value resulted for each section, with an error less than $0.25 \%$, validating the conservation of the mass. Comparing both cases simulated, without and with air, the average velocity calculated was $0.249 \mathrm{~m} / \mathrm{s}$ and $0.098 \mathrm{~m} / \mathrm{s}$ correspondingly. Hence, the average flowrate circulating inside the outer channel reduced by $60 \%$ when the aeration was supplied. Furthermore, it is important to highlight that the hydraulic influence of the influent over the internal fluid behaviour can be neglected since the influent flowrate entering the tank was compared with the flowrate circulating internally in the channel, representing less than $1 \%$.

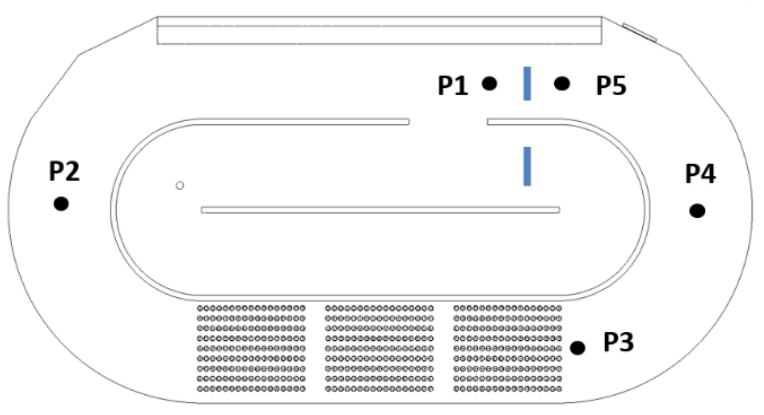



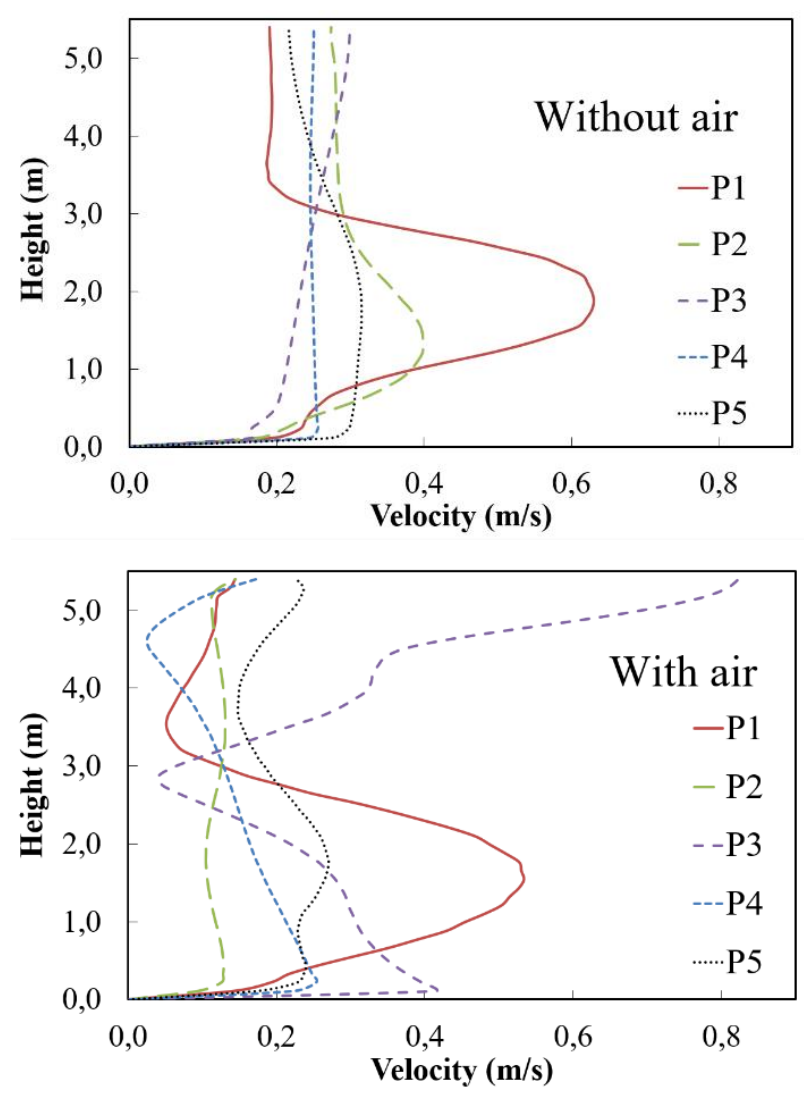

Figure B.6: Vertical velocity profiles around the outer channel (P1 - P5) without and with air.

\section{B.3.2.2 Single-phase CFD model validation}

Figure B.7 shows the experimental measurements performed to validate the singlephase simulations. It shows the $(\mathrm{x}, \mathrm{y}$ and $\mathrm{z})$ velocity components compared to the CFD simulation results. The figure includes the graphical scheme in the $\mathrm{X}, \mathrm{Y}$ plan view and the legend of the velocity components. The 14 positions of the measuring points were spread all over covering each of the critical zones of the tank and the width dimension of the channel. Thus, 3 different heights were measured in each position which gives a total of 42 measurements. The left axis of the figures shows the height $(\mathrm{m})$ from the bottom to the top, which corresponds to the $\mathrm{Z}$ axis. 

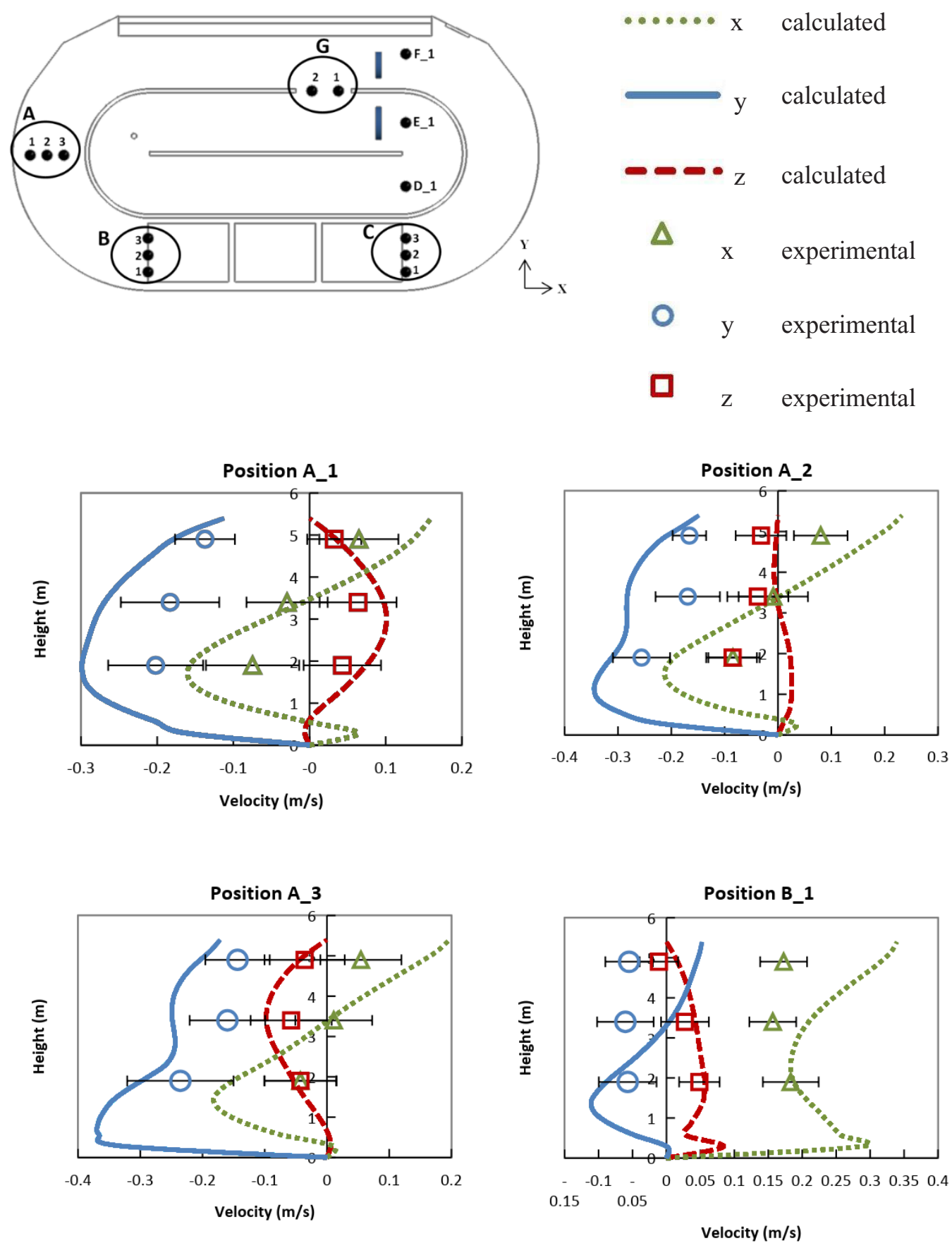

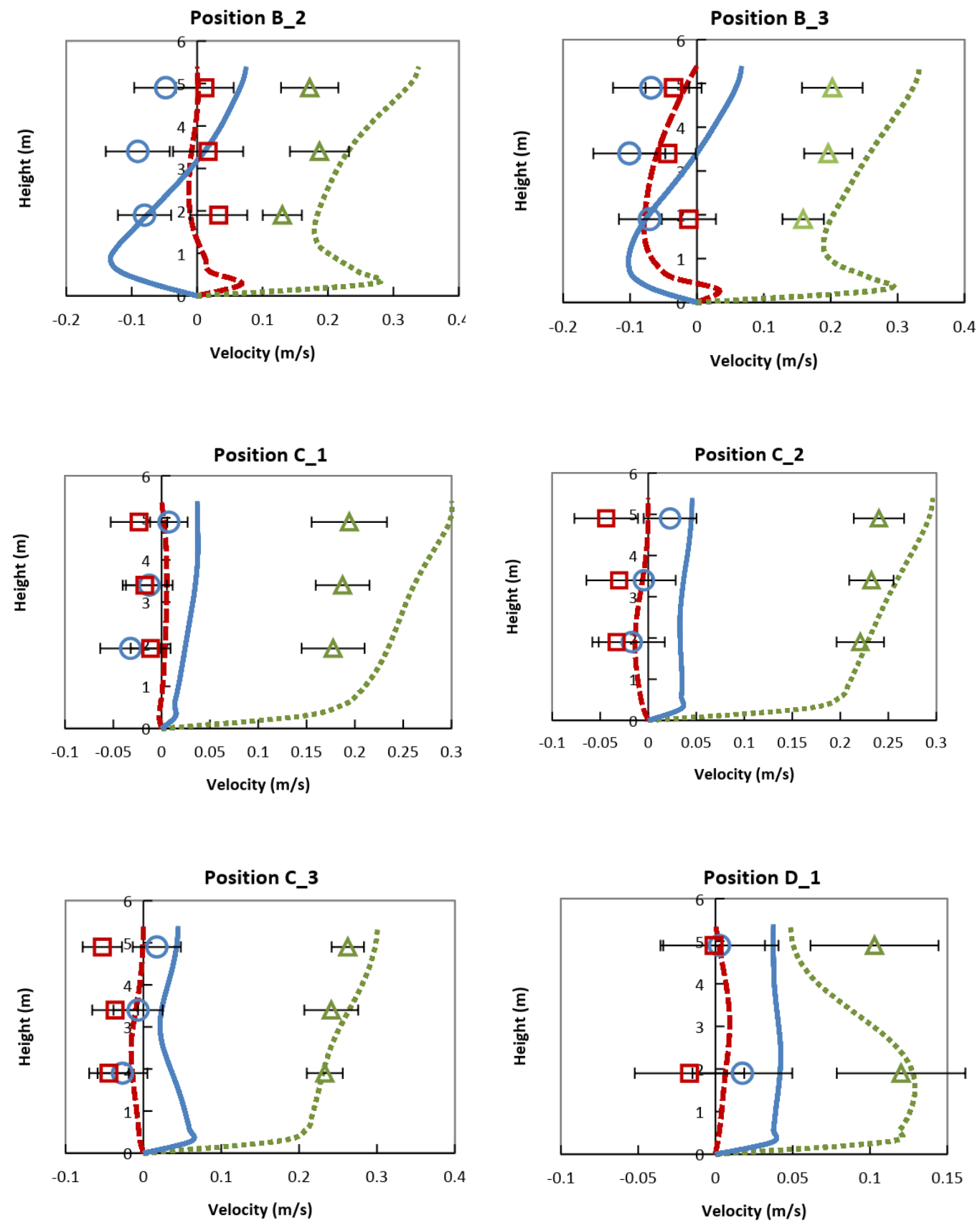

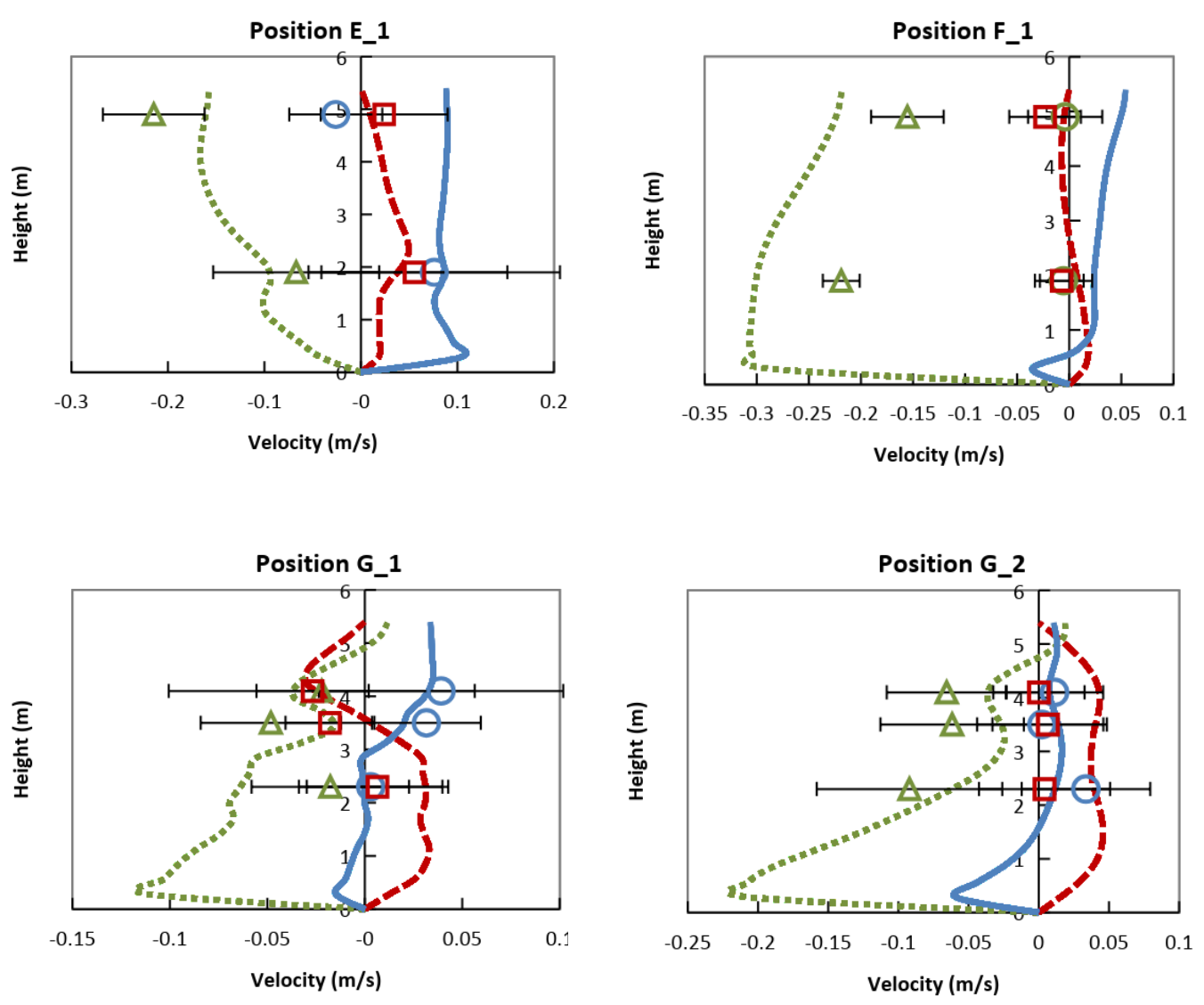

Figure B.7: Comparison of the fluid velocity components calculated and measured without air.

In general, the results provided by the CFD model reproduced correctly the trends of the velocity in each component in all the positions measured. The distribution of the fluid velocity components for the single-phase model depended considerably on the geometry of the tank and as previously analysed, on the relative distance of the position from the propellers. Thus, the 3 positions located in A and B presented the velocity components distributed in the directions $\mathrm{X}$ and $\mathrm{Y}$ due to the influence of the curved wall of the tank. Hence, Position A showed the maximum velocity values in $\mathrm{Y}$ while position $\mathrm{B}$ in $\mathrm{X}$. In both positions, the fluid velocity profiles are more pronounced at $2 \mathrm{~m}$ height where the propeller is located. Conversely, position $\mathrm{C}$ presented only one velocity component as the predominant, in the $\mathrm{X}$ direction, due to the straighter layout of the cannel which influences the flow stream. As 
previously explained, the suction effect of the propeller can be appreciated in position $\mathrm{F}$ comparing the velocity component in $\mathrm{X}$ to the position $\mathrm{C}$. Although the diameter of the internal propeller is higher, and the section of the inner channel is lower than the outer channel, the experimental measurements performed in the positions $\mathrm{D}$ and $\mathrm{E}$ reveals lower fluid velocity. It was reproduced with high accuracy by the CFD model. Finally, it is important to highlight the difficulty of performing the velocity measurements in position $G$ and to describe the fluid behaviour in $3 \mathrm{D}$ through the channel spacing.

The average velocity is a more common way to fit the experimental measurements by the CFD model, which tends to reduce the error for validation. This work attempts to reproduce the fluid velocity, component by component in each measuring point, to provide a very detailed performance which is a more difficult way to agree with the experimental data. It is often tedious to locate the velocimeter with high accuracy in the full-scale tank and matching the same position in the 3D CFD model to evaluate their results with the experimental data. The error bar was included as the standard deviation associated to the experimental measurements. In order to provide a quantitative measurement for the quality of the simulation, the experimental dataset was compared to the corresponding values in the simulation through a linear regression. The resulting root mean squared error was found to be $0.048 \mathrm{~m} / \mathrm{s}$, with a coefficient of determination $\left(\mathrm{R}^{2}\right)$ of 0.88 (York, 1966). It can be said that the CFD model performs to a satisfactory degree in each of the velocity components. Nevertheless, we note that the calibration procedure led to an average over-prediction of flow velocities about $25 \%$, i.e. the momentum source should be smaller, so further improvements need to be done in the modelling of impellers as volumetric sources to make the model more general.

\section{B.3.2.3 Two-phase flow CFD model validation}

As in the previous section, figure B.8 shows the experimental measurements with air performed in 7 positions to validate the two-phase CFD simulations. Following the same procedure of the single-phase measurements, 3 different heights were evaluated which gave a total of 21 measurements. It was also included a graphical scheme in the X, Y plan view and the legend of the velocity components. The left axis of the figures shows the height $(\mathrm{m})$ from the bottom to the top, which corresponds to the $\mathrm{Z}$ axis.

The inner channel offered a similar fluid behaviour as the single-phase case because it was virtually not affected by the aeration. Thus, lower number of sampling points were evaluated, all them concentrated at the outer channel.

The results calculated for each velocity component reproduced correctly the general trend compared to the experimental data. As analysed in section B.3.2.1, the experimental measurements performed with air in position A, exhibited a reduction in velocity, maintaining the distribution of the components but flattening the 
vertical profile. As mentioned above, the characteristic plumes of the aeration and the vertical motion of the dispersed phase reduced the axial velocity of the mixed liquor circulating within the outer channel.

The plumes of air increase the free surface height which induces the acceleration of the flux at the top and causes the recirculation of the current flow before the grid zone. The backflow was observed along the free surface. Position B showed a marked profile of velocity component $\mathrm{X}$, which changed drastically from negative values at the top to positive velocity values at the bottom. Conversely, position $\mathrm{C}$ showed high values of the $\mathrm{x}$ component in the direction of the current flow at the top, and negative values at the bottom, caused by the convective cell induced by the raising bubble columns.

As with the single-phase simulation, the goodness of the simulation was evaluated, obtaining a root mean squared error of $0.098 \mathrm{~m} / \mathrm{s} \quad\left(\mathrm{R}^{2}=0.71\right)$. This error is significantly higher than the single-phase value, implying that the two-phase models currently used need further development.
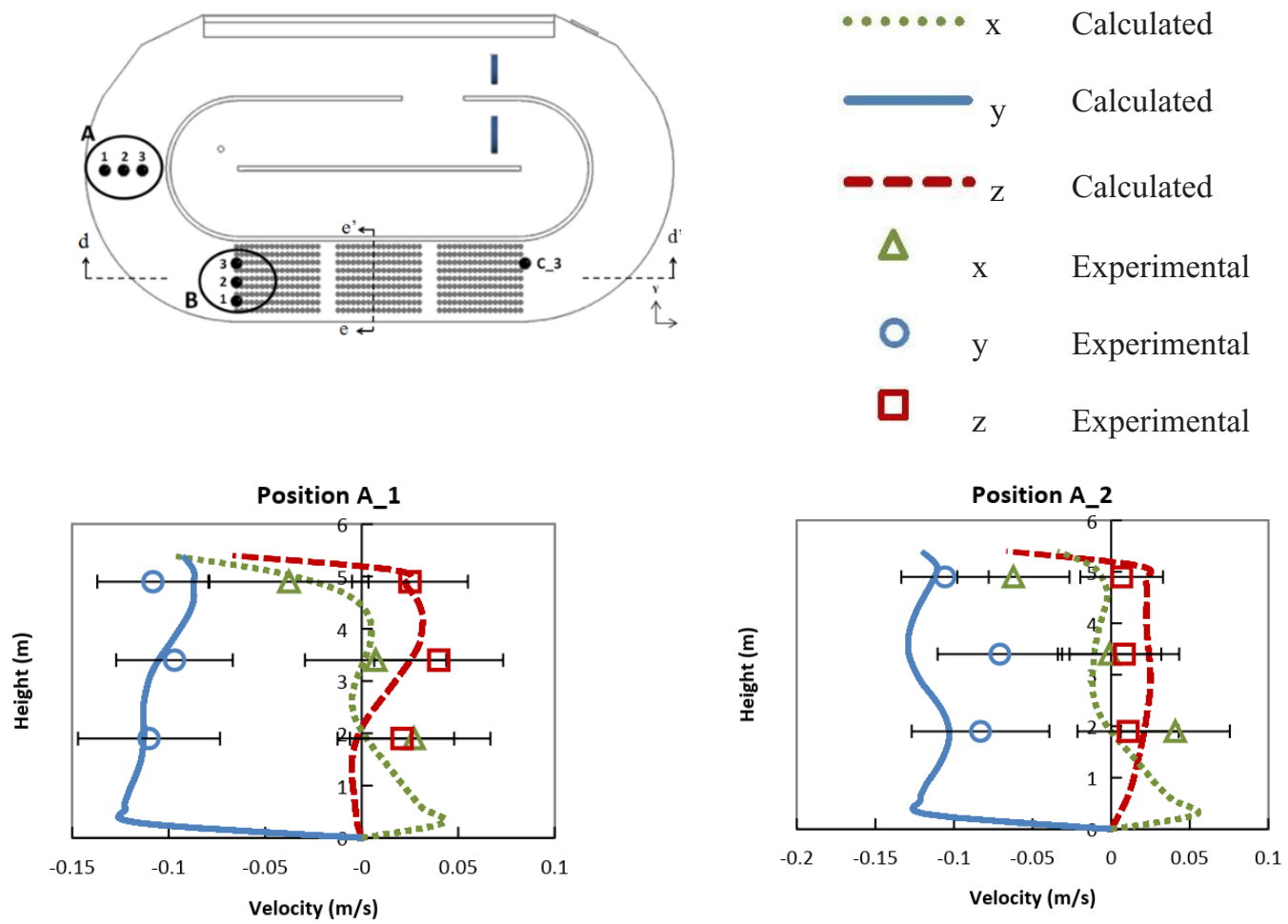

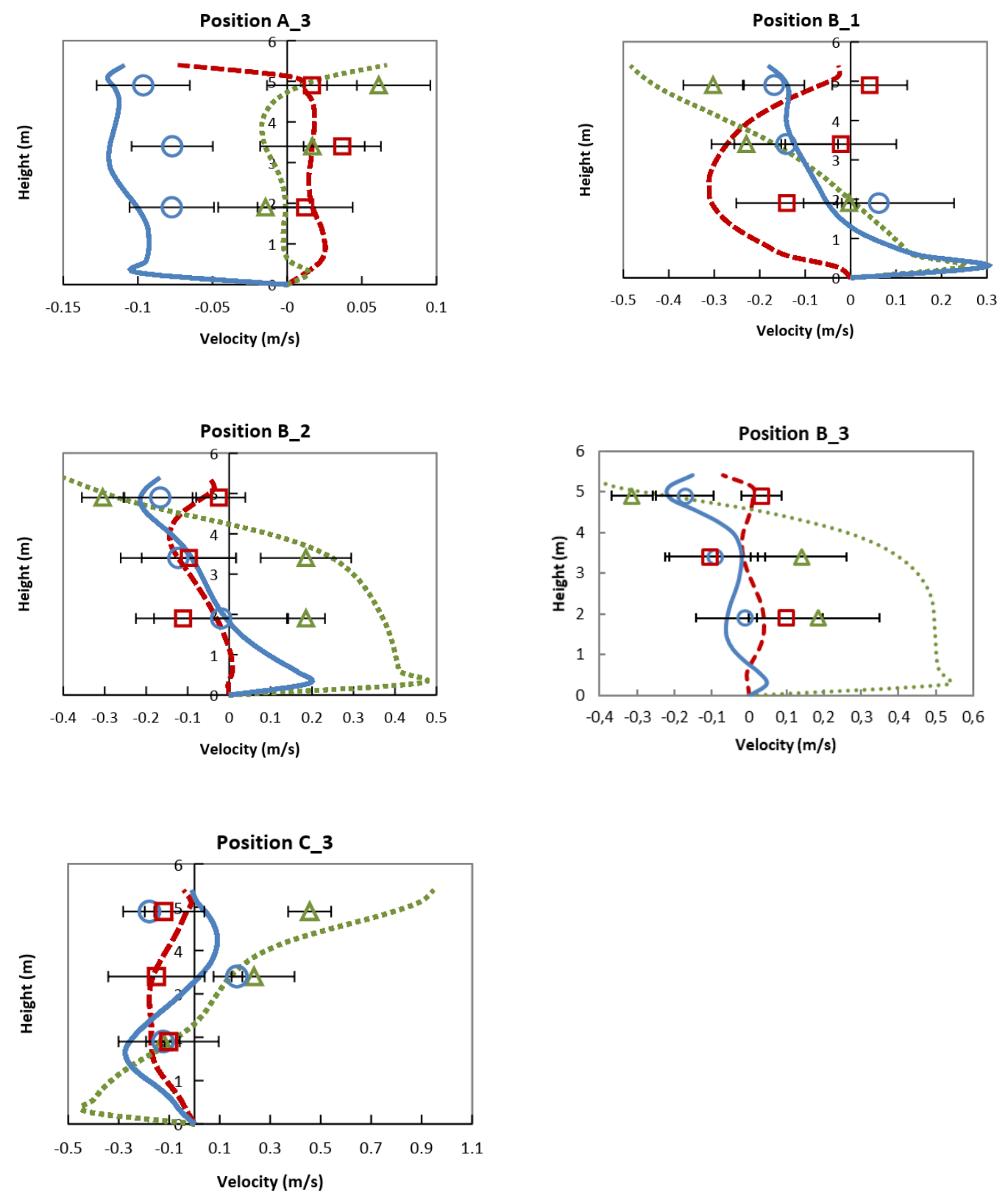

Figure B.8: Comparison of fluid velocity components calculated and measured with air. 


\section{B.3.2.4 Two-phase flow performance using PBM}

The main region of interest to be studied in the two-phase flow is the zone over the grids where the hydrodynamics is especially complex. Figure B.9 shows the gas hold-up plotted at the plane $\mathrm{d}^{-} \mathrm{d}^{\prime}$ defined in figure B.8. This contour is a good representation to evaluate the gas performance. The motion of the bubble columns induces a vertical convective flux cell before and after the grids of the diffusers, represented throughout equally spaced vectors. This is the reason the axial mixed liquor velocity decreases inside the outer channel. The three main plumes of air bubbles, corresponding to the three diffusers grids, showed good stability for the steady state calculation. Once achieved a certain height, they merged into one due to the layout of the grids which maintain them close enough to produce this phenomenon. Moreover, the free surface approach used, allowed the increase of the mixed liquor level to be analysed. This contributed to induce the convective flux cell: a backflow in the first half region over the grids, and an increase of the flux velocity in the second half part alongside the free surface. Figure B.9 shows also the vortex core regions displaying the turbulent structures over the mixed liquor beyond the grid region.
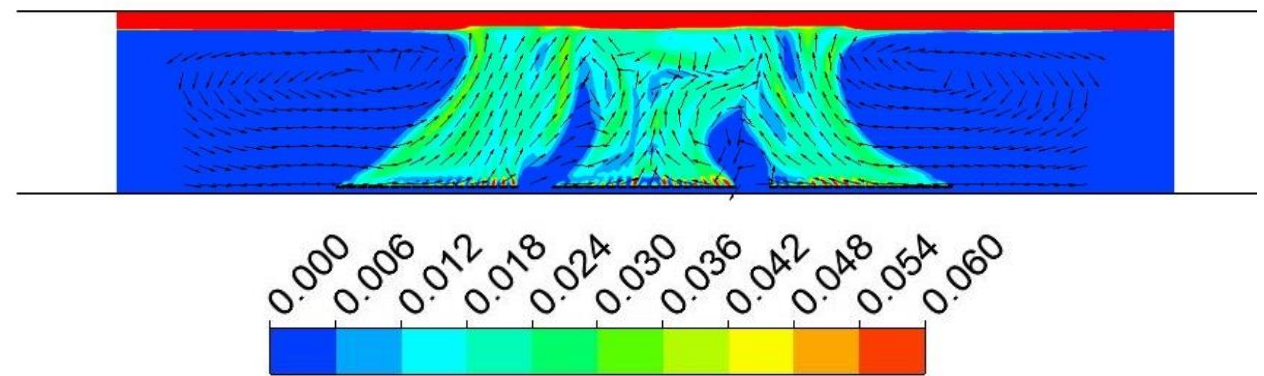

Gas Hold Up

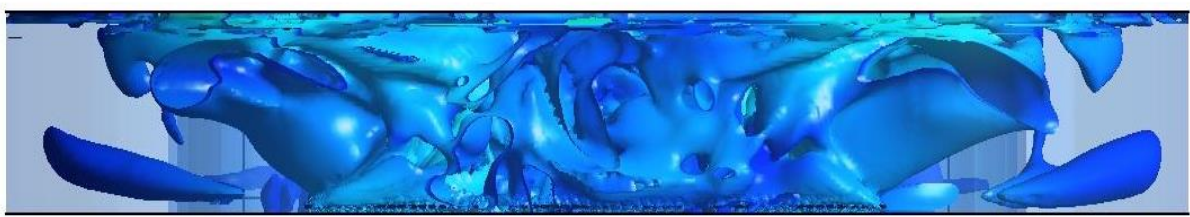

Figure B.9. Contour of gas hold-up air bubble plumes (above) and the vortex core regions in 3D (below) both plotted in section d-d' (figure B.8). 
To analyse the results from the PBM, one must distinguish between the hold-up provided by the dispersed phase, $\alpha_{g}$, and the i-th group hold-up provided, $\alpha_{i}$, defined as $\alpha_{i}=s_{i} \alpha_{g}$, being the size fraction of the $\mathrm{i}$-th group. As the sum of the size fractions for all the groups must sum unity, the sum of the group hold-ups must equal the hold-up.We start the analysis by isolating the volume in the domain where the hold-up exceeds $0.05 \%$ for all the groups (Fig. B.10). The histogram in figure B.10 shows the diameter distribution of the bubbles in this region. The effects of bubble coalescence can be clearly noticed given that diameters lower than $3 \mathrm{~mm}$ (size of the injected bubbles) can be neglected. Also, note that bubbles with diameters between 3 and $4 \mathrm{~mm}$ represented $75 \%$ of the volume while bubble diameters greater than $4 \mathrm{~mm}$ occupied about $25 \%$ of the volume. The highest diameter calculated corresponded to $7.46 \mathrm{~mm}$. From this histogram, one can finally conclude that bubble break-up is negligible.

Figure B.11 shows the volume where there is presence of large bubbles represented by Groups 7 to 10 . These regions are located mainly in the sides of the channel. This is caused by the increased turbulence in the limits of the bubble plume close to the walls. The bubble plume raises the liquid, whereas the non-slip condition at the wall prevents its movement. The resulting high-shear and turbulence level enhances the bubble collisions, thus increasing the bubble coalescence. Moreover, it was determined that the coalescence in these regions is so high due to there are no bubbles with diameters below $4 \mathrm{~mm}$.

To get a better insight into the break-up, a third volume was selected corresponding to regions where there is presence of the Groups 1 and 2 (Fig. B.12). Again, these regions are located near the walls, as the main mechanism for the bubble break-up consists of the shearing-off of large bubbles. Only $1 \%$ of this volume is occupied by bubbles smaller than $3 \mathrm{~mm}$. This result can be interpreted given the shearing-off mechanism that produces the small bubbles. Big bubbles are sheared by high velocity gradients near the wall and rarely split into two equal volume smaller bubbles (Lasheras et al., 2002), but rather into one big and one small bubble.
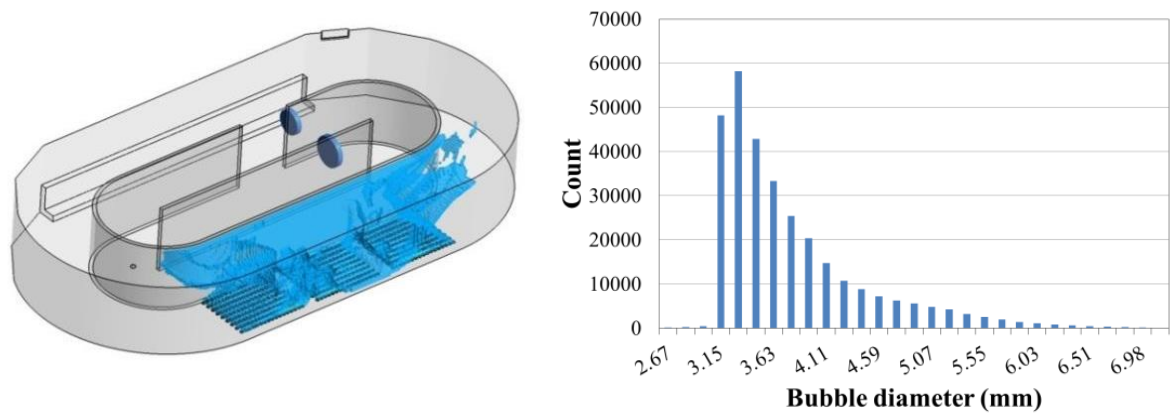

Figure B.10: Isovolume of all the groups of bubbles (left) and its bubble size 
distribution (right)

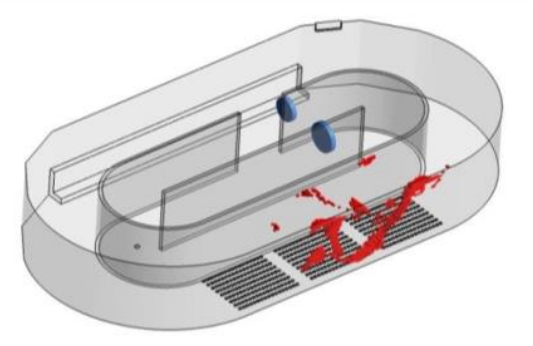

Figure B.11: Isovolume of bubbles of groups 7 to 10

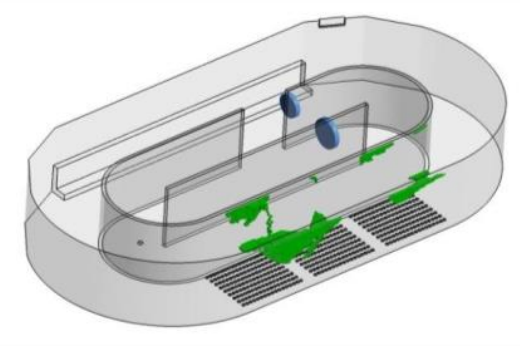

Figure B.12: Isovolume of bubbles of groups 1 and 2

Figure B.13 represents the interfacial area density calculated by the PBM inside a volume of air. This was defined by selecting the hold-up below to $3.5 \%$ in order to exclude the free-surface contribution. The two highest bars of the histogram were concentrated around $15 \mathrm{~m}^{-1}$. Values between 30 and $60 \mathrm{~m}^{-1}$ represented an important contribution of $42 \%$ of the volume, while values under $10 \mathrm{~m}^{-1}$ and above $60 \mathrm{~m}^{-1}$ represented about $7 \%$ in each case.
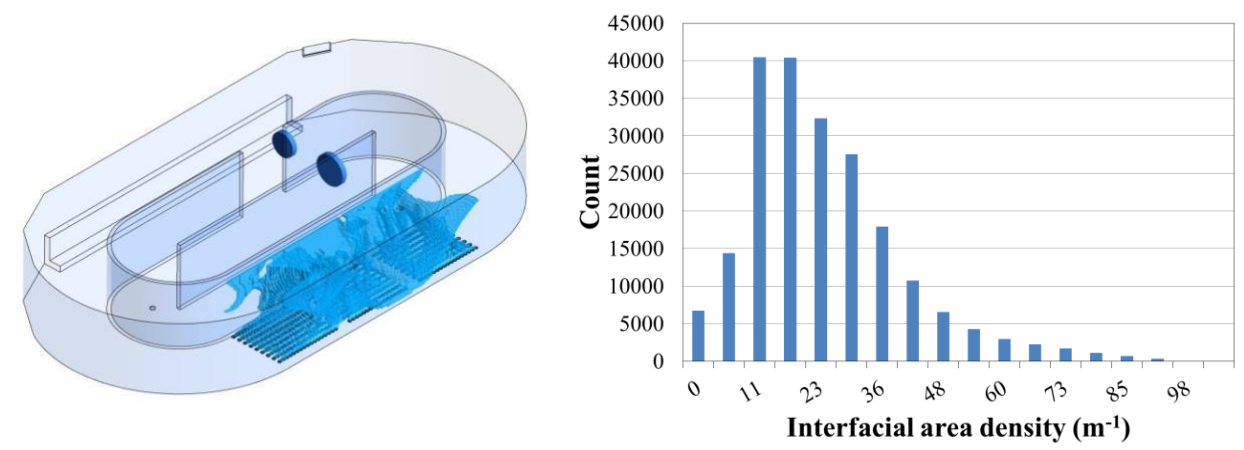

Figure B.13: Isovolume of hold-up represented up to 3.5\% (left), and its corresponding interfacial area density (right) 
Figure B.14 shows the plumes across the width of the channel by means of the hold-up, section e-e' (indicated in Fig. B.9). It can be considered a representative performance of the dispersed phase. Note that the air bubbles are injected through the diffusers vertically, but every column gets attracted by the one that is placed next to it towards the interior of the channel. Consequently, bubble columns tend to group/collide (see figure B.9 for a similar effect). Also, near to the walls recirculation vortexes do appear. In this case, the asymmetry of the diffuser distribution along the width of the tank enhances this effect, which is especially noticeable over the recirculation formed in the bottom left corner. Figure B.14 shows also the mean bubble diameter distribution. Note that the larger bubbles tend to go near the walls. This is caused by two phenomena: first, the lift tends to direct them towards the walls; second, bubble coalescence is driven by turbulent collisions, matching the regions with higher turbulence levels with higher bubble diameters. Also, turbulent impact of eddies against big bubbles can lead to breakup, which can lead to regions with smaller diameters near regions with large bubbles and turbulence, as for example near the air-liquid interface. In addition, ascending bubbles act as a source of turbulence, so the turbulence level increases with the height over the channel ground. Hence, a certain trend can be observed where the larger bubbles take place at the upper region and close to the walls, while the medium sizes are located at the central and the bottom zone.
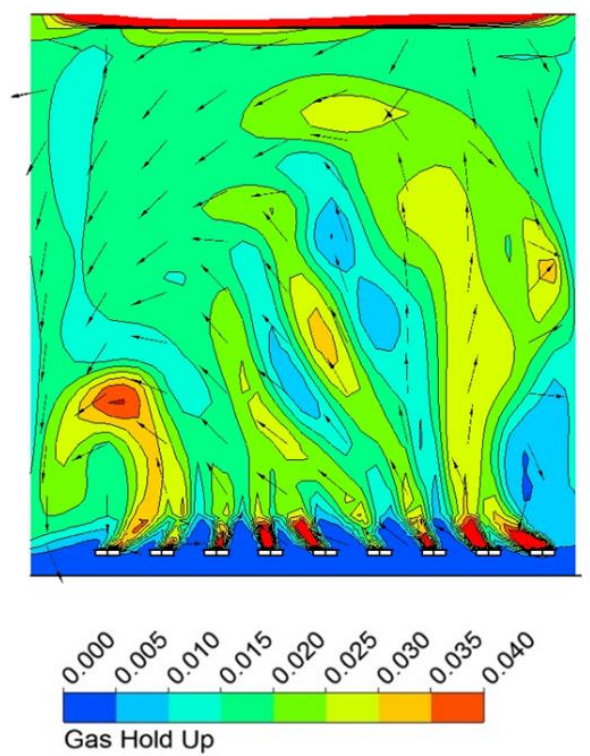
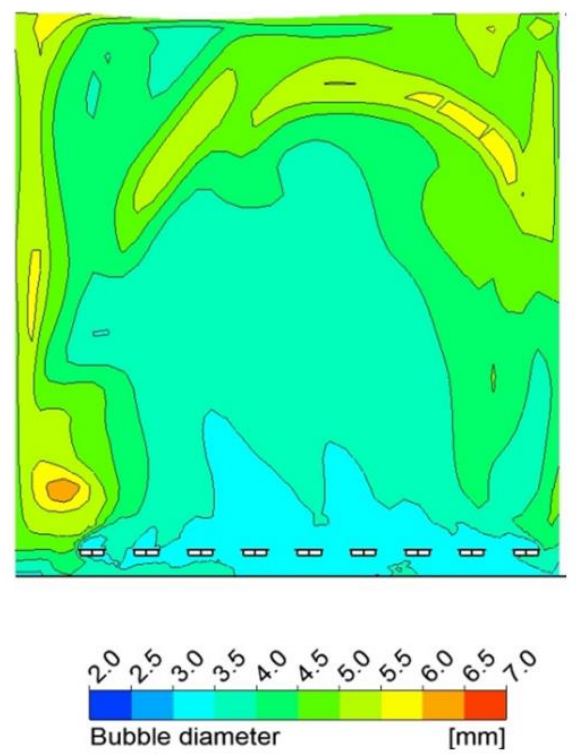

Figure B.14: Hold-up (left) and bubble diameter (right) both in section e-e'

Multiphase modelling is needed when the purpose of the CFD model aims for a deeper knowledge of the dispersed phase; it entails certain complexity level, and 
difficulties of validating the submodels, as well as limitations in computational power.

To sum up, the multiphase modelling depicts a scenario where the bubble plumes generated by the diffusers collide leading to coalescence. This is an undesired effect, as the aeration efficiency is reduced. Given the difficulties to measure the actual sizes of the bubbles in real tanks, CFD simulations can be used as a tool for the optimization of the air flow injected through the diffusers, taking into account the influence of both increase in turbulence and bubble sizes onto the mass transfer. Also, the multiphase simulation shows that a bubble column filling the width of the channel significantly reduces the flow velocity in the whole tank, as it generates a drag that tends to stop the flow. This might be considered a faulty hydrodynamic design, and might be of interest for future studies.

\section{B.3.3 Optimization}

The positioning of the propellers within the tank is based on various heuristic guidelines and correlations, for instance, increasing the surface turbulence facilitates the entrainment of oxygen, not desirable for anoxic tanks, and the correct vertical position can ensure the suspension of the solids minimizing the wall friction (Agitadores FLYGT, 2013). The set of the CFD models of this section study alternatives to the initial configuration, considering the standard regulation specified by different manufacturers (Agitadores FLYGT, 2013; Agitadores WILO, 2014) provided that the minimum distance to the walls is guaranteed.

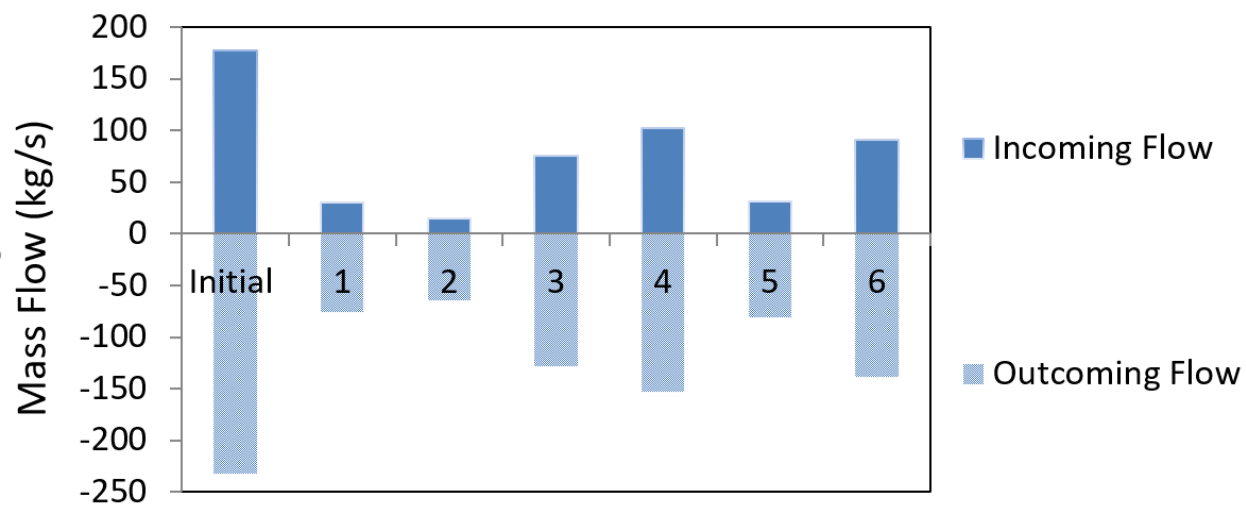

Figure B.15: Mass flow rate incoming and outcoming through the channel spacing

Several configurations were tested modifying the position of the two propellers for minimizing the incoming flow through the channel spacing, which affected negatively the hydrodynamic behaviour in the inner channel. Considering that an improvement in the fluid behaviour within the tank will provide a better performance of the AS process, six alternative configurations for the propeller's 
layout have been studied to enhance hydrodynamics and therefore, improving the biological nutrient removal process by reducing the oxygen entrainment to the inner channel.

Figure B.15 shows the results of the calculations of the 6 configurations simulated. They were analysed considering these two requirements: (1) minimizing the incoming flux entering from the outer to the inner channel and (2) the accomplishment of the distance to the wall. As a result, a modified configuration was proposed. Firstly, a detailed study of fluid flow was performed in the channel spacing. This zone was considered one of the most critical because of the coexistence of both the incoming and the outcoming flow. Based on the criteria explained above, the configuration 2 was selected as the optimal proposal which minimized the mass flow entering from the outer to the inner channel drastically, improving the fluid behaviour inside the inner channel (figure B.16).

Figures B.16 and B.17 show the optimal configuration selected which improves the mixing in the inner channel, reducing the low velocity zones and minimizes the reflux of the fluid from the outer to the inner channel by $92 \%$. This configuration maintained the average fluid velocity along the outer channel increasing the average fluid velocity in the inner channel due to the internal propeller, and inducing a more stable plume of fluid.

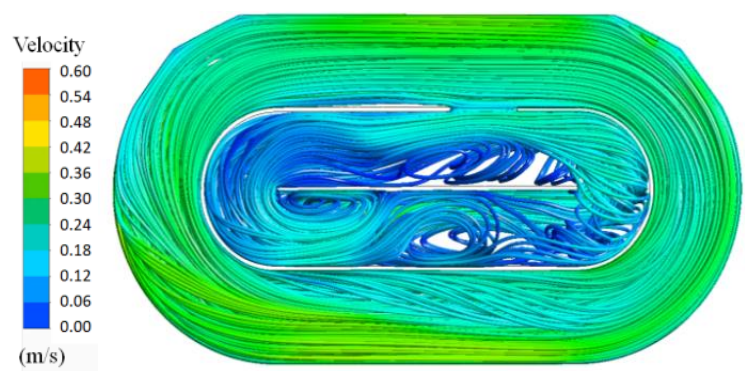

Figure B.16: Velocity of the streamlines at the optimum configuration

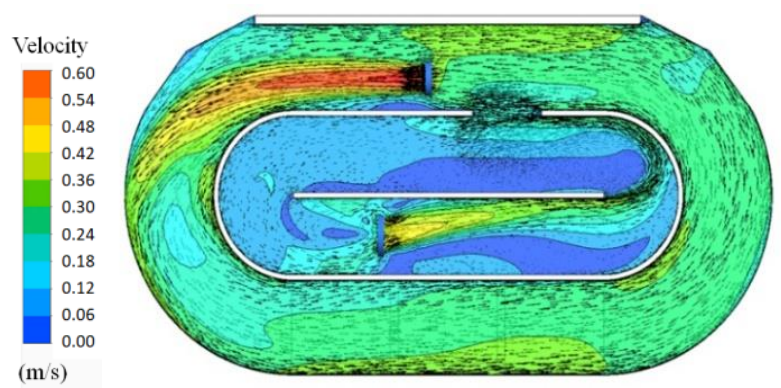

Figure B.17: Velocity contour at $2 \mathrm{~m}$ high 


\section{B.4 Conclusions}

A two-phase CFD model, including a PBM, was performed to reproduce the interaction between the dispersed phase motion and the liquid behaviour inside the aeration tank. Despite the high computing time and the limitations to validate experimentally the PBM, it is important to highlight that this is valuable when it is necessary to focus the study on the design diffuser layouts in the oxidation ditch. The main results from this study are that:

- Tracer tests can provide the global fluid behaviour of each channel when there is a clear separation between them. Inadequate mixing was determined for the inner channel by the RTD obtained at the channel spacing.

- A hydrodynamic analysis was performed with and without air and it was extensively validated by means of the three velocity component measurements.

- The single-phase model approach provided good results when there was no dispersed phase. Singularities of the mixing were detected and calculated successfully in steady state.

- The two-phase flow CFD model investigated showed a good stability of the bubble plumes. The free-surface approach allowed the backflow measured experimentally at the interface to be calculated.

- The multiphase CFD model predicted a reduction of $60 \%$ in the axial fluid velocity in the outer channel with respect to the non-aerated case. This prediction was in good agreement with experimental measurements.

- The analysis of the bubble size and the interfacial area density revealed that, in the oxidation ditch performance, the coalescence is predominant and the break-up can be neglected.

- The best mixing option to reduce the reflux of the fluid from the outer to the inner channel was successfully investigated by the CFD model under a variety of operational conditions, depending on the location of the propellers. The optimal configuration provided a reduction of $92 \%$ in the fluid entering the inner channel through the channel spacing. 


\section{References}

Al Issa, S. and Lucas, D., (2009). Two phase flow 1D turbulence model for polydisperse upward flow in a vertical pipe. Nuclear Engineering and Design, Volume 239, Issue 10, October 2009, Pages 1933-1943

Alex, J., Magdeburg, V., Benedetti, L., Copp, J., Gernaey, K.V., Jeppsson, U., Nopens, I., Pons, M.N., Rosen, C., Steyer, J.P., Vanrolleghem, P., (2008). Benchmark Simulation Model no. 1 (BSM1) IWA Taskgroup on Benchmarking of Control Stategies for WWTPs.

Alvarado, A., Vesvikar, M., Cisneros, J.F., Maere, T., Goethals, P., Nopens, I., (2013). CFD study to determine the optimal configuration of aerators in a fullscale waste stabilization pond. Water Res 47, 4528-4537.

ANSYS ${ }^{\circledR}$ Academic Research, Release 16.2, Help System, ANSYS CFX Reference Guide, ANSYS Inc. 2015.

ANSYS ${ }^{\circledR}$ Academic Research, Release 19.2, Help System, ANSYS CFX Reference Guide, ANSYS Inc. 2019.

Antal, S.P., Lahey, R.T., Flaherty, J.E., (1991). Int Analysis of Phase Distribution in Fully Developed Laminar Bubbly Two-Phase Flow,. Journal of Multiphase Flow, Vol 17, 635-652

APHA, (2012). Standard Methods for the Examination of Water and Wastewater, twenty-second ed. American Public Health Association, American Water Works Association, Water Environment Federation, Washington.

Arnaldos, M., Amerlinck, Y., Rehman, U., Maere, T., Van Hoey, S., Naessens, W., Nopens, I., (2015). From the affinity constant to the half-saturation index: Understanding conventional modeling concepts in novel wastewater treatment processes. Water Res. 70, 458-470.

Arnold, U.; Hottges, J.; Rouv, G. (1989). Turbulence and mixing mechanisms in compound open channel flow. In Proceedings of the 23th IAHR Congress, Ottawa, ON, Canada, 21-25 August 1989. 
ASME, "Standard for Verification and Validation in Computational Fluid Dynamics and Heat Transfer - V\&V 20”, ASME, (2009).

Aubin, J., Fletcherb, D.F., Xuereba, C., (2004). Modeling turbulent flow in stirred tanks with CFD: the influence of the modelling approach, turbulence model and numerical scheme, Exp. Therm. Fluid Sci. 28, 431-445.

Biggs, C.A., (2000). Activated sludge flocculation: investigating the effect of shear rate and cation concentration on flocculation dynamics. PhD Thesis, Advanced Wastewater Management Center, Dept. of Chem. Eng., University of Queensland, Australia.

Birjandi, A. H., Bibeau, E. L., (2011). Improvement of Acoustic Doppler Velocimetry in bubbly flow measurements as applied to river characterization for kinetic turbines, Int. J. Multiph. Flow 37, 919-929.

Bischof, F., Höfken, M., Durst, F., (1999). Design and construction of aeration systems for optimum operation of large wastewater treatment plants. Water Science and Technology, 1996. 33: p. 189-198. McInerney M. J.

Bischoff, K.B., Mccracken, E.A., (1966). Tracer tests in flow systems. Ind. Eng. Chem. 58, 18-31.

Börjesson, T. and Fahlfgren, M. (2000). Mechanics of fluids in mixing-bringing mathematical modelling clase to reality. Scientific Impeller, 7, 55-68.

Borroto, J.I., Domínguez, J., Griffith, J., Fick, M., Leclerc, J.P., (2003). Technetium-99m as a tracer for the liquid RTD measurement in opaque anaerobic digester: Application in a sugar wastewater treatment plant. Chem. Eng. Process. Process Intensif. 42, 857-865.

Brackbill, J.U., Kothe, D.B., Zemach, C., (1992). A continuum method for modelling surface tension, J. Comp. Phys. 100, 335-354.

Brannock, M., (2003). Computational Fluid Dynamics Tools for the Design of Mixed Anoxic Wastewater Treatment Vessels. PhD Thesis, University of Queensland.

Brannock, M., Wang, Y., Leslie, G., (2010). Mixing characterisation of full-scale membrane bioreactors: CFD modelling with experimental validation. Water Res. 44, 3181-3191.

Brennan, D., (2001). The Numerical Simulation of Two-Phase Flows in Settling Tanks. Thesis 127. Ph.D. Dissertation, Imperial College, London. 
Bürger, R., Diehl, S., Nopens, I., (2011). A consistent modelling methodology for secondary settling tanks in wastewater treatment. Water Research 45, 22472260.

Burns, A.D., Frank, T,. Hamill, I., Shi, J.-M (2004) The Favre averaged drag model for turbulence dispersion in Eulerian multi-phase flows, Proceedings of the 5th International Conference on Multiphase Flow, ICMF'2004, Yokohama, Japan

Burns, A.D., Frank, Th., Hamill, I., Shi, J-M., (2004). The Favre Averaged Drag Model for Turbulent Dispersion in Eulerian Multi-Phase Flows, In: 5th International Conference on Multiphase Flow, ICMF-2004, Yokohama, Japan.

Burrows, L.J., Stokes, A.J., West, J.R., Forster, C.F., Martin, A.D., (1999). Evaluation of different analytical methods for tracer studies in aeration lanes of activated sludge plants. Water Res. 33, 367-374.

Buyevich, Yu. A. and Shchelchkova, I. N. Flow of dense suspensions (1979). Progress in Aerospace Sciences, Volume 18, Pages 121-150

Byung S. Choi, Bin Wan, Susan Philyaw, Kumar Dhanasekharan, and Terry A. Ring.(2004) Residence Time Distributions in a Stirred Tank: Comparison of CFD Predictions with Experiment. Ind. Eng. Chem. Res. 2004, 43, 6548-6556

Capela, I., Bilé, M.J., Silva, F., Nadais, H., Prates, A., Arroja, L., (2009). Hydrodynamic behaviour of a full-scale anaerobic contact reactor using residence time distribution technique. J. Chem. Technol. Biotechnol. 84, 716724.

Casalini, T., Salvalaglio, M., Perale, G., Masi, M., Cavallotti, C., (2011). Diffusion and aggregation of sodium fluorescein in aqueous solutions. J. Phys. Chem. B. $115,12896-12904$.

Chazarenc, F., Merlin, J., Gonthier, Y., (2003). Hydrodynamics of horizontal subsurface flow constructed wetlands. Ecological Engineering, 21, 165-173

Cholette, A., Cloutier, L., (1959). Mixing efficiency determinations for continuous flow systems. Can J Chem Eng 1959:35. Can. J. Chem. Eng.

Clarke, K.G., Correia, L.D.C., (2008). Oxygen transfer in hydrocarbon-aqueous dispersions and its applicability to alkane bioprocesses: A review. Biochemical Engineering Journal 39, 405-429.

Cockx A., Do-Quang Z., Audic J.M., Liné A., Roustan M. (2001). Global and local mass transfer coefficients in waste water treatment process by computational fluid dynamics. Chemical Engineering and Processing 40, 187-194. 
Cook, C.B. and Richmond, M.C. (2001). Simulation of Tailrace Hydrodynamics Using Computational Fluid Dynamics Models. US Army Corp of Engineers Portland District Report PNNL-13467, U.S. Dept of Commerce, National Technical Information Service, Springfield, VA.

Copp, J. B. (2002). The COST simulation benchmark: Description and simulator manual. Luxembourg: Office for Official Publications of the European Communities.

Copp, J., Jeppsson, U., Rosen, C., (2003). Towards an ASM1-ADM1 state variable interface for plant-wide wastewater treatment modelling. In: Proceedings of the 76th Annual WEF Conference and Exposition. 11-15 October 2003, Los Angeles, USA.

Danckwerts, P. V., (1953). “Continuous flow systems. distribution of residence times". Department of Chemical Engineering, Tennis Court Road, Cambridge, England, U.K.

De Clercq, B., (2003). Fluid dynamics of settling tanks: development of experiments and rheological, settling, and scraper submodels. Ph.D. Thesis. Universiteit Gent.

De Clercq, B., Nopens, I., Govoreanu, R., Der Meeren, P.V., Vanrolleghem, P., (2005). Sludge (De)flocculation Dynamics in Secondary Clarifiers.

De Clercq, J., (2006). Batch and continuous settling of activated sludge: in-depth monitoring and 1D compression modelling. Ph.D. Dissertation, University of Gent, Belgium.

Deju, L., Cheunga, S.C.P., Yeoh, G.H., Tu, J.Y., (2013). Applied Mathematical Modelling Volume 37, Issues 18-19, 1 October 2013, Pages 8557-8577

Delafosse, A., Delvigne, F., Collignon, M., Crine, M., Thonart, P., Toye, D., (2010). Development of a compartmental model based on CFD simulations for description of mixing in bioreactors. Biotechnol. Agron. Soc. Environ. 14, 517 522.

Delnoij, E., Kuipers, J. A. M., van Swaaij, W. P. M. (1997.). Computational fluid dynamics applied to gas-liquid contactors. Chemical Engineering Science, Volume 52, Issues 21-22, November 1997, Pages 3623-3638

Drew, D.A. and Lahey, R.T. (1987). The virtual mass and lift force on a sphere in rotating and straining inviscid flow. Int. Journal Multiphase Flow, v.13, n. 1, pp. 113-121 
Droppo, I.G., Leppard, G.G., Liss, S. N., Milligan, T.G., (2005). Flocculation in Natural and Engineered Environmental Systems. CRC Press, ISBN 1-56670615-7.

Dudley, J., (1995). Process testing of aerators in oxidation ditches. Water Res. 29, 2217-2219.

Dustin, J. S, Hansen, C., L. (2012) Completely Stirred Tank Reactor Behavior in an Unmixed Anaerobic Digester: The Induced Bed Reactor. Water Environment Research, Volume 84, Number 9.

Elawwad, A., Matta, M., Abo-Zaid, M., Abdel-Halim, H.,(2019). Plant-wide modeling and optimization of a large-scale WWTP using BioWin's ASDM model. Journal of Water Process Engineering Volume 31.

Ervin, E.A., Tryggvason, G., (1997). The rise of bubbles in a vertical shear flow, Journal of Fluids Engineering. 119 443-449

Eshtiaghi, N., Baudez, J.C., Slatter, P., (2013). Rheological Behaviour of Anaerobic Digested Sludge: Impact of Concentration and Temperature. http://www.redbiogas.cl/wp-content/uploads/2013/07/IWA-10854.pdf

Eshtiaghi, N., Markis, F., Yap, S.D., Baudez, J.C., Slatter, P., (2013). Rheological characterisation of municipal sludge: A review. Water Res. 47, 5493-5510.

Essemiani, K., Vermande, S., Marsal, S., Phan, L., Meinhold, J., (2004). Optimisation of WWTP units using CFD - A tool grown for real scale application. In 2nd IWA Leading-Edge Conference on Water and Wastewater Treatment Technologies, Prague.

Fan, W., Yuan, L., Qu, X., (2018). CFD simulation of hydrodynamic behaviors and aerobic sludge granulation in a stirred tank with lower ratio of height to diameter. Biochemical Engineering Journal, 137 78-94.

Fayolle, Y., Gillot, S., Cockx, A., Bensinhom, L., Roustan, M., Héduit, A., (2010). In situ characterisation of local hydrodynamic parameters in closed-loop aeration tanks, Chem. Eng. J. 158, 207-212.

Fayolle, Y., Gillot, S., Roustan, M., Héduit, A., (2007). Oxygen transfer prediction in aeration tanks using CFD. Chem. Eng. Sci. 62, 7163-7171.

Fikar M., Chachuat B., Lafiti M.A. (2005). Optimal operation of alternating activated sludge processes. Control Eng. Pract. 13 (2005) 853-861. 
Flamant, O., Cockx, A., Guimet, V., Doquang, Z., (2004). Experimental analysis and simulation of settling process $82,312-318$.

FLYGT Agitadores sumergibles (2013). Conceptos básicos de cálculo.

Frank, T., Zwart, PJ., Krepper, E., Prasser, H.-M., Lucas, D., (2008). Validation of CFD models for mono- and polydisperse air-water two-phase flows in pipes, Nuclear Engineering and Design 238, 647-659

García, M.H. (2008). "Sediment Transport and Morphodynamics." Sedimentation Engineering, M.H. García, ed., American Society of Civil Engineers, Reston, VA.

Garcia-Ochoa, F., Gomez, E., (2009). Bioreactor scale-up and oxygen transfer rate in microbial processes: An overview. Biotechnology Advances 27, 153-176.

Gessler, D. and Rasmussen, B. (2005). "Before the Flood." Desktop Engineering, Oct 2005 .

Ghirelli F., Leckner B. (2004). Transport equation for the local residence time of a fluid. Department of Engineering Conversion, Chalmers University of Technology, Göteborg 41296 Sweden. Chemical Engineering Science 59 (2004) 513-523.

Ghirelli, F., Leckner, B., (2004). Transport equation for the local residence time of a fluid. Chem. Eng. Sci. 59, 513-523.

Gillot, S., Capela-Marsal, S., Roustan, M., Héduit, A., (2005). Predicting oxygen transfer of fine bubble diffused aertion systems-model issued from dimensional analysis. Water Research 39, 1379-1387.

Glover, G.C., Printemps, C., Essemiani, K., Meinhold, J., (2006). Modelling of wastewater treatment plants - How far shall we go with sophisticated modelling tools? Water Sci. Technol. 53, 79-89.

Goula, A. M., Kostoglou, M., Karapantsios, T. D., Zouboulis, A. I., (2008). A CFD methodology for the design of sedimentation tanks in potable water treatment. Chemical Engineering Journal 140, 110-121

Grace, J. R., Wairegi, T., and Nguyen, T. H., (1976). Shapes and velocities of single drops and bubbles moving freely Through Immiscible Liquids, Trans. Inst. Chem. Eng. 54, 167-173.

Grady, C. P. L., Daigger, G. T., Love, N. G., (2011). Biological Wastewater Treatment. 3rd Edition. IWA Publishing, London. 
Grau, P., de Gracia, M., Vanrolleghem, P.A., Ayesa, E., (2007). A new plant-wide modelling methodology for WWTPs. Water Research 41, 4357- 4372

Gresch, M., Armbruster, M., Braun, D., Gujer, W., (2011). Effects of aeration patterns on the flow field in wastewater aeration tanks. Water Research 45, 810 818.

Gresch, M., Braun, D., Gujer, W., (2010). The role of the flow pattern in wastewater aeration tanks. Water Sci. Technol. 61, 407-414.

Gresch, M., Braun, D., Gujer, W., (2010). Using reactive tracers to detect flow field anomalies in water treatment reactors, Water Res. 45, 1984-1994.

Griborio, A., (2004). Secondary clarifier modeling: a multi-process approach. $\mathrm{PhD}$ Thesis, University of New Orleans, LA, USA.

Gualtieri, C. Numerical simulation of flow and tracer transport in a disinfection contact tank. In Proceedings of the 3rd Biennial Meeting of the International Environmental Modelling and Software Society, Burlington,

Gualtieri, C., Angeloudis, A., Bombardelli, F., S., Jha and T. Stoesser. (2017). On the Values for the Turbulent Schmidt Number in Environmental Flows . Fluids 2017, 2, 17; doi:10.3390/fluids2020017

Guha, D., Dudukovic, M.P., Ramachandran, P.A., Mehta, S., Alvare, J., (2006). CFDbased compartmental modeling of single phase stirred-tank reactors. AIChE Journal 52, 1836-1846.

Guo X., Zhou X., Chen Q., (2013). Liu J. Flow field and dissolved oxygen distributions in the outer channel of the Orbal oxidation ditch by monitor and CFD simulation. Journal of Environmental Sciences 2013, 25 (4) 645-651.

Guo, X., Zhou, X., Chen, Q., Liu, J., (2012). Flow field CFD modeling of hydrodynamics and biological reactions in activated sludge reactors. Research Center for Eco-Environtmental Sciences, Chinese Academy of Science, Beijing 100085, China.

Hasanen, A., Orivuori, P., Aittamaa, J., (2005). Measurements of local bubble size distributions from various flexible membrane diffusers. Chemical Engineering and Processing 45, 291-302.

Henze M., Gujer W., Mina T. and M. C. M. van Loosdrecht (2000). Activated Sludge Models ASM1, ASM2, ASM2D and ASM3. Scientific and Technical Report series. London, IWA Publishing 
Henze, M., van Loosdrecht, M., Ekama, G. A., Brdjanovic, D., (2008). Biological Wastewater Treatment Principles, Modelling and Design IWA Publishing. ISBN: 1843391880.

Hewitt G.F. (2012) Gas-Liquid Flow, , Thermopedia.

Higbie, R., (1935). The rate of absorption of a pure gas into a still liquid during a short time of exposure. Transactions of the American Institute of Chemical Engineers 31, 365-389.

Howes, T., Brannock, M., Corre, G., (2003). Development of simplified flow models from CFD simulations. In: P Schwarz, Third International Conference on CFD in the Minerals and Process Industries. Third International Conference on CFD in the Minerals and Pros, CSIRO, (1-6). 10-12 December 2003.

Hreiz, R., Potier, O., Wicks, J., Commenge, J.-M., (2018). CFD Investigation of the effects of bubble aerator layouts on hydrodynamics of an activated sludge channel reactor, Environ. Technol. 39, 1-14.

Hulsbeek, J.J., Kruit, J., Roeleveld, P., van Loosdrecht, M., (2002). A practical protocol for dynamic modelling of activated sludge systems. Water Sci. Technol., 45 (6) (pp. 127-136.

Ishii, M., Zuber, N., (1979). Drag coefficient and relative velocity in bubbly, droplet or particulate flows, AICHE J. 25, 843-855.

James A., Mueller William, C., Boyle, H., Pöpel, J., (2002). Aeration: Principles and Practice. Water Quality Management Library.

Jamialahmadi, M., Branch, C., Müller-Steinhagen, H., (1994). Terminal bubble rise velocity in liquids, Trans. Inst. Chem. Eng. 72, 119-122.

Jeppsson, U., (1996). Modelling aspects of wastewater treatment processes. Doctoral thesis. Lund Institute of Technology, Sweden.

Jones, D.R., Jung, R.F., (1990). Analytical problems arising from the use of bromide and rhodamine WT as co-tracers in streams. Water Res. 24, 125-128.

Jones, W.P., Launder, B.E. (1972), The prediction of laminarization with a twoequation model of turbulence. International Journal of Heat and Mass Transfer Volume 15, Issue 2, February 1972, Pages 301-314

Kadlec, R.H., Wallace, S.D., (2009). Treatment Wetlands. $2^{\text {nd }}$ Ed. Taylor \& Francis Group, LLC. International Standard Book Number-13: 978-1-56670-526-4 
Karim, K., Varma, R., Vesvikar, M., Al-Dahhan, M. H., (2004). Flow pattern visualization of a simulated digester, Water Research, 38, pp. 3659-3670.

Karpinska, A. M., Bridgeman, J., (2016). CFD-aided modelling of activated sludge systems: A critical review Standard Method of Moments. Water Res. 88, 861879.

Karpinska, A. M., Bridgeman, J., (2017). Towards a robust CFD model for aeration tanks for sewage treatment - a lab-scale study, Engineering Applications of Computational Fluid Mechanics, 11:1, 371-395.

Karpinska, A. M., Bridgeman, J., (2018). CFD as a Tool to Optimize Aeration Tank Design and Operation. Journal of Environmental Engineering, Volume 144, Issue 2.

Kerrn-Jespersen, JP and Henze, M 1993, 'Biological phosphorus uptake under anoxic and aerobic conditions' Water Research, vol 27, no. 4, pp. 617-624.

Kinnear, D. J., (2002). Biological solids sedimentation: a model incorporating fundamental settling parameters. $\mathrm{PhD}$ Thesis.

Kocamustafaogullari, G., Huang, W. D. (1994). Internal structure and interfacial velocity development for bubbly two-phase flow Nuclear Engineering and Design, Volume 151, Issue 1, Pages 79-101

Kocamustafaogullari, G., Ishii, M. (1995). Foundation of the interfacial area transport equation and its closure relations International Journal of Heat and Mass Transfer, Volume 38, Issue 3, Pages 481-493

Krebs, P., Vischer, D., Gujer, W., (1995). Inlet-structure design for final clarifiers, J Env. Eng, 121, 558-564.

Krepper, E., Lucas, D., Prasser, H.-M. (2005). On the Modelling of bubbly flow in vertical pipes, Nuclear Engineering and Design, 235, 597-611

Kumar, S., Ramkrishna, D., (1996a). On the solution of population balance equations by discretization. 2. A moving pivot technique. Chem. Eng. Sci. 51 (8), 1333-1342.

Kumar, S., Ramkrishna, D., (1996b). On the solution of population balance equations by discretization. 1. A fixed pivot technique. Chem. Eng. Sci. 51 (8),1311-1332.

Laborde-Boutet, C., Larachi, F., Dromard, N., Delsart, O., Schweich, D., (2009). CFD simulation of bubble column flows: Investigations on turbulence models in RANS approach. Chem Eng Sci 64, 4399-4413. 
Laín, S., Brödera, D., Sommerfeld, M., Göza, M.F. (2002). Modelling hydrodynamics and turbulence in a bubble column using the Euler-Lagrange procedure. International Journal of Multiphase Flow. Volume 28, Issue 8, Pages 1381-1407

Lapin, A., Ltibbert, A., (1994). Numerical simulation of the dynamics of two-phase gas-liquid flow in bubble columns. Chem. Engng Sci. 49, 36613674.

Larsen, P., (1977). On the hydraulics of rectangular settling basins, experimental and theoretical studies, Report No. 1001. Water Research Engineering, Lund Institute of Technology: Lund.

Lasheras, J.C., Eastwood, C., Martínez-Bazán, C., Montañés, J.L., (2002). A review of statistical models for the break-up of an immiscible fluid immersed into a fully developed turbulent flow, Int. J. Multiph. Flow 28, 247-278.

Laurent, J., Boius, P., Nuel, M., Wanko, A. (2015). Systemic models of full-scale Surface Flow Treatment Wetlands: Determination by application of fluorescent tracers. Chemical Engineering Journal, Volume 264, 15 March 2015, Pages 389398

Laurent, J., Samtag, R.W., Ducoste, J.M., Griborio, A., Nopens, I., Baststone, D.J., Wicks, J.D., Saunders, S., Potier, O., (2014). A protocol for the use of computational fluid dynamics as a supportive tool for wastewater treatment plant modeling. Water Science and Technology 70, 1575-84.

Le Moullec Y., Gentric C., Potier O. and J. P. Leclerc (2010). Comparison of systemic,compartmental and CFD modelling approaches: Application to the simulation of a biological reactor of wastewater treatment. Chemical Engineering Science.

Le Moullec Y., Potier O., Gentric C. and J. P. Leclerc (2011). Activated sludge pilot plant: Comparison between experimental and predicted concentration profiles using three different modelling approaches. Water Research 45: 30853097.

Le Moullec, Y., Potier O., Gentric, C., Leclerc, J. P., (2010). CFD simulation of the hydrodynamics and reactions in an activated sludge channel reactor of wastewater treatment. Chemical Engineering Science 65, 492 - 498.

Le Moullec, Y., Potier, O., Gentric, C., Leclerc, J. P., (2008). Flow field and residence time distribution simulation of a cross-flow gas-liquid wastewater treatment reactor using CFD, Chem. Eng. Sci. 63, 2436-2449. 
Lehr, F. (2002). Bubble-size distributions and flow fields in bubble columns, AIChE. J. 48, 2426-2443.

Lei L., Ni J. (2014). Three-dimensional three-phase model for simulation of hydrodynamics, oxygen mass transfer, carbon oxidation, nitrififcation and denitrification in an oxidation ditch. Water Research 53 (2014) 200-214.

Lesage N., Spérandio M., Lafforgue C. and Cockx A. (2003) Calibration and application of a 1-d model for oxidation ditches. Laboratoire d'Ingénierie des Procédés de l'Environnement, Toulouse, France Institution of Chemical Engineers

Levenspiel O. (1999). Chemical Reaction Engineering. Wiley, New York..

Levenspiel, O., (1972). Chemical Engineering Reactor. John Wiley \& Sons, New York.

Levenspiel, O., (1989). The Chemical Reactor Omnibook. OSU Book Stores, Corvallis.

Liao, Y., Lucas, D., (2009). A literature review of theoretical models for drop and bubble breakup in turbulent dispersions, Chem. Eng. Sci. 64, 3389-3406.

Liao, Y., Lucas, D., (2010). A literature review on mechanisms and models for the coalescence process of fluid particles, Chem. Eng. Sci. 65, 2851-2864.

Lindmark, J., Thorin, E., Bel Fdhila, R., Dahlquist, E., (2014). Effects of mixing on the result of anaerobic digestion: review. Renewable Sustainable Energy Rev., 40, pp. 1030-1047.

Littleton, H.X., Daigger, G.T. Strom, P.F., (2001). Application of computational fluid dynamics to closed loop bioreactors. In Proceedings of WEFTEC 2001, Atlanta, Georgia, US.

Littleton, H.X., Daigger, G.T., Strom, P., (2007). Application of computational fluid dynamics to closed loop bioreactors: I. analysis of macro-environment variations in simultaneous biological nutrient removal systems. Water Environment Research 79 (6), 600-612.

Littleton, H.X., Daigger, G.T., Strom, P.F., Cowan, R.A., (2003). Simultaneous biological nutrient removal: evaluation of autotrophic denitrification, heterotrophic nitrification and biological removal in full-scale.

Lo, S.M., (1996). Application of population balance to CFD modelling of bubbly flow via the MUSIG model. AEA Technology, AEAT-1096. 
Ludzack, F.J., Ettinger, M.B., (1962). Controlling operation to minimize activated sludge effluent nitrogen. JWPCF 34 920-931.

Luo, H., Svendsen, H.F., (1996). Theoretical model for drop and bubble breakup in turbulent dispersions, AICHE J. 42, 1225-1233.

MacMullin, R. B., Weber, M., (1935). The theory of short-circuiting in continuousflow mixing vessels in series and kinetics of chemical reactions in such systems. Transactions of American Institute of Chemical Engineers, vol. 31, no. 2, pp. 409-458,

Makinia, J., (2010). Mathematical Modelling and Computer Simulation of Activated Sludge Systems. IWA Publishing, London.

Marchisio, D.L., Fox, R.O., (2005). Solution of population balance equation using the direct quadrature method of moments. J. Aerosol. Sci. 36, 43-73.

Matko, T., Fawcett, N., Sharp, A., Stephenson, T., (1996). Recent progress in the numerical modelling of wastewater sedimentation tanks. Institution of Chemical Engineers, Vol 74, Part B, 245-258.

McGraw, R., (1997). Description of aerosol dynamics by the quadrature method of moments, Aerosol Sci. Tech., 27: 255-265.

McLeod, J.D., Othman, M.Z. Parthasarathy, R., (2019). "Process intensification of anaerobic digestion: Influence on mixing and process performance", Bioresource Technology, Vol. 274, pp. 533-540.

Meier M., Fahlenkamp H. and P. Ehrhard. (2008). CFD modeling of hydrodynamics and biological reactions in activated sludge reactor. Biochemical and Chemical Engineering, Fluid Mechanics, TU Dortmund, Emil-Figge-Str. 68, 44227 Dortmund, Germany.

Meister, M., Rezavand, M., Ebner, C., Pümpel, T., Rauch, W., (2018). Mixing nonNewtonian flows in anaerobic digesters by impellers and pumped recirculation, Advances in Engineering Software, Elsevier, Vol. 115, pp. 194-203.

Menter, F.R., (1994). Two-Equation Eddy-Viscosity Turbulence Models for Engineering Applications. AIAA J. 32, 1598-1605.

Metcalf \& Eddy., (2004). Wastewater Engineering: Treatment and Reuse, 4th Edition, McGraw-Hill. 
Mino T, van Loosdrecht M C M, Heijnen J J, 1998. Microbiologyand biochemistry of the enhanced biological phosphateremoval process.Water Research, 32(11): 3193-3207.

Monod, J., (1942). Recherches sur la croissance des cultures bactériennes,. Hermann \& cie, Paris.

Moraga, F. J., Bonetto, F. J., Lahey, R. T (1999). Lateral forces on spheres in turbulent uniform shear flow. International Journal of Multiphase Flow, 25, Issues 6-7, 11, pp 1321-1372

Nana, Q., Zhang, H., Jin, B., Zhang, K., (2011). “CFD modelling of hydrodynamics and degradation kinetics in an annular slurry photocatalytic reactor for wastewater treatment". Chemical Engineering Journal 172, 84- 95

Nelson M.I., Sidhu H.S. (2009). Analysis of the activated sludge model (number 1). The University of Wollongong, NSW 2522, Australia. Applied Mathematics Letters.

Nigmatulin, R., (1979). Spatial averaging in the mechanics of heterogeneous and dispersed systems International Journal of Multiphase Flow, Volume 5, Issue 5, Pages 353-385

Nopens, I., (2005). Modelling the activated sludge flocculation process: a population balance approach. PhD Thesis, University of Ghent, Belgium.

Nopens, I., Batstone, D.J., Griborio, A., Samstag, R., Wicklein, E., Wicks, J., (2012). Computational Fluid Dynamics (CFD): What is Good CFD-Modeling Practice and What Can Be the Added Value of CFD Models to WWTP Modeling? Proceedings of the Water Environment Federation 2012, 7400-7405.

Nopens, I., Torfs, E., Ducoste, J., Vanrolleghem, P., Gernaey, K., (2014). Population Balance Models: A useful complementary modelling framework for future WWTP modelling. In Proceedings. 4th IWA/WEF Wastewater treatment modelling. Water Environment Federation.

Ochoa-Herrera, V., Banihani, Q., León, G., Khatri, C., Fiel, J.A., Sierra-Alvarez, R., (2009). "Toxicity of fluoride to microorganisms in biological wastewater treatment systems." Water Research. 43:3177-3186.

Olukanni, D. O., Ducoste, J J., (2011). Optimization of waste stabilization pond design for developing nations using computational fluid dynamics. Ecological Engineering 37, 1878- 1888.

Ovezea, A., (2009). Saving energy: Using fine bubble diffusers. Filtration \& Separation 46, 24-27. 
Parker, D.S., Kaufman, W.J., Jenkins, D., (1971). Physical conditioning of activated sludge floc. Journal WPCF 43(9), 1817-1833.

Parker, D.S., Kaufman, W.J., Jenkins, D., (1972). Floc breakup in turbulent processes. Journal of the Sanitary Engineering Division, ASCE, SA1 98, 79-99.

Pereira, J., Karpinska, A., Gomes, P., Martins, A., Dias, M. and Santos, R., (2011). Activated Sludge Models coupled to CFD simulations. In: R. Dias, R. Lima, A. A. Martins \& T.M. Mata (eds), Single and Two-Phase Flows on Chemical and Biomedical. Engineering. Bentham Science Publishers, Dubai, UAE.

Perry, J.H., (1973). “Chemical Engineers’ Handbook.” Mc Graw-Hill, 5th edition.

Petersen, B., 2000. Calibration, identifiability and optimal experimental design of activated sludge models. Ph.D. Thesis, Ghent University, Belgium

Pons, M.N., Potier, O., Roche, N., Colin, F., Prost, C., (1993). Simulation of municipal wastewater treatment plants by activated sludge. Comput. Chem. Eng 17, (Suppl.) S227-S232.

Potier, O., Leclerc, J.P., Pons, M.N., (2005). Influence of geometrical and operational parameters on the axial dispersion in an aerated channel reactor, Water Res. 39, 4454-4462.

Prince, M. J., Blanch, H.W., (1990). Bubble coalescence and break-up in airsparged bubble columns, AICHE J. 36, 1485-1499.

Ramin, E., (2014). Modelling of secondary sedimentation under wet-weather and filamentous bulking conditions. PhD Thesis, DTU Environment.

Ramkrishna, D., (1985). The status of population balances. Rev. Chem. Eng., 3 (1985), pp. 49-95

Ratkovich, N., Horn, W., Helmus, F.P., Rosenberg, S., Naessens, W., Nopens, I., Bentzen, T.R., (2013). Activated sludge rheology: A critical review on data collection and modelling. Water Research 47, 463-482.

Rehman, U., (2016). Next generation bioreactor models for wastewater treatment systems by means of detailed combined modelling of mixing and biokinetics. PhD. Ghent University. Faculty of Bioscience Engineering, Ghent, Belgium.

Rehman, U., (2016). Next generation bioreactor models for wastewater treatment systems by means of detailed combined modelling of mixing and biokinetics, $\mathrm{PhD}$ thesis, Ghent University, Belgium 
Rice, E.W., Baird, R.B., Eaton, A.D., Clesceri, L.S., (2012). Standard Methods for the Examination of Water and Wastewater. American Public Health Association, American Water Works Association, Water Environment Federation, New York.

Rieckermann, J., Vojtěch, B., Krachta, O., Braunc, D., Gujer, W., (2007). Estimating sewer leakage from continuous tracer experiments. Water Research Volume 41, Issue 9, Pages 1960-1972

Rieger, L., Gillot, S., Langergraber, G., Ohtsuki, T., Shaw, A., Takács, I., Winkler, S., (2013). Guidelines for Using Activated Sludge Models. IWA Publishing, London.

Rigopoulos, S., Jones, A., (2003). A hybrid CFD-reaction engineering framework formultiphase reactor modelling: basic concept and application to bubble columns.Chemical Engineering Science 58, 3077-3089.

Roache, P. J., (1998). Verification of codes and calculations, AIAA J. 36, 696-702.

Rodi, W., and Scheuerer, G., (1986). Scrutinizing the k-e turbulence model under adverse pressure gradient conditions, J. Fluids Eng. 108

Runkel, R.L., (2015). On the use of rhodamine WT for the characterization of stream hydrodynamics and transient storage. Water Resour. Res. 51, 6125-6142.

Rzehak, R., Krepper, E. (2013) CFD modeling of bubble-induced turbulence International Journal of Multiphase Flow, Volume 55, October 2013, Pages 138155.

Rzehak, R., Krepper, E., Liao, Y., Ziegenhein, Th., Kriebitzsch, S., Lucas, D., (2015). Baseline model for the simulation of bubbly flows. Chemical Engineering Science 38, 1972-1978.

Samstag, R. W., Dittmar, D. F., Vitasovic, Z., McCorquodale, J. A., (1989). Under flow geometry in secondary sedimentation, Wat. Environ. Res, 64, 204-212.

Samstag, R.W., Ducoste, J.J., Griborio, A., Nopens, I., Batstone, D.J., Wicks, J.D., Saunders, S., Wicklein, E.A., Kenny, G., Laurent, J., (2016). CFD for wastewater treatment: An overview. Water Sci. Technol. 74, 549-63.

Samstag, R.W., Wicklein, E.A., Reardon, R.D., Leetch, R.J., Parks, R.M., Groff, C.D., (2012). Field and CFD Analysis of Jet Aeration and Mixing, In Proc. of the Water Environ. Fed. 12, 4113-4139. 
Santos André A. C., Filho J. A. and Navarro M., (2011). Verification and Validation of a numeric procedure for flow simulation of a $2 \times 2$ PWR rod bundle. 2011 International Nuclear Atlantic Conference - INAC 2011. Belo Horizonte, MG, Brazil, October 24-28, 2011

Sanyal J., Marchisio D. L., Fox O., and Dhanasekharan K., (2005). On the comparison between population balance models for CFD simulation of bubble columns. Industrial and Engineering Chemistry Research, vol. 44, no. 14, pp. 5063-5072

Sato, Y., Sekoguchi, K., (1975). Liquid velocity distribution in two-phase bubbly flow, Int. J. Multiph. Flow 2, 79-95.

Seco, A., Ribes, J., Serralta, J., Ferrer, J., (2004). Biological nutrient removal model no. 1 (BNRM1). Water. Sci. Technol. 50, 69-78.

Siegrist, H., Tschui, M., (1992). Interpretation of experimental data with regard to the activated sludge model No.1 and calibration of the model for municipal wastewater treatment plants. Water Sci. Technol. 25, 167-183.

Simulink@ The MathWorks, Inc., 1994-2019.

Smith, L. C., Elliot, D.J. and James A. (1993) Characterisation of mixing patterns in an anaerobic digester by means of tracer curve analysis. Ecological Modelling, $69,267-285$

Smith, L.C., Elliot, D.J., James, A., (1993). Characterisation of mixing patterns in an anaerobic digester by means of tracer curve analysis. Ecol. Modell. 69, 267285.

Sokolichin, A., Eigenberger, G., (1994). Gas liquid flow in bubble columns and loop reactors. Part I. Detailed modelling and numerical simulation. Chem. Engng Sci. 49, 5735-5746.

Sokolichin, A., Eigenberger, G., (1996). Dynamic numerical simulation of gasliquid two-phase flows Euler/Euler versus Euler/Lagrange. Chemical En lineerin 9 Science, Vol. 52, No. 4, pp. 611-626.

Stern, F., Wilson, R.,Shao, J. (2006). Quantitative V\&V of CFD simulations and certication of CFD codes. INTERNATIONAL JOURNAL FOR NUMERICAL METHODS IN FLUIDS Int. J. Numer. Meth. Fluids 2006; 50:1335-1355.

Takacs, I., Patry, G. G., Nolasco, D., (1991). A dynamic model of the clarificationthickening process, Water Res, 25, 1263-1271. 
Tanaka, M., (2014). Investigation of V\&V process for thermal fatigue issue in a sodium cooled fast reactor - Application of uncertainty quantification scheme in verification and validation with fluid-structure thermal interaction problem in $\mathrm{T}$ junction piping system, Nucl. Eng. Des. 279, 91-103.

Tanaka, M., Ohno, S., Ohshima, H., (2016). Development of V2UP (V\&V plus uncertainty quantification and prediction) procedure for high cycle thermal fatigue in fast reactor-Framework for $\mathrm{V} \& \mathrm{~V}$ and numerical prediction, Nucl. Eng. Des. 299, 174-183

Terashima, M., Goel, R., Komatsu, K., Yasui, H., Takahashi, H., Li, Y. Y., Noike, T., (2009). CFD simulation of mixing in anaerobic digesters, Bioresource Technology. Elsevier Ltd, 100(7), pp. 2228-2233. doi: 10.1016/j.biortech.2008.07.069.

The Journal of experimental biology (2011). 214, 3138-3158.

Tomiyama, A., Sou, A., Zun, I., Kanami, N. \& Sakaguchi, T. (1995). Effects of Eötvös number and dimensionless liquid volumetric flux on lateral motion of a bubble in a laminar duct flow Adv. Multiphase Flow, 3-15

Tomiyama, A., Tamai, H., Zun, I., Hosokawa, S., (2002). Transverse migration of single bubbles in simple shear flows, Chem. Eng. Sci. 57, 1849-1858.

Torvik, R., Svendsen, H. F., (1990). Modelling of slurry reactors: a fundamental approach. Chem. Engng Sci. 45, 2325-2332.

Uby, L. (2001). A case for mixer thrust. IChemE FMPSG seminar. University College of London.

Van Haandel, A., van der Lubbe, J., (2012). Handbook of Biological Wastewater Treatment: Design and optimization of Activated Sludge Systems. 2nd Edition. IWA Publishing, London.

Versteeg, H. K. and Malalasekera, W., (2007). An Introduction to Computational Fluid Dynamics. (C) Pearson Education Limited 1995, 2007, Second Ed. ISBN: 978-0-13-127498-3

Vesvikar, M. S., Al-Dahhan, M., (2005). Flow pattern visualization in a mimic anaerobic digester using CF , Biotechnology and Bioengineering, 89, pp. 719732.

Vieser, W., Esch, T., Menter F. (2008). Heat transfer predictions using advanced two-equation turbulence models, Ansys CFX Validation Report, ANSYS Germany. 
VT, USA, 9-12 July 2006. Anderson, G. K., Campos, C. M. M., Chernicharo C. A. L. and Smith, L. C. (1991). Evaluation of the inhibitory effects of lithium when used as a tracer for anaerobic digesters. Department of Civil Engineering, University of Newcastle upon Tyne, Newcastle upon Tyne NEI 7RU, England

Wang X., Ding, J., Guo, W.Q., Ren, N.Q., (2010). A hydrodynamics-reaction kinetics coupled model for evaluating bioreactors derived from CFD simulation. State Key Laboratory of Urban Water Resource and Environment, China.

Wang, T.F., (2011). Simulation of bubble column reactors using CFD coupled with a population balance model, Chem. Sci. Eng. 5, 162-172.

Wang, T.F., Wang, J., Jin, Y., (2005). Population balance model for gas-liquid flows: Influence of bubble coalescence and breakup models, Ind. Eng. Chem. Res. 44, 7540-7549.

Wang, T.F., Wang, J., Jin, Y., (2005). Theoretical prediction of flow regime transition in bubble columns by the population balance model, Chem. Eng. Sci. 60, 6199-6209.

Wang, X. (2010). Simulations of Two-phase Flows Using Interfacial Area Transport Equation, Wang X., 2010, Ph.D. Thesis, The Ohio State University, USA.

Wang, X., Ding, J., Guo, W.Q., Ren, N.Q., (2010). A hydrodynamics-reaction kinetics coupled model for evaluating bioreactors derived from CFD simulation. Bioresour Technol 101, 9749-9757.

Wang, Y., Waite, T.D., Leslie, G.L., (2013). Computational fluid dynamics (CFD) analysis of membrane reactors: modelling of membrane bioreactors for municipal wastewater treatment, in: Handbook of Membrane Reactors. Elsevier, pp. 532-568.

Water Environment Federation, (2006). Biological Nutrient Removal Processes, American Society of Civil Engineers, Reston.

Water Environment Federation, (2007). Process performance improvements, in: Operation of Municipal Wastewater Treatment Plants. WEF Manual of Practice No11. Volume I. McGraw Hil, New York.

Webb, C., Que, F., Senior, P. R., (1992). Dynamic simulation of gas-liquid dispersion behaviour in a 2-D bubble column using a graphics minisupercomputer. Chem. Engng Sci. 47, 3305-3312. 
White, K.E., (1974). The use of radioactive tracers to study mixing and residencetime distributions in systems exhibiting three-dimensional dispersion., in: In: Proceedings of the First European conference on mixing and centrifugal separation. (Ed.), . Churchill College, Cambridge, England.

Wicklein, E., Batstone, D. J., Ducoste, J., Laurent, J., Griborio, A., Wicks, J., Saunders, S., Samstag, R., Potier, O., Nopens, I., (2016). Good modelling practice in applying computational fluid dynamics for WWTP modelling. Water Science and Technology 73, 969-982.

Wilcox, D. C., (1994). Turbulence Modelling for CFD. DCW Industries, Inc. La Cañada, California. ISBN 0-9636051-0-0.

WILO Agitadores sumergibles (2014). Jornada WILO-SDM.

Wolf, D. and Resnick, (1963). W. Residence time distribution in real systems. Chemical Engineering Department, Israel Institute of Technology, Haga, Israel. VOL. 2 No. 4 November 1963287

Wu, B., (2011). CFD investigation of turbulence models for mechanical agitation of non-Newtonian fluids in anaerobic digester, Water Research. Elsevier Ltd, 45, pp. 2082-2094.

Wu, Q., Kim, S., Ishii, M., Beus, S.G., (1998). One-group interfacial area transport in vertical bubbly flow, Int. J. Heat Mass Transf. 41, 1103-1112.

Xie, H., Yang, J., Hu, Y., Zhang, H., Yang, Y., Zhang, K., (2014). Simulation of flow field and sludge settling in a full-scale oxidation ditch by using a two-phase flow CFD model, Chem. Eng. Sci. 109, 296-305.

Yakhot, V. and Orszag, S. A. (1986) Journal of Scientific Computing 1, 3.

Yao, W., Morel, C., (2004). Volumetric Interfacial Area Prediction in Upward Bubbly Two- Phase Flow. International Journal of Heat and Mass Transfer, 47, 307-328.

Yeoh, G. H., Sherman C. P. Cheung, Tu, J. Y. (2012) On the Prediction of Bubble Size Distribution and Void Fraction in Vertical Gas-Liquid Flows. Journal of Computational Multiphase Flows, Volume 4, number 1.

York, D., (1966). Least-squares fitting of a straight line, Can. J. Phys. 44, 10791086.

Zhang L., Pan Q. and Garry L. Rempel (2007). Residence Time Distribution in a Multistage Agitated Contactor with Newtonian Fluids: CFD Prediction and Experimental Validation. Department of Chemical Engineering, University of 
Waterloo, Waterloo N2L 3G1, Canada Ind. Eng. Chem. Res. 2007, 46, 35383546 .

Zhang, D., Guo, L., Xu, D., Chen, Y., (2010). Simulation of component distributions in a full-scale corrousel oxidation ditch: a model coupling sludgewastewater two-phase turbulent hydrodynamics with bioreaction kinetics. Environ. Eng. Sci. 27, 159-168.

Zhou, S., McCorquodale, J. A., Vitasovic, Z., (1992). Influences of density on circular clarifiers with baffles, J Env. Eng. ASCE, 829-847.

Zuber, N. and Findlay, J.A. (1965) Average Volumetric Concentration in TwoPhase Flow Systems. Journal of Heat Transfer, 87, 453-468. 